\title{
Zhizi Yang
}

\section{Märchenadaptionen in Romanen und Novellen von Christoph Martin Wieland zu Thomas Mann}

Eine exemplarische Untersuchung

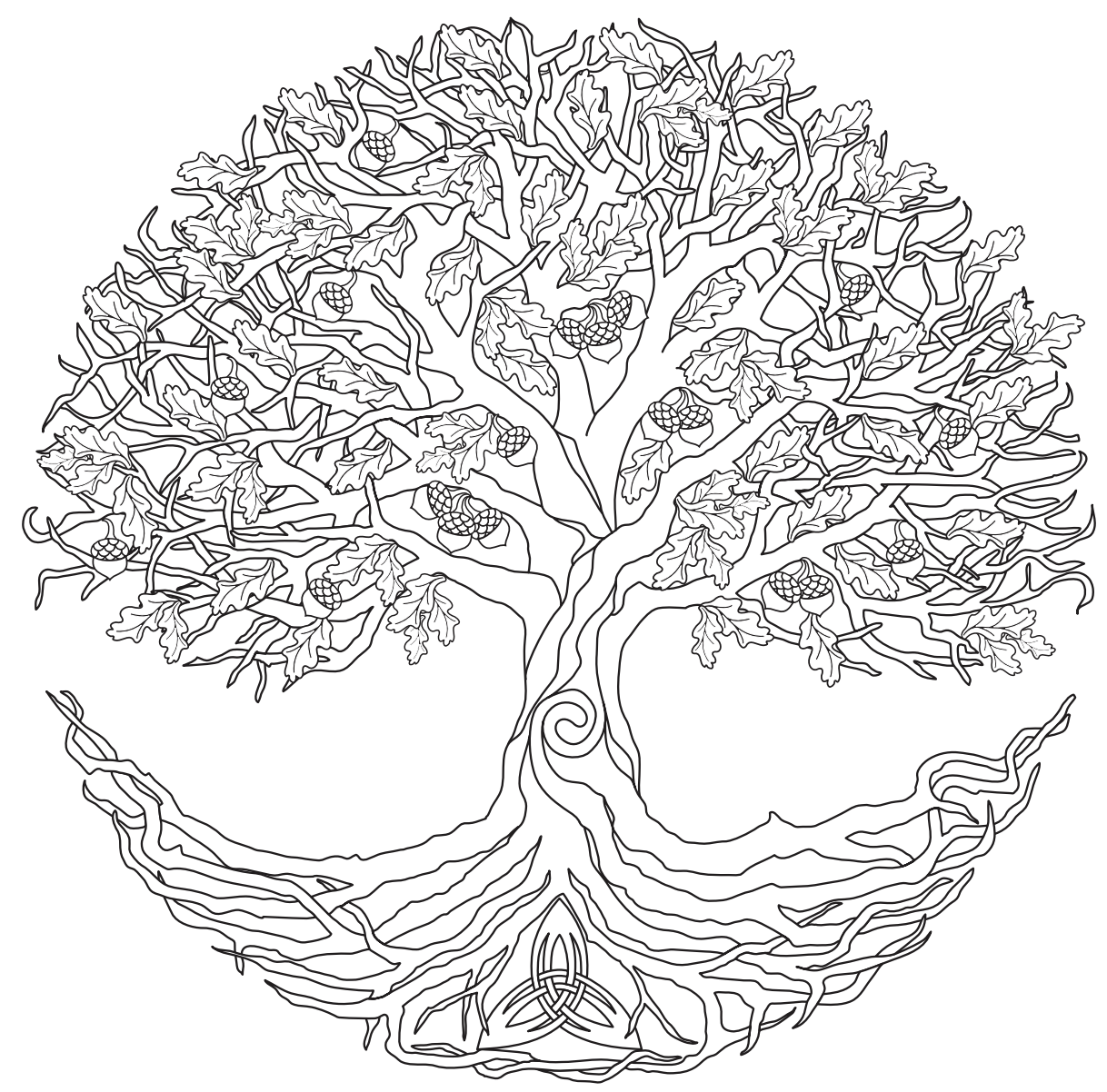



Zhizi Yang

Märchenadaptionen in Romanen und Novellen von Christoph Martin Wieland zu Thomas Mann

Dieses Werk ist lizenziert unter einer Creative Commons Namensnennung - Weitergabe unter gleichen Bedingungen 4.0 International Lizenz.

(c) ${ }_{\mathrm{BY}}(\mathrm{PA}$ 
erschienen im Universitätsverlag Göttingen 2018 
Zhizi Yang

Märchenadaptionen in Romanen und Novellen von Christoph Martin Wieland zu Thomas Mann

Eine exemplarische Untersuchung

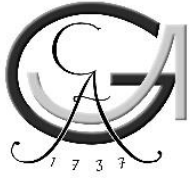

Universitätsverlag Göttingen 2018 


\title{
Bibliographische Information der Deutschen Nationalbibliothek
}

Die Deutsche Nationalbibliothek verzeichnet diese Publikation in der Deutschen Nationalbibliographie; detaillierte bibliographische Daten sind im Internet über $<$ http://dnb.dnb.de $>$ abrufbar.

Gefördert durch ein Promotions-Stipendium des China Scholarship Council und den Gesonderten Förderpreis der Märchen-Stiftung Walter Kahn

\section{Autorenkontakt}

Zhizi Yang

E-Mail: btsakurayang@googlemail.com

\author{
Dissertation \\ zur Erlangung des philosophischen Doktorgrades \\ an der Philosophischen Fakultät der Georg-August-Universität Göttingen
}

Dieses Buch ist auch als freie Onlineversion über die Homepage des Verlags sowie über den Göttinger Universitätskatalog (GUK) bei der Niedersächsischen Staats- und Universitätsbibliothek Göttingen (http://www.sub.uni-goettingen.de) erreichbar. Es gelten die Lizenzbestimmungen der Onlineversion.

Satz und Layout: Zhizi Yang Umschlaggestaltung: Margo Bargheer

Titelabbildung: Aon Celtic Art/Shutterstock.com

Titel und Untertitel gesetzt in Orange Blossoms (C Dez C 2018, DezCustomCreations@gmail.com)

(C) 2018 Universitätsverlag Göttingen https://univerlag.uni-goettingen.de ISBN: 978-3-86395-369-0

DOI: https://doi.org/10.17875/gup2018-1105 


\section{Inhaltsverzeichnis}

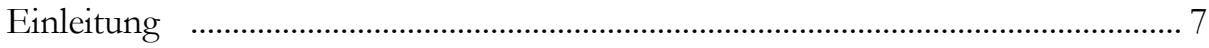

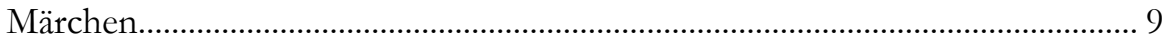

Das Kunstmärchen und die ,Grenze` zwischen Kunstmärchen, Novelle und Roman ....................................................................................... 12

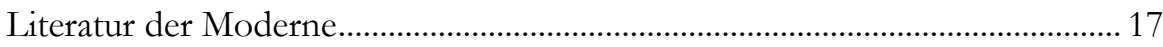

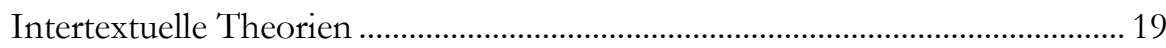

1. Christoph Martin Wieland: Die Abenteuer des Don Sylvio von Rosalva ................... 25

1.1 Die Märchentheorie der Aufklärung - Wielands Märchentheorie.............. 28

1.2 Die Märchenstruktur und die Märchenadaptionen

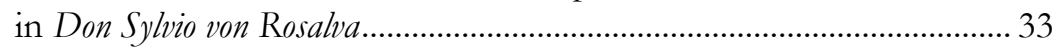

1.3 Das intertextuelle Spiel in Don Sylvio von Rosalva.......................................... 42

1.4 Vom Märchen zum Entwicklungsroman ....................................................... 48

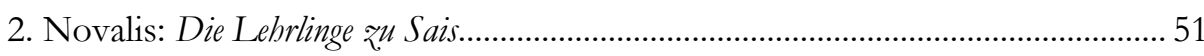

2.1 Die Roman- sowie Märchentheorie von Novalis............................................ 53

2.2 Die Lehrlinge zu Sais als das Fragment eines romantischen Romans............ 56

2.3 Die Figuren in Die Lehrlinge zu Sais............................................................... 58

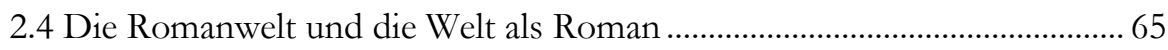

2.5. Potenzierung und Logarythmisierung in dem Romanfragment ................. 66

3. Chamisso: Peter Scblemibls wundersame Geschichte...................................................... 69

3.1 Struktur der Erzählung - Märchenadaption und Abweichung von der Romantik................................................................................. 71

3.2 Die verkehrte Welt in Peter Schlemibl............................................................... 78

3.3 Peter Schlemihl als märchenhafte Figur ...................................................... 84

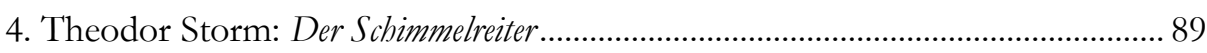

4.1 Die Volksmärchenadaption in Der Schimmelreiter........................................ 90

4.2 Der Schimmelreiter und romantische Kunstmärchen....................................... 95

4.3 Das Scheitern eines Märchens........................................................................ 103

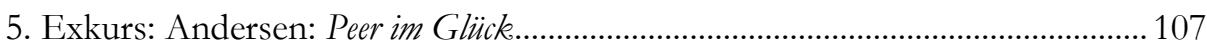

5.1 Die deutsche Romantik und Peer im Glück ................................................ 108

5.2 Andersens Märchen und Erzählungen als Prätexte zu Peer im Glück........115 
5.3 Der glückliche Peer und das Lebensmärchen Andersens .......................... 122

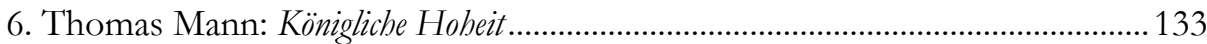

6.1 Die Funktion des Realistischen in dem Märchenroman

Königliche Hoheit ..................................................................................... 135

6.2 Die Märchenstruktur und Märchenmotive in Königliche Hoheit.................. 140

6.3 Die Funktion der Märchenadaptionen und Königliche Hoheit

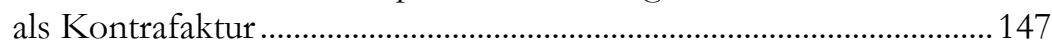

6.4 Das Märchenhafte als Maske einer autobiographischen Schrift............... 151

6.5 Die Menschwerdung von Klaus Heinrich und die Märchenwerdung der Königlichen Hoheit ................................................................................ 153

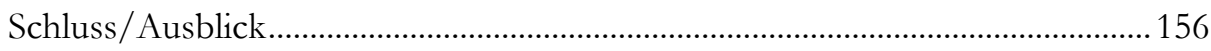

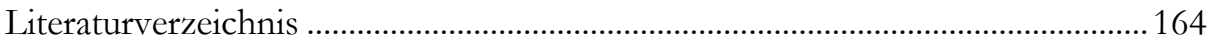




\section{Einleitung}

Das Lesen zahlreicher, wenn nicht der allermeisten Leser beginnt mit dem Märchen. Jeder Leser und somit jeder Autor eines literarischen Werkes, der notwendigerweise auch Leser sein muss, ist mehr oder weniger, direkt oder indirekt beeinflusst von Märchen. „Because to influence a person is to give him one's own soul“" 1 - wird Henry Wottons Aussage in The Picture of Dorian Gray wörtlich genommen, dann lässt sich sagen, dass die Seele des Märchens in jedem Text eines Autors, der Märchen gelesen oder gehört hat, existiert. Wenn Harold Blooms Theorie von Einfluss und Abwehr Glauben geschenkt wird, gehört die Auseinandersetzung mit den gelesenen oder gehörten Märchen zu den Aufgaben jedes literarischen Werkes.

Der Prozess des Beeinflussens geschieht häufig unbewusst. Nicht alle Autoren greifen absichtlich auf Märchen zurück, während sie Erzähltexte schreiben. Es gibt allerdings in der neueren Literaturgeschichte Autoren, die sich des Einflusses von Märchen bewusst sind und sich des Märchens zum Zweck der Textgestaltung bedienen, seitdem das Märchen als eine literarische Gattung erkannt und geschätzt wird. Es ist ein spezielles Schreibverfahren, wenn der Autor nicht nur Motive und Stoffe aus Märchen in den eigenen Erzähltext transportiert, sondern auch die gesamte Struktur oder das Handlungsschema von Märchen. Dieses Schreibverfah-

1 Wilde 2005, S. 20. 
ren setzt ein Gattungsbewusstsein und eine entsprechende Selbstreflexion auf der Textebene voraus und gehört dadurch zu den eher modernen Schreibverfahren. $\mathrm{Da}$ das Märchen in verschiedenen ästhetischen und geistigen Epochen für seine Leser unterschiedliche Stellungen im Gattungssystem, verschiedene Formen und sogar verschiedene Gattungsbezeichnungen hatte, hat die Märchenadaption für Autoren aus verschiedenen Zeiten keine gleiche Bedeutung und Form. Die vorliegende Arbeit wählt deswegen eine Gruppe von Erzähltexten aus einem Zeitraum von Christoph Martin Wieland bis zu Thomas Mann aus. In diesen Erzähltexten ist ein relativ auffälliges Schreibverfahren der Märchenadaption vorhanden. Sie sind in Bezug auf dieses Schreibverfahren bis jetzt noch wenig oder mindestens unvollständig erforscht worden. Die zu untersuchenden Texte, deren Verständnis und Adaption von Märchen für die jeweilige literarische Epoche repräsentativ sind, sind Christoph Martin Wielands Roman Don Sylvio von Rosalva, der in einer Übergangsperiode zwischen Rokoko und Aufklärung des Autors entstand und die Märchenschwärmerei zum Thema hat, Friedrich von Hardenbergs (Novalis) frühromantisches Romanfragment Die Lebrlinge zu Sais, das von einem Roman allmählich zu einem Märchen übergehen soll, Adalbert von Chamissos Novelle Peter Schlemibls wundersame Geschicbte, die den literarischen Übergang von der deutschen Romantik zu der Biedermeier-Literatur sowie eine Reflexion auf die Frühromantik zeigt, Theodor Storms Novelle Der Schimmelreiter, die ein Werk aus der Gründerzeit ist und in der realistische und phantastische Elemente sich verbinden, sowie Thomas Manns Märchenroman Königliche Hoheit, der von den zeitgenössischen Rezipienten als altmodischer Hofroman missverstanden wurde. Um einen Ausblick auf das Märchenadaptionsverfahren der europäischen Literatur zu geben, analysiert die vorliegende Arbeit darüber hinaus noch Peer im Glück, einen Roman des bekannten dänischen Märchendichters Hans Christian Andersen, dessen Dichtung von der deutschen Romantik stark beeinflusst wurde und der selbst auch Briefe und Essays auf Deutsch schrieb. Während die anderen Erzähltexte einen eindeutigen Bezug auf einzelne Märchen und/oder die Gattung Märchen zeigen, hat die Novelle Der Schimmelreiter von Storm eine Sonderstellung in dieser Gruppe, weil die bisherigen Forschungen sich vielmehr auf ihre Sagenadaption konzentriert. Die Suche nach den Anlehnungen von Märchenelementen ist ein Deutungsversuch aus einer anderen Perspektive.

Der Gegenstand der vorliegenden Arbeit ist die Märchenadaption in ausgewählten modernen Erzähltexten. Mit dieser Formulierung entstehen bereits einige Fragen, die beantwortet werden sollen, bevor die textanalytische Untersuchung beginnt: Welches sind die Merkmale der literarischen Gattung Märchen (Märchentheorien)? Was bedeutet Moderne für die Literaturwissenschaft und für die vorliegende Arbeit? Welche Möglichkeiten gibt es für eine Adaption anderer Texte (Intertextualität)? Im Folgenden werden diese Fragen jeweils kurz beantwortet. 


\section{Märchen}

Um die Theorien der literarischen Gattung Märchen zu erklären, soll zuerst eine kurze Erklärung des Begriffs Literarische Gattung gegeben werden. Die literarische Gattung bezeichnet zum einen die drei Naturformen der Literatur nach Goethe: Lyrik, Drama und Epik, zum anderen die spezifischeren, anhand verschiedener Kriterien definierten Literaturtypen. ${ }^{2}$ Die Bestimmungskriterien sind unterschiedliche eigenschaftliche Aspekte von einem Text (zum Beispiel Faktualität/ Fiktionalität oder Mündlichkeit/Schriftlichkeit). Daher kreuzen sich verschiedene Gattungen oft. Die Gattungsmerkmale sind zum Teil historisch konstant und obligatorisch, zum Teil fakultativ und historisch relativ. In jedem literarischen Text soll mindestens ein obligatorisches Merkmal auftreten, durch das der Text mit mindestens einer literarischen Gattung assoziiert werden kann. Im Falle von Märchen sind solche Merkmale nach allgemeinen Verständnissen die Formelhaftigkeit und die selbstverständliche Erscheinung von Wundern.

Eine scharfe Trennung der Gattung Märchen von der Erzählung als Gattung gibt es nicht, denn die deutschen Wörter Märchen oder Märlein als Verkleinerungsformen zu Mär bezeichneten ursprünglich eine kurze Erzählung. Während diese Gattungsbezeichnungen nach den Belegen des 13. bis 16. Jahrhunderts eine Bedeutungsabwertung erlebten, wurden sie im 18. Jahrhundert wieder positiv bewertet, kamen als Feenmärchen und orientalische Märchen unter französischem Einfluss in Mode und die Gedanken zur „Volksdichtung“ im Sturm und Drang entstanden. ${ }^{3}$ Der französische Dichter Charles Perrault machte 1696/97 mit seinen Histoires ou Contes du temps passé, avec des moralités, die später auch Contes de ma Mère l'Oye genannt wurden, das Volksmärchen literaturfähig. ${ }^{4}$ Mit den Volksmärchensammlungen der Brüder Grimm und Ludwig Bechsteins beziehungsweise mit den Märchendichtungen der deutschen Romantiker und besonders Hans Christian Andersens wurde das Märchen eine weltweit beliebte literarische Gattung. Besonders die Märchensammlung der Brüder Grimm bietet schematische Muster für die Volksmärchendichtung. Zurzeit gelten „Volksmärchen“ und „Kunstmärchen“ als „wertungsfrei bestimmte Erzählgattungen. . ${ }^{5}$

Da die Zauber- oder Wundermärchen als Kern und Schwerpunkt der eigentlichen Märchen gelten, werden mit der Bezeichnung Märchen häufig Zauber, Wunder und Übernatürliches assoziiert. In zahlreichen Definitionsversuchen von Märchen gehören das Wunderbare (Bolte-Polivka), „Wundermotive“ (Helsinki), „marvelous“ (Thompson), „Verwobenheit mit dem Wunderbaren“ (Löwis of Menar) zu den zentralen Kategorien. ${ }^{6}$ Doch unterscheiden die Jenseitsmotive wie Zauber, Wunder und jenseitige Wesen das Märchen nicht von den benachbarten Gattun-

\footnotetext{
2 Wenzel 2008, S. 229.

${ }^{3}$ Lüthi 1996, S. 1.

${ }^{4}$ Lüthi 2005, S. 5.

${ }^{5}$ Lüthi 1996, S. 1.

${ }^{6}$ Vgl. Lüthi 1990, S. 3, Lüthi 2005, S. 6.
} 
gen Sage und Legende. Max Lüthi zufolge wird im Märchen „das Wunderbare mit dem Natürlichen, das Nahe mit dem Fernen, Begreifliches mit Unbegreiflichem“"7 absichtslos gemischt, was sich von Sage und Legende unterscheidet, die das Wunderbare als solches darzustellen beabsichtigen. Sage und Legende wollen von einem Ereignis, das für wahr zu halten ist, berichten und der Gegenstand der Erzählung bestimmt die Form der Erzählung. Anders beim Märchen, wo nicht die Stoffe und die Motive ausschlaggebend sind, sondern vielmehr die Art und Weise, wie sie verwendet werden. Daher fehlt dem Märchen die Hervorhebung des Numinosen. In einem Märchen kommt das Wunderbare eher selbstverständlich und als ganz natürlich vor.

Nach Lüthi zeichnet sich das europäische Volksmärchen durch seine Eindimensionalität, Flächenhaftigkeit, seinen abstrakten Stil, die sichtbare Isolation und unsichtbare Allverbundenheit seiner Figuren und seiner Handlung und schließlich die Sublimation sowie Welthaltigkeit aus.

- Eindimensionalität: Mit der Eindimensionalität meint Lüthi die Verhältnisse zwischen der diesseitigen und der jenseitigen Welt im Märchen. Die beiden Welten sind geographisch häufig weit geschieden. Der Held muss ausziehen, um dem Jenseitigen zu begegnen. Doch fehlt den Menschen im Märchen „das Erlebnis des Abstandes zwischen sich und jenen andern Wesen." ${ }^{8}$ Das jenseitige Wesen ist ihnen nur in seiner Funktion als Helfer oder Gegner bedeutend, erregt aber keine Angst oder Bewunderung aufgrund seiner „Andersartigkeit.“9 Sowohl das Diesseitige als auch das Jenseitige scheint für den Menschen zur gleichen Dimension zu gehören.

- Flächenhaftigkeit: Das Märchen ist „überhaupt und in jedem Sinne ohne Tiefengliederung. Seine Gestalten sind Figuren ohne Körperlichkeit, ohne Innenwelt, ohne Umwelt; ihnen fehlt die Beziehung zur Vorwelt und zur Nachwelt, zur Zeit überhaupt. “10 Die Dinge im Märchen sind nicht in den Lebensraum ihres Besitzers eingebettet und bleiben in sich isoliert. Auch die Menschen im Märchen haben weder Gefühlswelt noch seelische Tiefe und zeichnen sich durch die mechanistische Eindeutigkeit ihres Handelns aus. Sie besitzen ebenfalls keine Umwelt und neigen dazu, die Heimat zu verlassen und Wanderer zu werden. Feste und dauernde Beziehungen zu den Mitmenschen, zur Familie und erotische Verhältnisse der Menschen gibt es im Märchen nicht. ${ }^{11}$ Der Märchenheld ist eine isolierte Figur. Schließlich fehlt der Märchenwelt auch die Dimension der Zeit. Alle Formveränderungen vollziehen sich mechanistisch schlagartig. Die räumliche,

\footnotetext{
${ }^{7}$ Lüthi 2005, S. 6.

${ }^{8}$ Lüthi 2005, S. 9.

${ }^{9}$ Lüthi 2005, S. 11.

${ }^{10}$ Lüthi 2005, S. 13.

${ }^{11}$ Die Ehe ist im Märchen kein ersehntes Ziel des Helden, sondern nur der Schlusspunkt seiner Abenteuer. Lüthi 2005, S. 18.
} 
zeitliche, geistige und seelische Tiefengliederung werden durch Handlungen, Figurenkonstellation und Äußerlichkeit auf einer Fläche ersetzt. Das Märchen erscheint daher wirklichkeitsfern.

- Abstrakter Stil: Das Märchen versucht nicht, die konkrete Welt realistisch nachzubilden, sondern sie in eine andere Form umzuschaffen. Das Märchen bevorzugt scharfe Konturen und reine Farben. Es schildert die einzelnen Dinge nicht, sondern nennt diese und es verzichtet konsequent auf die Charakterisierung des Individuums. Die Dinge im Märchen besitzen häufig ,eine scharfe Umrißlinie“12 und bestehen aus festen Stoffen. ${ }^{13}$ Metalle und Minerale mit einer strengen Linearität sowie starre Formeln wie die Dreizahl, formelhafte Wendungen ${ }^{14}$ und Wiederholungen sind bevorzugt. Abstrakte Bestimmtheit wird im Märchen erstrebt. Auch die Handlung des Märchens ist eher einsträngig. Statt das vielschichtige Miteinander von Handlungen zu schildern, wird die Handlungslinie in eine Mehrzahl von aufeinander folgenden Episoden gegliedert. Extreme Fälle, deren Inbegriff das Wunder ist, kommen im Märchen häufig vor. Durch den abstrakten Stil erhält das Märchen bestimmte Gesetze und feste Gestalt.

- Isolation und Allverbundenheit: Einerseits sind Märchenfiguren beziehungsisolierend und die Handlungslinie ist durch mehrere ,in sich verkapselt $[\mathrm{e}]{ }^{\text {“15 }}$ Episoden, die sich nacheinander wiederholen, gegliedert. Andererseits fügen sich isolierte Figuren unsichtbar gelenkt zu harmonischem Zusammenspiel. ${ }^{16}$ Die Menschen sind gerade deswegen universal beziehungsfähig, da sie, anders als die Menschen in Sagen, die in eine Dorfgemeinschaft oder Sippe eingebettet sind, keine festen Bindungen $\mathrm{zu}$ anderen Menschen und keine Gefühlsbindungen besitzen. Auch eine Verbindung mit dem Jenseitigen ist dem Märchenhelden aufgrund seiner Isoliertheit nicht nur möglich, sondern selbstverständlich. Die Wiederholung von Episoden bedeutet auch keine Abhängigkeit zwischen den einzelnen Ereignissen, sondern die erneuerte Bildung durch eine formende Kraft nach strengen Gesetzen. ${ }^{17}$

\footnotetext{
${ }^{12}$ Lüthi 2005, S. 26. Aufhebung im Original.

13 Während Ringe, Stäbe, Schwerter, Haare, Nüsse, Eier, Kästchen, Geldbeutel, Äpfel als Gaben von Jenseitigen zu den Diesseitigen wandern, wohnen die Jenseitigen in festen Häusern, Schlössern oder unterirdischen Prachtbauten. Lüthi 2005, S. 26f.

${ }^{14}$ „Es war einmal“ und „wenn sie nicht gestorben sind, dann leben sie heute noch“ als formelhafter Anfang und Schlusssatz vom Märchen.

${ }^{15}$ Lüthi 2005, S. 38.

${ }^{16}$ Lüthi 2005, S. 49.

17 „Die spätere Szene ist nicht die Kopie der früheren; sie gleicht ihr nur deshalb so genau, weil sie denselben Ursprung hat wie sie. Unter sich sind die beiden Szenen isoliert; aber beide sind Kinder des das Ganze durchdringenden gleichförmig schaffenden Willens.“ Lüthi 2005, S. 49. Die Entstehung der Märchenwelt als eine Verwirklichung/Verbildung eines schaffenden Willens stimmt mit Schopenhauers philosophischem System überein, das später insbesondere Thomas Manns fiktivem Werk zugrunde liegt.
} 
- Sublimation und Welthaltigkeit: Der abstrakt-isolierende Stil des Märchens schafft alle profanen und numinosen Motive um. Das Wesen des Zaubers ein Willensakt, der ursprüngliche magische Gewalt ist, geht in dem Abstraktionsprozess verloren. Die ursprünglichen Motive aus Mythen und Sagen werden entmachtet und verwandelt. Die profanen Motive wie Liebe und Erotik werden zu einem Bild mit scharfer Kontur entwirklicht. ${ }^{18}$ Auch die Figuren sind keine realitätsbezogenen Typen, sondern reine Handlungsträger. „[D]ie einzige Forderung, die sie zu erfüllen [haben], ist scharfe Sichtbarkeit, extreme Ausformung. "19 Die innerseelischen Vorgänge der Figuren werden zu sichtbaren Handlungsbildern sublimiert.

Aufgrund der Isoliertheit und der Sinnentleerung der Märchenelemente eignen sie sich besonders dazu, zu einem Symbol zu werden und als bewegliche Requisiten von anderen Texten adaptiert zu werden. Da das ursprüngliche Signifikat eines Symbols als formelhaftes Zeichen (zum Beispiel die Innerlichkeit einer Märchenfigur) entleert ist, gilt es, dem Signifikant (die Märchenfigur) eine neue Bedeutung zu verleihen. Wenn Thomas Mann beispielsweise die Märchenfiguren Hänsel und Gretel zu den stöbernden fürstlichen Geschwistern Klaus Heinrich und Ditlind transformiert, zitiert er nicht nur die sich verlaufenden Kinderfiguren aus dem Grimm'schen Märchen, sondern verleiht dem Märchenstoff auch eine Hindeutung auf die bedrohliche mütterliche Welt sowie auf die Flucht vor dieser.

\section{Das Kunstmärchen und die ,Grenze' zwischen Kunstmärchen, Novelle und Roman}

In der gegenwärtigen Forschung ist unter dem Begriff Kunstmärchen eine Märchenerzählung zu verstehen, die, anders als das anonym überlieferte Volksmärchen, auf einen bestimmten Autor zurückzuführen ist und „die sich thematisch, strukturell und vor allem motivisch an das Modell des Volksmärchens anlehnt."20 Die Bezeichnung Kunstmärchen weist nicht nur auf den artifiziellen Wert dieser Märchen hin, sondern auf deren synthetisches Sein. ${ }^{21}$ Das Kunstmärchen ist ein Produkt künstlerischer Erfindungskraft. Damit spielen die sich distanzierende Selbstreflexion des Autors und die absichtliche Anlehnung an das Märchenmodell eine erhebliche Rolle im Kunstmärchen. Das Märchenwunder gilt häufig nicht mehr als

\footnotetext{
${ }^{18}$ Durch die Entleerung aller Motive gehen „Konkretheit und Realität, Erlebnis und Beziehungstiefe, Nuancierung und Inhaltsschwere“ (Lüthi 2005, S. 69) des Märchens verloren. Andererseits fügen sich die entleerten und isolierten Motive mühelos zu einem Zusammenspiel, in dem die Welt als Universum eingeschlossen ist. Alle wesentlichen Elemente des menschlichen Seins werden im Märchen gespiegelt. Die entmachteten Motive sind „Zwar keine Realität mehr; aber sie repräsentieren sie“ (Lüthi 2005, S. 75).

${ }^{19}$ Lüthi 2005, S. 68.

${ }^{20}$ Rölleke 2009, S. 447.

${ }^{21}$ Vgl. Mayer/Tismar 2003, S. 1f; Klotz 2002, S. 7 u. S. 9.
} 
selbstverständliches Geschehnis und eine Kette der Handlungslinie, sondern als „Gattungskonstituierend (und oft im Mittelpunkt stehend). "22 Während die Gegenüberstellung des Wunderbaren zu der Realität typisch für die modernen Kunstmärchen ist, wird das Wunderbare durch den Autor doppel- oder mehrperspektivisch interpretiert. Insofern rückt das Kunstmärchen der phantastischen Literatur näher, ,in der in einer realistisch gezeichneten Welt als übernatürlich erscheinende Ereignisse eintreten, deren Status häufig nicht oder nicht eindeutig geklärt werden kann." 23 Darüber hinaus unterscheidet sich das Kunstmärchen dadurch vom Volksmärchen, dass seine Figuren nicht mehr durch Flächenhaftigkeit und Isolation gekennzeichnet sind und dass es oft auf ein schematisches Happy Ending verzichtet. ${ }^{24}$

Die ersten europäischen Kunstmärchen entstanden im 16. Jahrhundert nach den antiken mythischen sowie den mittelalterlichen epischen Vorformen. ${ }^{25}$ In den Sammlungen Il novellino ${ }^{26}$, Straparolas Le piacevoli notti (1550-53), Basiles Lo cunto de li cunti (1634-36) und Perraults Contes de ma mère l'oie sind sowohl eigenständige Märchendichtungen als auch Bearbeitungen von Volksmärchen zu finden. Schon durch diese Sammlungen ist zu beobachten, dass die Entstehungsgeschichte des Kunstmärchens mit derjenigen der Novelle verbunden ist. Eine Novelle im engeren Sinne ist ein literarischer einsträngiger Erzähltext mittlerer Länge, in deren Zentrum ein Ereignis mit fokussiertem Geschehensmoment erzählt wird, wie es Goethes Definition der Novelle nahelegt:

D] Jenn was ist eine Novelle anders als eine sich ereignete unerhörte Begebenheit. Dies ist der eigentliche Begriff, und so vieles, was in Deutschland unter dem Titel Novelle geht, ist gar keine Novelle, sondern bloß Erzählung oder was Sie sonst wollen. In jenem ursprünglichen Sinne einer unerhörten Begebenheit kommt auch die Novelle in den Wablverwandtschaften vor. [Gespräch vom 29. 01. 1827, HA VI, 726]

Häufig werden Novellen in zyklischer Form präsentiert und in eine Rahmengeschichte eingefasst. ${ }^{27}$ In weiterem Sinne handelt es sich bei dem Begriff der Novelle um einen epischen Text mittlerer Länge und ist identisch mit der Begriff Erzählung. ${ }^{28}$ Denn zahlreiche Texte, die als Novelle gelten, kennen weder ein fokussiertes Geschehensmoment noch ein unerhörtes Ereignis (beispielsweise Eichen-

\footnotetext{
22 Rölleke 2009, S. 447.

${ }^{23}$ Dunker 2009, S. 240. „Das Fantastische ist die Unschlüssigkeit, die ein Mensch empfindet, der nur die natürlichen Gesetze kennt und sich einem Ereignis gegenübersteht, das den Anschein des Übernatürlichen hat." Todorov, S. 26.

${ }^{24}$ Rölleke 2009, S. 447.

${ }^{25}$ Rölleke 2009, S. 448.

${ }^{26}$ Die Sammlung erschien 1525 in der Bearbeitung von Carlo Gualteruzzi und Pietro Bembo, während ihr ursprünglicher Verfasser nicht mehr bekannt ist.

27 Kindt 2009, S. 540.

${ }^{28}$ Vgl. Polheim 1981, S. 16.
} 
dorffs Aus dem Leben eines Taugenichts oder Thomas Manns Tonio Kröger). Seit der Barock-Zeit und der Frühaufklärung erhält die Novelle einen Anspruch auf eine „moralische Exemplarität" ${ }^{\text {“29 }}$ und besitzt keine literarische Eigengesetzlichkeit. Die empirische Wirklichkeit wird in der Novelle nachgeahmt. Gegen Ende des 18. Jahrhundert setzt sich die neue Einsicht durch, „dass es im Medium der Poesie anders zugehen darf als in der Lebenswelt. “30 Die Befreiung der Dichtung von der frühaufklärerischen Verpflichtung auf die Bedürfnisse der Rationalität erfolgt erst durch die französischen Vorbilder zweier Formen: die conte moral und die conte de fées. Die conte moral (etwa Jean-François Marmontels Contes Moraux) erzählt humorvoll-unterhaltsame und moralisch rechte Dinge. Mit dem Moralischen ist das Allgemein Menschliche gemeint, indem es gerade keine scharfe Trennung zwischen dem Guten und dem Bösen gibt. Das französische Feenmärchen findet seine Vorbilder in den romanischen Märchensammlungen des 16. und 17. Jahrhunderts. In der oben genannten Sammlung Lo cunto de li cunti (dt.: Das Märchen der Märchen), in der das Zyklus-Modell des Decameron mit der Phantastik von Tausendundeine Nacbt gemischt wird, werden fünfzig Märchen von fünf Frauen erzählt, unter denen auch Aschenputtel, Schneewittchen und Froschkönig zu finden sind. Diese aus der Volkstradition stammenden Märchen werden „[i]m Gewand eines Novellenzyklus"31 in die europäische Hochliteratur eingeführt und dringen über die französische Rezeption durch Perraults Contes de ma mère l'oye in die deutsch-romantische Dichtung ein. Mit Goethes Novellenzyklus Unterbaltungen deutscher Ausgewanderten inklusive des Märchens setzte sich die Wendung des literarischen Anspruchs vom moralisch didaktischen Zweck zu dem freien Spiel der Einbildungskraft durch.

Anders als die contes de fées im französischen Geschmack [...] verlangt das ,Märchen' der Unterbaltungen nicht nach seiner Entzauberung. Das Erzäblen bietet bier weit mehr, als einer verbindlichen Deutung gut tun kann: ,es füblt ein jeder, er weiß nur nicht was' (Goethe zu Friedrich Wilhelm Riemer, 21. 3. 1809). [...] Weil das Märchen zugleich, bedeutend und deutungslos' (Goethe an Wilhelm von Humboldt, 27. 5. 1796) ist, suspendiert es die Ansprüche des Verstandes an Verständlichkeit und zeigt sich in einer Selbstgewissheit des Ästhetischen, vor der keine Parteilichkeit noch Bestand hat. ${ }^{32}$

Die Unschlïssigkeit (Todorov) wird später auch von zahlreichen Novellen aufgenommen. ${ }^{33}$ Mit dem Manifest von Novalis, ,alles Poëtische muß mährchenhaft seyn" [N III, 449] wird nicht nur die Stellung des Märchens von der Gemütsunterbaltungsliteratur erhöht, sondern auch gefordert, dass die freie Erfindungskraft des

\footnotetext{
${ }^{29}$ Meier/Vrckovski 2014, S. 39.

30 Meier/Vrckovski 2014, S. 45.

31 Meier/Vrckovski 2014, S. 29.

32 Meier/Vrckovski 2014, S. 53.

33 E. T. A. Hoffmanns Ritter Gluck und Theodor Storms Schimmelritter beispielsweise zeigen das Wunderbare im Alltag und bringen einen Freiraum für die Einbildungskraft hervor.
} 
Märchens von allem Poetischen übernommen wird. Diverse Novellen adaptieren bewusst und reflektierend Märchenmotive und -stoffe (zum Beispiel der Taugenichts in Aus dem Leben eines Tangenichts oder das Äpfelweib in Der goldne Topf) und manche Autoren bezeichnen ihre novellistischen Texte als ,Märchen“ oder „Kunstmärchen“ (Der goldne Topff) oder umgekehrt, manche Märchenerzählungen werden lediglich ,Novelle ${ }^{6}$ oder ,Erzählung ${ }^{6}$ genannt (Undine), was die Grenze zwischen Kunstmärchen und Novelle noch weiter verwischt. Den phantastischen Novellen Ludwig Tiecks und E. T. A. Hoffmanns werden sowohl in Schumachers Narziß an der Quelle, Das romantische Kunstmärchen sowie in Klotz' Das europäische Kunstmärchen als auch im Handbuch der deutschen Erzählung sowie in Meiers Novelle. Eine Einführung Besprechungen gewidmet.

Der im Hinblick auf die Zuordnung problematischste Fall in dieser Arbeit ist Chamissos Peter Schlemibls wundersame Geschichte, in der das Übernatürliche (die Schattenlosigkeit des Titelhelden) einerseits den anderen Personen im Text natürlich und selbstverständlich vorkommt, andererseits dem Helden unnatürlich und schauerlich erscheint. Chamisso selbst bezeichnete sein Buch als „ein ganz fabelhaftes, nämlich eine Fabel." 34 Sein Freund Julius Eduard Hitzig, dessen Frau und Kindern er dieses Buch widmete, nannte es ein „Märchen“ [SW I, 777]. Thomas Mann dagegen bestimmte den Text als eine ,phantastische Novelle, da der Text „zu ernst, zu modern-leidenschaftlich“ sei und der Verfasser „die realistischbürgerliche Allüre [...] mit aller Genauigkeit festzuhalten weiß“ [GW IX, 48]. Ernst Loeb sieht in dem Text eine Erzählung, in der die Wirklichkeit gegenüber „den herkömmlichen Märchenrequisiten“ das Übergewicht hat. ${ }^{35}$ Andere Forscher wie Paul-Wolfgang Wührl und Detlef Kremer halten den Text für ein „Wirklichkeitsmärchen" 36 oder ein romantisches Kunstmärchen. ${ }^{37}$ In diesen Erzähltext werden zahlreiche Märchenrequisiten und -motive integriert: „Die echte Springwurzel, Alraunwurzel, Wechselpfennige, Raubtaler, das Tellertuch von Rolands Knappen, Galgenmännlein und Fortunati Hütlein“" [SW I, 35], der Pakt mit dem Teufel und die Siebenmeilenstiefel. Eine märchenhafte Aura wird durch diese Requisiten geschaffen. Jedoch wird eine scharfe Grenze zwischen der ,wirklichen' und der märchenhaften Welt gezogen: Chamisso, Fouqué und Hitzig kommen nur in der Rahmenerzählung, nicht in der Märchenwelt vor und das Manuskript von Schlemibl tritt wie aus dem Nichts in die Welt der Rahmenerzählung ein. Eine Verbindung zwischen dem Märchenhaften und dem Realistischen sowie deren Gegenüberstellung existiert nicht im Text. Für die drei Leser des Manuskripts gilt die wundersame Geschichte wörtlich als ,unerhörtes Ereignis‘. Auch die Binnengeschichte von Peter Schlemihl lässt sich schwer als Märchen verstehen: Sie handelt von der persönlichen und psychologischen Entwicklung des Hel-

\footnotetext{
${ }^{34}$ Chamissos Brief an Louis de la Foye aus dem Jahr 1814. Zit. nach Walach 1982, S. 46.

35 Loeb 1965, S. 401.

36 Wührl 1984, S. 154.

${ }^{37}$ Kremer 2007, S. 195 f.
} 
den. Schlemihl tritt als naiver Einwanderer in die märchenhafte Welt ein und zieht sich schließlich als sentimentalischer Einsiedler in die Natur zurück. Diese Entwicklungslinie ähnelt weit mehr Eichendorffs Roman Ahnung und Gegenwart als einem Kunstmärchen, dessen Zentrum das Märchenwunder bildet. Die Konzentration auf die individuelle Entwicklung statt auf die wundersame Handlung durch den Text ist der Hauptgrund dafür, dass die vorliegende Arbeit Peter Schlemibls wundersame Geschichte als Novelle behandelt.

Der Unterschied zwischen einem Kunstmärchen und einem Roman liegt vor allem in der Länge des Letzteren. Ein Roman gilt generell als „,eine längere Erzählung in Prosa." "38 Eine einheitliche Form von Romanen gibt es nicht. Ein Roman kann je nach thematischen Merkmalen zum Beispiel Abenteuerroman, Liebesroman, Gesellschaftsroman, Bildungsroman ${ }^{39}$, politischer Roman sein, oder je nach strukturellen Merkmalen zum Beispiel Briefroman, Episodenroman, Tagebuchroman sein, wobei strukturelle Merkmale sich häufig aus der Thematik ableiten..$^{40}$ Im Vergleich mit dem Märchen oder mit der Novelle, die auf ein fokussiertes Geschehensmoment zielt, neigt der Roman dazu, „das Leben in seiner Totalität darzustellen. “41 Während die früheren deutschen Romane aus Barock und Frühaufklärung bis auf einige Ausnahmen (beispielsweise Der abenteuerliche Simplicissimus Teutsch von Grimmelshausen) als trivialliterarische Werke angesehen werden, beginnt der deutsche Roman mit Wielands Geschichte des Agathon (1767) intellektuelle Ansprüche zu erfüllen. Der auktoriale Erzähler, der die Romanhandlung kommentierend begleitet, die Psychologisierung und innere Entwicklung der Figur sowie die reflektierende Distanz zu dem Erzählten kennzeichnen die Entstehung des modernen deutschen Romans. ${ }^{42}$ Die vorliegende Arbeit wählt Wielands Die Abentener des Don Sylvio von Rosalva (1764) als den historischen Ausgangspunkt für die nachfolgenden Einzeluntersuchungen, da dieser Roman einerseits noch lustspielhafte Züge der barocken Zeit trägt und die psychologische Entwicklung der Hauptperson oft durch kritische Bemerkungen des Erzählers ersetzt, andererseits aber die oben gelisteten Merkmale moderner Romane zeigt und damit ein Grenzwerk zwischen barockem und modernem Roman ist. Gerade die reflektierende Auseinandersetzung mit dem Märchen durch die Figuren und den Erzähler begründet die Modernität dieses Romans. Dass der Roman zwar kein Märchen ist, diesem aber ein märchenhaftes strukturelles Vorbild zugrunde liegt und er so aus einer anderen Optik auch als eine märchenhafte Geschichte zu verstehen ist, ${ }^{43}$ teilt Don Sylvio von Rosalva mit anderen fiktionalen Texten, die in der vorliegenden Ar-

\footnotetext{
${ }^{38}$ Fludernik 2009, S. 627.

${ }^{39}$ Der Bildungsroman gilt sowohl im Handbuch der literarischen Gattungen (2009) als auch in Formen der Literatur in Einzeldarstellung (1981) als eigenständige Gattung.

${ }^{40}$ Fludernik 2009, S. 637.

${ }^{41}$ Neuhauser 1981, S. 299.

42 Neuhauser 1981, S. 301.

43 Ob Don Sylvios glückliche Verbindung mit Donna Felicia das Ergebnis der Führung durch eine gewisse übernatürliche Kraft ist, bleibt offen.
} 
beit behandelt werden. Die Doppelbödigkeit von Realismus und Märchenhaftigkeit ist die Gemeinsamkeit dieser modernen Erzähltexte. Es lässt sich daher überlegen, ob die bewusste Adaption und die reflektierte Abweichung von einer märchenhaften Struktur zu den speziellen Schreibverfahren der modernen fiktionalen Literatur gehören.

\section{Literatur der Moderne}

Die Literatur der Moderne ist nach zahlreichen Forschern ${ }^{44}$ eine Literatur, die „,in Auseinandersetzung mit der gesellschaftlichen Moderne " ${ }^{\prime 45}$ entsteht. Seit der Debatte über die Moderne im Internationalen Archiv für Sozialgeschichte der deutschen Literatur gibt es mehrere interdisziplinäre Beiträge zu diesem Thema. Die aktuelle literaturwissenschaftliche Forschung unterscheidet im Wesentlichen zwischen zwei Moderne-Begriffen. Nach dem engeren Begriff wird die Moderne als eine Mikroepoche verstanden, die einen ,politisch-institutionellen Umbruch [...] zu Volkssouveränität, geschriebener Verfassung, Demokratie usw."46 und den Anbruch des Maschinenzeitalters voraussetzt und durch die „Pluralisierung, Diversifizierung der Erfahrungsrealität infolge von Masse, Vermassung, Beschleunigung und Schnelllebigkeit, soziale und kulturelle Mobilität, Ganzheitsverlust, u.a. "47, durch einen „für die Gesellschaft [...] der Nachkriegszeit entscheidenden Denkschritt vom Individualismus zum Kollektivismus“48 und durch die „Dominanz kollektiver Milieus" 49 gekennzeichnet ist. Die Moderne bezeichnet dementsprechend ein Zeitalter der Massenzivilisation und Industrialisierung. Die Mikroepoche der Moderne beginnt im späten 19. Jahrhundert und umfasst die ersten drei Jahrzehnte des 20. Jahrhunderts. ${ }^{50}$ Dieser mikroepochale Begriff ist mit dem deutschsprachigen Moderne-Begriff, der in dem Vortrag von Eugen Wolff im Rahmen einer Sitzung des naturalistischen Literaturvereins Durch! 1886 entsteht, verbunden. Da Wolffs Vortrag zur Abgrenzung des Naturalismus vom Klassizismus diente, gilt die Moderne in ihrer Ursprungsbedeutung als ein „Kampfbegriff zur Durchsetzung von Neuerungen“" 51 , was zwangsläufig in dem mikroepochalen Moderne-Begriff als Nebensinn eingeschlossen ist. Es ist daher problematisch, ob Autoren wie Thomas Mann, in deren Texten kein radikaler Traditionsbruch nachzuweisen ist, auch als moderne Autoren einzuordnen sind. Der Vorschlag, von

\footnotetext{
${ }^{44}$ Zum Beispiel Sabine Beckers Jenseits der Moderne. Thomas Manns Romanästhetik in der Weimarer Republik (2009); Anke-Marie Lohmeiers Was ist eigentlich modern? (2007) und Dirk von Petersdorffs Die Öffnung des ästhetischen Feldes (2009).

45 Becker 2009, S. 87.

${ }^{46}$ Dipper 2009, S. 200.

${ }^{47}$ Becker 2009, S. 83.

48 Becker 2009, S. 88.

49 Becker 2009, S. 93.

${ }^{50}$ Löwe 2016, S. 12.

${ }^{51}$ Engel 2014, S. 249.
} 
Moderne als eine Makroepoche zu sprechen, die im späten 18. Jahrhundert beginnt, kann diese Problematik vermeiden und besitzt zudem den Vorteil, ,interdisziplinär anschlussfähig“ ${ }^{\text {52 }}$ zu sein. Die historischen und sozialwissenschaftlichen Begriffe der Moderne beziehen sich ja zumeist auf diesen weiten Begriffsgebrauch. Die Ansicht der Historiker, dass die Moderne immer noch zukunftsoffen ist ${ }^{53}$, lässt sich beispielsweise zu den Merkmalen des makroepochalen Moderne-Begriffe rechnen. In der modernen Gesellschaft bilden sich funktionale ausdifferenzierte Teilsysteme eigenständiger Art. „Sie entziehen sich der gegenseitigen Steuerbarkeit und der Koordination von gemeinsamen Zukünften.“" ${ }^{54}$ Die moderne Gesellschaft ist „keine operierende Einheit“ und „keine zu Intentionen, Zwecken oder Zielen strebende Entität“ ${ }^{45} \mathrm{mehr}$, sondern nur „die zunächst ungeordnete, chaotische, sich selbst alles andere als ,bewusste', ungeplante und in Echtheit operierende Einheit aller möglichen sozialen Handlungen, Kommunikationen, Prozesse." 56 Die moderne Gesellschaft zeichnet sich daher durch die Ambivalenz und den Verlust der Ganzheit der Perspektiven aus. Die moderne Kunst entsteht unter den Bedingungen der modernen Gesellschaft und soll „diese Bedingungen direkt oder indirekt reflektierend mitvollziehen ". ${ }^{57}$ Eine solche moderne Kunst entsteht im späten 18. Jahrhundert, als die Künstler anfingen, die Kunst von den Aufgaben, der Politik, Religion, Moral oder Wissenschaft, auf die sie verpflichtet war, zu befreien. Die moderne - autonome - Kunst versteht sich als ein eigenständiges Organ zur Beobachtung und Deutung der Wirklichkeit. Sie ist seit dem 18. Jahrhundert zugleich eines der „Reflexionsorgane“ und eines der „Vollzugsorgane“ ${ }^{\text {“58 }}$ von Modernisierung und muss sich daher „mit einer Umwelt auseinandersetzen, in der verschiedene und konkurrierende Weltdeutungen existieren." $59 \mathrm{Da}$ das Zentrum der Gesellschaft nicht mehr existiert, kann sich die Kunst nur auf Teilbereiche beziehen. Sie kann zwar ein neues Zentrum imaginieren und postulieren, aber genau das setzt das Fehlen des Zentrums voraus. Sie kann den Wahrheitspluralismus nicht mehr vermeiden und aufheben. Schließlich existiert „kein zwangsläufiger, ontologisch abgesicherter Modus der Umweltwahrnehmung " ${ }^{\prime 60} \mathrm{mehr}$. Die moderne Kunst kann ihrer Diskussion über ihre Verhältnisse zu der Umwelt kein

\footnotetext{
52 Löwe 2016, S. 15.

${ }^{53}$ Für die Frage, ob die Moderne ein Ende hat oder bereits zu Ende ist, haben die Historiker und die Soziologen verschiedene Antworten. „Die Mehrzahl der Soziologen und die wenigen Historiker, die sich die Frage überhaupt vorlegen, vertreten die Ansicht, dass wir vor kurzem in einen neuen Abschnitt eingetreten sind, und nennen diesen überwiegend Postmoderne." Dipper 2009, S. 209. Nach Dipper sei es möglich, dass die Moderne zu Ende gegangen wäre. Doch sei es für uns Modernen erkenntnistheoretisch unmöglich, die Indizien dieses Endes zu erkennen.

54 Petersdorff 2009, S. 230.

55 Nassehi, 2006, S. 421.

56 Nassehi 2006, S. 421.

57 Petersdorff 2009, S. 231.

58 Lohmeier 2007, S. 9.

59 Petersdorff 2009, S. 231.

60 Petersdorff 2009, S. 231.
} 
Ende setzen. Eine solche ästhetische Moderne umfasst nicht nur die Kunst seit dem späten 19. Jahrhundert. Sowohl die aufklärerische Literatur, die seine Leser auffordert, Mut zu haben („Sapere aude! “) und sich des eigenen Verstandes zu bedienen, die romantische Literatur, die die Welt nicht mehr als eine Ganzheit und die fragmentarische Form der Kunst als das angemessene Sein der Literatur versteht und die sich ironisch selbst reflektiert, als auch die realistische Literatur, die die Wirklichkeit poetisch rekonstruiert, gehören dennoch zur modernen Literatur. Auch Thomas Manns fiktionale Texte, die aufgrund ihrer ,ironischen Grundstruktur"61 die gesellschaftliche Modernisierung weder abwehren noch bejahen, gelten als moderne Kunst.

Die vorliegende Arbeit diskutiert die intertextuellen Verhältnisse der Erzähltexte aus einem Zeitraum von Christoph Martin Wieland bis zu Thomas Mann. Die Adaption der Märchenprätexte durch diese Texte verleiht ihnen einen erweiterten Sinnhorizont und trägt zu ihrem Bedeutungspluralismus bei. Die vorliegende Arbeit versteht die Moderne im Sinne der Makroepoche. In dem Hauptteil wird die literarische Modernität des jeweiligen Textes berücksichtigt und ein kurzer Ausblick darauf, dass die Märchenadaption ein spezielles Verfahren der literarischen Moderne ist, wird in dem Schlusskapitel der Arbeit gegeben.

\section{Intertextuelle Theorien}

Der Begriff Märchenadaption impliziert eine spezielle Form der Präsenz des Märchens in einem anderen Erzähltext. In den von der vorliegenden Arbeit behandelten Erzähltexten kann diese Präsenzform Zitat, Anspielung, Kontrafaktur, Parodie, Imitation oder Bearbeitung sein. Die Art, wie die Erzähltexte auf Märchen referieren, kann systematisch differenziert werden, je nachdem, ob auf Einzeltexte oder auf die Gattung generell referiert wird. Aufgrund der Vielfältigkeit der Referenzformen wendet die vorliegende Arbeit nicht die intertextuelle Theorie eines bestimmten Theoretikers, sondern greift nach unterschiedlichen Theorien und Begrifflichkeiten, die als Grundlage für die Untersuchung von verschiedenen zu behandelnden Formen der Märchenadaption jeweils einleuchtend sind.

Die Intertextualität wird im Reallexikon der deutschen Literaturvissenschaft als der „Bezug zwischen einem Text und anderen Texten“62 definiert. Um den Bezug zwischen einem Text und seinem Prätext/seinen Prätexten zu erkennen, muss der Leser ihre Ähnlichkeit und die Differenz finden. Bestimmte Merkmale in einem Erzähltext sollen erkennbar sein, die auf die Verbindungen zwischen dem vorliegenden Text und seinen Prätext verweisen. In den von der vorliegenden Arbeit untersuchten Erzähltexten kennzeichnen beispielsweise bestimmte Requisiten

\footnotetext{
61 Ewen 2013, S. 79.

${ }^{62}$ Broich 2000, S. 175. In: Fricke 2000, S. 175 - 179.
} 
direkt aus bekannten Märchentexten ${ }^{63}$ oder motivische oder thematische Anspielung von Märchen ${ }^{64}$ oder die Nachahmung von Struktur und Gattungsmerkmalen des Märchens (Figurenkonstellation, Raum- und Zeitlosigkeit, abstrakter Stil) die Existenz der Prätexte. Die Differenz zwischen Prätext und neuem Text kann nicht nur erkennbar sein an variierenden Bearbeitungen der prätextuellen Elemente, sondern auch an gezielten Abweichungen von Prätexten.

Die verzerrende oder verspottende Wiedergabe des Prätextes heißt Parodie. Obwohl die Parodie nicht notwendig eine komische Nachahmung sein muss, wird der Begriff in der Literaturwissenschaft häufig in diesem Sinn gebraucht. „Die strengste Form der Parodie, die Minimalparodie, besteht $[. .$.$] in der wörtlichen$ Wiederholung eines bekannten Textes, dem eine neue Bedeutung gegeben wird."“65 Wörtliche Wiederholung ist allerdings die extreme Form der Parodie. ${ }^{66}$ Die Parodie verweist auf die Elemente oder die Struktur der Vorlage und verzerrt deren Thema oder bringt eine komische Wirkung hervor. Der komische Gebrauch von Märchenelementen und -strukturen durch Don Sylvio von Rosalva und besonders das eingebettete erotische Kunstmärchen von Prinzen Biribinker können als Parodie des Feenmärchens gelten, durch die das Thema Zauber und Fatalismus durch menschliche Vernunft und menschliches Begehren ersetzt wird.

Die Kontrafaktur ist ein Schreibverfahren, „,bei dem konstitutive Merkmale der Ausdrucksebene eines Einzeltextes oder mehrerer Texte zur Formulierung einer Botschaft übernommen werden" ${ }^{\text {"67 }}$, aber keine komische Nachahmung ihrer Vorlagen. Weiterhin unterscheidet sie sich von der Parodie durch den Verzicht auf den Verweis auf ihre Vorlagen. Die Vorlagen sind für die Kontrafaktur „nicht zugleich Thema der Adaption, sondern lediglich Objekt der Aneignung ${ }^{\text {"60 }}$, weshalb eine Kontrafaktur weder unbedingt komisch reflektierend noch kritisch distanzierend sein muss. Sie stelle nach Verweyen/Witting nur eine „Ausnutzung eines kommunikativen Potentials der Vorlage für die eigene Äußerungsabsicht" ${ }^{\text {“69 }}$ dar und will die Vorlagen nicht komisch herabsetzen. Da diese Begrifflichkeit die satirischen Fälle ausschließt, die lediglich das kommunikative Potential der Vorlagen ausnutzen und sich gegen die Vorlagen richten, ist Verweyen/Wittings Definition von Kontrafaktur durch Harald Frickes These zu verbessern: Die Kontrafaktur richtet sich ,gegen die eigentliche Aussage des variierten oder gar genau umgedrehten Ausspruchs" ${ }^{\text {"70 }}$.

\footnotetext{
${ }^{63}$ Zum Beispiel die Siebenmeilenstiefel in Peter Schlemihls wunderbare Geschichten aus Ludwig Tiecks Leben und Thaten des kleinen Thomas, genannt Däumchen. Ein Märchen in drei Akten. ${ }^{64}$ Zum Beispiel der Tisch mit einer ,achteckige[n] Platte aus milchiger Perlenmutter“ [GKFA 4.1, 63] in dem Silbersaal in Königliche Hoheit als Anspielung von dem Schloss der Schneekönigin.

65 Genette 1993, S. 29.

${ }^{66}$ Böhn 2001, S. 49.

${ }^{67}$ Verweyen/Witting 2007, S. 337.

68 Verweyen/Witting 1987, S. 27.

${ }^{69}$ Verweyen/Witting 1987, S. 75.

${ }^{70}$ Fricke 1984, S. 147. Vgl. Ranke 1992, S. 18, Anmerkung 27.
} 
Insofern können die meisten Märchenadaptionen durch die von der vorliegenden Arbeit untersuchten Erzähltexte als Kontrafaktur verstanden werden. Die Märchenadaptionen durch Thomas Manns Königliche Hoheit beispielsweise beziehen sich auf Hans Christian Andersens Märchen, zielen allerdings nicht auf die Märchentexte an sich, sondern auf deren Themen (Einsamkeit, Absonderlichkeit und so weiter). Damit bedient sich Thomas Mann seiner Vorlagen als Vermittlung zur Kommunikation mit den erwählten Lesern. Das kommunikative Potential der Prätexte (die Märchen) wird von Thomas Manns neuem Text als ein zugrundeliegendes Codesystem ausgenutzt.

Jeder Autor muss auch Leser sein und jeder literarische Text setzt eine Auseinandersetzung mit Vorlagen voraus. Nach Gérard Genette überlagert jeder literarische Text andere Texte und ist dadurch Literatur auf zweiter Stufe. In seinem Buch Palimpseste. Die Literatur zpeiter Stufe untersucht er das Phänomen der Transtextualität, die er in einer früheren Untersuchung Paratextualität genannt hat. ${ }^{71}$ Die Transtextualität oder textuelle Transzendenz des Textes bezeichnet Genette als alles, „was ihn in eine manifeste oder geheime Beziehung zu anderen Texten bringt ${ }^{\text {" } 72}$ und ist nach Genette somit der Oberbegriff aller transtextuellen Beziehungen. Es gibt insgesamt fünf Typen transtextueller Beziehungen: Intertextualität, Paratextualität, Metatextualität, Hypertextualität, Architextualität. ${ }^{73}$ Eine ausführliche Zuordnung jeder intertextuellen Einzelheit in Bezug auf die Märchenadaption aus allen sechs Erzähltexten zu Genettes Systematik ist allerdings nicht das Ziel von der vorliegenden Arbeit. Aus diesen Begrifflichkeit bediene ich mich unter anderem der Paratextualität.

Paratextualität betrifft die Beziehung des Textes zu seinem Paratext.

Titel, Untertitel, Zwischentitel; Vorworte, Nachworte, Hinweise an den Leser, Einleitungen usw.; Marginalien, Fußnoten, Anmerkungen; Motti; Illustrationen; $W$ aschzettel, Schleifen, Umschlag und viele andere Arten zusätzlicher, auto- oder allographer Signale, die den Text mit einer (variablen) Umgebung ausstatten und manchmal mit einem offiziellen oder offiziösen Kommentar versehen, dem sich auch der puristischste und äußeren Informationen gegenüber skeptischste Leser nicht so leicht entziehen kann, wie er möchte und es zu tun behauptet. ${ }^{74}$

\footnotetext{
${ }^{71}$ Genette 1993, S. 9.

${ }^{72}$ Genette 1993, S. 9.

${ }^{73}$ Während Genette in Palimpseste die Oberbegriff Intertextualität durch Transtextualität ersetzt und diese als die „Beziehung der Kopräsenz zweier oder mehrerer Texte, d. h. [...] effektive Präsenz eines Textes in einem anderen Text" (Genette 1993, S. 10) erklärt, beschränkt er die Bedeutung der Intertextualität in seiner Systematik auf Zitat, Plagiat oder Anspielung. Bei der Metatextualität handelt es sich um den Kommentar zu einem Text durch einen anderen. Unter Hypertextualität versteht Genette jede Beziehung zwischen einen Text und seinem Prätext, wobei der Text den Prätext „auf eine Art und Weise überlagert, die nicht die des Kommentars ist" (Genette 1993, S. 15. Genettes Bezeichnung Hypotext wird in der vorliegenden Arbeit Prätext genannt). Bei der Architextualität handelt es sich um die Zugehörigkeit eines Textes zu einer oder mehreren bestimmten Gattungen.

${ }^{74}$ Genette 1993, S. $11 \mathrm{f}$.
} 
Mit der Wirkung des Paratextes auf die Leser schließt der Autor einen „Gattungsvertrag ${ }^{\text {‘ } 75}$ mit den Lesern ab. Der ,Roman` auf dem Umschlag von Königliche Hoheit ist beispielsweise ein Hinweis für die Leser, dass dieses Buch als Roman gelesen werden soll, während der Autor Thomas Mann den Roman in seinen beiden Essays über Königliche Hoheit als Märchen bezeichnet und in dem Vorwort zu einer amerikanischen Ausgabe von Königliche Hoheit das autobiographische Schreibverfahren betont. Die Leser sollen deswegen besondere Aufmerksamkeit auf das Märchenhafte und das Autobiographische in dem Roman richten und sich über deren Rolle im Roman Gedanken machen. „Du bist Kaiser (Czar) - lebe allein!“ [GKFA 4.2, 345], was in Thomas Manns Notizbuch als mögliches Motto erwogen wird, lenkt die Aufmerksamkeit der Leser auf die Einsamkeit des fürstlichen Daseins. Schließlich weisen die märchenhaften Titel der letzten zwei Kapitel (Die Erfüllung und Der Rosenstock) auf die variierende Adaption von Märchen hin. Alle Paratexte dieses Romans verweisen auf verschiedene Aspekte des Erzähltextes, die zum Verständnis des Textes nach der Absicht des Autors beitragen sollen.

Die Intertextualität eines Erzähltextes kann markiert oder nicht-markiert sein. $\mathrm{Da}$ alle Elemente eines Textes zwangsläufig Vorbilder in dessen sämtlichen Prätexten als Sinnsystemen finden, setzt die Unterscheidung zwischen markierter und nicht-markierter Intertextualität einen engeren Intertextualitätsbegriff voraus. „Nach diesem Konzept liegt Intertextualität dann vor, wenn ein Autor bei der Abfassung seines Textes sich nicht nur der Verwendung anderer Texte bewußt ist, sondern auch vom Rezipienten erwartet, daß er diese Beziehung zwischen seinem Text und anderen Texten als vom Autor intendiert und als wichtig für das Verständnis seines Textes erkennt. ${ }^{\text {" }} 6$ Nicht nur der Autor, sondern auch der Leser gehört die Intertextualität des Textes zu dem Bereich des Gemeinsinnes in ihrem Kommunikationsprozess. Um diesen Kommunikationsprozess zu ermöglichen, markiert der Autor die intertextuellen Bezüge seines Textes. Der Rezipient soll diese Bezüge erkennen und als solche entziffern. Dies gilt für die Märchenadaption in einem Erzähltext, wenn diese als ein intendiertes Schreibverfahren zu rezipieren ist und wenn die Existenz des Märchens oder des Märchenhaften im Erzähltext zu berücksichtigen ist. Wenn der Autor sich der Intertextualität seines Textes nicht bewusst ist und die Intertextualität sich vielmehr als ein unbewusstes Beeinflusstsein durch Prätexte zeigt, werden alle Intertextualitätssignale wahrscheinlich fehlen. Solche Signale sind allerdings nicht notwendig, wenn der Autor seinem Leser auf die Intertextualität hinweisen möchte. Besonders bei Verweisen auf Klassiker, die Bibel oder nicht zuletzt auch Märchen ist es der Fall. ${ }^{77}$ Bekannte Requisiten aus Feenmärchen befinden sich beispielsweise in Wielands Don Sylvio von Rosalva. In der ersten Fassung aus dem Jahr 1764 werden sie nicht markiert, während ihre Prätexte in zwei späteren Fassungen (1772 und 1795) durch Fuß-

\footnotetext{
75 Begriff von Philippe Lejeune. Genette 1993, S. 12.

${ }^{76}$ Broich 19851, S. 31.

77 Vgl. Broich 19851, S. 32.
} 
noten bekanntgegeben sind. Die Markierung unterbricht das Lesen und den selbstständigen Entzifferungsvorgang von den intertextuellen Beziehungen des Lesers, gewährleistet stattdessen den Kommunikationsprozess zwischen dem Autor und seinem Leser.

Schließlich ist noch zwischen der intertextuellen Einzeltextreferenz und der Systemreferenz zu unterscheiden. Wenn in einem Text auf einen anderen Text referiert wird, spricht man von Einzeltextreferenz und der andere Text wird Prätext genannt. Nach Broich gehören die meisten historischen intertextuellen Formen zur Einzeltextreferenz: Zitat, Motto, Cento, Übersetzung, Bearbeitung, imitation, Paraphrase, Resümee, Kontrafaktor und so weiter. Pastiche, Allusion, Parodie und Travestie können sowohl Einzeltextreferenz als auch Systemreferenz sein. ${ }^{78}$ Da die Kontrafaktur in der vorliegenden Arbeit als eine „Ausnutzung eines kommunikativen Potentials" der Vorlagen gilt und sich auch auf die Merkmale einer bestimmten literarischen Gattung beziehen kann, verstehe ich die Kontrafaktur ebenfalls als eine Verbindung von Einzeltext- und Systemreferenz. In den allermeisten Texten, in denen das Verfahren der Einzeltextreferenz vorkommt, sind mehrere Prätexte vorhanden. Wenn die Prätexte eine bestimmte Gruppe von Texten oder gar die Gesamtheit aller Texte bilden, spricht man von einer Systemreferenz. Weil die referierten Systeme sprachliche oder versprachliche Systeme sein sollen, ist die Referenz auf eine historische Figur keine intertextuelle Referenz. Die intertextuellen Bezüge auf eine literarische Gestalt, die in mehreren Texten vorkommt, sind dieses Verfahren eine Einzeltextreferenz statt Systemreferenz. Es gibt die folgenden Dimensionen der Systemreferenz: 1) der Bezug auf die sprachlichen Codes und das Normensystem der Textualität; 2) die Referenz auf ein ausdifferenziertes Subsystem, also an einen bestimmten Diskurs (der religiöse, philosophische, wissenschaftliche, politische und so weiter); 3) die Referenz auf literarische Schreibweisen oder Gattungen; 4) die Referenz auf Mythen oder Archetypen. ${ }^{79}$ Diese Arbeit interessiert sich unter anderem auf die Referenz auf die literarische Gattung Märchen, was sowohl vorgegebene Gattungsmuster fortschreiben als auch diese variieren, durchbrechen, bewusst machen oder thematisieren kann. Die Unterscheidung zwischen Einzeltext- und Systemreferenz in einem Text ist nicht immer eindeutig, weil die beiden manchmal zugleich vorkommen. In den meisten Erzähltexten, die durch die vorliegende Arbeit zu behandeln sind, sind die beiden Fälle vorhanden. Ob ein bestimmtes Märchenrequisit auf seinen herkünftlichen Märchentext oder auf die Gattung Märchen hinweist und welche Bedeutungen solche Referenz besitzt, sind im Hauptteil dieser Arbeit exemplarisch zu beantworten.

\footnotetext{
78 Broich $1985^{2}$, S. 49.

${ }^{79}$ Vgl. Pfister 1985, S. $55 \mathrm{ff}$.
} 



\section{Christoph Martin Wieland: Die Abenteuer des Don Sylvio von Rosalva}

Christoph Martin Wielands Roman Der Sieg der Natur über die Schwärmerei oder die Abenteuer des Don Sylvio von Rosalva. Eine Geschichte worinn alles Wunderbare natürlich zugeht $(1764)^{80}$ ist nach Wolfgang Kayser der erste moderne deutsche Roman wegen seines persönlichen Erzählers. Sven-Aage Jørgensen schreibt in seinem Nachwort zu diesem Roman, dass Don Sylvio von Rosalva als „de[r] erste[ deutsche[ Roman für den ästhetischen Kopf, von modernem Geschmack zu charakterisieren" 81 sei. Don Sylvio von Rosalva schließt an die Tradition der neueren englischen und französischen Romane (z. B. Histoire de Gil Blas de Santillane von Alain-René Lesage und die Romane von Henry Fielding und Lawrence Sterne) an. Ein moderner Entwicklungsroman ist dieser Erstlingsroman Wielands jedoch noch nicht, weil die Psychologisierung der Figuren hier zum großen Teil durch die kritischen Betrachtungen des Erzählers ersetzt ist. Der Roman kennzeichnet einen Markstein auf Wielands Weg von der Rokoko-Literatur zum psychologischen Roman.

Die Grundstruktur und das Grundthema von Wielands späterem Erzählen entstehen schon in Don Sylvio von Rosalva. Stilistisch befindet sich der Roman zwi-

\footnotetext{
${ }^{80}$ In dieser Arbeit wird der Titel des Romans als Don Sylvio von Rosalva abgekürzt.

81 Jørgensen 2001, S. 509.
} 
schen Rokoko-Lustspiel und aufklärerischem Roman. In diesem Roman verbinden sich „Phantasie, Gefühl, Ironie, Philosophie und psychologisch-pädagogischer Aufklärung “82. Hier werden der witzig-anmutige Stil des Rokoko mit der humanistischen Entwicklungs- und Bildungsphilosophie verknüpft, obwohl die lustspielhafte Typenhaftigkeit des Rokoko in Bezug auf die Figuren immer noch eine gröBere Rolle als die geistige Entwicklung spielt. Thematisch zeigt der Roman eine Wandlung des Titelhelden vom Egozentrismus zur Weltbürgerschaft. Die für Wielands Roman charakteristischen Themen werden in diesem Roman zum ersten Mal vorgeführt: „Abbau der metaphysischen Lebensaspekte, Wendung zur diesseitigen Wirklichkeit, zur Psychologie von Seele und Leib, Wendung zur inneren ,geheimen“ Geschichte des einzelnen Menschen“83. Der „einzelne Mensch“ ist hier noch kein ganz persönliches Individuum, sondern ein typisches und generelles Exemplar einer Gruppe, wie Don Sylvio ein typischer Märchenschwärmer ist. Diese Eigenschaften des Übergangs von Rokoko zur Modernen sind der Grund, warum die vorliegende Arbeit die erste Fassung des Romans statt der späteren zwei Fassungen zum Untersuchungsobjekt nimmt.

1774 bekennt Wieland, dass der Roman eine „Nachahmung des Spanischen Don Quichotte“"84 sei. Die Geschichte des Don Sylvio verläuft nach dem Vorbild des Don Quijote (1605/1615): Der spanische junge Adlige Don Sylvio verfällt Feenmärchen. In Begleitung von seinem Diener Pedrillo macht sich der Held auf den Weg, um eine vermeintlich verzauberte Prinzessin zu befreien, deren Portrait er zufällig gefunden hat. Nach mehreren Abenteuern parodistischer Art ${ }^{85}$ begegnet er Donna Felicia, die genauso wie das Bildnis aussieht. Durch die Liebe zu Felicia und das satirische Märchen vom Prinzen Biribinker, das Don Gabriel in der Gesellschaft von Felicia erzählt, erkennt Don Sylvio seine Verwechselung zwischen Fiktion und Wirklichkeit und wird von seinem Wahn geheilt. Die grundlegende Idee des Textes übernimmt Wieland offensichtlich von Don Quijote und ersetzt dessen Ritterromane durch Feenmärchen. Don Sylvio von Rosalva verweist allerdings nicht nur auf Cervantes' Roman. Wie die Skizze des Romaninhalts bereits zeigt, bezieht sich die Entwicklung der Geschichte auf das Märchenmuster. Don Sylvio lässt sich als ein Märchenheld verstehen, weil er nach seinen Abenteuern erlöst wird und seine „Märchenprinzessin“" wunschgemäß heiratet. Als Band 36 wird die französische Übersetzung des Romans (Les Aventures merveilleuses de Don Silvio de Rosalva) 1786 in die Märchensammlung Le Cabinet des Fées aufgenommen.

\footnotetext{
82 Martini 1964, S. 915.

83 Martini 1964, S. 916.

${ }^{84}$ Kurrelmeyer 1919, S. 141.

${ }^{85}$ Die Abenteuer mit dem Frosch, mit den Grasnymphen und mit vielen anderen sind insofern parodistisch, dass sie aus der Ansicht von Don Sylvio eine treue Wiedergabe der Märchentexte sind, während ihnen eine realistische Bedeutung verleiht werden. Daher erscheinen die Abenteuer als komische Nachahmungen von Märchentexten durch Don Sylvios Einbildungskraft.
} 
Der Roman parodiert viele Elemente aus Märchen, indem er das Wunderbare als reines Bewusstseinsphänomen relativiert, erzählt andererseits eine märchenhafte Geschichte in einer Welt, die sich als Fiktion entpuppt: Donna Felicia ist nämlich die Enkelin von Gil Blas und Dorothea von Jutella aus Histoire de Gil Blas de Santillane (1715-1735). Die Adaption von Märchenelementen in diesem Roman zu untersuchen, ist ein Ziel dieses Kapitels.

Die intertextuelle Bezugnahme des Romans auf andere Texte und Gattungen beschränkt sich nicht auf die inhaltlichen und strukturellen Adaptionen. Wie Walter Erhart bemerkt repräsentieren alle Hauptfiguren verschiedene Typen von Lesern. ${ }^{86}$ Viele Hauptfiguren sind auch Erzähler und ihr Erzählen ist häufig von der literarischen Gattung, die sie bevorzugen, geprägt. Etwas Besondere ist das Märchen-Erzählen von Don Sylvio. Denn als ein in der subjektiven Welt lebender Schwärmer sind seine Abenteuer oder sein Weg nach Lirias an sich schon eine Märchenerzählung parodistischer Art. Sein Märchen ist jedoch keine eigenständige Dichtung, weil er nicht zwischen Sein und Bewusstsein unterscheidet und kein Schöpfer einer abgeschlossenen Welt sein kann. Er ist vielmehr ein Held in schon vorhandenen Märchen als der Dichter eines neuen Werkes. Die Erlösung von Don Sylvio erfolgt ironischerweise durch seine Desillusion - das Ende seines ,Märchens‘. Die intertextuellen Gattungsspiele und Don Sylvios Rolle in seiner Märchenwelt zu analysieren, ist die Aufgabe von dem dritten Abschnitt in diesem Kapitel.

Das letzte Untersuchungsobjekt ist Don Sylvios Wandlung von einem egozentrischen Schwärmer zu einem Weltbürger. Die Entwicklung Don Sylvios ${ }^{87}$ entspricht dem aufklärerischen Konzept der menschlichen Entwicklung. Das Märchen mit Don Sylvio als Helden ist mit seiner Erlösung beendet. Als nächstes soll der gesellschaftlich integrierte junge Mann versuchen, ein neues Werk aus seinen Erfahrungen mit kritischem Bewusstsein zu dichten und seine Mitbürger dadurch zu erziehen, was auch das Ziel des unterhaltsamen Romans Don Sylvio von Rosalva ist.

Um die gelisteten Aufgaben zu erfüllen, sollen die aufklärerischen Märchentheorien sowie Wielands Märchentheorie als Voraussetzung der Untersuchung in dem nächsten Abschnitt wiedergegeben werden.

\footnotetext{
86 Erhart 1991, S. 66.

${ }^{87}$ Die Ausbildung des Helden durch die Ideen wirklicher Dinge wird nur am Ende des Romans vorausgesagt.
} 


\subsection{Die Märchentheorie der Aufklärung - Wielands Märchentheorie}

Der Begriff Kunstmärchen ist trotz seiner großen Beliebtheit in der deutschen Literatur des 18. sowie 19. Jahrhunderts keine deutsche Erfindung. Die Ursprünge dieser Literaturgattung finden sich im Frankreich des ausgehenden 17. Jahrhunderts. Nacheinander erschienen Charles Perraults Contes de ma mère l'Oye (1695) und die vierbändige Märchensammlung unter dem Titel Contes des fées (1696-1698) von Madame d'Aulnoy. Die einfachen Feenmärchen wurden in der ausgebildeten Hofgesellschaft und in den Salons zum Zeitvertreib erzählt. Neben dieser Mode der kleinen Erzählungen europäischen Stils wurden orientalische Märchen sehr beliebt. Zwischen 1704 und 1717 wurde eine zwölfbändige Übersetzung der Tausendundeinen Nacht durch Galland veröffentlicht, die einer literarischen Neugestaltung nahekommt. „Verlockend Neues wurde nicht allein durch die exotischen Handlungsräume mit ihren kolossal üppigen Palästen und den wimmelnden Bazars geboten, sondern vor allem durch die Dominanz des Sexuellen." ${ }^{\text {"88 }}$ Die offene Darstellung eines literarischen Tabus ist ein Grund der Beliebtheit des orientalischen Märchens unter den französischen Lesern. Dieser Kontrast zu der galanten, arkadischen Form der französischen Salonmärchen brachte der Gattung Conte de fées eine exotische Auffrischung. Die französischen Autoren fingen an, Märchen in orientalischer Manier zu schreiben oder morgenländische mit Feenmärchen zu einer Mischform zu verbinden. ${ }^{89}$

In der ersten Hälfte des 18. Jahrhunderts wurden die französischen Märchen kaum ins Deutsche übersetzt, während die orientalischen Sammlungen schon am Anfang des 18. Jahrhunderts ins Deutsche übertragen wurden..$^{90}$ Erst als der Einfluss der Contes de fées in Frankreich schon abnahm, wurden die französischen Feenmärchen in Form von mehrbändigen Anthologien übersetzt. ${ }^{91}$ Obwohl die Leserbedürfnisse und die pädagogische Funktion des Märchens den Anlass zu einer Märchenproduktion in Deutschland geben, war ein ,wesensmäßiger Unterschied zwischen deutscher und französischer Märchenauffassung oder -rezeption [...] bis in das zweite Drittel des 18. Jahrhunderts nicht erkennbar ${ }^{\text {( } 92}$.

\footnotetext{
88 Mayer/Tismar 2003, S. 28. Die eingebettete Geschichte vom Prinzen Biribinker in Don Sylvio von Rosalvo ist ein erotisches Märchen mit exotischem Hintergrund, das sowohl orientalische als auch französische Märchenelemente adaptiert. Die Figur des Königs ist beispielsweise „der Gallerie von Caricaturen des orientalischen Despotismus" entnehmen. Mayer 1892, S. 399. Das Motiv des von einer gekränkten Fee verwünschten Königskindes entspricht Perraults La Belle au bois dormant. Petrikowski 2012, S. 372.

${ }^{89}$ Vgl. Mayer/Tismar 2003, S. 28.

90 Vgl. Grätz 1988, S. 33ff. Die erste Übertragung von Tausendundeiner Nacht erschien schon 1710 und eine zweite Auflage 1712.

${ }^{91}$ Einflussreiche Sammlungen sind der elfbändige Abendzeitvertreib in verschiedenen Erzeblungen sowie ihre vierzehnbändige Fortsetzung von Justus Heinrich Saal und das neunbändige Cabinett der Feen von Friedrich Immanuel Bierling. Vgl. Mayer/Tismar 2003, S. 32.

${ }^{92}$ Grätz 1988, S. 86.
} 
Eine Entwicklung der Märchentheorien im deutschsprachigen Raum kam früher als die eigenständige Produktion von Kunstmärchen und beeinflusste diese. In diesen theoretischen Abhandlungen wird die Rolle des Wunderbaren im Märchen vor dem Hintergrund der Aufklärung besonders diskutiert. In seinem Versuch einer critischen Dichtkunst (1730) forderte der Aufklärer Johann Christoph Gottsched „Wahrscheinlichkeit“ für eine moderne Poesie. Die Dichtung müsse zwar nicht unbedingt die empirische Wirklichkeit abbilden, könne auch die „hypothetische Wahrscheinlichkeit“"93 einer möglichen Welt gestalten. Wenn ein allegorischer Sinn in der Darstellung vom Wunderbaren stecke, gelte das Wunderbare als ein gutes Mittel, „bey der Belustigung zu bessern und zu lehren“"94. Eine strukturelle Entsprechung des Wunderbaren mit der Wirklichkeit wurde gefordert. Während die didaktische Funktion des Wunderbaren in der Dichtung akzeptiert wurde, hatte Gottsched kein positives Urteil über die Gattung Märchen: „Die Contes de Fées dienen ja nur zum Spotte und Zeitvertreibe müßiger Dirnen, und witzarmer Stutzer; führen aber auch nicht die geringste Wahrscheinlichkeit bey sich." ${ }^{\text {“95 }}$

Die Zürcher aufklärerischen Theoretiker Bodmer und Breitinger forderten trotz ihrer Gegenposition zu Gottscheds Versuch einer critischen Dichtkunst ebenfalls die didaktische Aufgabe der Dichtung, nämlich „das Ergetzen und die Verbesserung des größern Haufens der Menschen“"96. Da nur das Neue und das Wunderbare ergötzen kann, sei es nötig, dass „ein lehrreiches Wunderbares“ “97 die Moral dem menschlichen Gemüt auf eine versteckte und angenehme Weise beibringe. „Gerade um ihre Belehrungsfunktion aufrechtzuerhalten, muß man zwischen ,dem Wahren des Verstandes“ und dem ,Wahren der Einbildung' unterscheiden. “98 Während das Wahre des Verstandes ,in der alles vermögenden Kraft des Schöpfers der Natur" ${ }^{\circ 99}$ gründet, orientiert das Wahre der Poesie sich auf die Einbildungskraft des Dichters. Da die Poesie als „die Nachahmung der Natur in dem Möglichen“100 gilt, kommt dem Dichter der Name eines Schöpfers zu, „,weil er nicht alleine durch seine Kunst unsichtbaren Dingen sichtbare Leiber mittheilet, sondern auch die Dinge, die nicht für die Sinnen sind, gleichsam erschaffet, das ist, aus dem Stande der Möglichkeit in den Stand der Würcklichkeit hinüberbringet, und ihm also den Schein und den Namen der Würcklichkeit mittheilet"101. Es ist nicht mehr die Natur, sondern die Natürlichkeit im wirkungspoetischen Sinne, die die dichterische Tätigkeit bestimmt. ${ }^{102}$ Die Aufwertung des Wunderbaren und

\footnotetext{
${ }^{93}$ Gottsched VI/1, S. 256.

${ }^{94}$ Gottsched VI/1, S. 225.

${ }^{95}$ Gottsched VI/1, S. 238.

${ }^{96}$ Breitinger Bd. 1, S. 59.

${ }^{97}$ Breitinger Bd. 1, S. 166.

98 Apel 1978, S. 81.

${ }^{99}$ Breitinger Bd. 1, S. 56.

100 Breitinger Bd I, S. 57.

${ }^{101}$ Breitinger Bd. 1, S. 60.

102 Stahl, S. 175. Vgl. Tismar/Mayer 2003, S. 34.
} 
die Diskussion über die schöpferische Rolle des Dichters werden von Wieland, dem Schüler der Zürcher in seiner erzählerischen Dichtung adaptiert. Die metadiegetischen Erzählungen sowie das „subjektive“ Wunderbare der Figuren in Don Sylvio von Rosalva beispielsweise sind eine Fortsetzung der Abhandlung über die Dichterrolle.

In seiner schweizerischen Zeit folgte Wieland der Lehre über die Einbildungskraft und das Wunderbare von Bodmer und Breitinger, was in seiner Abhandlung Von den Schönheiten des Noab zu bemerken ist. Erst als er sich aus dem Einfluss der Zürcher löste, entwickelte er eine eigene Theorie des Wunderbaren. Mit seinem Erstlingsroman Don Sylvio von Rosalva schuf er nicht nur das erste deutsche Kunstmärchen und einen modernen Roman nach dem Märchenmuster, sondern er führte eine eigene theoretische Abhandlung mittels eines Romans aus. Apel kennzeichnet diesen Roman als „eine Befreiung vom Einfluß Bodmers“103. Ein Märchen soll unter anderem seinen Leser belustigen, wie Don Sylvios Abenteuer die fiktiven Leser im ,Nachwort' oder die Abenteuer des Biribinker die Gesellschaft in Lirias belustigen. Die humanistische Erziehung und Ausbildung beziehen sich auf das Feld von Witz und Humor. Denn ,die Thorheiten der Menschen, ihre Vorurtheile und irrige Meynungen, und die Ausschweiffungen ihrer Einbildungskraft und ihrer Leidenschaften zu verspotten, sey nicht nur erlaubt sondern so gar nützlich" [WW 7.1, 6] und der lachende Spott und die beißende Ironie seien die besten Waffen gegen den Aberglauben [WW 7.1, 7]. Die Komik des Romans liegt nicht nur in dem Satirischen der Handlung, sondern auch in der launigen Stimmung der Textgestaltung ${ }^{104}$ und in den humorvollen Bemerkungen des kritisierenden Erzählers.

Die heutigen Leser können in Don Sylvio von Rosalva einen Roman mit Märchenadaption sehen. Doch hatte Wieland selbst kein sicheres Kriterium für die literarische Gattungsbezeichnung Märchen. In seinen früheren Verserzählungen gibt es keine eindeutige Unterscheidung zwischen Novellen und Märchen. In Wielands gesamtem Werk ,,sind beide Tendenzen, die realistische der Novelle und die phantastische des Märchens, unauflöslich miteinander verknüpft, ja diese Verbin-

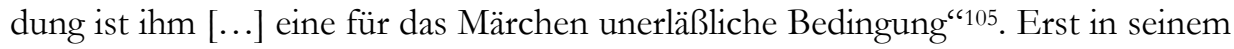
Pentameron (1804) werden Märchen, Novelle und Anekdote als verschiedene Gattungen relativ deutlich unterschieden. In seiner früheren Dichtung gab Wieland seinen Märchen keine feste Bezeichnung. Für verschiedene Werke benutzte der Dichter Begriffe wie Geschichte, Feerei, Erzäblung von den Feen. ${ }^{106}$ Da sowohl Die Geschichte vom Prinzen Biribinker als auch die einzigen beiden als eigene Dichtung bestimmten Märchen in der Sammlung Dschinnistan oder auserlesene Feen= und Geis-

\footnotetext{
103 Apel 1978, S. 84.

${ }^{104}$ Etwa der Nachbericht, ,,welcher aus Versehen des Abschreibers zu einem Vorberichte gemacht worden" [WW 7.1,3].

105 Müller-Solger 1969, S. 100.

106 Vgl. Müller-Solger 1969, S. 101.
} 
ter-Mährchen - Der Stein der Weisen und Die Salamandrin und die Bildsäule von dem Dichter als Erzählung gekennzeichnet werden, liegt es nahe, dass die Bezeichnung Erzählung nach Wieland auf die Originalität und die Künstlichkeit des Werkes verweist, während das Märchen oder Märlein auf „die Leichtigkeit der Form und die Nichtigkeit des Inhalts" 107 weist. Doch erweiterte Wieland die Bedeutung vom Begriff des allegorischen Märchens zugleich. Müller-Solger zitiert das Beispiel von Wielands Rezension des Versuchs über den Roman von Blanckenburg in seinem Kapitel über Wielands Märchendichtung als Beweis für die Unschärfe in Bezug auf die Grenzen zwischen verschiedenen Gattungen. Wieland vermisst die Einbeziehung der Märchen in diesem Werk: „Die Werke bloßer Imagination, wie die Feenmärchen, hätten nicht ganz mit Stillschweigen übergangen, wenigstens als Allegorien betrachtet werden sollen.“ [WW 11.1, 717] „Feerei“ und Märchen/ Märchenroman werden auf diese Weise in die Gattung Roman einbeschlossen, weil nur der fiktive Charakter der Dichtung für Wieland entscheidend bleibt. Die Gattungsbezogenen Unterscheidungen zwischen Roman, Märchen und Erzählung spielen eine weniger wichtige Rolle. Deswegen findet man häufig Märchenelemente in seinen Romanen und Verserzählungen. Die Handlung des Don Sylvio von Rosalva beispielsweise entspricht dem Verlauf eines Zaubermärchens: Ein Jüngling zieht aus, um sein Glück zu finden und heiratet eine schöne reiche Frau nach mehreren Abenteuern und Proben. Dann wird dann mit der individuellen Entwicklungsgeschichte eines Bildungsromans verbunden.

Nach Wieland gibt es drei traditionelle Stoffbereiche der Märchen des 18. Jahrhunderts: Feenmärchen, orientalische Märchen und Elementargeister-Stoffe aus Der Graf von Gabalis - Gespräche über die verschiedenen Wissenschaften. ${ }^{108}$ Alle drei Bereiche finden ihre Adaptionen in seinem Märchen des Prinzen Biribinker. Die drei Feen, denen Biribinker nacheinander verfällt, sind eine Cristalline (Erde), eine Ondine (Wasser) und eine Salamandrin (Feuer).

Das Märchen ist für Wieland ,die geselligste Form der Dichtung“109, weil die Märchendichtung eine Kunst der Bearbeitung durch die Erzähler und die Zuhörer/Leser sei. Die Märchendichtung ist ein Prozess der Adaption. In seinem Vorwort zu Dschinnistan bemerkte er: „Der Erfinder eines Süjets ist oft ein bloßer Finder, der wahre Erfinder ist Der, der aus einem wo es auch sei, gefundenen Süjet ein so schönes und vollkommenes Ganzes zu machen weiß, als seiner Natur nach daraus werden kann." [W 30, 14] Aus der Zerstreutheit eines Stoffes wird eine Ganzheit gemacht. Diese Ganzheit soll auch mit anderen Stoffen in demselben Märchen koordiniert werden, damit der Geist in dem allen lebt und webt. Der Geist verbindet alle Teile eines Märchens. Ein Märchen ist trotzdem durch die Vielfältigkeit der Nuancen gekennzeichnet, die die Leser unterhalten soll, weil das Märchen schließlich unter anderem der Belustigung des Verstandes dient.

107 Müller-Solger 1969, S. 102.

108 Müller-Solger 1969, S. 103.

109 Müller-Solger 1969, S. 119. 
Ein Märchen kann ernsthaft oder munter sein. Dieser Ton der Ganzheit, der „eigentlich die Kunst des Märchenerzählens ausmacht" "110, erzeugt eine Stimmung, die dem Leser vermittelt werden soll. Die Wahrnehmung durch den Leser gleicht einer Einbildung, die sich von dem Erzähler auf den Leser fortpflanzt. Wie Wieland in Dschinnistan meint: „Die Imagination stimmt sich bei einer solchen spielenden Beschäftigung mit fremden Erfindungen unvermerkt zu eigenen." [W 30, 11] Im Unterschied zum modernen Rezeptionsverständnis, dem gemäß von einer „subjektiven Produktion des Textes durch den Lese" zu sprechen wäre, ist diese Stimmung ein „durch Kunst zu erzeugender Zustand“"111. Durch diese durch das Märchen übertragene Stimmung sind der Erzähler und der Leser verbunden und die im Märchen verborgenen fremden Stoffe zeigen sich für den Leser als eigene Erfindung des Erzählers, die wiederum mit der Imagination des Lesers übereinstimmt.

Der Geist, der alle Teile eines Märchens verbindet, ist in Don Sylvio von Rosalva sowie in dem eingebauten Märchen vom Prinzen Biribinker das Thema des leichtfertigen Enthusiasmus oder der Schwärmerei. Alle Figuren in dem Roman inklusive des spiegelbildhaften Biribinker beziehen sich auf den Wahn des Helden. Die Schwärmerei ist das Thema vieler fiktionalen Werke Wielands. ${ }^{112}$ Wieland nennt die Schwärmerei „eine Erhitzung der Seele von Gegenständen, die entweder gar nicht in der Natur sind, oder wenigstens das nicht sind, wofür die berauschte Seele sie ansieht" [W 32, 369]. Sie unterscheidet sich von dem Enthusiasmus, der zwar auch Erhitzung der Seele ist, aber „Wirkung des unmittelbaren Anschauens des Schönen und Guten, Vollkommenen und Göttlichen in der Natur und unserm Innersten, ihrem Spiegel“ [W 32, 369] ist. Denn das, wovon die Seele glüht, ist „Berührung des Gottes“ [W 32, 370] und der Enthusiasmus ist die Einwirkung der Gottheit, während die Schwärmerei „Krankheit der Seele“ [W 32, 370] und von einem Fetisch begeistert ist. Der Enthusiasmus besitzt die Kraft der Verwandlung. Er „schafft eine neue Natur und versetzt uns in der That in fremde Welten, welche nach ganz andern Gesetzen als die unsrige regiert werden" [W 2,16]. Die Einbildungskraft, die die Entfremdung von der Wirklichkeit durch die ,göttliche Berührung“ bewirkt, „verschönert“ [W 1, 157] und zeigt „ihre Geschöpfe in einem überirdischen Glanze" [W 1, 114]. Wenn die Phantasie nicht durch die Vernunft kontrolliert wird, sondern, umgekehrt, die Phantasie Herr der Vernunft wird, ist die Einbildungskraft schwärmerisch. Phantasie an sich ist notwendig, weil sie jede Erwartung des Lebens bestimmt. Eine schwärmerische Erwartung steigert sich jedoch in den irrealen Bereich, sodass der Schwärmer (zum Beispiel Don Sylvio) unrealistische Erwartung hegt. „Was die Phantasie in ihrem ,Zauberspiegel' [W 22, 80] zeigt, wird zum Ziel der Sehnsucht, die Spannung zwischen Wirklichkeit und Phantasie wird zur Spannung zwischen Gegenwart und

\footnotetext{
110 Müller-Solger 1969, S. 119.

111 Müller-Solger 1969, S. 119.

112 Peregrinus Proteus, dessen erste Ausgabe 1791 erschien, habe die Schwärmerei ebenfalls zum Thema.
} 
Zukunft."113 Die Verfehlung von Wirklichkeit in der provinziellen Umgebung von Rosalva beispielsweise ist der Grund, dass der jugendliche Schwärmer Don Sylvio nach Ausgleich im Zauberreich sucht. „Diese Ungenügsamkeit ist nichts anderes als das Bestreben der Einbildungskraft, die Wirklichkeit immer wieder zu transzendieren." 114 Nur im Hang zum Wunderbaren erlebt der Schwärmer die Befriedigung der Bedürfnisse nach starken Emotionen. Denn alles was die Einbildungskraft „in uns [als] unaufhörlich thätige Kraft der menschlichen Seele in Bewegung setzt, alles was ihr neue Bilder verschafft [...] hat einen besonders hohen Grad des Vergnügens für uns. [...] Nichts beschäftigt und unterhält [...] unsere Einbildungskraft mehr, als das Wunderbare" ${ }^{\text {"115, }}$, so der Zeitgenosse von Wieland C. F. Pockels. Die

lebhafte Bewegung, in welche unsere Phantasie allemahl durch außerordentliche Begebenheiten versetzt wird, theilt sich zugleich einer Menge unserer Leidenschaften mit, die sich bald mit Schrecken und Furcht, bald mit einer überwiegenden Freude, bald in beiden, oder gemischten Empfindungen äußern, je nachdem das Wunderbare einer Begebenheit bald so, bald anders auf unser Herz. würk.t, und auf dieses würk.t es allemal ${ }^{116}$.

Die Erfüllung der schwärmerischen Erwartung kommt nur im Rauschzustand vor. In Don Sylvio von Rosalva zeigt sich der Rauschzustand entweder als Traum, in dem der Held der Fee begegnet, oder als Tagetraum, in dem Don Sylvio die dicke Magd Maritorne für seine Geliebte hält und von dem ,,von Knoblauch und Käse so kräftig durchwürzten Kuß“ [WW 7.1, 20] stark enttäuscht wird.

\subsection{Die Märchenstruktur und die Märchenadaptionen in Don Sylvio von Rosalva}

1764 erschien Don Sylvio von Rosalva als der erste veröffentliche Prosaroman von Wieland in Ulm in zwei Teilen. Die Arbeit an diesem Roman begann 1763. Am 5. August 1763 erwähnte Wieland dieses Werk im Brief an seinem schweizerischen Verleger Salomon Geßner zum ersten Mal, nachdem seine Arbeit an dem Roman Agathon wegen eines neuen Romanprojekts unterbrochen worden war:

Vor einem paar Monaten kam ich an einem Regen-Tag auf den Einfall einen kleinen Roman zu schreiben, worinn Kluge und Narren viel zu lachen fänden, und der mich selbst amusirte obne mich im mindesten anzustrengen. Ich machte meinen Plan und fieng gleich an zu schreiben. Dieses amusement interessirte mich unvermerk.t so stark daß ich eine Arbeit daraus machte und daß ich beschloß, aus meinem Fond,

\footnotetext{
113 Viering 1976, S. 40.

114 Viering 1976, S. 41.

115 Pockels 1788, 3. Bd., 3. Stück, S. 86f.

116 Pockels 1788, 3. Bd., 3. Stück, S. 93.
} 
der an sich närrisch genug ist, etwas so gescheidtes zu machen als mir nur möglich wäre. [...] Es ist eine Art von satyrischem Roman, der unter dem Schein der Frivolitat philosophisch genug ist, und wie ich mir einbilde keiner Art von Lesern, die austere ausgenommen, Langeweile machen soll. Indeßen muß ich doch gestehen daß weder der Nabme Wieland, noch Orell Geßner u: Comp. noch viel weniger der Nabme einer Republik darauf stehen darf, welche so sevèr ist, daß ein Bal schon binreichend ist, alle Patrioten zu allarmieren und selbst aus dem Munde der Unmündigen und Säuglinge Weissagungen von dem Untergang eines solchen zweyten Ninive hervor zu zwingen. " $[\mathrm{Br} 3,169]$

In dem Brief wird die Idee von einem solchen Werk, welches die Leser sowie den Autor amüsieren soll, entworfen. Ein unterhaltsames, aber nicht trivialliterarisches Buch soll der Roman sein. Später schrieb Wieland in einem anderen Brief, er wolle „,ein Buch machen, das für die Meisten wäre, und wovor mir ein jeder Buchhändler [...] gerne eine beträchtliche Summe baar bezahlen würde“ [ $\mathrm{Br} 3,197]$. Don Sylvio von Rosalva sei das einzige Buch, das Wieland um eine Summe Gelds zu bekommen schrieb ${ }^{117}$, und zwar aus privaten Gründen: Seine Geliebte Christine Hogel (genannt Bibi), ein bürgerliches und katholisches Mädchen, war von ihm schwanger und für sie musste Wieland ein beträchtliches Honorar erhalten. Eine Summe von 500 Gulden erhielt der Dichter allerdings nicht von dem schweizerischen Verleger, sondern von Albrecht Friedrich Bartholomäi aus Ulm.

Der Roman Don Sylvio von Rosalva half seinem Autor nicht nur aus der finanziellen Schwierigkeit, die Unterhaltsamkeit dieses Werkes diente Wieland auch als ein Zufluchtsort. Wie die Feenmärchen in der Romanwelt für den jugendlichen Don Sylvio gelten die Märchen in der Rokoko-Zeit häufig als eine angenehme Art der Flucht vor der Realität und des Zeitvertreibs. ${ }^{118}$ Es wird deswegen kein Zufall sein, dass Wieland seinen Erstlingsroman mithilfe von vielen parodierten Motiven und Stoffen aus Feen- und orientalischen Märchen konstruierte.

Zu den Prätexten von Don Sylvio gehört allerdings unter anderem Don Quijote von Cervantes, der - wie schon gesagt - das „Grundmuster“119 des Romans ist. Don Sylvio ist wie Don Quijote ein Schwärmer, der von der Bücherwelt verblendet ist. Er ,,ist ein kindlicher, zarter, sehr empfindsamer Nachkomme des spanischen Ritters de la Mancha. [...] Aber während Don Quijotes abenteuerliche Einbildungskraft, leidenschaftlich und über alle Grenzen hinaus zum Unbedingten zielend, immer wieder in komisch-tragischer Desillusion einer niedrig-vulgären Wirklichkeit begegnet, von ihr verprügelt, betrogen und zerfetzt, hat Wieland seinem Don Sylvio ein sanfteres, märchenhaft-harmonisches Geschick vergönnt"'120.

\footnotetext{
117 Vgl. Heinz 2008, S. 251.

118 Sengle 2005, S. $180 f$.

119 Martini 1964, S. 921.

120 Martini 1964, S. 921.
} 
Darüber hinaus ist Don Sylvio von Rosalva deutlich von Henry Fieldings Tom Jones, the History of a Foundling (1749), Lawrence Sternes Tristram Shandy sowie die Feenmärchen von Madame d'Aulnoy, von denen das unschuldige Gemüt des Don Sylvio erfüllt wird, ${ }^{121}$ beeinflusst. Aus den zeitgenössischen Lustspielen übernimmt Wieland nicht nur die zeitliche und räumliche Einheit, sondern auch wichtige Motive, wie man von der menschlichen Torheit geheilt wird und wie gewisse lächerliche Fehler der Menschen verbessert werden. ${ }^{122}$ Die Geschlossenheit und der didaktische Gehalt der Gattung Lustspiel tragen dazu bei, dass der Roman von Wieland die Gefahr der Formlosigkeit vermeidet. ${ }^{123}$

Die Handlung von Don Sylvio entspricht - wie oben schon angedeutet - derjenigen eines Zaubermärchens: Ein Jüngling zieht aus, einerseits um eine unerwünschte Eheschließung zu vermeiden, andererseits um sein Glück, das durch einen wunderbaren blauen Schmetterling verkörpert ist, zu suchen und findet schließlich seine Geliebte und großen Reichtum. Dieses Motiv der Glückssuche kommt später nicht nur in der Volksmärchensammlung der Brüder Grimm immer wieder vor, sondern wird auch von den Romantikern Novalis, Ludwig Tieck und vielen anderen bearbeitet. Die Titel von mehreren Kapiteln in dem ersten Teil des Don Sylvio von Rosalva weisen ebenfalls auf den märchenhaften Charakter des Romans hin (I/6: Abenteuer mit dem Laubfrosch; I/9: Abenteuer mit dem SommerVogel, III/7: Abenteuer mit der Zigeunerin; IV/8: Das höchstklägliche Abenteuer mit den Gras-Nymphen). Diese Episoden mit vernünftig erklärbaren Ereignis$\operatorname{sen}^{124}$ werden durch Don Sylvios Einbildungskraft märchenhaft gefärbt. Der märchenhafte Charakter des Romans wird allerdings durch den Kontrast zwischen der Alltäglichkeit der Ereignisse und der schwärmerischen Begeisterung des Romanhelden sowie durch Bemerkungen des Erzählers in Paratexten ${ }^{125}$ oder Bemerkungen, die den Verlauf der Geschichte unterbrechen, aufgehoben und absurd gemacht.

Wieland verbirgt viele Motive und Stoffe aus bekannten Märchen absichtlich in seinem Text, ${ }^{126}$ damit das Lesen eine spannende Enträtselung für die Leser wird. Bevor der Held auszieht, werden eine Reihe von Figuren und Motiven aus französischen Märchen schon aufgelistet, die Don Sylvio in seiner Lektüre entdeckt und die ihn faszinieren. Viele davon kommen in der Geschichte des Prinzen Biribinker und in Don Sylvios eigenen Abenteuern noch einmal vor. Karl Otto Mayer beispielsweise entdeckt, dass Donna Mergelina, die im Text als ein Anto-

\footnotetext{
121 Vgl. Jahn 1981, S. 312.

122 Vgl. Jahn 1981, S. 309.

123 Vgl. Jahn 1981, S. 309.

${ }^{124}$ In dem Abenteuer mit dem Laubfrosch geht es beispielsweise nur um einen Storch, der einen Laubfrosch erhaschen will.

${ }^{125}$ Der Titel von I/ 6 lautet Abenteuer mit dem Laubfrosch. Warum Don Sylvio nicht gemerkt, daß der Frosch keine Fee war?

${ }^{126}$ In den Fußnoten der beiden späteren Fassungen werden die Quellen dieser Märchenrequisiten bekanntgegeben.
} 
nym zu einer Märchenprinzessin beschrieben wird, ${ }^{127}$ vielen Figuren in d'Aulnoys Märchen ähnelt. ${ }^{128}$ Die Gemeinsamkeit zwischen Mergelina und Märchenfiguren entdeckt nicht nur Don Sylvio, sondern auch sein Diener Pedrillo. Es ist Pedrillo, der Donna Mergelina zuerst „des grünen Zwergs leibliche Schwester“ [WW 7.1, 58] nennt und ein geeignetes Paar in Donna Mergelina und dem Zwerg Migonnet sieht. Migonnet ist der komisch aussehende König der Zwerge in Madame d'Aulnoys La chatte blanche. In diesem Märchen wird Migonnet als ein ungewöhnlich kleiner Zwerg mit Adlerfüßen, einem sehr großen Kopf (,so groß wie ein Scheffelmaß") und einer Nase ,von einem so ansehnlichen Schnitt, daß er ein halb Dutzend Vögel darauf zu tragen pflegte, an deren Gesang er sich belustigte“"129 [SW 4, 115] - ein Ebenbild von Donna Mergelina - beschrieben. Die Feen bestimmten den Zwerg der Prinzessin Weißkätzchen zum Gemahl, „, ehe die Heldin durch die Verwandlung in eine weiße Katze für ihre Ungehorsam bestraft worden war" [SW 4, 115]. Die weiße Katze kommt in Don Sylvios Lektüre ebenfalls vor. [WW 7.1,19] Da Don Sylvio seiner Heirat mit Mergelina entgeht und seiner Geliebten Donna Felicia in einem „Palast der weißen Katze“ begegnet, soll den erfahrenen Lesern nahegelegt werden, Parallelitäten zwischen Madame d'Aulnoys Feenmärchen und Wielands Roman zu finden. Einerseits wird der Leser herausgefordert, mehr Märchenelemente in dem Roman zu suchen und dadurch eine Vernetzung mit Prätexten zu sehen; andererseits wird darauf hingewiesen, dass das Märchenhafte nicht nur in Don Sylvios Einbildung existiert. Die erzählte Welt des Romans hat ihrerseits viele Märchenbezüge. Obwohl alle Orte bis hin zu Rosalva wirkliche Orte sind, wird Lirias, der Ort, an dem Don Sylvio sein Glück findet, als die fiktive Bühne des Romans Gil Blas entblößt. Wie Martini in seinem Nachwort bemerkt, gestaltet Wieland den Roman nach seinen eigenen Märchenkriterien von Leichtigkeit und Unwirklichkeit als ein Kunstmärchen. ${ }^{130}$

Dass der Roman viele Märchenbezüge besitzt, wird besonders durch die eingebettete Geschicbte vom Prinzen Biribinker gegen Ende des Romans herausgestellt. Das Kunstmärchen, das Don Sylvio durch seine bis ins Absurde übertriebene und anstößige Umgestaltung von Märchenstoffen als eine Therapie dienen soll, „fasst $[\ldots]$ in einer Fülle witziger Anspielungen und Analogien alle Fäden der Handlung so in sich zusammen, daß die Komposition des Romanganzen erst hier richtig zutage tritt"“131. Biribinker lässt sich als ein karikiertes Ebenbild von Don Sylvio ansehen. Die beiden Helden sind schöne Jünglinge von 17 Jahren. Der Anlass ihrer Abenteuer ist Eros. Die beiden Helden begegnen ihrer späteren Geliebten vor den Abenteuern: Don Sylvio findet ein Miniaturporträt und hält die junge

\footnotetext{
127 „Sie hatte weder blonde Haare wie Ceres, noch braune wie Venus, noch goldfarbe wie die Schöne mit den goldnen Haaren, die ihrige waren feuerfarbig und dabey von Natur so geradlinicht und kurz, daß sie die Kunst und Gedult einer Cypaßis zu Schanden gemacht hätte." [WW 7.1, 52]

128 Mayer 1892, S. 395.

${ }^{129}$ Diese Anmerkung befindet sich in der dritten Fassung des Don Sylvio von Rosalva.

130 Martini 1964, S. 924.

131 Jahn 1981, S. 313.
} 
Frau darauf für eine verzauberte Prinzessin; Biribinker sieht ein Milchmädchen in seiner zukünftigen Braut, die in der Tat eine richtige Märchenprinzessin ist. Die beiden Helden erleben eine Irrfahrt auf dem Weg zu ihrer Braut: Don Sylvio erleidet Schaden bei der Zigeunerin beziehungsweise bei den „Grasnymphen“ und vernachlässigt Donna Felicia zuerst zugunsten seiner eingebildeten Märchenprinzessin; Biribinker lässt sich von drei Feen auf seiner Suche nach der geliebten Galactine verführen. Beiden vermählen sich am Schluss mit der richtigen Geliebten. Nur der Ausblick am Ende der beiden Geschichten ist unterschiedlich: Während Don Sylvio sich durch die Kraft der Liebe und durch die „Schocktherapie“132 der Biribinker-Geschichte von seiner Schwärmerei frei macht, verändert sich der Prinz Biribinker nach der Eheschließung nicht: Aus seinem zauberhaften Namen Biribinker wird nun König Caramiello („Honigscheißer“ auf Italienisch). Die beiden Namen weisen auf köstliche Sachen hin, die der Prinz ausscheidet. Die Treulosigkeit des Helden ändert sich ebenfalls nicht: „[D]ie schöne Mirabella nebst der Fee Cristalline unterliessen niemals bey Hofe zu erscheinen, so oft die Königin in die Wochen kam.“ [WW 7.1, 302] Die „eben so lehrreiche als wahrhafte“ [WW 7.1, 302] Geschichte des in der Zauberwelt gebannten Prinzen Biribinker ist eine Warnung und ein Spiegelbild für Don Sylvio: Die Natur in dieser ganzen Geschichte ist „vom Anfang bis zum Ende auf den Kopf gestellt“ [WW 7.1, 302].

Don Sylvio entkommt seiner schwärmerischen Märchenwelt und Don Sylvio von Rosalva ist wegen seines Mangels an phantastischen Elementen, seiner reflektierenden Auseinandersetzung mit dem Märchen und nicht zuletzt wegen seiner Länge ein Roman. Doch besitzt der Roman in den folgenden drei Aspekten Märchenzüge.

Erstens ist die Welt in dem Roman in sich abgeschlossen. In dem ersten Kapitel des ersten Buches erwähnt der Erzähler den zeitlichen Hintergrund: die Geschichte von Don Sylvio geschieht etwa 30 Jahre nach dem Successions-Krieg, während der Krieg 1724 endet. Deswegen liegen die Abenteuer von Don Sylvio zeitlich nur ein wenig früher als die Abfassungszeit des Romans (1763). Dieser historische Hintergrund spielt keine Rolle in dem Roman. Don Sylvio wächst als Waisenkind bei seiner Tante in einem verfallenen Schloss der spanischen Provinz Valencia auf. Das erfundene Schloss befindet sich auf dem abgelegenen Land und das einsame Leben von Don Sylvio ist völlig isoliert von der gesellschaftlichen Kommunikation mit Ebenbürtigen. Der Mangel an historischer Kontinuität ist ein typisches Merkmal des Märchens, das häufig zeitlos ist. Zugleich entspricht die Zeitlosigkeit des Romans in anderer Hinsicht den Prinzipien der Aufklärung - der zeitlosen Geltung der Vernunft. Das Zeitalter der Aufklärung ,versteht sich nicht als Moment einer historischen Entwicklung, in der es Ergebnis und Weiterentwicklung einer vorhergehenden Epoche wäre, sondern es bildet sich gerade in der Verleugnung dieser Kontinuität"133. Das Neue setzt sich von dem Vergangenen

132 Lorentzen 2005, S. 39.

133 Brenner 1981, S. 2. 
als Folie ab, indem es dessen Illegitimität mithilfe eines Prozesses gegen das Vergangene erweist. Mit der Verleugnung der eigenen Geschichte erlangt man in der Aufklärung die „Selbstauffassung der Vernunft als des Organs eines absoluten Anfangs" ${ }^{134}$. Das Thema von Don Sylvio entspricht diesen Prinzipien, weil das Überwinden der alten Schwärmerei das Ziel der Geschichte ist und die Schwärmerei des Helden durch die Reflexion des Erzählers und zum Teil der absurden Selbstreflexion des Don Sylvio immer wieder in Frage gestellt wird. Der Roman zielt nicht auf das Leben in dem verfallenen Schloss in Rosalva, sondern darauf, die schwärmerische Vorstellung von Welt des Don Sylvio zu zerstören und eine neue Welt zu schaffen.

Die geographische Gestaltung der Welt im Roman ist ebenfalls idealisiert. ${ }^{135}$ Es geht um eine subjektiv gefärbte Umgebung. Am Anfang der Abenteuer sieht der abergläubige Pedrillo alles in Gespenster verwandeln. [WW 7.1, 71] Die realistische Umgebung tritt hinter die subjektive Wahrnehmung der Welt zurück: Als Don Sylvio in den Saal des Schlosses von Lirias eintritt, ,dessen Schönheit und kostbare Auszierung einer Fee würdig schien“ " [WW 7.1, 182] und er eine Menge Katzen von allen Farben erblickt, meint er, dass er sich im Schloss der weißen Katze befinde. Die Umgebung in dem Roman ist wie die Welt im Märchen ein vereinfachtes Hilfsmittel, das zu der Entwicklung der Handlung beiträgt. ${ }^{136}$

Zweitens trägt der Held des Romans Züge eines Märchenhelden und viele andere Figuren im Text sind auch märchenhafte Figuren. Don Sylvio wird als ein schöner Jüngling mit einem ,angenehmen und leutseligen Wesen]“ [WW 7.1, 30] und adliger Gesinnung beschrieben, der durch weltferne Naivität und eine treue Liebe zu seiner vermeintlichen Fee gekennzeichnet ist. Die persönliche Ausstrahlungskraft entspricht den Charakteren eines typischen Märchenhelden, der eine „empfindsam-schöne Seele im Geist des 18. Jahrhunderts“137 sein soll. Im Vergleich mit Agathon, in dem „ein komplizierter Prozeß innerer, meist erotischer Erfahrung mitsamt ihren Verwirrungen und Krisen in psychologisch differenzierender Weise gestaltet wird“138, wird die Psychologisierung der Figur Don Sylvio häufig durch ironische Bemerkungen des Erzählers ersetzt (beispielsweise in der Psychologischen Betrachtung im Drittel Kapitel des Ersten Buches). Der Leser distanziert sich von dem Helden, statt ins Innere der Figur zu sehen. Zwar wird die schwärmerische Anlage Don Sylvios durch die familiäre Abkunft und die unbefriedigten Bedürfnisse nach Spannung in dem einsamen Landleben erklärt, aber

\footnotetext{
134 Blumenberg 1974, S. 167.

135 Auffällig ist, dass Rosalva der einzige erfundene Ort im Roman ist. Seit der Eheschließung mit der viel reicheren Felicia leben die ,liebenswürdigste] und glücklichste[ Familie“ [WW 7.1, 354, gemeint ist die Familie inklusive Don Eugenio, Seraphina und der beiden Diener Pedrillo und Laura] sehr wahrscheinlich im Schloss von Lirias.

136 „Umgebung ist für den Roman nur insofern bedeutsam, als sie dem Fortgang der Handlung dient." Brenner 1976, S. 167.

137 Martini 1964, S. 922.

138 Jahn 1981, S. 310.
} 
seine innerliche Umwandlung erscheint nicht als ein plausibler psychologischer Prozess, sondern als eine neue Bezauberung:

Ihr erster Blick, der dem Seinigen begegnete, schien ibre Seelen auszutauschen.

Die ganze Gewalt dieser unbeschreiblichen Entzückung, womit eine sympathetische Liebe, zumal wenn es die erste ist, bey Erblickung ihres Gegenstands, eine empfindliche und zu dieser glücklichen Art von Schwärmerey aufgelegte Seele berauschen kan, durchdrang, erfüllte, überwältigte sein ganzes Wesen - - Alle seine vorige Ideen schienen ausgelöscht, neue Sinnen schienen plötzlich in seinem Innersten sich zu entwickeln, um alle diese unzähliche Reitzungen aufzufassen, die ibm entgegen stralten - - Kurz, er war so sebr ausser sich selbst, daß er die verbindliche Anrede der vermeynten Fee mit nichts anderm als stammlenden und abgebrochenen Sylben zu beantworten vermochte. [WW 7.1, 186f]

Dass die Liebe auf den ersten Blick eine Zauberkraft besitzt, wird im letzten Kapitel des letzten Buches durch den Erzähler bestätigt: „Don Sylvio, der nunmehr keine andere Feen erkennt als seine angebetete Felicia, und keine andere Bezauberung als die aus ihren Augen entspringt, ist auf dem Wege, glücklich [...] zu werden." [WW 7.1, 332] Wielands Roman zielt nicht darauf, einen psychologisch begründeten inneren Prozess des Helden vorzuführen, sondern unter anderem auf eine Verspottung von der Schwärmerei und eine Gegenüberstellung von Vernunft und Wahn. Nach Jahn bleibt „die Minne des Feenritters, die den Brennpunkt seiner Erlebnisse bildet, von barocker Beständigkeit" "139. Die Heilung von der Schwärmerei erfolgt nur durch das Gefühl des Herzens und die Entwicklung des Helden wirkt abrupt.

Die anderen Figuren treten noch weniger als psychologisierte Personen auf, sondern als Typen, „denen eine bestimmte Funktion im Lauf der Handlung zukommt ${ }^{\text {"140 }}$. Ganz auffällig ist, dass viele Hauptfiguren jeweils einen verschiedenen Typ von Lesern vertreten: Don Sylvio ist Märchenschwärmer; seine Tante Donna Mencia sieht in den heroisch-aristokratischen Ritterbüchern „de[n] ganze[n] Reichtum der erhabensten und nützlichsten Kenntnisse“ [WW 7.1, 12]; der Diener Pedrillo ist ,,in den Ritterbüchern und Märchen nicht weniger bewandert [...] als sein Herr" [WW 7.1, 30f] und zugleich ganz stark beeinflusst vom volkstümlichen Aberglauben; Hyacinthe ist eine begeisterte Leserin von Samuel Richardsons empfindsamen Romanen (unter anderem Pamela or virtue rewarded) und nimmt die tugendhaften Heldinnen in diesen Büchern als eigene Vorbilder; die idyllische Schäferdichtung hat bei Donna Felicia „ungefehr die nehmliche Würkung gethan, wie die Feen-Märchen bey unserm Helden“ [WW 7.1, 117]. Das Thema der Prägung durch Lektüre wird bei jeder Figur wiederholt und mit dem Fieber des Helden verglichen. Mit diesen Figuren wird die thematische Einheit des Romans gebildet. Jede Figur ist ausschließlich durch ihre Funktion im Text, die auf die Heilung von

\footnotetext{
139 Jahn 1981, S. 311.

140 Brenner 1976, S. 171.
} 
Don Sylvio gerichtet ist, bestimmt und nicht psychologisch selbständig. Diese Funktion ist wiederum zum großen Teil durch die jeweilige Attitüde der Figuren als Leser bestimmt. Donna Mencia erscheint beispielsweise als deus ex machina in Feenmärchen und Theaterstücken und fördert die dreifache Hochzeit. Sie wird zugleich als die böse Stiefmutter des Helden wegen ihrer strengen Erziehung von Don Sylvio nach den Vorbildern in Ritterbüchern angesehen. Don Sylvios Schwester Hyazinthe ist trotz ihres wichtigen Beitrages zum glücklichen Ende und trotz ihrer langen autobiographischen Erzählung eine ,ziemlich blasse Randfigur "141, deren wahrer Charakter und Innerlichkeit hinter ihrer Selbstidentifikation mit den Heldinnen von Pamela or virtue rewarded und Clarissa or the history of a young lady zurücktreten, wobei die Heldinnen in den moralischen Romanen häufig an sich schon starre Persönlichkeiten sind. Auch Pedrillo, der neben Don Sylvio viel Raum im Roman einnimmt, ist trotz seines witzigen Profils vielmehr durch seine Funktion als närrischer Begleiter im Text bestimmt.

Pedrillo gilt als eine Ergänzung zu Don Sylvio in ihrer Herr-KnechtBeziehung. Wie Wieland in seinem Brief an Salomon Geßner im November 1763 schrieb, haben der Aberglaube und der Enthusiasmus ähnliche Keime, „wovon jener den pöbelhaftern und tierischern, und dieser den edlern und bessern Teil des menschlichen Geschlechts karakterisiert" [Br 3, 207]. Während der Enthusiasmus „durch die albernen Einbildungen, die abenteuerlichen und übertriebenen Leidenschaften, die sonderliche Art zu denken und die ausschweifenden Entwürfe und Handlungen“ hervorbringt, ist die Frucht des Aberglaubens „die leichtgläubige Einfalt, die Vorurteile, [der] Eigensinn und die Brutalität" $[\mathrm{Br} 3,207]$. Wie der abenteuerliche und leidenschaftliche Don Sylvio die Schwärmerei vertritt, repräsentiert der ängstliche und einfältige Pedrillo den Aberglauben. ${ }^{142}$ Die beiden Figuren erscheinen als ein Gegensatzpaar mit gleichen geistigen Wurzeln und die beiden erhalten das reale Lebensglück nach Verwirrungen auf dem Weg, das in der Eheschließung mit einem Herrin-Zofe-Paar versinnbildlicht wird. Martini nennt Pedrillo „den Bruder Sanchos (allerdings auch der Slislop und Patridge bei Fielding)“"143. Es liegt nah, dass das Profil von Pedrillo nur zum Teil durch seine verworrenen und abergläubischen Reden gebildet ist. Die Gestaltung dieser Figur ist zum großen Teil mithilfe von beim Leser vorausgesehenen Kenntnissen der Weltliteratur ergänzt. Pedrillo gehört zusammen mit Seinesgleichen zu den heiterspielerischen Narren in Lustspielen und satirischer Literatur.

Die Handlungsträger des Romans - das Paar Don Sylvio und Donna Felicia erscheinen ebenfalls als ein Märchenpaar. Während Don Sylvio, der seine Heirat mit Mergelina entgeht, die der Rolle der verzauberten Prinzessin Weißkätzchen ${ }^{144}$

\footnotetext{
141 Jahn 1981, S. 312.

142 Andererseits gilt Pedrillo als praktische Person mit komischem Mutterwitz, während Don Sylvio von dem märchenhaften Ideal schwärmt.

143 Martini 1964, S. 923.

144 Die Prinzessin trägt ebenfalls das Bildnis ihres verstorbenen Geliebten als Amulett. Der Prinz
} 
in dem als Vorlage dienenden Märchen La chatte blanche entspricht, spielt Donna Felicia die Rolle des Prinzen, der die Prinzessin entzaubert. ${ }^{145}$ Don Sylvio spielt eine passive Rolle in dieser Liebesbeziehung. Da die Liebe zu Donna Felicia seine Treue zu seiner Fee vernachlässigt und dieser Umstand ihn in Verlegenheit setzt, fängt er an, ,über die Bezauberung, welche Donna Felicia über seine Seele auszuüben schien, mißtrauisch zu werden“ und beschließt, ,aus diesem gefährlichen Schlosse zu entfernen“ [WW 7.1, 199]. Dagegen ist die lebenskluge Witwe Donna Felicia ihrer Sympathie zu dem Jüngling sicher. Sie erblickt die Torheit von Don Sylvio in einer Art von Schwärmerei und will sie in kurzer Zeit beseitigen. Die Geschwister Don Eugenio und Donna Felicia schenken einander „die Einwürfe, die eines jeden eigene Vernunft so gut als des andern seine gegen den Entschluß ihres Herzens zu machen wußte, und richteten ihre vereinigte Aufmerksamkeit bloß darauf, wie die Hindernisse, die ihren Wünschen im Wege stunden, am besten gehoben werden könnten“" [WW 7.1, 194f]. Bewusst und selbstsicher übernimmt sie die Rolle des Erlösers im Märchen und des Prinzen im Märchen La chatte blanche im Besonderen.

Schließlich ist die Don Sylvios Schwärmerei an sich schon märchenhaft. Nach Erharts Analyse evoziert die Schwärmerei Nähe zum Fremden ${ }^{146}$. In Menander und Glycerion weigert sich Glycerion, sich in ihrer neuen Bekanntschaft mit Hermotimus erneut „,von einem Strom schwärmerischer Gefühle hinreissen zu lassen“ [SW 39, 136], auch wenn ihr eine innerliche Stimme zuflüstert: „Wagte ichs, dieser Stimme zu gehorchen, ich würde ihm bis zu den Garamanten und Indiern folgen." [SW 39, 136] Folgte man seiner schwärmerischen inneren Stimme, würde man ins topographisch oder zeichenhaft Fremde verbannt, was mit der oben zitierten abenteuerlichen und übertriebenen Leidenschaft in Wielands Brief erklärt werden kann. Das Fremde wird von Wieland vielmehr metaphorisch ,als ironisches Indiz für unvernünftige Abweichungen und als Schwärmertum“"147 gemeint. Die Schwärmerei gilt als ein gesteigertes Selbstgefühl. Die Schwärmer grenzen sich ab von der Menschenvernunft, die sich immer äußern muss und daher mit Sprache und Gesellschaft verbunden ist. In der „schönen Gesellschaft“ entsteht die Vernunft. Die „,schöne Gesellschaft“ ist nach Wieland ein solches zivilisiertes Unternehmen, das „Geist, Toleranz, Verbindlichkeit, Mäßigung und Heiterkeit" ${ }^{\text {“148 }}$ von seinen Mitgliedern fordert. In einer schönen Gesellschaft wird der Menschen zu sich selbst verholfen. Wegen des Verzichts auf die Geselligkeit verwandelt sich die Schwärmerei allmählich ,in ein Zeichen für Individualismus [...] - in dem

\footnotetext{
sieht genauso wie das Bildnis aus.

${ }^{145}$ Der Transgender spielt hier - anders als in Thomas Manns Königliche Hobeit - keine Rolle. Dass Donna Felicia - der Rolle des Prinzen in dem referierten Märchen der Weißen Katze entsprechend eine aktive Rolle in ihren Beziehungen zu Don Sylvio spielt, ist ein intertextuelles Spiel des Autors mit dem Leser.

${ }^{146}$ Erhart 2005, S. 138.

147 Erhart 2005, S. 139.

148 Jacob 1969, S. 12.
} 
Maße, wie das Individuelle und Subjektive in ihrer Gegnerschaft und ihrem Widerspruch zu modernen Gesellschaft profiliert werden"149. Insofern lässt sich die Schwärmerei als eine vereinsamende Verblendung ${ }^{150}$ und Verzauberung sehen: Sie ist sowohl eine subjektive Verzauberung der Welt als auch eine Verbannung des Individuums in eine verzauberte Welt. In Don Sylvio von Rosalva zeigt sich die verzaubernde Schwärmerei als Don Sylvios Flucht vor der wirklichen Gesellschaft und wird durch die Verbindung mit Felicia - den ersten Schritt zur gesellschaftlichen Integration - beendet. Das Motiv der erlösenden Liebe wird auch hundert Jahre später in Hans Christian Andersens Kunstmärchen (etwa in der Schneekönigin) und Thomas Manns Märchenroman Königliche Hoheit wieder aufgenommen.

Das Motiv des Fremden wird in Don Sylvio von Rosalva allerdings ironisiert. Während es im Feenmärchen die Polarität zwischen der Heimat und dem Fremden ein übliches Motiv ist, ${ }^{151}$ ist das „Fremde“ im Roman als das Schloss in Lirias nur eine benachbarte Ortschaft von Rosalva.

\subsection{Das intertextuelle Spiel in Don Sylvio von Rosalva}

Wie im letzten Kapitel erläutert, sind alle Hauptfiguren in Don Sylvio von Rosalva Leser. Auch ihre Beziehungen zueinander sind zum großen Teil durch ihren literarischen Geschmack bestimmt: Don Sylvio erbt neben dem Schloss auch das Interesse an Märchen von seinem Vater Don Pedro; in Pedrillo (die Verkleinerungsform von Pedro), der Milchbruder von Sylvio beziehungsweise das Patenkind von Don Pedro, werden die Märchenkenntnisse seiner Herrn und der Glaube an Hirngespinste, welche nach Sylvio „die alte Hure, deine [Pedrillos - Z. Y.] Großmutter, von ihrer Älter-Mutter geerbt und dir in dein dummes Hirn gesetzt hat " [WW 7.1, 76], vermischt; Donna Mencia, die stiefmütterliche Tante, teilt die Hochschätzung von aristokratischen Manieren, die sie aus den Ritterbüchern erlernt hat, mit der bürgerlichen Donna Mergelina; ${ }^{152}$ Donna Felicia ist das begehrte Glück von Don Sylvio und ihr Name ist nicht zufällig die feminine Form von Felix (lat. Glück). Zwischen Don Sylvio und Donna Felicia besteht eine „sympathetische Liebe [...], eine natürliche Verwandtschaft unter Seelen, und wie es ein Englischer Dichter nennt, Schwester-Seelen[...]“ [WW 7.1, 120]: „, diese Sympathie [befindet] sich eben so würklich in der Natur [...], als die Schwere, die Anziehung, die Elasticität, oder die magnetische Kräfte“" [WW 7.1, 120]. Die geheimnisvolle Sympathie zwischen dem Paar lässt sich durch die geistigen Gemeinsamkeiten

\footnotetext{
149 Erhart 2005, S. 141.

150 Vgl. Jacob 1969, S. 9.

151 Vgl. Klotz 1985, S. 322.

152 „Donna Mergelina hatte Anlaß ihre gute Erziehung sehen zu lassen, indem sie mit vielen Complimenten und Verneigungen die Ungelegenheit bedauerte, die man sich ihrentwegen mache; Complimente und Verneigungen und Grimaßen, die von der höflichen Donna Mencia mit eben so vielen Gegen-Complimenten und Gegen-Grimaßen beantwortet wurden." [WW 7.1, 53]
} 
erklären: „Die Poeten hatten bey ihr [Donna Felicia - Z. Y.] ungefehr die nehmliche Würkung gehtan, wie die Feen-Märchen bey unserm Helden." [WW 7.1, 117] Die Imagination idyllischem Lebens und zärtlicher Liebesgeschichten spielt sowohl in der Schäferdichtung als auch im Feenmärchen eine wichtige Rolle. Die Sympathie zwischen dem Paar entspricht den Ähnlichkeiten der beiden literarischen Gattungen, die die beiden Figuren jeweils vertreten. Als Donna Felicia Don Sylvio zum ersten Mal sieht, tritt sie als eine adlige Frau in der Bekleidung einer Schäferin auf, was der verwandelnden Einbildungskraft des Märchens entspricht; der Name der Hyacinthe, die sich am Ende des Romans als Sylvios Schwester Donna Seraphina entpuppt, kommt schon im elften Kapitel des ersten Buches („mit Narcissen und Hyacinthen" [WW 7.1, 43]) vor, und zwar als eine Anspielung auf den griechischen Mythos des schönen Jünglings Narziss. ${ }^{153}$ Sowohl Don Sylvio als auch Hyazinthe sind narzisstisch gesinnt. Auch Hyazinthe ist eine Leserin von Romanzen und Märchen [WW 7.1, 204] und bezieht eine Art von Sittenlehre daraus, die ihre Verhaltensweise bestimmt. Wie ihr Bruder verwechselt sie die Fiktion und die Wirklichkeit und will einen moralischen Roman aus dem Leben schaffen: „[M]eine Einbildung mahlte mir eine Menge von Abentheuern vor, die ich in alten Romanen gelesen hatte, und meine kleine Eitelkeit fand sich durch den Gedanken geschmeichelt, daß ich vermuthlich selbst die Heldin eines Romans werden könnte." [WW 7.1, 215] Ihre Erzählung über das frühere Leben ist daher stark subjektiv gefärbt und eine Vermischung zwischen Literatur und Realität. ${ }^{154}$ Die Geschwister von Rosalva beziehen alles auf sich und beobachten die Welt aus ihrer subjektiven Perspektive.

Es ist auffällig in diesem Roman, dass die Figurenkonstellation nach ihren intertextuellen Vorbildern entworfen ist. Die Abenteuer des Don Sylvio, die der „Herausgeber“ des Romans in seinem aus Versehen des Abschreibers zu einem Vorbericht gemachten Nachbericht als „eine Allegorie oder Parabola“ bezeichnet, sind deswegen ein intertextuelles Spiel mit den Prätexten und ihren literarischen Gattungen. Die erzählte Welt in Rosalva und Lirias, in der märchenhafte Figuren und eine Kinder verschleppende Zigeunerin auftauchen, ist weder eine Nachbildung der historischen spanischen Wirklichkeit in der ersten Hälfte des 18. Jahrhunderts noch der Gesellschaftsform im zeitgenössischen Deutschland. Sie ist vielmehr ein „Ideal und pädagogisch gemeinte[r] Entwurf“"155 von Wielands Romankunst. Der Roman besteht zum großen Teil aus Dialogen. Verschiedene Konzepte werden in Gesprächen darstellt. Jede Figur repräsentiert ihre eigene literarische Gattung und den darin verborgenen Geist. Die Gespräche im Roman

\footnotetext{
153 Dass die Schwärmerei egozentrische Bezüge trägt und daher eine frühe Stufe der humanistischen Ausbildung ist, wird im nächsten Kapitel genauer erörtert.

${ }^{154}$ Die Erwägung des Klosters als Zufluchtsort weist zum Beispiel auf Marivaux' Mariane. Hyacinthes Erlebnisse in einem Bordell ähneln Szenen in Richardsons Clarissa. Weitere Vergleiche zwischen Hyacinthes Erzählung und ihren literarischen Vorbildern vgl. Kurth 1969, S. 151. 155 Jacobs 1969, S. 14.
} 
lassen sich daher nicht nur als ideologischer Austausch zwischen Individuen, sondern auch zwischen verschiedenen Gattungen verstehen.

Nachdem Hyacinthe ihre autobiographische Geschichte erzählt hat, verwundert es Don Sylvio, dass in dieser Erzählung „die Feen nicht das geringste zu thun gehabt haben sollten“ [WW 7.1, 234]. Er glaubt, „daß die Feerey an Hyacinthens Geschichte mehr Antheil gehabt, als sie sich selbst einbildet“ [WW 7.1, 238]. Hyazinthes Erzählung wäre ihm angenehmer, wenn - wie Hyazinthe ironischerweise formuliert - „, die alte Zigäunerin in eine Carabosse, die gute Dame zu Calatrava in eine Lüminöse, und Don Fernand von Zamora, wo nicht zu einem schelmischen Zwerg, doch wenigstens zu einem Sylphen oder Salamander" [WW 7.1, 235] umerzählt wäre. Scherzend äußert Donna Felicia, dass der Erzählstil zu „frostig“ klinge und führt ein Beispiel mit poetischen Stoffen an: ,aber so bald er [ein Dichter - Z.Y.] sagt: Freywillige Blumen drangen auf Flora's Befehl hervor, den schönen Seladon zum weichen Polster zu dienen, gauckelnde Zephirs fächelten ihm mit ihren Rosenflügeln, Kühlung und ambrosiche Geruche zu, und eine Nymphe, reitzend wie die junge Hebe, bot ihm freundlich-lächelnd crystallenes Wasser in einer Perlenmuschel dar - dann glauben wir erst, daß der Poet sein Amt gethan, und die Natur geschildert habe, wie er soll.“ [WW 7.1, 235] Don Gabriel, der ältere Philosoph in diesem Kreis und ,ein grösserer Liebhaber von Mährchen als von metaphysischen Systemen“ [WW 7.1, 307], relativiert die Existenz der Feen zu einer Möglichkeit: „Die Feen könnten dem ungeachtet, wie ich nicht zweiffeln will, die geheimen Treibfedern aller ihrer wundervollen Zufälle gewesen seyn $[\ldots]^{\text {“ }}$ [WW 7.1, 235]. Jede Figur spricht für die von ihr favorisierte Gattung und macht Bemerkungen über die anderen Gattungen.

Bis auf Don Sylvio können alle Figuren sich aber von der geliebten Literatur abgrenzen. Donna Felicia hat ,die liebenswürdigste Jugend von Valencia aufgeopfert" [WW 7.1, 120], und zwar um den Reichtum ihres alten Gatten zu erhalten. Sie kleidet sich erst, als sie reiche Witwe geworden ist, wie eine Schäferin in der Dichtung. Pedrillo weiß trotz seines Aberglaubens und seiner Märchenkenntnisse, dass die Gestalt seiner geliebten Laura, die er sieht, ihre eigene ist und keine Illusion der zauberhaften Verwandlung einer Zwergin ist. Don Gabriel ist der Dichter des Kunstmärchens vom Prinzen Biribinker und weiß, dass die Absicht der Feenmärchen darin liegt, die Einbildungskraft zu belustigen. [WW 7.1, 307] Sogar Hyacinthe, die wie Don Sylvio die Umwelt nur auf sich selbst bezieht, kennt den Unterschied zwischen den alten Romanen und dem neuen erfundenen Roman über ihr Leben, dessen Heldin sie sein möchte. Die alten Romane sind ihre Vorbilder, aber sie lebt nicht in der Welt der schon geschriebenen Romane. Sie will einen eigenen Roman dichten.

Bei Don Sylvio ist der Fall anders. Für den Märchenschwärmer gehören die Märchenwelt und seine eigene Welt zusammen. Die Märchenfiguren wie die redende Kürbisse und die singenden Fische aus dem Biribinker-Märchen sind für ihn natürlich und möglich, weil man „,nicht den unendlich kleinen Theil der Natur, 
den wir vor Augen haben, oder das, was wir alle Tage begegnen sehen, zum Maasstab dessen, was der Natur möglich ist, machen“" [WW 7.1, 305] soll. Das Märchenhafte lasse sich wegen der Beschränkung der menschlichen Kenntnisse oder wegen des Referenzstandards ${ }^{156}$ nicht beobachten oder als solches verstehen. Er möchte nicht - wie seine Schwester - aus seinem Leben ein neues Märchen dichten. Stattdessen ist das Leben an sich schon Märchen. Deswegen sollen nicht nur seine Träumerzählung, sondern auch seine Abenteuer als Märchen gelten.

Buddecke argumentiert in seinem Beitrag, dass Don Sylvio Schöpfer und Dichter seiner Geschichte ist. Honold erörtert ebenfalls, dass Don Sylvio zugleich Schöpfer und Geschöpf sei. ${ }^{157}$ Das Schöpfertum Don Sylvios ist aber nicht problemlos. In Don Sylvios Märchenwelt ist nämlich nichts neu erfunden. Nach Blumenberg ahmen die Verständnisweisen für das Kunstwerk durch den Künstler die Wirklichkeitsbegriffe in ihrem geschichtlichen Zusammenhang nach. Die Nachahmungstheorie ist an zwei ontologische Voraussetzungen gebunden:

- die Gegebenheit oder Annahme eines Bereiches eigentlicher und aus sich einleuchtender exemplarischer Realität;

- die Möglichkeit zur Entscheidung, ob etwas zu diesem Bericht gehört oder nicht. ${ }^{158}$

Nach Blumenbergs Theorie ist die aus sich einleuchtende exemplarische Realität für Don Sylvio der Bereich der Märchenwelt, der für ihn auch die eigentliche Realität ist. Eine Vollständigkeit dieses Bereiches durch neue mögliche Gehalte und Gestalten von Wirklichkeit wird allerdings nicht völlig erreicht, weil Don Sylvio fast nur schon erfundene Märchenmotive weiter benutzt und kaum eine eigene Erfindung hat. Die Motive von „,[den] Schlösser[n] von Diamanten und Rubinen, [den] verwandelten oder in Thürme und unterirdische Palläste eingesperrte[n] Princessinnen und [den] zärtlichen Liebhaber[n], die unter dem wunderthätigen Schutz einer guten Fee den Nachstellungen einer bösen glücklich entgehen" [WW 7.1, 18] und viele andere übernimmt er aus französischen Feenmärchen. Sogar die Eigennamen vieler Stoffe in seinen Abenteuern sind Entlehnung aus den anderen Märchen: die böse Fee Fanferlüsch und der grüne Zwerg, das Schloss der weißen Katze und sein Hund Pimpimp, der vorher Amorett hieß und umbenannt worden ist, ,weil das Hündchen der Princeßin Wunderschön so geheissen hatte“ [WW 7.1, 18f]. Nur der Name der von ihm erretteten Fee Radiente („die Strahlende") ist eine eigene Erfindung von Don Sylvio. Die Gestalt dieser Fee ist allerdings nach den Vorbildern vieler ähnlicher Feen geschaffen: „Du weißst, daß wir alle hundert Jahre acht Tage lang die Gestalt irgend eines Vogels oder Thiers annehmen müs-

\footnotetext{
156 „Es ist wahr, Caraculiamborix ist in Vergleichung mit einem gewöhnlichen Menschen, ein Ungeheuer, aber er wird selbst zum Pygmeen, wenn wir ihn mit den Einwohnern des Saturnus vergleichen, die nach dem Bericht eines grossen Astronomi mit Meilenstäben ausgemessen werden müssen." [WW 7.1, 305]

157 Honold 2010, S. 186f.

158 Blumenberg 1969, S. 14 f.
} 
sen, daß wir in dieser Zeit den Gebrauch aller unsrer Macht verliehren, und allen Zufällen ausgesetzt sind, denen die thierische Natur unterworfen ist." [WW 7.1, 36f] Die Rede der Radiente in Don Sylvios Traum weist darauf hin, dass sie die Repräsentation vieler anderen Feen in Märchen ist. Die namen- und charakterlose verzauberte Prinzessin ist ebenfalls eine stereotypische Märchenprinzessin und die Verkörperung von Don Sylvios Begierde. Diese Prinzessin existiert schon, bevor Don Sylvio das Bildnis von Donna Felicia findet: Nach der Lektüre von Märchen bringt der Held „oft halbe Nächte mit Träumereyen über die wunderbaren Begebenheiten zu, die er sich wünschte, und die er in kurzem zu erfahren hofte" [WW 7.1, 19]. In seinen Träumen ist „[e]ine schöne Princeßin, die er liebte“ der Gegenstand. Die Prinzessin erhält ihr Aussehen jedoch erst, nachdem Don Sylvio das Bildnis gefunden hat, weil er in seiner ,strengen Einsamkeit“ [WW 7.1, 25] außer ein paar unattraktiven Frauen kaum eine Frau gesehen hat. Zu der Vervollständigung seiner Märchenwelt trägt Don Sylvio in der Tat ganz wenig bei. Seine Abenteuer sind mehr eine Nacherzählung der vorhandenen Märchen als eine neue Erzählung. Unreflektiert übernimmt er die anderen Märchen und erzählt sie noch einmal durch seinen Weg.

Don Sylvio glaubt, dass er alle Regeln in dieser Märchenwelt kenne und gestaltet seine Märchenwelt unbewusst nach diesen Regeln. Er wird aber immer wieder durch den Kontrast zwischen Märchen und Wirklichkeit in Verlegenheit oder sogar in Gefahr (beispielsweise bei den „Grasnymphen“) gebracht. Er ist nämlich kein allwissender Erzähler seiner Geschichte, sondern unter anderem ein im Märchengeschehen immanenter Leser. ${ }^{159}$

Der Erzähler einer Erzählung soll seinen Leser berücksichtigen. Von dem Leser wird verlangt, dass er die Grenze zwischen Wirklichkeit und Fiktion auflöscht. ${ }^{160}$ Der Leser soll sich ausgeben, als ob er das Erzählten für Wahres nähme. Auf diese Weise wird der Leser eine Rolle (identifikatorischer Leser) in der Erzählung. Ein solcher Leser ist dem Erzähler untergeordnet. „Das Erzählte, das der Erzähler vermittelt, bestimmt die Funktion, die dem Leser zufällt.“161 Der Vorgang des Lesens ist ein Zusammenspiel zwischen dem Dichter und dem Leser und vollendet sich in der Übereinstimmung zwischen der Fiktion des Dichters und der Illusion des Lesers. Indem der Leser mitwirkt, entsteht die Fiktion des Erzählten. ${ }^{162}$ Andererseits soll der Leser - als distanzierter Leser - die Grenze zwischen der Erzählung und der Wirklichkeit kennen. Er soll während des Lesens kritikbereit bleiben. Wieland beispielsweise fordert die distanzierende Beobachtung durch den aufgeklärten Leser. Nur weil der Leser das Erzählte reflektiert, wird das Erzählte erweitert und eine abgeschlossene Ganzheit der erzählten Welt entsteht.

\footnotetext{
159 Vgl. Seiler 1977, S. $153 \mathrm{ff}$.

160 Vgl. Kayser 1956, S. 227.

161 Seiler 1977, S. 154.

162 Vgl. Storz 1971, S. 410.
} 
Don Sylvio liest unreflektiert. Er „las nicht, er sah, er hörte, er fühlte“ [WW 7.1, 17]. Es entsteht keine vernünftige Kommunikation zwischen dem Erzähler und dem Leser ${ }^{163}$ und die Einbildungskraft des Lesers wird nicht belustigt. Stattdessen hält Don Sylvio „die Vermischung des Wunderbaren mit der Einfalt der Natur [...] für [...] ein untrügliches Kennzeichen ihrer Wahrheit" [WW 7.1, 17]. Er ist völlig in das Erzählte einbezogen und grenzt sich nicht kritisch davon ab. Sein Lesen unterscheidet sich deutlich von dem „vernünftigen“ Lesen, das Wieland von seinen Lesern fordert. Don Sylvio von Rosalva ist ein Buch, dessen Themen das Lesen und die Schwärmerei sind. Darüber hinaus tragen die kritischen Bemerkungen des Erzählers und die Paratexte des Romans dazu bei, dass der Leser in der Lage ist, sich von der fiktiven Welt zu distanzieren. Es lässt sich vorstellen, dass der Text ohne den Erzähler eine autodiegetische Erzählung des Helden Don Sylvio wäre und die subjektiven Erlebnisse des Erzählers zu einem Märchen würden. Nur mit der Anwesenheit und den psychologischen Betrachtungen des heterodiegetischen Erzählers wird das geistige Fieber Don Sylvios als eine Schwärmerei entlarvt und die eintägigen Abenteuer erscheinen lustspielhaft statt heroisch und phantastisch. Er weist nämlich auf die satirischen Elemente in Don Sylvios Zauberwelt hin. ${ }^{164}$

Bickenbach erläutert, dass die Paratexte in diesem Roman einer komplexen Leserlenkung dienen und die Fußnoten im Roman als Teil des dialogischen Prinzips zu verstehen sind. Die barocke Titelgestaltung des Romans (Der Sieg der Natur über die Schwärmerei oder die Abenteuer des Don Sylvio von Rosalva. Eine Geschichte worin alles Wunderbare natürlich qugeht. Zwei Theile) ist eine Anspielung auf Don Quijote von La Mancha sowie auf Alain René Lesages Gil Blas von Santillane. ${ }^{165}$ Die intertextuellen Beziehungen des Romans zu den anderen Texten werden dadurch vorgeführt. Ein erfahrener Leser soll aufmerksam während des Lesens sein und zwischen diesem Roman und den Referenztexten vergleichen. Sie können als direktes Sprechen des Erzählers zum Leser mit Assoziation an den wissenschaftlichen Schreibstil gelten. Sie beziehen sich auf fiktionsexterne Quellen, bleiben jedoch Teil der fiktiven Wirklichkeit. ${ }^{166}$ „Ihre Verweisfunktion, die etwa auf wissenschaftliche Erkenntnisse der Zeit jenseits des Textes verweist, markiert eine ,Schwelle' (d.i. Genettes Metapher für Paratexte), deren Funktion weniger die Überschreitung als die Einbeziehung der Wirklichkeit in die Fiktion ist." ${ }^{167}$ Die Fußnoten thematisie-

\footnotetext{
${ }^{163} \mathrm{Zu}$ bemerken ist, dass Don Sylvio sich während seiner Erzählung von Träumen auch auf Kommunikation mit seinem Zuhörer Pedrillo verzichtet.

164 Zum Beispiel bemerkt der Erzähler zusammen mit seinen Lesern, nachdem Don Sylvio sich in die „verzauberte“ Prinzessin auf ihrem Bildnis verliebt hat und sich entschlossen hat, sie zu erlösen, erinnert ihn sein Magen, dass er seit gestern Mittag gefastet hat, denn „die Bezauberung erstreckte sich bey ihm niemals bis auf den Magen“ [WW 7.1, 34].

165 Bickenbach 2013, S. 292.

166 Die Fußnoten stammen vom fiktiven Herausgeber der fiktionalen Erzählung eines fiktiven spanischen Autors.

167 Bickenbach 2013, S. $296 f$.
} 
ren und unterstreichen den Unterschied zwischen Innen- und Außenraum der Fiktion. Innerliterarische Perspektive wird mit außerliterarischer Perspektive vernetzt. Die Fußnoten unterbrechen den Lesefluss und „reiß[en] den Leser aus der

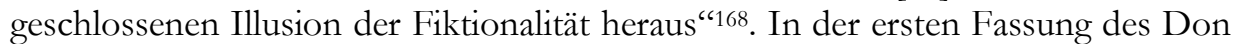
Sylvio gibt es nur drei „Anmerkungen des Herausgebers“ als Fußnoten, während zahlreiche Fußnoten in den zwei späteren Fassungen (1772 und 1795) eingefügt werden. Die Leserlenkung wird dadurch verstärkt. Da die Fußnoten von dem vermeintlichen deutschen Herausgeber statt vom Erzähler verfasst sind, gehören sie nicht zur gleichen Erzählebene wie die Betrachtungen des Erzählers: Der Erzähler fungiert als Vermittlungsinstanz zwischen Don Sylvios Welt und der fiktiven Welt der textimmanenten Leser, wobei der Erzähler in den Fußnoten des Herausgebers ebenfalls in die fiktionale Welt einbezogen ist und diese dadurch um eine neue Schicht erweitert. Eine Analogie entsteht zwischen den Beziehungen des Erzählers zu Don Sylvios subjektiver Märchenwelt (oder seinen Tätigkeiten als Nacherzählung von Märchen) und denjenigen der Fußnoten zu der fiktiven Welt inklusive des Erzählers. Die Erzählerkommentare fungieren als „Fußnoten“ zu Don Sylvios „Text“. Der Roman lässt sich in diesem Sinne als ein Feenmärchen mit einer kritisch kommentierenden Schicht verstehen.

\subsection{Vom Märchen zum Entwicklungsroman}

Die Abenteuer enden schon im Fünften Buch. Der zweite Teil des Romans ist dagegen ein Salonroman mit mehrperspektivischer Betrachtung von Don Sylvios „Märchentext“. In diesem Teil ist Don Sylvio aus seiner individuellen Welt ${ }^{169}$ herausgetreten und tritt zum ersten Mal ins gesellschaftliche Leben ein. Während der Kommunikation mit ebenbürtigen Leuten erkennt der Held den Unterschied zwischen der objektiven und subjektiven Wirklichkeit und dass das Wunderbare eher ein Bewusstsein als ein Sein ist. Er muss erst eine Desillusion erleben und dann in die Gesellschaft integrieren. Die Verwandlung von Don Sylvio entspricht den Entwicklungsstufen des Menschen nach der aufklärerischen Vorstellung.

Für den Aufklärer Wieland gibt es zwei grundlegende Voraussetzungen für das Menschenbild: die eine ist die zweigeteilte Welt aus dem Gegensatzpaar von Ichgefühl und Lebenserfahrung. ${ }^{170}$ Wie Wieland in Don Sylvio erläutert, gibt es „eine zweyfache Art von Würklichkeit“ [WW 7.1, 44]. Gemeint sind Dinge, die bloß in unserem Gehirn existieren und Dinge, die außer uns sind. Zwischen den beiden Bereichen zu unterscheiden, ist nach Wieland, in concreto nicht allemal so leicht [...], als manche Leute denken“ [WW 7.1, 44]. Die zweite Voraussetzung ist die

\footnotetext{
168 Bickenbach 2013, S. 298.

${ }^{169}$ Der Aberglaube des Pedrillo kann als eine Ergänzung zu Don Sylvios Schwärmerei verstanden werden.

170 Vgl. Schindler-Hürlimann 1963, S. 88.
} 
Bildsamkeit des Menschen, ,also die Fähigkeit, seine Entscheidungen zu ändern, zu verbessern“171. Der Jüngling Don Sylvio ist nach Schindler-Hürlimann der Inbegriff des Menschen, der erst gebildet werden muss. Die Ausbildung sowie Entwicklung des Menschen, die durch seine Situation zwischen den beiden Wirklichkeiten geprägt ist, besteht aus drei Stufen. Die erste Stufe ist nach Wieland die sogenannte Schwärmer-Stufe, oder wie Buddecke formuliert, bestimmt „,durch eine grenzenlose Subjektivität und Egozentrik“"172. In dieser Stufe bleibt der Mensch in sich beschränkt. Eine Grenze zwischen dem erlebenden Subjekt und dem erlebten Objekt gibt es noch nicht. In der Liebe erreicht der Mensch die entscheidende zweite Stufe seiner Entwicklung. Denn die Liebe ist das stärkste Gefühl des Herzens und „das innige Bewusstseyn dessen, was wir fühlen“ [SW 24, 44], ist zugleich das sicherste Kennzeichen für die Wahrheit. In der Liebe tritt der Mensch zum ersten Mal aus seiner Subjektivität nach außen. Don Sylvios Ernüchterung erfolgt in seiner Liebe zu Donna Felicia. Nur als Liebender wird „das ganze Feuer [seiner] Einbildungs-Kraft ausgelöscht" [WW 7.1, 322]. Im Vergleich mit der Schocktherapie des Biribinker-Märchens und der philosophischen Diskussion wirkt die bezaubernde Entzauberungskraft der Liebe viel heftiger. Schon Don Gabriel muss gestehen, dass „ein paar schöne Augen in etlichen Minuten stärker überzeugen und schneller bekehren, als die Academie, das Lyceum und die Stoa mit vereinigten Kräften kaum in eben so viel Jahren zu thun vermöchten" [WW 7.1, 326]. Die Liebe bietet dem Menschen die Möglichkeit, sich mit den anderen zu verbinden.

Die Kommunikation mit den Anderen gehört nach Wieland zu dem ethisch Aufgegebenen. Die dritte Stufe der Entwicklung ist die Sublimation des Individuums zu der Menschheit als Ganzes, oder wie Wieland sagt, zu einem Weltbürger. Der Weltbürger ist ein Mensch,

der, obne mit irgend einer Particulargesellschaft in besonderer Verbindung zu stehen, den Erdboden für sein V aterland, und alle Geschöpfe seiner Gattung gleichgültig gegen den zufälligen Unterschied, den Lage, Luft, Lebensart, Sprache, Sitten, Policei und Privatinteresse unter ibnen machen, als sein Mitleiden, wenn er ibnen nicht belfen kann, an seine Zurechtweisung, wenn er sie irren siebt, an seine Mitfreude, wenn sie sich ibres Dasein freuen. [WW 9.1, 65]

Der Weltbürger soll im Staat etwas Großes leisten und die anderen erzielen, wie es bei Don Gabriel der Fall ist. Das endgültige Ziel dieser Stufe ist, dass jedes Mitglied einer Gesellschaft Weltbürger werden und dass der Staat eine ideale Form der Gemeinschaft und eine vergrößerte schöne Gesellschaft wird. „Der Mensch ist in verpflichtet zum Dienst an der Gemeinschaft, zur tätigen Sorge für den Nächsten, die je nach Beruf und Berufung die verschiedensten Inhalte und Formen gewinnen mag, von der Förderung materiellen Wohls bis zur Verschönerung

\footnotetext{
171 Schindler-Hürlimann 1963, S. 88.

172 Buddecke 1966, S. 76.
} 
des Lebens durch ästhetische Produktionen." "173 Am Ende des Romans befindet sich Don Sylvio ganz offensichtlich zwischen der zweiten und der dritten Stufe. Er ist nämlich bereit dazu, ,den leeren Raum, den die Verbannung der Feen darinn gelassen hatte, nunmehr mit den Ideen würklicher Dinge anzufüllen" [WW 7.1, 333] und entschließt sich, eine Reise in die vornehmsten Theile von Europa zu machen. Dieser Bruch mit der Isolation des Landlebens stimmt mit Wielands Begriff vom Weltbürger überein.

Es bleibt verhüllt, was für einen gesellschaftlichen Dienst der zukünftige Weltbürger Don Sylvio nach seiner zweijährigen Reise leisten wird. Es liegt allerdings nahe, dass der junge Märchen-Nachdichter später ein eigenes lehrreiches Werk schreiben wird, weil sein geistiger Tutor Don Gabriel Dichter ist und er die Verzauberungs- und Entzauberungskraft der Literatur gut kennt. Während die Geschichte des Prinzen Biribinker eine kritische Verarbeitung seines realen Lebens durch Don Gabriel ist, ist er dazu berufen, seine frühere Schwärmerei distanzierend zu analysieren. Es ist möglich, dass Don Sylvio der Dichter eines Entwicklungsromans mit autobiographischen Bezügen wird, vielleicht des spanischen Manuskripts Don Sylvio von Rosalva.

173 Buddecke 1966, S. 118. 


\section{Novalis: Die Lehrlinge zu Sais}

Die erste Erwähnung des Romanfragments Die Lehrlinge zu Sais findet sich in einem Brief des Dichters Novalis (1772-1801) an August Wilhelm Schlegel vom 24.02.1798: „Ich habe noch einige Bogen logologische Fragmente, Poëticismen, und einen Anfang, unter dem Titel, der Lehrling zu Saïs - ebenfalls Fragmente nur alle in Beziehung auf Natur" [N IV, 251]. Der erste Teil des Fragments Der Lehrling entsteht Anfang des Jahres 1798 parallel zu den in Freiberg ausgeführten naturwissenschaftlichen und naturphilosophischen Studien von Novalis. In den 1797/98 verfassten Blüthenstaub-Fragmenten kommt die Natur nur ganz wenig zur Sprache. Deswegen hatte Novalis am Anfang der Werkplanung vor, ein neues Werk - vielleicht eine andere Sammlung von Fragmenten - speziell zum Thema Natur zu schreiben. Das in der zweiten Hälfte des Jahres 1798 entwickelte Enzyklopädieprojekt Das allgemeine Brouillon (1798/99) sollte ebenfalls im Zusammenhang mit dem poetischen Projekt stehen. Ende des Jahres 1799 schrieb Novalis einige Entwurfsnotizen zu der Fortsetzung der Lehrlinge zu Sais. Die Erscheinung der zukünftigen Natur als nemes Jerusalem [N I, 111] - eine sinnbildhafte Harmonie zwischen der Natur und dem menschlichen Geist - war bereits entworfen, wurde aber nicht mehr ausgeführt. Zu dieser Zeit wurde die Arbeit an Die Lebrlinge ₹ $u$ Sais wahrscheinlich schon unterbrochen, denn am 31. Februar 1800 schrieb der Dichter an Friedrich Schlegel: „Der Lehrling zu Saïs kommt nach der Vollendung des obigen R[omans Heinrich von Afterdingen] sogleich in die Arbeit" [N IV, 318]. Wenig später äußerte Novalis in einem Brief an Ludwig Tieck sein Vorhaben, das 
Fragment umzuschreiben: „Um so besser ist es, daß die Lehrlinge ruhn - die jezt auf eine ganz andre Art erscheinen sollen - Es soll ein ächtsinnbildlicher, Naturroman werden. Erst muß Heinrich fertig seyn - Eins nach den Andern, sonst wird nichts fertig“" [N IV , 322f]. Doch bleibt der Roman wegen des frühen Todes von Novalis unvollendet.

Mit der Frage, ob dieser unvollendete Text eine kompositorische Einheit bildet, beschäftigen sich viele Novalis-Forscher. Im 19. Jahrhundert sahen Forscher wie Haym und Huber „[e]ine noch völlig ungestaltete Dichtung“"174 beziehungsweise „viel Erwartung ohne Erfüllung“"175. Sogar Paul Kluckhohn, der Herausgeber der Historischen Kritischen Ausgabe, nannte dieses Fragment immer noch „Bruchstücke“ 176 in seinem einleitenden Text Friedrich von Hardenbergs Entwicklung und Dichtung. Seit Striedters Beitrag über die Komposition der Lehrlinge im Jahr 1955 hat sich der Forschungsstand geändert. Striedter untersuchte den Aufbau des Gesamttextes mit dem Schwerpunkt auf den ersten Teil und zeigte, dass der Text auf einer geschlossenen Konzeption basiert. Die Triadik des geschichtlichen Verlaufes und die „Hin-und-Her-Direktion“ in der thematischen sowie förmlichen Stufenfolge der Aussage wurden einleuchtend untersucht. „In der künftigen Welt ist alles, wie in der ehemaligen Welt - und doch alles ganz Anders. Die künftige Welt ist das Vernünftige Chaos - das Chaos, das sich selbst durchdrang [... “" [N III, 281]. Nach Hans-Joachim Mähl liegt dem Roman die geschichtsphilosophische Triadik zugrunde. Auch die Untersuchungen zu den Beziehungen zwischen dem eingebetteten Hyazinth-Märchen und dem Rahmentext ${ }^{177}$ tragen dazu bei, dass die meisten neueren Forscher ein ,genau durchdachtes Strukturmodell“178 im Gesamttext sehen. ${ }^{179}$

Da Novalis ein Vertreter der Frühromantik war, der forderte, „die grundlegenden strukturellen Merkmale des Märchens exemplarisch für die romantische Poesie insgesamt anzusetzen"180, gelten seine Märchentheorie und seine praktischen Anwendungen des Märchens in poetischen Texten für die Untersuchung der Märchenstruktur sowie der Märchenadaption in Erzählungen und Romanen als wegbereitend und einzigartig. Novalis’ Begriffe des Märchens und des Romans sind nämlich von seiner Weltabbildungslehre geprägt und daher anders, als die vieler späterer Dichter. Die Lehrlinge zu Sais entstehen zu einer Zeit, als sich Novalis von einem Theoretiker zu einem Poeten und Romandichter wandelte. Dieser

\footnotetext{
174 Haym 1870, S. 347.

175 Huber 1899, S. 102.

176 Kluckhohn 1960, S. 40.

177 Ingrid Kreuzer beispielsweise argumentiert, dass das Märchen „Achse“ und Vollendung des Lehrlingsromans sei. Der Lehrlingsroman und das eingebettete Märchen entsprächen zwei Formen des Kunstmärchens: „,eines von reduktiver Strenge, das Lebensfülle ausschießt; ein anderes, das Lebensfülle verdichtend konzentriert“. Kreuzer 1979, S. 305.

178 Gaier 1970, S. 33.

$179 \mathrm{Vgl}$. Uerlings 1991, S. 354-360.

180 Kremer 2007, S. 187 f.
} 
Übergang zeigt sich zusammen mit Novalis' Gedanken über die Naturwissenschaft, die Naturphilosophie, die Geschichtsphilosophie sowie die Anthropologie über den magischen Idealismus und nicht zuletzt über die literarischen Gattungen Roman und Märchen in dem dreißigseitigen, kurzen Text. Dies ist der Beweggrund zur Erforschung der Märchenadaption und der Märchenstruktur in Die Lehrlinge zu Sais - ein Werk, das nicht nur den Übergang von theoretischen Fragmenten zu ästhetischer Dichtung kennzeichnet, sondern auch den Übergang vom Roman zum Märchen darstellt. Die Frage, warum und wie soll ein Roman allmählich ein Märchen werden, wird in diesem Kapitel durch ein textnahes Lesen des Werkes und durch einen Versuch, die philosophische und literarische Theorie von Novalis in Die Lebrlinge zu Sais zu anzuwenden, beantwortet.

Dieses Kapitel besteht aus den folgenden Teilen: Die Roman- und Märchentheorie von Novalis gilt als Ausgangspunkt der Untersuchung. In den nächsten zwei Teilen werden die Figuren und die Welt der Lebrlinge zu Sais als exemplarische Kombination der philosophischen und literarischen Theorien des Novalis und somit als eine Veranschaulichung des Geistes - das Märchenideal von Novalis betrachtet. In dem letzten Teil wird die „Hin-und-Her-Direktion“ der Form und des Themas hinsichtlich der Aussage in dem zweiten Teil Die Natur in Anschluss an Striedter behandelt.

\subsection{Die Roman- sowie Märchentheorie von Novalis}

In seinen gesammelten Materialien zur Enzyklopädistik 1788/89 schreibt Novalis unter dem Titel Romantik: „Alle Romane, wo wahre Liebe vorkommt, sind Mährchen - magische Begebenheiten" [N III, 255]. Eine eindeutige Unterscheidung zwischen den Gattungen Roman und Märchen kommt also bei Novalis nicht vor. Es liegt sogar nah, dass Novalis das Ideal aller Romane im Märchen sieht.

Die Begriffe Romantik und Roman haben etymologisch den gleichen Ursprung in der altfranzösischen Wortform romanz: Aus dem französischen romance entwickelte sich roman, das im 17. Jahrhundert in den deutschen Sprachgebrauch als Fremdwort übernommen wurde und den Typus des beliebten Ritter- und Abenteuerbuches bezeichnete. Gemäß Friedrich Schlegel sollen alle getrennten Gattungen der Poesie in dem Roman wieder vereinigt werden. ${ }^{181}$ Der Roman soll eine universalistische allumfassende poetische Darstellungsweise sein . Ganz in diesem Sinne meint Novalis, der „Darsteller [müsse] alles darstellen können und wollen. Dadurch entsteh[e] der große Styl der Darstellung“ [N II, 422]. Als der Frühromantiker Novalis die Verbalisierung romantisieren als das leitende Prinzip seiner revolutionären Planung benutzte [Vgl. N II, 545, N III, 256], verwies er unter anderem auf Merkmale des traditionellen Romanverständnisses - etwas Romanhaftes, Abenteuerliches, Phantastisches und Sonderbares im Gegensatz zu der

${ }^{181}$ Kremer 2007, S. 115. 
bürgerlichen Alltäglichkeit und Realität. Damit zeigt sich die Wertschätzung der Gattung Roman durch Novalis: Das Romantisieren bezeichnet auch „eine Geis-

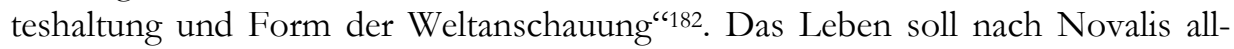
mählich das Werk des Geistes - ein Roman - werden. Die Romandichtung sei eine „Selbstentäußerung“" „Der erste Schritt wird Blick nach innen - absondernde Beschauung unsres Selbst - Wer hier stehn bleibt geräth nur halb. Der 2te Schritt muß wircksamer Blick nach außen - selbstthätige, gehaltne Beobachtung der AuBenwelt seyn“ [N II, 422]. Der Dichter sei beauftragt, die beobachtete Welt zu verinnerlichen und dann seine Geisterwelt von innen heraus mithilfe seiner produktiven Einbildungskraft zu einem vielfältigen Ensemble zu gestalten. Das dargestellte Leben bestehe aus bekannten Begebenheiten und bekannten Personen, weil das Erkennen der Welt mit dem Erkennen des Ich übereinstimme und weil jedes Individuum eine Variation eines vollständigen Individuums sei. „Aber eine Idee läßt sich nicht, in einen Satz fassen. Eine Idee ist eine unendliche Reibe von Sätzen - eine irrationale Größe - unsetzbar (musik[alisch]) - incommensurabel“" [N II, 570]. Deswegen solle ein Roman eine unendliche und sich erweiternde Poesie werden. Novalis selbst habe auch Lust, sein ,ganzes Leben an Einen Roman zu wenden - der allein eine ganze Bibliothek ausmachen - vielleicht Lehrjahre einer Nation enthalten soll" " [N IV, 281]. Die Absicht des Romandichters soll die Nachbildung des Universalen sein, wobei die Weltschöpfung aus der unendlichen Idee der Liebe - dem „Schöpfungsatem“ [N IV, Brief an Friedrich Schlegel am 16. Juli 1796] - eingeschlossen werden müsse. Die angemessene Darstellung solcher wahren Liebe sei das Märchen.

Am 05. April 1800 schrieb Novalis an Friedrich Schlegel in Bezug auf seinen Roman Heinrich von Ofterdingen: „Es sollte mir lieb seyn, wenn ihr Roman und Märchen in einer glücklichen Mischung zu bemerken glaubtet [...]. Der Roman soll allmählich in Märchen übergehn." [N IV 330] Diese Bemerkung gilt nicht nur für das aktuelle Romanprojekt des Dichters, sondern auch für die Gattung Roman überhaupt. Denn das Märchen sei gleichsam der Canon der Poesie - „alles poëtische muß mährchenhaft seyn" [N III, 449]. Nicht nur die bedeutende Rolle der Einbildungskraft im Märchen ist der Grund für diese Hochschätzung, sondern auch die Meinung, alle Märchen seien „Träume von jener heymathlichen Welt, die überall und nirgends ist“ [N II, 564]. Ein Märchen solle „ein Ensemble wunderbarer Dinge und Begebenheiten“" - die Natur selbst sein [N III, 454]. In einem echten Märchen müsse alles wunderbar, geheimnisvoll und unzusammenhängend sein. Die ganze Natur müsse auf eine wunderliche Art mit der ganzen Geisterwelt vermischt sein, so Novalis in Allgemeines Brouillon über die Romantiketc. [N III, 208]. Die Natur und die Geisterwelt, die bei Novalis mit der höheren Welt gleichzusetzen ist, sollen das Ganze bilden. ${ }^{183}$

182 Schulz 1968, S. 81.

183 Diese Idee gewann Novalis aus der Lehre von Fichtes transzendentaler Erkenntnis: Die Natur sei das Produkt eines ewigen Geistes. Da das Produzierende als solches in seinen Produkten anwesend 
Eckhard Heftrich untersucht die Reihenfolge der Aufzählung in dem oben zitierten Artikel Romantik etc. - „Märchen. Nessir und Zulima. Romantisierung der Alcine. Novellen. Tausend und eine Nacht. Dschinnistan. La Belle et la Bête. Musäus' Volksmärchen. Romantischer Geist der neuern Romane. Meister. Werther. Griechische Volksmärchen, indische Märchen. Neue originelle Märchen. “ [N III, 208] - in seiner Abhandlung und kommt zu dem Ergebnis, dass die indischen Märchen für den Dichter für die älteste Zeit stünden, die „am unmittelbarsten in die Zukunft der Wiederkehr weist" "184. Das echte Märchen solle daher einerseits die Zeit vor der Geschichte widerspiegeln, andererseits prophetisch sein, und der Märchendichter müsse Seher der Zukunft werden. Denn die Vollendung der Geschichte sei die Wiederkehr des Chaos, der unzusammenhängende und geheimnisvoll erscheinende Zustand vor der Welt (Staat). „In der künftigen Welt ist alles wie in der ehemaligen Welt und doch alles ganz anders. Die künftige Welt ist das vernünftige Chaos; das Chaos, das sich selbst durchdrang, in sich und außer sich ist" [N III, 281]. Der Märchendichter sei göttlich schöpferisch, weil er die Bedeutung der Abstraktion für das höhere Märchen erkenne: „Abstracte Welten Traumwelt - Folgerungen von der Abstraction etc. auf d[en] Zustand nach dem Tode“ [N III, 458]. Die Abstraktion steht hier nicht im Sinne einer theoretischen Abstraktion, wie in der modernen Verwendung des Begriffes, sondern viel mehr im Sinne eines „vorkritische[n] und unaufgeklärte[n] Denken[s]“"185, also einer unreflektierten Abbildung des zugrundeliegenden Geistes. Die Zahlen und die abstrakten Ausdrücke, „alles aus Nichts erschaffene Reale“ [N III, 440] hat noch Novalis eine wunderbare Verwandtschaft mit einer höheren Welt. Er behauptet, dass Mathematik echte Wissenschaft sei, weil sie gemachte Kenntnisse enthalte, Produkt geistiger Selbsttätigkeit sei, und weil sie methodisch ,genialisiere“ [N III, 440f]. Diese höhere Welt sei daher identisch mit dem Zustand, bevor der Geist in der gegenständlichen Natur verzaubert worden sei. Das Märchen zeigt die entzauberte Natur in ihrem erlösten und lebendigen Zustand.

Das Märchen stelle die Zeit nach der Geschichte in ihrer Gesetzlosigkeit und Anarchie dar. „Der Prozeß, in dem die Schöpfung sich vollendet, poetisiert die Welt, verwandelt sie in Gemüt. In dieser künftigen Welt des Gemüts, die als die kommende zugleich ewiges Reich der Geister, der lebendigen Ideen, der Urbilder

\footnotetext{
sei, sei der Geist in der Natur anwesend. Die Natur stelle sich jedoch nicht als geistig dar, sondern als etwas Dingliches und Nicht-Geist, worin auch der Geist anwesend sei. In diesem Sinne sei die gegenständliche Natur „der in einen Geheimniszustand versetzte Geist selbst, und das Geheimnisvolle dieses Zustands besteht darin, daß der Geist sich selbst im natürlichen und im wissenschaftlichen Bewußtsein als Nicht-Geist, als Dingwelt erscheint". Mahoney 2001, S. 122 f. Die im natürlichen Bewusstsein erscheinende Natur, der Gegenstand der naturwissenschaftlichen Forschungen, sei der verzauberte Geist. Die Natur bedürfe daher eines Wortes, das sie aus dieser Verzauberung erlösen solle. Dieses Wort sei das dichterische Wort, ein befreiender Zauber. Vgl. Mahoney 2001, S. 123. ${ }_{184}$ Heftrich 1969, S. 119.

185 Heftrich 1969, S. 124.
} 
ist, sind Freiheit und Notwendigkeit eins." ${ }^{186}$ In Märchen und in einem prophetischen Traum herrscht - wie in dem zukünftigen Reich nach der Vollendung der Geschichte - die absolute Freiheit, auf die nicht nur alle literarischen Gattungen abzielen, sondern auch das menschliche Leben selbst sich ausrichten soll, weshalb das Märchen der Kanon der Literatur ist. Das Märchen soll einen solchen Prozess vorbildlich vorführen: „Anfänglich eine Bezauberung - dann die wunderbare Versöhnung - etc. Die Erfüllung der Verwünschungsbedingung“" [N III, 639].

\subsection{Die Lehrlinge zu Sais als das Fragment eines romantischen Romans}

Die Lebrlinge zu Sais sind die erste prosaische Fiktion von Novalis. Als der Dichter dieses Werk in seinem Brief an August Wilhelm Schlegel am 14. 02. 1798 zum ersten Mal erwähnte, galt Der Lehrling zu Sais nur als „Fragmente - nur alle in Beziehung auf Natur" [N IV, 251] und noch nicht als Roman. Vielleicht bezieht sich die spätere Erwähnung eines „Roman[s] in Sedez“ [N IV, 254] im Mai 1798 auf dieses Werk. Als Novalis Jakob Böhme „im Zusammenhange“ [N IV, 322] las und ihn zu verstehen anfing, vertiefte er seine Idee über „[e]in ächtes Chaos voll dunkler Begier und wunderbaren Leben - einen wahren, auseinandergehenden Microcosmus“ [N IV, 322f]: „Um so besser ist es, daß Die Lehrlinge ruhn - die jetzt auf eine ganz andere Art erscheinen sollen. - Es soll ein echt sinnbildlicher Naturroman werden. Erst muß Heinrich fertig sein." [N IV, 322f] Hier werden die Gattung des Werkes - Roman - sowie der jetzige Titel Die Lebrlinge [zu Sais] zum ersten Mal genannt. Der Plan, einen Roman zu verfassen, schien dem Dichter erst allmählich deutlich zu werden. Auch die Frage, ob nur eine Hauptfigur oder ein Ensemble von Lehrlingen im Zentrum des Textes stehen soll, wurde erst später oder sogar nie eindeutig beantwortet, weil der Titel des ersten Teils immer noch Der Lebrling lautet.

Kristin Pfefferkorn stellt die These auf, dass die beiden poetischen Fragmente von Novalis - Die Lehrlinge zu Sais und Heinrich von Ofterdingen - die der Dichter selbst „Roman“ nannte, in der Tat Kunstmärchen seien, während die eingebetteten „Märchen“ in diesen Werken allegorische Fabeln seien. Sowohl der Traum am Anfang des Heinrich von Ofterdingen als auch das Goldene Zeitalter in dem ersten Teil des Romans signifizieren beispielsweise symbolisch die Überwindung der Zeit. Der erste Teil dieses unvollendeten Werks entspreche seiner Struktur nach aus den folgenden Gründen einem Märchen:

first, because it is weak in character development or psychology and in the suspenseful succession of events, which are the strong points of the novel; second, because it is rich in suggestions of the miraculous, the marvelous, and the uncanny, all of which

186 Heftrich 1969, S. 123. 
are the Märchen's usual fare; third, because social rank, historical dates, and geographical places, all of which serve the novel to achieve an air of reality, are used in Heinrich von Ofterdingen only as framework within which to embed an entirely implausible and magical tale; and last and most important, because in its relation to time it resembles the Märchen in that it brackets the flow of time. But as a Kunstmärchen, that is a raised Volksmärchen, it achieves the bracketing by means of a dream of transcendence and an allegory of the Golden Age, which is the age of an atemporal, paradisiacal eternity. ${ }^{187}$

Die genannten Eigenschaften des Heinrich von Ofterdingen gelten ebenfalls für Die Lehrlinge zu Sais, weshalb auch Ingrid Kreuzer argumentiert, dass nicht nur das eingelegte Märchen von Hyazinth und Rosenblüte, sondern auch der Lehrlingstext als Ganzes Strukturprinzipien des Kunstmärchens zeige: „Namenlosigkeit (oder nur Gattungsbezeichnung) der Protagonisten; Fehlen von Real-Raum und Real-Zeit; Fixierung an Zahlenrhythmen (wie 3 und 7); Aktionslosigkeit; eingegrenztes Feld der Darstellung; Strukturprinzipien der Repetition, Variation, der konzentrischen Reihung und der (hier auditiven) Spiegelung; die Beschlossenheit im Kunstraum, ohne alle Transzendenz; die Aussagekraft der Struktursymbolik anstelle der Symbolik von Inhalten; alles Züge, die auch Goethes Märchen ${ }^{188}$ zeigt.“ Für Kreuzer sei es falsch, den Text von Die Lehrlinge zu Sais einer eindeutigen literarischen Gattung zuzuordnen. Der Text partizipiere an Genres „,mit unterschiedlichem Fiktionalitätsbefund“"189, wie die des Romans, des Kunstmärchens und der erkenntnistheoretischen Abhandlung des Lehrgesprächs.

Wie im ersten Abschnitt gezeigt worden ist, entspricht der Begriff Roman von Novalis Friedrich Schlegels Definition im Brief über den Roman: Ein Roman sei ein romantisches Buch. ${ }^{190}$ Der romantische Roman sei eine universale Poesie, die von der Phantasie entworfen werden und Gedanken mitteilen oder allegorisch einkleiden solle. ${ }^{191}$ Der Roman solle alle Gattungen in sich begreifen, weshalb die bunte Mischung mehrerer Gattungen in Die Lehrlinge zu Sais und die allegorische Einkleidung der Naturgedanken genuine Merkmale eines typisch romantischen Romans sind. Der Roman soll in ein Märchen übergehen. Sowohl nach dem allegorisch-prophetischen Ton der ersten beiden Kapitel als auch nach der späteren „Verwandlung des Tempels zu Sais“ in den Paralipomena („Erscheinung der Isis“, „Ankunft der griechischen Götter“, „Neues Testament - und neue Natur - als neues Jerusalem" usw. [N I, 111]) soll der Roman immer märchenhafter werden und mit dem neuen Goldenen Zeitalter enden.

Allerdings ist der erste Teil des Textes noch kein Märchen. Eine Gesetzlosigkeit und Freiheit kommen nämlich im ersten Teil nur in dem Rückblick auf die

\footnotetext{
187 Pfefferkorn 1988, S. 174.

188 Kreuzer 1979, S. 304.

189 Kreuzer 1979, S. 285.

190 Schlegel, KA II, S. 336.

191 Kluckhohn 1960, S. 39.
} 
Jugend des Lehrers - in der Vergangenheit - vor. Es gibt eine klare Trennlinie zwischen der Handlung nach dem Ende des ersten Goldenen Zeitalters und der „Verwandlung des Tempels“ beziehungsweise der Entwicklung des Romans sowie der Romanwelt zum Märchen: Es ist die Erzählung des Hyazinth-Märchens durch den munteren Gespielen, „dem Rosen und Winden die Schläfe zierten“ [N I, 91] und der herbeigesprungen kommt - durch eine märchenhafte Figur also. Erst nach der Märchenerzählung fangen die tausendfaltigen Naturen in den Sälen an, das wunderbare Gespräch in zahllosen Sprachen zu führen. „Ihre innern Kräfte spielten gegen einander. Sie strebten in ihre Freiheit, in ihre alten Verhältnisse zurück." [N I, 95] Die wahre Liebe kommt in dem Märchen vor. Das Begreifen des absoluten Ichs in der Liebe ist durch das Erzählen des Märchens vollendet. Die Erlösung der Natur aus ihrem verzauberten Zustand ist der nächste Schritt der Romanhandlung. Nach Novalis' Entwurf soll das Phantastische in dem Text eine immer bedeutsamere Rolle spielen.

\subsection{Die Figuren in Die Lehrlinge zu Sais}

Die Figuren in Die Lebrlinge zu Sais sind bis auf die beiden Märchenhelden mit den naturallegorischen Namen Hyazinth und Rosenblüte anonym. Nicht nur ihre Namenlosigkeit, sondern auch der Mangel an Beschreibungen ihres Aussehens sowie ihre Psychologisierung zeichnet sie als flache märchenhafte Figuren aus. Sie sind lediglich Lehrer, Reisende, Redende und Lehrlinge inklusive des ungeschickten und traurigen Lehrlings und des Ich-Erzählers in dem ersten Teil. „Das Kind“ ist die einzige Figur in diesem Ensemble, deren Aussehen durch einige Gleichnisse genauer ausgedrückt wird: „Es hatte große dunkle Augen mit himmelblauem Grunde, wie Lilien glänzte seine Haut, und seine Locken wie lichte Wölkchen, wenn der Abend kommt" [N I, 80]. ,[E]s war kaum da, so wollte er [der Lehrer Z. Y.] ihm den Unterricht übergeben.“ " $\mathrm{N}$ I, 80] „Es lächelte unendlich ernst, und uns ward seltsam wohl mit ihm zu Mute. Einst wird es wiederkommen, sagte der Lehrer, und unter uns wohnen, dann hören die Lehrstunden auf.“ [N I, 80f] Die Assoziation mit der Natur und die spezielle Bedeutung des Kindes für den SaisTempel weist darauf hin, dass das Kind - wie die Paralipomena verweisen - der Messias der Natur sein soll. Daher ist die Beschreibung seines Aussehens statt einer Individualisierung vielmehr eine Allegorie. Die sprechenden Namen der beiden „bildschönen“ Kinder Hyazinth ${ }^{192}$ und Rosenblüte haben eine ähnliche Funktion: Die beiden Märchenfiguren, die mit der Natur reden können, setzen sich aus Allegorie und Mythos zusammen und repräsentieren „auf der einen Seite ein abstrakt-göttliches Prinzip“"193 und sind andererseits eine metaphorische Ver-

\footnotetext{
192 Hyazinth ist die Bezeichnung für das Mineral Zirkon in den Farb-Varianten rot, was Novalis, der Bergwerkskunde studiert hatte, bewusst sein musste.

193 Diez 1986, S. 136.
} 
schmelzung von Mensch und Natur (Blume und Mineral). Die Entwicklung von Hyazinth versinnbildlicht die Progression der Menschenwelt und spiegelt die Verwandlung der Natur wider, weil die Natur sich während der Entwicklung Hyazinths als lebendige Partner, stumme Gegenstände und wiederum belebte Gehilfen und vermenschlichte Geliebte zeigt.

Die Gestalten in diesem Romanfragment sind nicht individuell, was eine absichtliche Komposition von Novalis sein muss. Novalis hatte die PhysiognomieLehre Johann Caspar Lavaters und die Oryktognosie-Lehre Abraham Gottlob Werners studiert und mit seinen eigenen Theorien verbunden. „Unser Ich ist Gattung und Einzelnes - allg[emein] und bes[sonders]“ [N II, 248], so Novalis. Um eine eigene Erklärung für den Begriff „Gattung“ abzugeben zog Novalis Werners Theorie zu Rate. Die Gattung ist bei Werner als ein Begriff dem einzelnen Mineral oder Fossil zugeordnet und umgreift alle Individuen, bei denen das gleiche Mischungsverhältnis vorliegt. „Novalis indessen versucht mit seinem Gattungsbegriff noch sehr viel mehr einzufangen. Für ihn ist in der Gattung nicht nur alles Gleichgemischte, sondern sind alle Mischungen überhaupt aufgehoben - allerdings der doppelten Bedeutung entsprechend, die Hegel später dem Wort geben wird. Es ist negiert und aufbewahrt", 194 so analysiert Diez mit Recht. In Heinrich von Ofterdingen wird von Gott als dem „allerpersönlichsten Wesen“ [N I, 333] gesprochen. Gott soll in dem Sinne von Novalis die alle Individuen umfassende Existenz innehaben, während sich die gewöhnlichen individuellen Gestalten in Gott auflösen, was zum Aufbau einer höheren Gestalt führen soll. In dieser höheren Gestalt - Gott - verschwindet alles, was historisch vergänglich ist. Da alle Menschen „Variationen Eines vollständigen Individuums“ [N II, 564] sind, ist die alles umfassende Gestalt ein Urbild, von dem man sich entfernt hat. Dieses Urbild aller körperlichen und geistigen Schönheit und Vollkommenheit bedeutet für Novalis das Tugendhafte. ${ }^{195} \mathrm{Zu}$ dem Programm der „Moralisierung der Natur“ schreibt Novalis in den Fragmenten und Studien der Jahre 1799-1800: „In der Tugend verschwindet die locale und temporelle Personalitaet. Der Tugendhafte ist als solcher kein historisches Individuum - Es ist Gott selbst.“ [N III, 670] Aus mehreren historischen Individuen setzen sich ein substantielles Individuum - ein „die Eigentümlichkeit mehrerer Individuen umfassendes Wesen“196 - zusammen, das Novalis auch „Genius“ [N III, 290] nannte.

In dem zukünftigen Goldenen Zeitalter, das im Märchen vorausgesagt wird, sollen alle Menschen ein solches substantielles Individuum sein. Die namenlosen Gestalten in Die Lehrlinge zu Sais haben noch etwas historisch Vergängliches in sich: „Der Lehrling hört mit Bangigkeit die sich kreuzenden Stimmen. Es scheint ihm jede Recht zu haben, und eine sonderbare Verwirrung bemächtigt sich seines Gemüts. Allmählich legt sich der innre Aufruhr, und über die dunkeln sich an

\footnotetext{
194 Stadler 1997, S. 94.

195 Stadler 1997, S. 92.

196 Stadler 1997, S. 92.
} 
einander brechenden Wogen scheint ein Geist des Friedens heraufzuschweben, dessen Ankunft sich durch neuen Mut und überschauende Heiterkeit in der Seele des Jünglings ankündigt“" [N I, 91]. Die Bangigkeit, die Verwirrung und die innere Unruhe lassen sich beseitigen, indem der Lehrling durch das Hören des Märchens die Schöpfungskraft der Liebe und die Verwandlung der Mensch-NaturVerhältnisse erfahren hat. Novalis könnte allerdings mit diesen Gestalten versucht haben, die Möglichkeit und Tendenz zum Goldenen Zeitalter darzustellen. Der Lehrling kann noch vervollkommnet werden, indem er mehrere Individualitäten in sich aufnimmt: „Um die Stimme zu bilden muß der Mensch mehrere Stimmen sich anbilden - dadurch wird sein Organ substantieller. So um seine Individualitaet auszubilden muß er immer mehrere Individualitaeten anzunehmen und sich zu assimiliren wissen - dadurch wird er z $[\mathrm{um}]$ substantiellen Individuum. Genius.“ [N III, 290]

Indem das Individuum zu einer Einheit in der Mannigfaltigkeit wird, nähert es sich dem ewigen Urbild an. In Die Lehrlinge zu Sais wird diese Verwandlung unter anderem durch das Zuhören während des Gesprächs und das Anhören der Monologe über die Natur vollzogen. Die theoretischen Ausführungen über die Natur verlaufen als Gespräch und multiperspektivisches Verfahren. Der Lehrling hört der „wechselseitige[n] Ergänzung und Relativierung“" ${ }^{197}$ zu. Die verschiedenen Standpunkte werden von ihm aufgenommen. Auf diese Weise wird er reif für eine Potenzierung. Dass der Titel dieses Werkes während der Abfassung im Jahr 1798 Der Lebrling zu Sais lautete und in dem späteren Brief Anfang des Jahres 1800 bereits in den pluralischen Die Lebrlinge verändert wurde, ist wahrscheinlich ein Indiz dafür, dass die Hauptfigur des Romans im früheren Vorhaben nur ein Individuum gewesen war, nämlich der Ich-Erzähler in dem ersten Teil, den alles zu sich selbst zurückführt, während Novalis durch sein intensives Studium der Naturwissenschaft und seine Überlegung über die Menschenbildungslehre 1798/99 immer bewusster und sicherer wurde, dass die Gestalten in seinem Naturroman individuelle Personen mit mannigfaltigen Bezügen sein müssen.

Die Höherbildung kommt in dem Romanfragment nicht vor, weil der Lehrling das Fremde sich noch nicht zu assimilieren weiß. Die Stimmen verschiedener Individuen beherrscht er bereits, doch er kann diese noch nicht auflösen und fühlt sich daher verwirrt und unruhig. Dazu muss er noch lieben lernen. Die Liebe ist nach Novalis die echte Erkenntniskraft, die geheimnisvolle Eins- und Ganzwerdung. Sie ist „der Endzweck der Weltgeschichte - das Unum des Universums“ [N III, 248], ist die „synthetische Kraft“ [N II 292]. Nur durch die Liebe werden die Menschen befähigt, das eigentliche Sein des Gegenübers zu berühren und zu begreifen. „Denn nur gegenüber dem Liebenden öffnet sich der Geliebte, und erst durch die Liebe entwickelt sich in dem Liebenden der Sinn für die Individualität des Geliebten: ,Liebe popularisirt die Personalitaet - Sie macht Individualitaeten

197 Pikulik 1992, S. 249. 
mittheilbar und verständlich. (Liebesverständniß) [N II, 541].““198 Indem er geliebt wird, erhebt sich der Mensch über sich selbst und löst sich aus seinen Grenzen. „Wenn der Mensch erst ein wahrhaft innerliches Du hat - so entsteht ein höchstgeistiger und sinnlicher Umgang und d[ie] heftigste Leidenschaft ist möglich Genie ist vielleicht nichts, als Resultat eines solchen innern Plurals“" [N III, 577]. In der Liebe lernt der Mensch die geheimnisvolle Kraft der Universalisierung, weshalb der Märchenerzähler dem Lehrling sagt: „,beim ersten Kuß wird eine neue Welt dir aufgetan, mit ihm fährt Leben in tausend Strahlen in dein entzücktes Herz" [N I, 91]. Der Liebende erkennt die Welt mit ihrer Vielfältigkeit als eine mannigfaltig ausgestaltete Einheit und begreift die Liebe als den Urgrund der Welt: „Was man liebt, findet man überall, und sieht überall Ähnlichkeiten. Je gröBer die Liebe, desto weiter und mannichfaltiger diese ähnliche Welt. Meine Geliebte ist die Abbreviatur des Universums, das Universum die Elongatur meiner Geliebten“ [N II, 485]. Da die Liebe der Urgrund ist und alle Menschen „Variationen eines vollständigen Individuums, d. h., einer Ehe“ [N II, 564] seien, werde der Mensch durch die Liebe vollständig. Die Geliebte sei daher für den Liebenden nicht nur die Mittlerin zu der Welt, sondern auch zu seinem eigenen wahren Wesen. „Selbstverwirklichung“"199 geschehe nur durch die Liebe. „Mit der Entwicklung seiner [des Menschen - Z. Y.] vollzieht sich also seine Höherentwicklung, die zugleich die Erkenntnis und damit Verwirklichung der Durchdringung und Identität mit den übrigen Wirklichkeitsbereichen bedeutet.“"200 Die Entwicklung der Liebesfähigkeit und zugleich die Über-Sich-Erhebung des Menschen beginnt mit der Erkenntnis, dass das eigene Wesen des Menschen in der Liebe bestehe. Diese Erkenntnis sowie die Ausstrahlung der Liebe in die Welt nennt Novalis Selbstliebe: „Das Leben oder das Wesen des Geistes besteht also in Zeugung Gebährung und Erziehung seines Gleichen ... Act der Selbstumarmung" [N II, 541]. Von dieser Selbstliebe ausgehend kann der Mensch seine Liebesfähigkeit durch den Kontakt mit der aus der Liebe entfalteten Welt immer weiter verbessern. Je feiner die Liebesfähigkeit ist, desto näher kommt der Mensch der Vollkommenheit.

In dem eingebetteten Hyazinth-Märchen zieht der Held aus, um in fremden Ländern zu der „Mutter der Dinge“ zu gehen. Auf der langen Suche wächst die süße Sehnsucht in ihm und seine Liebe wird immer heißer. Schließlich steht er vor der himmlischen Jungfrau, „da hob er den leichten, glänzenden Schleyer, und Rosenblüthchen sank in seine Arme“ " N I, 95]. ${ }^{201}$ Durch das Hören dieses allegorischen Märchens erkennt der Lehrling die „transzendentale Kraft“ der Liebe und dass sein eigenes Wesen aus der Liebe wächst und in der Liebe besteht. Das ist der

\footnotetext{
198 Müller 1984, S. 171 f.

199 Senckel 1983, S. 172.

200 Senckel 1983, S. 172.

${ }^{201}$ In einer anderen Fassung des Märchenendes in den Paralipomena findet der Suchende nicht seine Geliebte unter dem Schleier, sondern sich selbst [N I, 110], was eine sinnbildliche Darstellung der Selbstumarmung ist.
} 
erste Schritt auf seinem eigenen Weg zu der Mutter der Dinge. In dem Romanfragment verliebt er sich noch nicht. Doch erhält er durch das Zuhören eine Ahnung von der Liebe und eine Liebesfähigkeit, die für die spätere Entwicklung des Naturromans („Erscheinung der Isis“ in den Paralipomena [N I, 111]) eine Voraussetzung sind.

Da die Erkenntnis der Liebe und der Selbstliebe für die Ausbildung des Lehrlings notwendig ist, stellt sich die Frage, was für eine Ausbildung der Lehrling in Sais erhält. Eine eindeutige Antwort gibt es in dem Romanfragment nicht. Dass die Lehrlinge Kristalle oder Blumen suchen, dass der traurige Lehrling „ein unscheinbares Steinchen von seltsamer Gestalt" [N I, 81] bringt und der Lehrer dieses Steinchen ,, auf einen leeren Platz, der mitten unter andern Steinen lag, gerade wo wie Strahlen viele Reihen sich berührten" [N I, 81] legt, weist darauf hin, dass diese Steine die wunderbare Sammlung der Steine der Weisen sind. Die Lehrlinge werden also im Tempel zu Sais offenbar dazu ausgebildet, Magier zu werden. Magier ist ein im Märchen häufig vorkommender Beruf, der für Novalis eine besondere Rolle spielt und eine besondere Sichtweise statt tatsächlicher Zauberkräfte bedeutet:

Wir müssen Magier zu werden suchen, um recht moralisch seyn zu können. Je moralischer, desto harmonischer mit Gott - desto göttlicher - desto verbündeter mit Gott. Nur durch den Moralischen Sinn wird uns Gott vernehmlich - der moralische Sinn ist der Sinn für Daseyn, obne äußre Affection - der Sinn für Bund der Sinn für das Höchste - der Sinn für Harmonie - der Sinn für freygewähltes, und erfundenes und dennoch gemeinschaftliches Leben - und Seyn - der Sinn fürs Ding an sich - der ächte Divinationssinn./diviniren, etwas obne Veranlassung, Berübrung, vernehmen. [N III, 250]

Wie schon erläutert, bedeutet Moralisierung das Verschwinden des historisch Vergänglichen. Was übrigbleibt, ist sowohl Freigewähltes als auch Gemeinschaftliches, weil das Wesen des Moralischen der göttlichen harmonischen Ordnung völlig entspricht. Ein Magier kann seinen Willen unbehindert ausüben, weil er den ewigen Geist, dessen Produkt die Natur ist und der in der Natur anwesend ist, unmittelbar wahrnimmt. Er begreift das Ding in seinem wahren Wesen, also den gleichen Geist hinter dem Dinglichen trotz der äußeren Form. „Als ,Sinn für Bund“ vernimmt er einerseits die einheitsstiftende Macht des Geistes bzw. Gottes, die die Synthese, die Vereinigung zwischen Verschiedenem - z. B. zwischen der Materie und dem Geist, zwischen Notwendigkeit und Freiheit - bewirkt, sowie andererseits, als Resultat dieser Kraft, den Bund selbst, der sich als ,Harmonie“, d. h. als Einheit in der Mannigfaltigkeit, erweist. "202 Der Lehrer in dem Romanfragment ist ein Magier. Schon als Kind sucht er die Ordnung der Steine, Blumen und Käfer aller Art. Als Erwachsener findet er

202 Senckel 1983, S. 108. 
überall Bekannte wieder, nur wunderlich gemischt, gepaart, und also ordneten sich selbst in ibm oft seltsame Dinge. Er merkte bald auf die Verbindungen in allem, auf Begegnungen, Zusammentreffungen. Nun sab er bald nichts mehr allein. - In große bunte Bilder drängten sich die Wabrnehmungen seiner Sinne: er hörte, sah, tastete und dachte zugleich. Er freute sich, Fremdlinge zusammen zu bringen. Bald waren ihm die Sterne Menschen, bald die Menschen Sterne, die Steine Tiere, die Wolken Pflanzen, er spielte mit den Kräften und Erscheinungen, er wußte wo und wie er dies und jenes finden, und erscheinen lassen konnte, und griff so selbst in den Saiten nach Tönen und Gängen umber. [N I, 80]

Ein Magier wie der Lehrer, dem die Geheimnisse der Natur teilhaftig sind, besitzt ein poetisches Gemüt. Die „Zufälligkeit der Natur“ scheint ihm „sich wie von selbst an die Idee menschlicher Persönlichkeit anzuschließen, und letztere am willigsten, als menschliches Wesen verständlich zu werden“ [N I, 84]. Die Naturordnung und das menschliche/eigene Wesen stimmen harmonisch überein, was dem Gefühl beim Hören eines echten Gedichts entspricht: „Wenn man ächte Gedichte liest und hört, so fühlt man einen innern Verstand der Natur sich bewegen, und schwebt, wie der himmlische Leib derselben, in ihr und über ihr zugleich“ [N I, 84]. Wie der Dichter Novalis seine Schriftstellerei „ein Bildungsmittel" [N IV , 266] nannte, werden die "Zauberlehrlinge“" in seinem ersten Romanfragment durch das Dichten ausgebildet. Nur schreiben die Lehrlinge kein Gedicht. Stattdessen verwandeln sie ihr Leben zum Roman. Der Roman ist nach Novalis die Kunst, das gewöhnliche Leben zu poetisieren [N II, 568]. Für ihn ist die Poesie „die Vereinigung des theoretischen Erkennens mit dem praktischen Handeln“203, die ,innigste Gemeinschaft des Endlichen und Unendlichen“" [N II, 533]. Man muss daher nicht unbedingt schreiben, um Poet zu sein. Die poetische Weltform sei eine „symbolische Construction der transcendentalen Welt" ${ }^{\text {“ }}$ [N II, 533]. Novalis behauptete: „[e]hemals war alles Geistererscheinung. Jezt sehn wir nichts, als todte Wiederholung, die wir nicht verstehn. Die Bedeutung der Hieroglyfe fehlt“ [N II, 545] Die von Menschen erfahrene Welt sei daher eine „Mitteilung“ ohne „Offenbarung des Geistes“ [N II, 545]. Unter dem Bekannten und Gewöhnlichen dieser Dingwelt verberge sich der unbekannte Sinn und das tiefere Geheimnis des Geistes. Um den verlorengegangen und höheren Sinn der Welt wieder begreiflich zu machen, sei eine verfremdende Poesie nötig: „weil sie die bekannte, im voraus verständliche und vordergründige Welt in die Ferne rückt

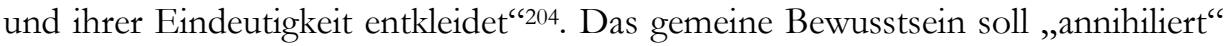
werden. Aus der Ferne betrachtet sei alles poetisch. Der romantische Dichter soll die Dingwelt nicht mimetisch abbilden, sondern den Sinn dieser Welt - den Geist - zur Sprache bringen. Eine solche Darstellung ist zugleich „befremdend“ und vertraut: „befremdend“, weil der wunderbare Sinn der prosaischen Alltagswelt 
freigelegt wird; vertraut, weil dieser Sinn schon immer in dem Dinglichen verborgen war und die Erscheinungswelt nur dessen Verkörperung ist. „Die Kunst, auf eine angenehme Art zu befremden, einen Gegenstand fremd zu machen und doch bekannt und anziehend, das ist die romantische Poetik" [N III, 685].

Die Außenwelt wird durchsichtig, und die Innenwelt mannigfaltig und bedeutungs-
voll, und so befindet sich der Mensch in einem innig lebendigen Zustande zwischen
zwei Welten in der vollkommensten Freiheit und dem freudigsten Machtgefübl. Es
ist natürlich, daß der Mensch diesen Zustand ₹u verewigen und ibn über die ganæe
Summe seiner Eindrücke ₹u verbreiten sucht; daß er nicht müde wird, diese Asso-
ziationen beider Welten zu verfolgen, und ibren Gesetzen und ibren Sympathien
und Antipatbien nachzuspüren. [N I, 97]

Der Lehrling, der die „Ursprache“ der Natur sucht und eine Assoziation der äußeren und inneren Welt verfolgt, ist ein frühromantischer Dichter. Über sich selbst äußert er: „Mich führt alles in mich selbst zurück. [...] Mich freuen die wunderlichen Haufen und Figuren in den Sälen, allein mir ist, als wären sie nur Bilder, Hüllen, Zierden, versammelt um ein göttlich Wunderbild, und dieses liegt mir immer in Gedanken. Sie such' ich nicht, in ihnen such' ich oft. Es ist, als sollten sie den Weg mir zeigen, wo in tiefem Schlaf die Jungfrau steht, nach der mein Geist sich sehnt“ [N I, 81]. Er erahnt die natürlichen Erscheinungen als „Bilder, Hüllen, Zierden“ und den wesentlichen Geist (das göttliche Wunderbild) in diesen. Die geheimnisvollen Verhältnisse zwischen seinem Wesen und dem Naturgeist (,die Mutter der Dinge“ oder die "Jungfrau“) nimmt er als „Sehnsucht" wahr. Nur findet er die Methode, zu dem ewigen Geist in jedem Ding zu gelangen, noch nicht. Dazu bedarf er des Märchens, das ihm die Liebesfähigkeit vermittelt. Doch das Märchen selbst ist auch ein poetisches Produkt, und zwar die Potenzierung und Verfremdung des Lebenswegs, den der Lehrling begleitet: In dem Märchen, das „Begebenheiten einer Maskerade - eine masquirte Begebenheit unter masquirten Personen“ " N II, 570] zeigt, finden der Zuhörer (der Lehrling) und die Leser des Romanfragments das vertraute Leben des Lehrlings wieder. Hyazinth ist der Lehrling in fremder Gestalt. Der Tempel zu Sais, in dem Hyazinth am Märchenende ankommt, ist der Ort, an dem das Märchen erzählt wird. Der Erzähler des Märchens ist ein munterer Gespiele, „dem Rosen und Winden die Schläfe zierten“ [N I, 91] und der „herbeispringt". Dadurch gilt er als ein Gegenbild zu dem Grübler. Er betrachtet das Leben des Lehrlings aus der Ferne, in dem er Bekanntes finden muss, weil das poetische Werk eine innerliche Beziehung zu dem Dichter hat. Das Märchen lässt sich daher sowohl als Erkenntnis des Erzählers als auch des Zuhörers begreifen und verbindet die beiden Figuren. Nach dem Erzählen umarmen sich die Lehrlinge, was als Andeutung einer allegorischen Selbstumarmung gelesen werden kann. 


\subsection{Die Romanwelt und die Welt als Roman}

Jedes Individuum ist eine Verbindung der Gattung und des Einzelnen, weshalb sich die Entwicklung der ganzen menschlichen Geschichte in jedem Individuum verbirgt. Die Geschichte ist für Novalis eine systematisierende, sinnstiftende Verarbeitung naturgegebener und unverbundener Materialien zu einem Kunstprodukt. Dieser Prozess bedarf geistiger Verarbeitung. „Indem der Mensch [...] in schöpferisch-geistiger Tätigkeit die vorgefundenen Daten sinnstiftend untereinander verbindet, entsteht das Kunstprodukt der Geschichte. “205 Jeder Mensch besitzt also nach Novalis schon die Voraussetzung, sich selbst zu einem Roman der menschlichen Geschichte zu potenzieren. Wenn der Mensch in der Lage ist, einen Sachverhalt auf verschiedene Weise zu deuten, und wenn der Verstand sich somit durch die Interpretationsfreiheit dem unerreichbar Absoluten nähert, „,begreift er sich in seiner schöpferischen Interpretation wesentlich als Organ eines übergeordneten Geschichtsgesetzes, dessen Erkenntnis ihn zur Projektion in die Zukunft berechtigt und befähigt und ihm somit Aussagen über den zukünftigen Entwicklungsgang ermöglicht“206. Die Bildung und die Erlösung der Geschichte zu dem „vernünftigen Chaos“ erfolgen durch den Menschen. In dem Augenblick der schöpferischen Freiheit, der Harmonie des menschlichen Gemüts mit der höheren Mitteilung, die durch den Menschen in seiner Kunst geäußert wird, wirkt das Goldene Zeitalter. Der Mensch kann und soll ein Roman - „die freye Gescbicbte“" [N III, 668] - sein. ,Jedes Leben hat ein Motto - einen Titel - einen Verleger - eine Vorrede - Einleitung - Text - Noten - etc. oder kann es haben“ [N II, 599].

In Die Lebrlinge zu Sais hört der Leser die Stimmen verschiedener Individuen, die die Natur aus verschiedenen Perspektiven betrachten. Diese Stimmen werden von den Sprechern gegenseitig wie in einem „Schallraum“ 207 vernommen. Jedes Individuum nähert sich mithilfe der Interpretationsfreiheit dem Absoluten an. Jede Figur lässt sich auf diese Weise als ein Roman - auch eine Verbindung der Gattung und des Einzelnen - ansehen. Zusammen bilden sie wiederum einen Roman und jedes Leben ist eine erneuerte Komposition des Naturthemas und eine Veranschaulichung derselben Idee. Es ist kein Zufall, dass jeder Monolog einer Figur immer einen Abschnitt bildet. In jeder neuen Variation, jeder neuen Figur schwingt das Vorhergehende mit und es ist als Entgegensetzung, Ergänzung oder Entsprechung immer mit gegenwärtig. ${ }^{208}$,Je mehr ausgesagt wurde, je weiter sich das Kunstwerk entfaltete, desto konkreter wurde das Aussagende, die Gestalt des Sprechenden [...].“' ${ }^{209}$ Der Roman ist ein Beispiel für die Verarbeitung einer Idee in einer unendlichen Reihe von Sätzen - „eine irrationale Größe - unsetzbar (musik[alisch]) - incommensurabel“ [N II, 570]. Der „Naturroman“ schildert die

\footnotetext{
205 Senckel 1983, S. 134.

206 Senckel 1983, S. 134.

207 Kreuzer 1979, S. 288.

208 Striedter 1985, S. 171.

209 Striedter 1985, S. 172.
} 
zur Sprache gebrachte schöpferische Freiheit der Natur, also mit der Natur als seinem Helden, der in verschiedenen Figuren symbolisiert wird und direkt wirkt.

\subsection{Potenzierung und Logarythmisierung in dem Romanfragment}

In seinem Beitrag aus dem Jahr 1955 untersucht Striedter die Form der Die Lehrlinge zu Sais und versucht, das Weltbild von Novalis dadurch zu beschreiben. Diese Form sei nach Striedter die „Kompositionsfigur der gegeneinanderlaufenden Tendenzen“210. In den ersten drei Abschnitten des ersten Teiles wirke der Sprecher von Abschnitt zu Abschnitt konkreter, fassbarer: Während der Sprecher in dem ersten Abschnitt nur indirekt in Erscheinung trete, gebe es im zweiten Abschnitt schon ein hörendes Ich, und zwar nur „,von weiterem“ [N I, 79]. „Erst im dritten Abschnitt wird aus dem Hören ein aktives Sprechen." 211 Eine thematische Stufenfolge zeige sich ebenfalls in diesen drei Abschnitten. „Wird im ersten Abschnitt noch von der, großen Chiffernschrift' gesprochen, so heißt sie im zweiten bereits die ,echte Sanskrit' und im dritten sogar die ,heilige Schrift'."212 Die Sprache verändere sich vom Begrenzten und Konkreten zum Unbegrenzten und Allgemeinen und löse sich von konkreten Gegenständen. Immer mehr beziehe sie sich auf ihre Gesamtheit und werde schließlich zum Abbild des bezeichneten Universums: ein „Akkord aus des Weltalls Symphonie“" [N I, 79].

Mit Novalis' eigener Terminologie könnte man im Hinblick auf das Thema von einer ,Potenzierung', im Hinblick auf die Form der Aussage von einer ,Logarythmisierung' sprechen - zwei Ausdrücke, mit denen er das Verallgemeinern und $V$ ergeistigen des Konkreten einerseits, das Vergegenständlichen des Geistigen und Abstrakten andererseits kennzeichnet [II, 335]. ${ }^{213}$

Die Logarythmisierung einerseits und die Potenzierung andererseits sind eine kompositorische Entsprechung des Begriffs ,Romantisieren' bei Novalis, die den zwei Schritten des Dichters (Verinnerlichung und dann Veräußerlichung) entspricht.

In dem zweiten Teil Die Natur findet sich eine ähnliche „Hin-und-HerDirektion“ (Striedter) zwischen der Form der Aussage und dem Thema. In der philosophischen Abhandlung der ersten Abschnitte spricht kein konkreter Sprecher. Erst nach drei Abschnitten ,dünkt es Einigen, es sei der Mühe gar nicht wert, den endlosen Zerspaltungen der Natur nachzugehn, und überdem ein gefährliches Unternehmen, ohne Frucht und Ausgang““ $[\mathrm{N} \mathrm{I}, 87]$. In dem nächsten

\footnotetext{
210 Striedter 1955, S. 9.

211 Striedter 1955, S. 8.

212 Striedter 1955, S. 8.

213 Striedter 1955, S. 9.
} 
Abschnitt „sagen Mutigere, laßt unser Geschlecht einen langsamen, wohldurchdachten Zerstörungskrieg mit dieser Natur führen“ [N I, 89]. Als nächstes äußern „Mehrere“ [N I, 89], dass eine Erkenntnis des wahren Sinns der Schlüssel zu der trüben Welt sei. Schließlich „sagt ein ernster Mann zu diesen“, dass „,ihre Natur ein Gedankenspiel, eine wüste Fantasie ihres Traumes ist“" [N I, 90]. In diesen Abschnitten vor der Märchenerzählung werden die Sprecher - parallel zu denen der ersten drei Abschnitte in Der Lehrling - konkreter. Das Wesen der Natur, das das Thema dieser Monologe ist, gilt für die Menschen am Anfang als gefährlich, dann als etwas, das es zu überwinden gilt, dann als ein Objekt des Erkennens und schließlich als ein Gedankenspiel des Menschen. Die menschlichen Verhältnisse zur Natur werden immer harmonischer, wobei die Natur immer mehr von dem Menschen verinnerlicht wird, wie es in dem 16. Fragment Blumenstaub erläutert wird: „Nach Innen geht der geheimnißvolle Weg. In uns, oder nirgends ist die Ewigkeit mit ihren Welten, die Vergangenheit und Zukunft" [N II, 418].

„Der Lehrling hört mit Bangigkeit die sich kreuzenden Stimmen“ [N I, 91]. Wegen seiner Verwirrung erzählt ihm sein „Gespiele“ das Hyazinth-Märchen. Das Märchen ist eine allegorische Verbildlichung der Triadik von „Harmonie - Störung - Harmonie“. Es ist eine prophetische Darstellung der menschlichen Verwandlung sowie des Zieles, zu dem der Lehrling gelangen soll. Doch der geheimnisvolle Weg nach Innen, wie er in den Abschnitten vor dem Märchen geschildert wird, reicht noch nicht. „Wer hier stehn bleibt, geräth nur halb. Der zweyte Schritt muß wircksamer Blick nach Außen, selbstthätige, gehaltne Beobachtung der AuBenwelt seyn" [N II, 423]. Der zweite Schritt erfolgt in der Diskussion nach dem Märchen. Die idealistische Lehre Fichtes, die die Natur als Abbild des menschlichen Geistes ansieht, genügt nicht. Fichte, der „sich selbst durchdrang, fand hier den typischen Keim einer unermeßlichen Welt" [N II, 455]. Nicht zufällig hören die „sich kreuzenden Stimmen“ vor der Märchenerzählung mit einem „ernsten Mann“ auf, der vermutlich repräsentativ für Fichtes Sichtweise steht. Die Natur soll eine selbständige Rolle in ihrem Verhältnis zum Menschen spielen. Darauf weist das Sprechen der Naturobjekte direkt nach der Erzählung des Märchens hin.

Das vielstimmige Gespräch der Reisenden, in dem die Gesprächspartner sich gegenseitig zuhören und ergänzen, kennzeichnet eine noch konkretere und sich entfaltende Form der Aussage, als „die sich kreuzenden Stimmen“ vor dem Märchen. In diesem Gespräch ist die Natur weder Objekt der menschlichen Tätigkeit noch Spiegelbild des menschlichen Geistes, sondern helfender Partner und Geliebte. Der Mensch vereinigt sich mit der Natur: „Er fühlt sich in ihr, wie am Busen seiner züchtigen Braut und vertraut auch nur dieser seine erlangten Einsichten in süßen vertraulichen Stunden" [N I, 106]. In dieser absoluten Vereinigung erfolgt nicht nur die Naturerkenntnis, sondern auch die Selbsterkenntnis. Die „Hinund-Her-Direktion“ des Themas der Aussage in Die Natur verläuft nicht wie in Der Lehrling nur in eine Richtung, sondern zuerst nach innen und dann nach auBen. Dieses Schweben entspricht den zwei Schritten des magischen Idealismus 
von Novalis: Der Mensch soll „das reale, widerständige Sein in das bewegliche Material des schöpferischen Bewußtseins“ verwandeln und sich „zum freien Herrn seiner Geschichte" erheben. ${ }^{214}$ Dann soll der Mensch den Blick nach außen wenden. „Dort stellen sich die Dinge nicht mehr als Teile des gewohnten Naturzusammenhangs oder eines philosophischen oder wissenschaftlichen Systems dar, sondern als Momente in dem universalen Prozeß der Selbstdurchdringung des Geistes, an dem der Mensch selbst Teil hat." ${ }^{215}$ So verwandelt der Mensch die Dinge zu Hieroglyphen, die auf den höheren zugrundeliegenden Geist verweisen. Die Natur wird dadurch aus dem verzauberten Zustand erlöst. Die heilige Schrift, die „ein Accord aus der Weltalls Symphonie“ [N I, 79] ist, zu finden und sich mit der Natur zu einem höheren Ich zu vereinigen, ist das Ziel der Lehrlinge und der Romanhandlung. Der Weg zu dieser Harmonie wird prophetisch in der Struktur des Textes umgesetzt. 


\section{Chamisso: Peter Schlemihls wundersame Geschichte}

Peter Schlemibls wundersame Geschichte ist das Werk, das seinem Autor Adelbert von Chamisso (1781-1838) zu Weltruhm als Dichter verholfen hat. Geschrieben im Jahr 1813, hat die Geschichte seit ihrer Veröffentlichung im Jahr 1814 viele Diskussionen angeregt. Die Kernfrage gilt der Bedeutung des Schattens beziehungsweise des Schattenverlustes. Da der Autor schon zeit seines Lebens mit der Frage „was ist denn der Schatten“ [SW I, 13] bestürmt wurde, machte sich Chamisso in der Vorrede zu der im Jahr 1838 erschienenen neuen französischen Übersetzung über die Frage lustig, indem er zwei Abschnitte aus René Just Haüys Lexikon Traités élémentaire de physique zitierte und dem Schatten eine naturwissenschaftliche Definition gab. ${ }^{216}$ Auch in seiner poetischen Widmung An meinen alten Freund Peter Schlemibl im Jahr 1834 warnte Chamisso vor dem vergeblichen Klügeln über das Wesen des Schattens: „Die wir dem Schatten Wesen sonst verliehen, Sehn Wesen jetzt als Schatten sich verziehen“ [ebd.]. Trotzdem wurde eine Deutung des „Schattenwesens" zwei Jahrhunderte lang immer wieder versucht. Wolfgang Neubauer

\footnotetext{
216 „Ein nicht leuchtender Körper kann nur teilweise von einem leuchtenden Körper erhellt werden. Der lichtlose Raum, welcher auf der Seite des nicht beleuchteten Teiles liegt, ist das was man Schatten nennt. Schatten bezeichnet also im eigentlichen Sinne einen körperlichen Raum, dessen Gestalt zugleich von der Gestalt des leuchtenden Körpers, von der des beleuchteten und von ihrer gegenseitigen Stellung gegen einander abhängt.“ [SW I, 777 f.].
} 
hat in seinem Beitrag aus dem Jahr 1986 die bedeutendsten Interpretationen je nach Klasse zusammengefasst. ${ }^{217}$ Doch kommt er zu dem Ergebnis, dass jede „inhaltliche Charakterisierung oder allegorisch-symbolische Auslegung [...] zu Widersprüchen" führe und scheitere. ${ }^{218}$

Die Frage nach dem Wesen des Schattens bleibt bis heute offen. Es liegt nahe, dass Peter Schlemibls wundersame Geschichte gerade wegen ihrer Vieldeutigkeit bis heute immer noch weltberühmt ist. Die fehlende Interpretation des Schattens steht dem Wesen von Schlemihls ,Manuskript ${ }^{`}$ als einer ,Interpretation' des eigenen Lebenssinns gegenüber. Nicht nur der ,Autor` des Textes, der Ich-Erzähler Peter Schlemihl, sondern auch der Text selbst sucht nach dem nicht vorhandenen Wesen. Dieses romantische Spiel der Selbstreflexion schließt die Leser in die unendliche und erfolglose Suche nach dem Schatten ein.

Nicht nur die Interpretation des Schattens, sondern auch die Gattungszugehörigkeit des Textes steht im Zentrum der Diskussion. Chamisso selbst bezeichnete sein Buch als „ein ganz fabelhaftes, nämlich eine Fabel“"219. Sein Freund Julius Eduard Hitzig, dessen Frau und Kindern er dieses Buch widmete, nannte es ein „Märchen“ [SW I, 777]. Thomas Mann dagegen bestimmte den Text als eine ,phantastische Novelle', weil der Text „zu ernst, zu modern-leidenschaftlich“ sei und der Verfasser „die realistisch-bürgerliche Allüre [...] mit aller Genauigkeit festzuhalten weii““. ${ }^{220}$ Ernst Loeb sieht in dem Text eine Erzählung, in der die Wirklichkeit gegenüber „den herkömmlichen Märchenrequisiten“ das Übergewicht hat. ${ }^{221}$ Andere Forscher wie Paul-Wolfgang Wührl und Detlef Kremer halten den Text für ein „Wirklichkeitsmärchen“222 oder ein romantisches Kunstmärchen. ${ }^{223}$

In dem vorliegenden Kapitel, dessen Schwerpunkt dem ,Märchenhaften“ im Text statt einer Sinndeutung des Schattens gilt, wird Peter Schlemibls wundersame Geschichte als eine Novelle mit Märchenbezügen hinsichtlich der Requisiten und der Struktur des Textes angesehen, weil dieser mit seiner „sich ereigneten unerhörten Begebenheit" Goethes Definition von der Novelle entspricht. ${ }^{224}$ Wegen der absichtlichen Orientierung an Märchen und der gleichzeitigen Abweichung von diesem durch die novellistische Erzählweise im Sonderfall der Ich-Erzählung ist es sinnvoll, einer speziellen Betrachtung des Vorhandenseins des Märchen-

\footnotetext{
${ }^{217}$ In dem ersten Teil dieses Beitrags meint Neubauer, dass der Schatten in dieser Novelle die unterschiedlichsten Interpretationen erfahren. Er sortiert diese Interpretationen je nach den folgenden Klassen: Biografische Interpretationen, Psychologische Interpretationen, Existentiale Interpretationen, Ökonomische Interpretationen, Funktionale Interpretationen. Vgl. Neubauer 1986, S. 24 - 31.

218 Neubauer 1986, S. 31.

${ }^{219}$ Chamissos Brief an Louis de la Foye aus dem Jahr 1814. Zit. nach Walach 1982, S. 46.

220 GW IX, 48.

${ }^{221}$ Loeb 1965, S. 401.

222 Wührl 2012, S. 154.

223 Kremer 2007, S. 195 f.

224 Aus dem Gespräch vom 29. 01. 1827. HA VI, 726.
} 
haften in Peter Schlemibls wundersame Geschichte zu unterziehen. Ich versuche in diesem Kapitel, die folgende These zu erläutern:

In Peter Schlemibls wundersame Geschichte findet sich eine Auseinandersetzung zwischen dem Realistischen und dem Märchenhaften. Die Titelfigur ist ein Märchenheld mit realistischer Selbstbesinnung, der in eine moderne Welt mit einem märchenhaften Schein geraten ist und in dieser Welt verweilt. Die Novelle erzählt von der Selbstgründung des Helden, die aus einer märchenhaften Willenlosigkeit durch Selbstbesinnung hervorgeht.

Dieses Kapitel versucht, der berühmten Novelle von Chamisso eine neue Deutungsmöglichkeit zu bieten. Wenn man die Novelle als ein Werk mit Märchenbezügen liest, findet man viele Motive und Stoffe aus Volksmärchen sowie aus den romantischen Kunstmärchen (etwa der Teufelspakt, die Siebenmeilenstiefel und viele andere) und einige strukturelle Aspekte, die typisch für die deutsche romantische Literatur sind (beispielsweise die Rahmenerzählung und die Auflösung der Grenze zwischen Fiktion und Realität). Andererseits weicht die Novelle absichtlich und sogar ironisch von diesen märchenhaften und romantischen Elementen ab. Beispielsweise ziehen der Titelheld ein Paar bürgerliche Pantoffeln über seine Siebenmeilenstiefel, um sie auf normales Schritttempo abzubremsen. Durch die Adaption und Parodie der romantischen Märchenaspekte sollen der Anschluss an die deutsche Romantik und die Abweichung von dieser durch den spät- bis postromantischen Autor signalisiert werden.

\subsection{Struktur der Erzählung - Märchenadaption und Abweichung von der Romantik}

Der ursprüngliche Zweck dafür, eine Erzählung über den erfundenen Kameraden Peter Schlemihl zu schreiben, war es, die Frau und die Kinder des Freundes Hitzig, die sich Chamisso als sein Publikum vorgestellt hatte, zu amüsieren. ${ }^{225} \mathrm{Ob}$ wohl der Autor während des Dichtens schon fürchtete, dass das Komische erlösche und das Larmoyante zu sehr überwiege, ist die Erzählung nicht nur als reine Kinderliteratur intendiert, denn sie ,besteht doch und soll bestehen aus a + b, Ideal und Karikatur, das tragische und komische Element. "226 Aus dem ursprünglich erdachten Unterhaltungsstück ist also allmählich eine „,aus der Seele geschnittene“ 227 Offenbarung sowie ein kompliziertes Kunstwerk geworden, das viele gemeinsame strukturelle Merkmale mit dem romantischen Kunstmärchen besitzt. Chamisso kannte die deutsch romantischen Theorien gut. Er kam nicht nur schon Anfang des 19. Jahrhundert häufig als Gast in die Berliner Salons, sondern be-

\footnotetext{
225 Brief an Karl Berhard von Trinius am 11.04.1829. Zit. nach Walach 1982, S. 54.

226 Brief an Julius Eduard Hitzig im September 1813. Zit. nach Walach 1982, S. 49.

227 Brief an Julius Eduard Hitzig im September 1813. Zit. nach Walach, 1982 S. 49.
} 
suchte im Winter 1803/04 auch den dritten Teil von August Wilhelm Schlegels Vorlesungen über schöne Literatur und Kunst zum Thema Gescbichte der romantischen Literatur. Im Jahr 1810 machte er Bekanntschaft mit A. W. Schlegel, Alexander von Humboldt sowie Ludwig Uhland und übersetzte A. W. Schlegels Wiener Vorlesungen über dramatische Kunst und Literatur ins Französische. Während dieser Jahre der politischen Wirren und seines Pendelns zwischen Frankreich und Deutschland in dem Zeitraum 1803-1812228 vertiefte sich Chamisso in den romantisch literarischen Kanon. In diesen Jahren befasste er sich mit Wackenroder, Tieck, Jacob Böhme, Des Knabens Wunderhorn, Jean Paul, Brentanos Godwi und vor allem mit Novalis, „dessen Märchen Klingsohr aus Heinrich von Ofterdingen dann sein allegorisches Märchen Adelberts Fabel beeinflusste“229.

Doch ist die ideologische Grundlage für Chamisso immer noch die französische Aufklärung. Durch die Lektüre von Jean-Jacques Rousseau erlernte er „die Ungleichheit und Unfreiheit der Menschen in der Ständeordnung “230. Im Volk sah er eine verdorbene Masse, was im Gegensatz zur romantischen Huldigung des Volks als vitaler Ressource eines sich organisch erneuernden Nationalgeists stand. Auf dieses Problem wird in seinem Peter Schlemibl durch das "philisterhafte“ Volk angespielt. Auch sein Interesse an Fortschritt, den Fakten der Geschichte und der sozialen Problematik teilte Chamisso nicht mit den Romantikern. Während die Leser in Chamissos im Jahr 1807 veröffentlichter Adelberts Fabel noch viele Einflüsse der Auffassung Novalis' von der weltverwandelnden Macht der Poesie und einer Verbindung zwischen den Tiefen des Geistes und dem Universum finden können, ist in Peter Schlemibl nur noch eine resignative Flucht in die Innenwelt erkennbar, die sich deutlich von dem ,geheimnisvolle[n] Weg nach innen“231 unterscheidet und eher eine Parodie der triadischen Fassung der Weltgeschichte nach

\footnotetext{
228 Viele Jahre lang fühlte sich Chamisso nirgendwohin hingehörig, „ob in Frankreich, ob in Deutschland oder am Genfersee“ (Lahnstein 1987, S. 62). Die völlige Vernichtung des preußischen Heeres bei Jena und Auerstädt (1806) ermöglichte dem preußischen Leutnant Chamisso, französischen Boden wieder zu betreten. Noch am 23. Dezember dieses Jahres schrieb er aus Paris an Karl August von Varnhagen: „Frankreich ist mir verhasst; und Deutschland ist nicht mehr und noch nicht wieder." (Zit. nach Lahnstein 1987, S. 62) Schon im nächsten Herbst war er wieder in Deutschland. Zwei Jahre (1807 - 1809) lang lebte er in dem vom französischen Militär besetzten Berlin. Dies war eine sehr schmerzhafte Zeit in seinem Leben, denn er musste einen starken Hass auf Frankreich durch die Berliner als geborener Franzose ertragen. Im Oktober 1808 schrieb er an Fouqué: „Übrigens ist die Welt überall mit Brettern zugenagelt, und ich weiß nicht wo aus noch ein.“ (Zit. nach Lahnstein 1987, S. 65) Ende 1809 erhielt Chamisso eine Nachricht, dass ihm eine Professur am Lycée zu Napoleonville angeboten sei und er reiste nach Paris zurück. Obwohl sich seine Hoffnung auf die Professur später zuschlug, blieb Chamisso bis 1811 in Frankreich. Während dieser Jahre erweiterte sich sein Freundeskreis um Madame de Staël und Ludwig Uhland. 1811 reiste er nach Coppet zu seiner Wirtin Madame de Staël. In der Schweiz beschäftigte er sich mit seinem Englisch- und Spanisch-Studium und fing an, Botanik zu studieren. Im September 1812 war Chamisso wieder in Berlin.

${ }^{229}$ Kroner 1971, S. 440. Vgl. Schlitt 2008, S. 99.

230 Kroner 1971, S. 439.

${ }^{231}$ N II, 418.
} 
Novalis darstellt. Der Grund für diese geistige Veränderung liegt in dem „,enttäuschten Glauben an die weltverwandelnde Kraft des Geistes und der Einsicht in die Ohnmacht des einzelnen gegenüber dem undurchschaubaren und unkontrollierbaren Ablauf der Ereignisse“ “232. In einem Brief schildert er diesen körperlichen und geistigen Schwebezustand:

je suis français en Allemagne et allemand en France, catholique chez les protestants, protestant chez les catholiques, philosophe chez les gens religieux et cagot chez les gens sans préjugés; homme du monde chez les savants, et pédant dans le monde, jacobin chez les aristocrates, et chez les démocrates un noble, un homme de l'Ancien Régime, etc. Je ne suis nulle part de mise, je suis partout étranger - je voudrais trop étreindre, tout m'échappe. Je suis malheureux...233

Trotz der ideologischen Unterschiede teilt Chamisso mit den Romantikern die Begeisterung für die Volksdichtung inklusive des Märchens. „Das Mährchen ist gleichsam der Canon der Poesie - alles poetische muss mährchenhaft seyn. Der Dichter betet den Zufall an“",234 so Novalis. Die strukturellen Merkmale der Märchenform sind in die romantische Dichtung adaptiert. ${ }^{235}$ Die alltägliche Notwendigkeit in der erzählten Welt soll aufgehoben werden, sodass der ,Zufall' sowie der Glaube an die ursprüngliche Natürlichkeit an die Stelle der rationalen Logik treten können. „Das als Maßstab zugrundegelegte Märchenschema [ist] die aktive Wiederherstellung einer zeitweilig gestörten Ordnung, geleitet von einer naiven Ästhetik“"236, die von einer „naiven Moral“ ${ }^{\text {“ } 37}$ nicht zu trennen ist. Das nicht fragwürdige „Miteinander von Wirklichkeit und Nichtwirklichkeit“"238 ist aber in den romantischen Kunstmärchen häufig zu dem Unheimlichen, Bedrohlichen und Grotesken transformiert.

Chamissos berühmteste Novelle hieß zuerst Peter Schlemibls Abentheuer, und der Titel erschien erst im Druck als Peter Schlemibls wundersame Geschichte, ${ }^{239}$ wobei das Adjektiv „,wundersam“ im endgültigen Titel der Novelle zum Modewort Anfang des 19. Jahrhunderts wurde und „im Sinne von selten, unbegreiflich, überraschend, bemerkenswert“ zu verstehen ist. ${ }^{240}$ Schon der Titel weist auf eine Annäherung an das Märchen hin. Eine Reihe von Requisiten aus der Volkspoesie (Teufelspakt, der Drache Faffner bei seinem Hort, Tarnkappe usw.) und der zeitgenös-

\footnotetext{
232 Schlitt 2008, S. 145.

233 Brief an Louis de La Foye am 06.02.1811.

234 N II, 691.

235 „Grundlegend ist hier eine Aufhebung der alltäglichen, rationalen Logik, die zu Metamorphosen, Mensch-Tier-Kreuzungen, belebter Dingwelt, Sprachfähigkeit der nichtmenschlichen Natur etc. führt." Kremer 2007, S. 189.

236 Mayer/Tismar 2003, S. 3.

237 Mayer/Tismar 2003, ebd.

238 Lüthi 1996, S. 3.

239 Baumgartner 1944, S. 37.

240 Lommel 2007, S. 34.
} 
sischen Literatur (Fouqués Zauberring, das unsichtbare Vogelnest aus Grimmelhausens Das wunderbarliche Vogelnest, die Siebenmeilenstiefel aus Tiecks Leben und Thaten des kleinen Thomas, genannt Däumchen. Ein Märchen in drei Akten und Uhlands Romanze vom kleinen Däumling sowie Perraults Contes de ma mère l'oye usw.) trägt dazu bei, dieser Novelle etwas Märchenhaftes und Phantastisches zu verleihen. In der Binnenerzählung bietet der Graue, der sich später als Teufel zu erkennen gibt, dem Titelhelden zusammen mit Fortunati Glücksäckel noch eine ganze Kollektion magischer Dinge an. Die echte Springwurzel, Alraunwurzel, Wechselpfennige, Raubtaler, das Tellertuch von Rolands Knappen, Galgenmännlein und Fortunati Hütlein ${ }^{241}$ erscheinen in der Erzählung als Waren eines Kaufmannes. Das höchste Prinzip dieser wunderbaren Welt ist also kein Märchenprinzip, sondern das prosaische Prinzip des Geldes. Die Grundlage des romantischen Märchens, die alltägliche Logik durch eine Märchenordnung zu ersetzen, wird dadurch außer Kraft gesetzt. Chamissos Novelle wendet sich ganz absichtlich vom romantischen Märchen ab und erzählt mithilfe von Märchenrequisiten eine realistische und märchen-parodierende Geschichte.

Die Struktur der Novelle trägt deutliche Märchenbezüge. Obwohl die Geschichte von Peter Schlemihl heute häufig als die eines Mann ohne Schatten resümiert wird, ist sie in erster Linie eine Geschichte über die Suche nach Glück, auf welcher der Held eine phantastische ,Hilfskraft ${ }^{`}$ erhält und - wie Hans im Glück seinen Schatten gegen Geld tauscht, was ihn zunächst aus seiner mittellosen Notlage zu retten scheint. ${ }^{242}$ Nach Max Lüthi neigt die Märchenhandlung dazu, „sich in einem Zweier- und Dreierrhythmus auszufalten“243. Wie viele Märchen ist auch Peter Scblemibl mehrteilig: Nach dem Tausch des Schattens gegen Fortunati Glücksäckel muss der Held zwangsläufig seine Seele gegen den verlorenen Schatten tauschen, um aus der neuen Notlage herauszukommen. Nachdem er den Glücksäckel in den Abgrund geworfen und sich damit von dem Teufel endgültig getrennt hat, beginnt mit dem Auftauchen der Siebenmeilenstiefel noch ein dritter Teil seiner Geschichte, der Züge einer märchenhaften Belohnung für Schlemihls Entscheidung trägt. Die für das Märchen typische Episodenstruktur wird von der Erzählung als Etwas selbverständliches aufgenommen, weil der Held bemerkt, dass er sich ,nicht lange an einem Ort aufhalten durfte, wo man [ihn] schon ohne Schatten gesehen, und wo [er] leicht verraten werden konnte" [SW I, 30]. Sowohl der Besuch bei Herrn John, die Begegnung mit der schönen Fanny ,am dritten Ort" [ebd.] als auch die Liebestragödie mit Mina bleiben episodisch in dieser ,wundersamen Geschichte'verankert.

\footnotetext{
${ }^{241}$ Die erwähnten zauberhaften Utensilien spielen fast alle auf literarische Sujets und Texte an. Vgl. Walach 1982, S. $18 f$.

242 „Wann lebte der Erste Philosoph des Glücks? Und wo lebte er? Das ist sehr schwer zu beantworten. Dafür kennt man einen seiner Vor-Namen: Hans - oder, etwas genauer, ,Hans im Glück“."Vgl. Marcuse 1972, S. 42.

${ }^{243}$ Lüthi 1996, S. 25.
} 
Die Erzählung muss aus märchenhaften Episoden bestehen, gerade weil der Held in eine Märchenwelt gerät und seinen Schatten verloren hat. Zwischen der Struktur und dem Inhalt des Textes besteht also ein bidirektional kausaler Zusammenhang, und die ,wundersame Geschichte، und ihr Erzähltext bilden auf diese Weise eine selbstreflektierende Einheit. Anders als das romantische Ideal einer sich organisch entwickelnden poetischen Selbstreflexion entsteht Peter Schlemibls Selbstreflexion aber aus einer Notlage. Der Held ist ratlos in diesen unerwünschten märchenhaften Zustand eingeschlossen. Er kennt seine Lage als ,Märchenfigur ${ }^{6}$ und sucht vergeblich nach einem Ausweg aus dieser Märchenwelt. Auch im letzten Teil der Binnenerzählung, als der Titelheld kraft der zauberhaften Stiefel die Distanz überwinden darf, besteht seine Welt beziehungsweise seine erzählte Welt aus Episoden, ,und so war, im Ursprung schon, alles, was ich sammeln und erbauen sollte, bloßes Fragment zu bleiben verdammt" [SW I, 62]. Nur, indem Schlemihl ein Paar bürgerliche Pantoffeln als Hemmschuhe überzieht, wird die romantische Fragmentierung aufgehoben. Chamissos Erzählung ist daher ein ironischer Kommentar zum romantischen Ideal.

Auch andere romantische Aspekte sind in dieser Erzählung parodiert. Am auffälligsten ist das scheinbar glückliche Ende von Schlemihls Geschichte: Der AuBenseiter Peter Schlemihl kehrt in die Natur zurück, nachdem er das Abenteuer in der Menschenwelt vollendet hat. Diese Rückkehr kann allerdings nicht als romantischer Gewinn einer höheren Naivität angesehen werden, sondern muss als eine resignierte Flucht aus der Menschenwelt gelten. Die Natur ist der „Ersatz“ [SW I, 60] der unerreichbaren menschlichen Gesellschaft. Indem Schlemihl die menschliche Gesellschaft verlässt und das Studium der Natur „zur Richtung und Kraft“ [ebd.] seines Lebens macht, wird er den verlorenen gesellschaftlichen Status wiedererhalten: „Ich werde Sorge tragen, dass vor meinem Tode meine Manuskripte bei der Berliner Universität niedergelegt werden“ [SW I, 66]. Das Ziel Schlemihls ist - wie bei seinem ersten Eintritt in die Menschenwelt nach der Seefahrt - immer noch die Anerkennung durch die wohlgeordnete bürgerliche Gesellschaft. Diese Anerkennung erhält der Held nur durch ein Surrogat - zunächst durch seinen Reichtum dann durch sein Werk - statt durch sein ,Ich', das aus der Menschenwelt verbannt worden ist. Die verlorene Einheit kann nicht mehr wiederhergestellt werden. Hans Schuhmacher bemerkt, dass der Schatten nicht mehr wieder zu erwerben sei, obwohl Schlemihl auf den Säckel verzichte, weshalb die Schattenlosigkeit „scheinbar mit einer bestimmten Bewußtseinsstufe identisch“ sei. ${ }^{244}$ Der kreisförmige Geschichtsverlauf des romantischen Ideals zeigt sich in dieser Erzählung als unerreichbar und unerwünscht.

Die Grenze zwischen der Wirklichkeit und der Fiktion der Erzählung ist nach dem romantischen Vorbild der Transzendentalpoesie stark verwischt. Friedrich Schlegels progressive Universalpoesie bleibt nicht auf das Gebiet der Literatur

${ }^{244}$ Schuhmacher 1977, S. 152. 
eingegrenzt, sondern ist „darüber hinaus auf eine wechselseitige Durchdringung mit dem Leben angelegt". .245 Die Poesie soll lebendig und gesellig gemacht und das Leben sowie die Gesellschaft poetisiert werden. Chamissos Erzählung ist nämlich die „Beichte“ [SW I, 14] der erfundenen Figur Peter Schlemihl an seinen Freund Chamisso und ist verknüpft mit mehreren Paratexten von Chamisso, Fouqué und Hitzig als Briefwechsel. Die Leser erfahren in den Paratexten, dass diese wundersame Geschichte, mitgeteilt von Adelbert von Chamisso und herausgegeben von Friedrich de la Motte Fouqué, eine Selbstäußerung ihres angeblich gemeinsamen Freundes Peter Schlemihl sei, der als „ein wunderlicher Mann“ [SW I, 15] mit einem langen grauen Bart und einer ganz abgenützten Kurtka Chamisso das Manuskript überreicht habe. ${ }^{246}$ Einerseits wird die Grenze zwischen der Wirklichkeit und der Fiktion durch diese Herausgeberfiktion ${ }^{247}$ verschoben, andererseits aber betont Chamisso dadurch den fiktionalen Charakter des Textes der SchlemihlErzählung:

Freilich muss ich selbst gestehen, dass es um die Geschichte schad ist, die unter des guten Mannes Feder nur albern geworden, dass sie nicht von einer geschickteren fremden Hand in ibrer ganzen komischen Kraft dargestellt werden kann. - Was würde nicht Jean Paul daraus gemacht haben! [SW I, 15]

Da der Adressat von Schlemihls Lebensbericht Chamisso ist, trägt die Erzählung den romantischen Charakter von Selbstreflexion und autobiographischem Schreiben. Der Adressat Chamisso kommt in Schlemihls Manuskript zweimal im Traum vor. Nachdem der Held eine große Menge Goldes aus dem unglücklichen Säckel gezogen hat und auf dem Golde liegend eingeschlafen ist, träumt er von Chamisso:

es ward mir, als stünde ich hinter der Glastüre Deines kleinen Zimmers, und sähe Dich von da an Deinem Arbeitstische zwischen einem Skelett und einem Bunde getrockneter Pflanzen sitzen, vor Dir waren Haller, Humboldt und Linné aufgeschlagen, auf Deinem Sofa lagen ein Band Goethe und der Zauberring, ich betracbtete Dich lange und jedes Ding in Deiner Stube, und dann Dich wieder, Du rührtest Dich aber nicht, Du boltest auch nicht Atem, Du warst tot.

Ich erwachte. [SW I, 24f]

Da Schlemihl später Naturwissenschaftler wird und sich in die Reihe der genannten Akademiker einreiht, ist dieser Traum vorausdeutend auf Schlemihls eigenes Schicksal. Zugleich entspricht Chamissos Tod zwischen Requisiten der Vergänglichkeit und der Literatur - im Sinne der toten Kunst - Schlemihls Verbannung

\footnotetext{
245 Kremer 2007, S. 92.

${ }^{246}$ Die Ich-Erzählung Schlemihls ist an Chamisso adressiert und ist in der Tat Lebensbeichte. Die Briefe, die als Paratexte gelten können, gehören selbst nicht zur Erzählung, mystifizieren aber deren Überlieferung.

247 Michael Schmidt untersucht das romantische Spiel mit der Herausgeberfiktion in einem neueren Beitrag.
} 
aus der Menschenwelt. In dem zweiten Traum teilte Chamisso sogar dessen Schattenlosigkeit. Während Chamisso im Vorwort Hitzig sein besseres Ich nennt, vor dem er kein Geheimnis bewahren kann, soll Chamisso, den Schlemihl zum Bewahren seiner wundersamen Geschichte erkoren hat, als das bessere Ich Schlemihls gelten. In diesem Sinne kann die Binnenerzählung als eine Selbstanalyse und Selbstbespiegelung des Erzählers gelten. Der Erzähler (Peter Schlemihl) versucht kraft seiner Selbstanalyse die verwirrenden Geschichten in seinem früheren Leben zu erfassen, indem er seinem besseren Ich die wundersamen Abenteuer nach deren Logik erzählt.

Allerdings weicht diese Novelle von Friedrich Schlegels Manifest im 116. Athenäums-Fragment in einer wichtigen Hinsicht ab. „Und doch kann auch sie am meisten zwischen dem Dargestellten und dem Darstellenden, frei von allem realen und idealen Interesse auf den Flügeln der poetischen Reflexion in der Mitte schweben, diese Reflexion immer wieder potenzieren und wie in einer endlosen Reihe von Spiegeln vervielfachen“"248, so Schlegels Kommentar zu der progressiven Universalpoesie. Die Novelle von Peter Schlemibl wendet sich von der romantischen Programmatik ab, nicht nur indem sie über die Siebenmeilenstiefel ein Paar biedermeierlicher Pantoffeln zieht, sondern weil die Spiegelung nicht endlos ist. Peter Schlemihls Geschichte ist kein Fragment, sondern ein geschlossenes Kunstwerk mit Vor- und Nachreden. Das Manuskript selbst dient als „nützliche Lehre“ [SW I, 66] für einen Freund und als ein Abschiedsgruß an denselben.

Auch für den Autor Chamisso gilt das Werk als „Abschiedsgruß an [...] sein zweites Vaterland“ [SW I, 777] und an seine literarischen Tätigkeiten. Tatsächlich allerdings ist Peter Schlemibls wundersame Geschichte nur eine kurze Unterbrechung während seines zwanzigjährigen Schweigens als Dichter zwischen Adelberts Fabel sowie zwei Drama-Fragmenten aus dem Jahr 1806 und den späten Liedern und Gedichten. Sich selbst sah Chamisso zur Entstehungszeit von Peter Schlemihl schon nicht mehr als Autor: „Autoren sind doch ein tolles Volk, ich bin froh, daß ich keiner bin. "249 Chamisso hatte diese Novelle als Offenbarung ,aus der Seele geschnitten und [...] abgeschrieben“"250. Das Werk ist abgeschlossen und der Autor ist ,tot“ und als „,tot“ thematisiert: „Du rührtest Dich aber nicht, Du holtest auch nicht Atem, Du warst tot ${ }^{\text {“ }}\left[\mathrm{SW}\right.$ I, 24f]. ${ }^{251}$

\footnotetext{
248 KA II, $182 \mathrm{f}$.

${ }^{249}$ Brief an Hitzig im August 1813. Zit. nach Walach 1982, S. 48.

${ }^{250}$ Brief an Hitzig im September 1813. Zit. nach Walach 1982, S. 49.

${ }^{251}$ Schmidt hat den Tod des Autors in diesem Traum genauer untersucht. Vgl. Schmidt 2016, S. 81 87.
} 


\subsection{Die verkehrte Welt in Peter Schlemihl}

Die menschliche Welt in Peter Scblemibl ist eine geschlossene Einheit, die von einem Besitz- sowie Herrschaftsprinzip dominiert wird und dem Titelhelden fremd gegenübersteht. Sie tritt allerdings nicht einfach als die uns vertraute Wirklichkeit auf. Ganz im Gegenteil werden mehrere phantastische Elemente oder Märchenrequisiten dieser Menschenwelt in der Novelle gezielt eingesetzt, weil das Gegenbild zu dieser Welt nicht die zeitgenössische Wirklichkeit, sondern die naive Welt Rousseaus ist. Diese erzählte Welt ist modern und realistisch, scheint jedoch märchenhaft zu sein, weil sie sich von der ursprünglichen Natur entfernt hat.

Das erste ,phantastische Element in der Erzählung ist die Zeit in der erzählten Welt. Walter Erhart bemerkt, dass diese wundersame Geschichte „,von eigentümlichen Rhythmen des Erzählens bestimmt ist“"252. Der Autor entwerfe ein komplexes Bild

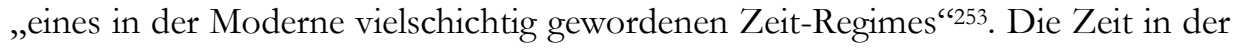
menschlichen Gesellschaft wird von Schlemihl als gerafft wahrgenommen. Auch der erste Eindruck von Herrn John in dem großen nenen Haus erweckt in dem Helden das Gefühl von Beschleunigung:

„So, so! von meinem Bruder, ich habe lange nichts von ihm gehört. Er ist doch gesund? - Dort, "fubr er gegen die Gesellschaft fort, ohne die Antwort zu erwarten, und wies mit dem Brief auf einen Hügel, ,dort lass ich das neue Gebäude aufführen. " $[\mathrm{SW}$ I, 18]

Der Inhalt dieses Gesprächs erscheint fragmentarisch und der logische Zusammenhang fehlt. Der Titelheld fühlt sich zuerst in diese Welt einbezogen („Oh wie wahr!"“ rief ich aus mit vollem überströmenden Gefühl [ebd.]), merkt aber später den ungewöhnlich raschen Verlauf der Geschehnisse in der ganzen Gesellschaft:

„Ein Fernrohr her!" rief John, und noch bevor das auf den Ruf erscheinende Dienervolk in Bewegung kam, hatte der graue Mann, bescheiden sich verneigend, die Hand schon in die Rocktasche gesteckt, daraus einen schönen Dollond hervorgezogen, und es dem Herrn John eingehändigt. Dieser, es sogleich an das Aug bringend, benachrichtigte die Gesellschaft, es sei das Schiff [...] [SW I, 19]

Der „Graue“ versorgt die Gesellschaft rund um Herrn John mit Gegenständen aus aller Welt: einem englischen Pflaster, einem englischen Fernrohr, einem türkischen Teppich, einem prachtvollen Lustzelt und drei Rappen mit Sattel und Zeug. „Wie in einem Brennspiegel tritt zu Beginn der Geschichte eine Verdichtung von Raum und Zeit hervor, die den Ich-Erzähler zugleich bedrängt und überfordert. "254 Die von der alltäglichen Logik entblößte Zeitraffung versetzt Schlemihl in „Schwindel“ [SW I, 23], weil seine innere Zeit im Gegensatz zu der beschleunigten

\footnotetext{
252 Erhart 2016, S. 50.

${ }^{253}$ Erhart 2016, S. 49.

${ }^{254}$ Erhart 2016, S. 52.
} 
Zeit der Menschenwelt ${ }^{255}$ stillsteht: Nach dem Traum von seinem „besseren Selbst“ Chamisso, der tot „zwischen einem Skelett und einem Bunde getrockneter Pflanzen“ [SW I, 18] sitzt, erwacht Schlemihl. Seine Uhr „stand“ [SW I, 25].

Der ungewohnte, geraffte Zeit-Rhythmus, mit dem Peter Schlemihl konfrontiert ist, kennzeichnet nach Zygmunt Bauman die ,flüchtige‘ Moderne:

Die lineare Zeit der Moderne erstreckt sich zwischen der Vergangenheit, die nicht dauern, und der Zukunft, die nicht sein kann. Es gibt keinen Raum für ein Mittleres. [...] Das Gegenwärtige ist obsolet. [...] Ihr Genuß kann nur einen flüchtigen Moment lang dauern: darüber binaus (und das Darüberbinaus beginnt am Anfangspunkt) gewinnt die Freude eine nekreophile Färbung, Leistung wird zur Sünde und Unbeweglichkeit zum Tod. ${ }^{256}$

Die Fragmentierung der Welt ist ein Ergebnis der Moderne. Peter Schlemihl, der nach einer Seefahrt in die menschliche Welt gelangt ist, begegnet einer modernen Gesellschaft als dem Gegensatz zu der ihm vertrauten Natur. Die ,Natur bedeutet nach Bauman das Schweigen des Menschen, den Zustand, bevor die Ordnung entsteht und als solche entdeckt wurde oder der Gegensatz zu der Ordnung, die Ungewissheit. ${ }^{257}$ Die Menschenwelt in der Binnenerzählung von Peter Schlemibl ist eine Welt voller Ordnung: Das auf dem Hügel aufzuführende Gebäude deutet auf eine Eroberung der Natur durch die Menschen hin. Sämtliche Haltungen sind durch Possessivität gekennzeichnet. Gemeint ist einerseits das obsessive Besitzstreben vom Kapital, andererseits die aristokratisch-hierarchisierten zwischenmenschlichen Beziehungen. Das ökonomische und das aristokratische Prinzip gelten als die beiden dominierenden Prinzipien dieser Welt.

Die erzählte Welt ist einerseits durch die Dominanz ökonomischer Macht, andererseits durch die feudalen Herrschaftsverhältnisse gekennzeichnet. ${ }^{258}$ Die Mitglieder in dieser philisterhaften Welt sind - wie in einem Volksmärchen - ,Herr und ,Diener ${ }^{6}$,Knecht ${ }^{6}$ in einem aristokratischen System. Herr John und die schö-

\footnotetext{
${ }^{255}$ Die Zeitraffung gilt nicht nur für Herrn Johns kleine Gesellschaft, sondern auch für andere Personen in der erzählten Welt: „Am Tore musst ich gleich wieder von der Schildwacht hören: ,Wo hat der Herr seinen Schatten gelassen?‘ und gleich wieder darauf von ein paar Frauen: Jesus Maria! der arme Mensch hat keinen Schatten! “ “SW I, 23] „, ,Wohl, mein Herr, ganz wohl!' erwiderte der Forstmeister, ,Sie werben um meine Tochter, das tun auch andere, ich habe als ein Vater für sie zu sorgen, ich gebe Ihnen drei Tage Frist, binnen welcher Sie sich nach einem Schatten umtun mögen; erscheinen Sie binnen drei Tagen vor mir mit einem wohlangepassten Schatten, so sollen Sie mir willkommen sein: am vierten Tage aber - das sag ich Ihnen - ist meine Tochter die Frau eines andern. “ " $[S W$ I, 41]

256 Bauman 2005, S. 27 f.

257 Vgl. Bauman 2005, S. 20.

258 „Chamisso greift im Peter Schlemihl [...] das Geld als Zeichen einer possessiven Haltung auf.“ 1 Schlitt 2008, S. 212. In der Gesellschaft des Neureichen Herrn, bei den Eltern von Minna, die ihre Tochter einen Verbrecher um des Geldes willen heiraten lassen, und schließlich bei dem Protagonisten selbst, der mithilfe des Glückssäckels von der Menschenwelt aufgenommen werden will, gilt das ökonomische Prinzip.
} 
ne Fanny, „Herrin des Tages“ [SW I, 19], sind in dem feudalistischen System die Herren des „Grauen“, der sie „bescheiden sich verneigend“ [ebd.] mit seinen phantastischen Gegenständen bedient und dem sie wenig Aufmerksamkeit schenken. In der ökonomischen Hinsicht aber ist der Graue der Herr von Thomas Johns Seele. Der aristokratische Herr ist somit dem Herrn des Geldes schuldig. $\mathrm{Da}$ ein seelenloses Sein trügerisch ist und die Seele und die Vielfältigkeit des irdischen Lebens ein Gegensatzpaar von Sein und Schein bilden, zählen die aristokratischen Beziehungen in dieser modernen Welt zum bloßen Schein eines wesentlich durch wirtschaftliche Beziehungen bestimmten Seins. Auf die verborgene Wahrheit dieser verkehrten Welt wird hingewiesen, als der Protagonist sich „fast noch mehr vor den Herren Bedienten, als vor den bedienten Herren " [SW I, 20] fürchtet. Unter den beiden Prinzipien dieser Welt ist das ökonomische das Sein und das aristokratische der Schein. Die menschliche Gesellschaft gilt als verlogen, was durch den trügerischen Handel mit dem Grauen schon gekennzeichnet ist: Mit dem Austausch des Schattens gegen den unerschöpflichen Geldsäckel ist der eigentliche Teufelspakt noch gar nicht abgeschlossen. Der Handel des ,Scheins ${ }^{` 259}$ gilt nur als Vorstufe des eigentlichen Teufelspakts - dem Handel mit der Seele, wobei der Teufel auch auf den schönen Schein des Schattens Wert zu legen scheint, wenn auch die bewunderte Schönheit des Schattens nach dem Handel nicht mehr erwähnt wird.

Die zwischenmenschlichen Herr-Knecht-Beziehungen zeigen sich auch am Verhältnis des Protagonisten zu anderen Mitgliedern der menschlichen Gesellschaft. In dem Städtchen, das im vierten Kapitel beschrieben wird, kniet die schöne Mina vor Peter Schlemihl nieder und hält ihm ,auf seidenem Kissen einen aus Lorbeer, Ölzweigen und Rosen geflochtenen Kranz entgegen, indem sie von Majestät, Ehrfurcht und Liebe einige Worte sprach" [SW I, 32]. Schlemihl muss die Rolle eines Königs spielen, ,und zwar einer der reichsten und königlichsten, die es immer geben mag“" [SW I, 35], weil „die guten Leute, die noch keinen [König] mit Augen gesehen [hatten], [...] mit gleichem Glück bald auf diesen, bald auf jenen [rieten]" [ebd.]. Er galt für das Volk, das ihm huldigte, in der Rolle der Königlichen Hoheit als eine märchenhafte Figur, die mit ihrer ,ganze[n] fabelhafte[n] Reise“ [ebd.] ihm Glück und eine gewisse Gehobenheit bringen könne. Während das frühromantische königliche Ideal nach Novalis eine Verkörperung von Würde ist und die Monarchie auf dem Glauben an einen höhergeborenen Menschen beruht, spielen die angeborene Identität und die Würde von Peter Schlemihl für das Volk gar keine Rolle. Was „die guten Leute“ beeindruckt, ist lediglich der märchenhafte Reichtum dieser geheimnisvollen Person. Die Anwesenheit des vermeintlichen „Königs“ vermittelt dem Volk keine erhöhte Identität, im Gegensatz zu Novalis, der in dem Monarchen ein utopisches Vorbild für das Volk sieht. Umgekehrt bingt Peter Schlemihl Mina ,als erster Untertan [s]eine Huldigung in

${ }^{259}$ Gemeint ist der Schatten, der in der Tat keine Notwendigkeit für das Leben ist. 
tiefer Ehrfurcht“ [SW I, 34]. Das Mädchen ist eine Person der Unschuld und Grazie mit einer festen bürgerlichen Identität. Die freiwillige Unterwerfung unter aristokratische Herrschaft in der Menschenwelt orientiert sich an zweiseitig ökonomischen Interessen.

Die Szene, in der die Stadtbewohner Peter Schlemihl für den König von PreuBen halten und ihm huldigen, kann als eine Parodie des Essays Glauben und Liebe oder Der König und die Königin von Novalis gelten. Dieses philosophische Fragment muss Chamisso durch sein Studium der romantischen Schriften gut gekannt haben. Doch dem romantischen Begriff des Volks als „höchstem Begriff des geistigen Lebens“ und zu „erneuernden Organismus“"260 stimmt Chamisso nicht zu. Wie oben schon erläutert, erscheint das Volk in dieser Novelle negativ. Das philisterhafte Volk ist dem trügerischen Peter Schlemihl freiwillig untertan, während der Protagonist dadurch gezwungen wird, die Rolle eines märchenhaften, namenlosen Königs zu spielen. Nur indem er schauspielerisch die Rolle einer Herrschaft spielt, kann er in diese Welt voller untertäniger Beziehungen aufgenommen werden, wobei er innerlich (wesentlich) immer noch ein Außenseiter bleibt.

Peter Schlemihl bezeichnet sich als „untertänigster Knecht“ des grauen „Herrn“, während der Graue die Relation scheinbar umkehrt: „Sie haben mich an meinem Gold, befehlen Sie auch in der Ferne über Ihren Knecht“ [SW I, 56 f.]. Mit dem Glückssäckel zu seiner Verfügung kann Schlemihl Dienstleistungen von dem Grauen erwerben. Allerdings wird er - wie Herr John - dem Teufel gegenüber zum Schuldner seiner Seele - seines Wesens. Seine Kontrolle über den Grauen ist nur Schein, der die Wahrheit verdeckt. Die prächtige Scheinwelt, die der Graue seinen Schuldnern zur Verfügung stellt, ist eine trügerische und zeitlich begrenzte Illusion. In der Illusion dient der Graue seinen Schuldnern als Knecht. In der wesentlichen Welt ist er Herr der Seelen und des Schattens, der bereits den homerischen Griechen als der Sitz der Seele gilt. ${ }^{261}$

Allein zwischen Schlemihl und demjenigen, mit dem er in einer echten seelischen Verbindung steht, herrscht keine untertänige Ordnung: Es ist Bendel, sein Freund und Vertrauter, der zwischen dem Schattenlosen und der Welt vermittelt. Sein besseres Selbst Chamisso sowie dessen Welt kommen in der erzählten Welt von Schlemihl nicht vor. Wie Neubauer scharfsinnig bemerkt, wird Peter Schlemihl als „Numero Zwölf“ in Kapitel XI charakterisiert [SW I, 64], während ein Kapitel XII in dieser Erzählung fehlt. ${ }^{262}$ Das fehlende Kapitel XII wäre ein Text (ein Post Scriptum, die Fortsetzung der vorherigen Kapitel und Schlemihls unendlicher Geschichte) und zugleich die nicht geschriebene Interpretation zu diesem Text. Das plötzlich in Chamissos Kammer auftauchende Manuskript ist Schlemihls Interpretation seiner wundersamen Geschichte und seines Lebens. Das auf wundersame Weise auftauchende Manuskript ist in Bezug auf seine Verbindungs-

\footnotetext{
260 Kroner 1971, S. 441.

261 Braun 2002, S. 151.

262 Neubauer 1986, S. 32.
} 
losigkeit identisch mit Peter Schlemihl selbst. Der Rahmenerzähler Chamisso, der den Text liest und dadurch nützliche Lehren erhalten soll, gehört nicht zu der wundersamen erzählten Welt. Die erzählte Menschenwelt in Peter Scblemibl ist eine bloß fiktionale Welt der Illusion sowohl für die wirklichen Leser als auch für die Leser im Rahmentext.

Das Phantastische wird in dieser Welt als ganz natürlich oder selbstverständlich dargestellt. Schlemihls Schattenlosigkeit wird zwar von den Menschen in der erzählten Welt als entsetzlich und unnatürlich bemerkt, der Grund ihres Entsetzens bezieht sich jedoch nicht auf die empirische Möglichkeit des Schattenverlustes, sondern lediglich auf dessen Umstände. ${ }^{263}$ „Ich gebe Ihnen drei Tage Frist, binnen welcher Sie sich nach einem Schatten umtun mögen“ [SW I, 41], so der Forstmeister, der Schlemihl auffordert, sich einen neuen Schatten zu besorgen. Sowohl für ihn als auch für Schlemihls Knecht Rascal gilt die Schattenlosigkeit nicht als empirisches unmögliches Phänomen, sondern als ein Zeichen für Unehrlichkeit, ${ }^{264}$ für ein falsches Wesen. Es kommt in dieser Welt auf das Ergebnis an, nämlich dass der Protagonist einen neuen Schatten besitzen soll, und nicht darauf, wie er den eigenen Schatten verloren hat ${ }^{265}$ und wie er einen neuen erwerben soll (der Prozess, das Sein). Auch an den Zauberkünsten des Grauen findet niemand etwas Merkwürdiges. Die schöne Fanny richtet sogar ,nachlässig' die ,leichtsinnige Frage an den grauen Mann: „ob er nicht auch vielleicht ein Zelt bei sich habe“ [SW I, 20]. Außerordentliches wird in dieser Welt als selbstverständlich genommen, besonders solange es für die Mitglieder der Welt vorteilhaft ist. Auf diese Weise kommt die Welt in der Erzählung dem Rezipienten des Textes auch dem Helden märchenhaft vor, aber zunächst weil innerhalb einer ontologisch realistischen Welt zugleich phantastische Elemente auftauchen können. ${ }^{266}$ Allerdings lässt sich die märchenhafte Selbstverständlichkeit des Wunderbaren noch auf eine andere Weise erklären. Der graue Mann, dem niemand in Thomas Johns Gesellschaft Aufmerksamkeit schenkt, ist ein ,guter Freund“ [SW I, 57] und Gläubiger von Herrn John. Der junge Mann in der Abendgesellschaft, der von minderem Ansehen als die anderen schien und dem Peter Schlemihl die Frage stellt, wer der Graue sei, behauptet, dass er den grauen Mann nicht kenne, „und, wie es schien, eine längere Unterhaltung mit [Schlemihl] zu vermeiden, wendet er sich weg und

\footnotetext{
${ }^{263}$ Lommel 2007, S. 34.

${ }^{264}$ Rascal: „Ein Knecht kann ein sehr ehrlicher Mann sein und einem Schattenlosen nicht dienen wollen, ich fordre meine Entlassung.“ [SW I, 39] „,Und Sie haben, " hub der Forstmeister grimmig wieder an, ,und Sie haben mit unerhörter Frechheit diese und mich zu betrügen keinen Anstand genommen; und Sie geben vor, sie zu lieben, die Sie so weit heruntergebracht haben?"“ [SW I, 40] ${ }_{265}$ Deshalb erfindet Peter Schlemihl jedes Mal eine neue Geschichte für den Grund seiner Schattenlosigkeit.

266 Am Anfang kommt die Schattenlosigkeit dem Protagonisten unmöglich vor: „Aber, mein Herr, verzeihen Sie Ihrem untertänigsten Knecht. Ich verstehe wohl Ihre Meinung nicht ganz gut, wie könnt ich nur meinen Schatten - " [SW I, 22], so sagt er zu dem Grauen. Erst nachdem er seinen Schatten schon verloren hat, erkennt er die Möglichkeit des Schattenverlustes.
} 
spricht von gleichgültigen Dingen mit einem andern“" [SW I, 20]. Die seltsame Reaktion muss den Verdacht hervorrufen, dass auch dieser junge Mann den grauen Mann kennt und sein Schuldner ist. Es liegt nahe, dass alle Mitglieder in Thomas Johns Abendgesellschaft den falschen Schein gemeinsam erfanden, sodass die Zauberkünste des grauen Mannes nicht als solche auffallen, weil sie alle Schuldner des Teufels sind. Der Teufel, der mit seinen Künsten und seinem Gold das prächtige Gebäude der Illusion aufführt, ist der Garant für die Stabilität der Scheinwelt. Alle Mitglieder der Welt sind ihm untertänig und arbeiteten zusammen, um den Schein der Welt zu gewährleisten.

Schließlich ist diese Welt eine verkehrte Welt wie eine Märchenwelt. Hier wird „zuweilen von leichtsinnigen Dingen wichtig, von wichtigen öfters leichtsinnig“ [SW I, 19] gesprochen. Der Graue, der der Knecht Herrn Johns und Peter Schlemihls zu sein scheint, ist in der Tat der Herr von Johns Seele und Schlemihls Schatten. Auf den Schatten, den „lichtlose[n] Raum, welcher auf der Seite des nicht beleuchteten Teiles liegt“"267, wird mehr Wert gelegt als auf den „Körper“ [SW I, 19] selbst. ${ }^{268}$ Schein und das Sein geraten in ein inverses Verhältnis. Der oberflächliche Schein wird zum Gegenstand der Beurteilung. „Und wenn Schlemihl von der öffentlichen Meinung zu Graf Peter gemacht wird, ist dies ein Indiz dafür, daß der Schein sogar das Sein begründen kann. “269

Doch gehen die verkehrte Welt und realistische Welt ineinander. In der Tat entsprechen die ökonomischen und menschlichen Verhältnisse in der Binnenerzählung denjenigen der zeitgenössischen Wirklichkeit. Die Verkehrung symbolisiert vielmehr die Entfremdung der Moderne vom unschuldigen Naturzustand in der Zivilisationskritik von Rousseau.

Mit dem Eintritt in den Kreis des Thomas John gerät Schlemibl in jenen von Rousseau kritisierten Gesellschaftszustand, in dem [...] die menschlichen Beziebungen durch materielle Dinge vermittelt sind, die Menschen sich an das Äußere verlieren und zu Sklaven der Dinge werden. ${ }^{270}$

Peter Schlemihl tritt als ein unschuldiger Mensch des Naturzustands („dass Sie übrigens die allerstrengsten Grundsätze haben und wie die Ehrlichkeit selbst denken, ist eine Liebhaberei“" [SW I, 56]) in diese entfremdete Welt ein, fühlt sich am Anfang in diese verkehrte Welt einbezogen und kehrt schließlich zur Natur zurück.

\footnotetext{
${ }^{267}$ SW I, 778.

268 „Es wäre doch am Ende ein Schatten, nichts als ein Schatten, man könne auch ohne das fertig werden, und es wäre nicht der Mühe wert, solchen Lärm davon zu erheben“ [SW I, 41].

${ }^{269}$ Schlitt 2008, S. 209.

270 Schlitt 2008, S. 209.
} 


\subsection{Peter Schlemihl als märchenhafte Figur}

Peter Schlemihl ist keine Volksmärchenfigur, weil er eine komplexe Persönlichkeit ist und ein psychisch reichhaltiges inneres Leben besitzt. Allerdings trägt dieser Held einige starke märchenhafte Züge. Wie oben erläutert, gilt Peter Schlemihl, der einen sprechenden Namen hat, 271 als eine naive Figur in einer fremden märchenhaften Welt. Wie Hans im Glück tauscht er seinen wertvollen Schatten gegen den Glückssäckel, das er später in den Abgrund wirft. Allerdings ist Peter Schlemihl, der wie jeder Märchenheld in einer unbekannten Welt nach dem Glück sucht, durch eine „passive Bereitschaft für eine neue Wirklichkeit“272 gekennzeichnet. Schlemihl hofft auf Anerkennung und Aufnahme durch die Gesellschaft. Es ist ironischerweise die mehrmalige Flucht vor dem Ungewissen und dem Bedrohlichen statt eines aktiven Integrationsversuchs, die zu der Entwicklung seiner wundersamen Geschichte beiträgt: Nachdem Schlemihl die Zauberkünste des grauen Mannes sowie die seltsame Reaktion der Abendgesellschaft um Thomas John gesehen hat, beschließt er, sich ,aus der Gesellschaft zu stehlen, was bei der unbedeutenden Rolle, die [er] darinnen spielte, [ihm] ein Leichtes schien." [SW I, 21] - „Wäre es mir nur so zu entkommen geglückt!“ [SW I, 21]. Der Held verhält sich hier ausweichend und passiv. Der Handel mit dem Schatten, die listige Vorstufe zu dem Seelenhandel, ist von Seiten des Protagonisten auch ein passives Akzeptieren des Angebots sowie Übernahme des teuflischen Vorschlags: „Ich aber hielt den Beutel bei den Schnüren fest, rund um mich her war die Erde sonnenhell, und in mir war keine Besinnung" [SW I, 23]. Seit dem Schattenverlust dienen die episodenhaften Aufenthalte an verschiedenen Orten der Flucht vor der Entlarvung seines Stigmas. Als er vor der endgültigen Entscheidung steht, durch seine Unterschrift den Vertrag abzuschließen, seine Seele gegen den Schatten zu tauschen, um gesellschaftliche Anerkennung zu erhalten und auch Mina vor Rascal zu erretten, befällt ihn eine tiefe Ohnmacht. „Nicht sein Wille, sondern die Ohnmacht rettet ihn vor der endgültigen Preisgabe der Seele und somit der Zerstörung. Nicht durch eigenen tatkräftigen Entschluß löst er sich von der BotmäBigkeit des Teufels, sondern durch eine rein christliche Verdammungsformel.“"273 Auch die Siebenmeilenstiefel kommen als eine märchenhafte Zufälligkeit in seine Hände an. Sein Handeln ist nicht autonom, wie es seit der Aufklärung zum Stignum des Menschen gehört. Es ist nicht der Mangel an Innerlichkeit, die Peter Schlemihl einige märchenhafte Züge verleiht, sondern seine passive Natur sowie

\footnotetext{
${ }^{271}$ Chamisso erklärt im Jahr 1821 die Namenswahl: „Schlemihl oder besser Schlemiel ist ein hebräischer Name, und bedeutet Gottlieb, Theophil oder aimé de Dieu. Dies ist in der gewöhnlichen Sprache der Juden die Benennung von ungeschickten oder unglücklichen Leuten, denen nichts in der Welt gelingt. Ein Schlemihl bricht sich den Finger in der Westentasche ab, er fällt auf den Rücken und bricht das Nasenbein, er kommt immer zur Unzeit.“ [SW I, 770]

272 Kroner 1971, S. 452.

273 Kroner 1971, S. 453.
} 
der Mangel am Willen, die Welt inklusive ihrer Ungewissheit zu erkennen und eine deutliche Unterscheidung zwischen Subjekt und Objekt zu treffen. ${ }^{274}$

Als Neuankömmling und Fremder ist Peter Schlemihl bereit, die Identität eines anderen zu erlernen und anzunehmen.

„Wer nicht Herr ist wenigstens einer Million", warf er hinein, „der ist, man verzeihe mir das Wort, ein Schuft!" „O wie wabr!" rief ich aus mit vollem überströmenden Gefühl. [SW I, 18]

Überall war er [Bendel] vor mir und mit mir, alles vorhersehend, Anstalten treffend, und wo Gefahr unversehens drohte, mich schnell mit seinem Schatten überdeckend, denn er war größer und stärker als ich. [SW I, 29f]

Dies sei das Gift meiner Tage: dass ich sie mit in den Abgrund hinreißen könne, sie, die das einzige Licht, das einzige Glück, das einzige Herz, meines Lebens sei. [SW I, 37]

Johns Konzept vom Reichtum beziehungsweise Bendels Vermittlung übernimmt Schlemihl schnell. In der Liebe von Mina fände er das Glück als Geliebter, Ehemann und Mitglied der bürgerlichen Gesellschaft, so meint er. Durch die Liebe und Ehe könnte seine Integration erfolgen, denn Liebe als ein symbolisch generalisiertes Kommunikationsmedium zielt darauf ab, „den egozentrischen Weltentwurf des anderen zu bestätigen oder abzulehnen“275. Die Liebende (die Handelnde) in dieser Beziehung ist aber allein die ,ganz hin sich opfernde“ [SW I, 36] Mina, die ihre bürgerliche Welt mit Schlemihl teilt, während der schauspielerische Protagonist passiv die Rolle eines Geliebten spielt. Die Identität eines autonom handelnden Menschen besitzt der Schattenlose noch nicht. Seine fremdbestimmte Identität verdankt sich den Zuschreibungen der anderen. Sein ,Ich“ ist immer noch durch die anderen Menschen bestimmt.

Die episodenhaften Erlebnisse in den ersten acht Kapiteln können eigentlich als eine entsagungsvolle und unbewusste Suche eines Außenseiters nach einem subjektiven ,Ich' angesehen werden. Schlemihl versucht, durch die Herstellung von menschlichen Beziehungen sein Selbst zu gründen, was jedoch an seinem Mangel an Selbstbewusstsein scheitert. Nur indem er mithilfe der Siebenmeilenstiefel von seinem Naturzustand zu einem flüchtigen und fragmentarischen Sein gelangt, das parallel zu der zeitgenössischen Moderne steht, hört er auf, das ,Ich“ durch die Welt zu gründen und fängt an, das Ungekannte der Welt und des ,Ich‘s in eine Ordnung zu bringen und damit aktiv zu handeln.

\footnotetext{
${ }^{274}$ In Heinrich Deterings Analyse des homoerotischen Subtextes dieser Novelle anhand der biographischen Materialien Chamissos wird untersucht, wie der Held einer Werbung mit homoerotischen Konnotationen durch den Grauen nachgibt und eigene homoerotische Neigungen erkennt, was eine andere Deutungsmöglichkeit der Passivität des Helden ergibt. Vgl. Detering 2002, S. 155 - 172, besonders S. $155-164$.

275 Luhmann 1994, S. 25.
} 
Es ist der Verzicht auf ein nur relatives Ich, das allein durch die Relation zu den anderen bestimmt ist, und die Herstellung von einem autarken Ich, das kraft selbständiger Tätigkeiten aus eigener Besinnung erwächst. Die Flucht ins Innere und in die Natur ist für Schlemihl eine Alternative zu seiner Glückssuche in der Gesellschaft: „Durch frühe Schuld von der menschlichen Gesellschaft ausgeschlossen, ward ich zum Ersatz an die Natur, die ich stets geliebt, gewiesen, die Erde mir zu einem reichen Garten gegeben, das Studium zur Richtung und Kraft meines Lebens, zu ihrem Ziel die Wissenschaft" [SW I, 60]. Was er in der Gesellschaft nicht erhalten kann, erhält er in der Natur, nämlich die Selbstgründung. Die Natur in Peter Scblemibl ist nicht der chiffrierte künstliche Raum bei den Frühromantikern wie Novalis oder Ludwig Tieck, der eine allegorisch zugerichtete Welt ist, „in der jedes Requisit und jeder Ort einen bestimmbaren Zeichenwert haben“"276. In dieser Erzählung bedeutet ,Natur" zugleich die eigentliche Heimat Schlemihls und der Bereich der Gegenstände seines Studiums: „Ich habe die Tatsachen mit möglichster Genauigkeit in klarer Ordnung aufgestellt in mehreren [sic] Werken, meine Folgerungen und Ansichten flüchtig in einigen Abhandlungen niedergelegt" [SW I, 66]. Die unbekannte Natur zu systematisieren, ist ein Forschungsprozess, der parallel zu der Selbstanalyse durch diese Erzählung läuft. Diese Parallelität zwischen der Systematisierung der äußeren und inneren Natur zeigt sich in der sprachlichen Parallelität in den letzten beiden Abschnitten von Schlemihls Manuskript:

Meine Historia stippium plantarum utriusque orbis steht da als ein großes Fragment der Flora universalis terrae, und als ein Glied meines Systema naturae. [...] Ich werde Sorge tragen, dass vor meinem Tode meine Manuskripte bei der Berliner Universität nieder gelegt werden.

Und Dich, mein lieber Chamisso, hab ich zum Bewabrer meiner wundersamen Geschichte erkoren, auf dass sie vielleicht, wenn ich von der Erde verschwunden bin, manchen ibrer Bewobner zur nützlichen Lebre gereichen könne. [SW I, 66]

In der Naturforschung findet Peter Schlemihl schließlich die Richtung und Kraft seines Lebens und einen Ausweg aus seinem entsagungsvollen Naturzustand.

Schlemihls Selbstbeheimatung in der Natur ist eine Rückkehr zu sich selbst auf einer neuen Erkenntnisstufe des Selbstbewusstseins, das allerdings als Parodie des romantischen Ideals das Ergebnis einer Entsagung ist. Friedrich von Hardenbergs Werk stellt die wieder zu erreichende reflektierte Einheit anhand der typischen triadischen Struktur prophetisch dar. In Hardenbergs Naturromanfragment Die Lehrlinge zu Sais wird die Natur von dem analytischen Naturforscher „mit scharfen Messerschnitten“ zertrennt und getötet, während sie dagegen vom Dichter „,noch mehr beseelt" wird und ihr Gemüt nur ,in der Gesellschaft der Dichter" zu erkennen ist. [N I 84] Wonach die Lehrlinge in diesem frühromantischen Werk streben, ist „die echte Sanscrit“ [N I 79], also die Ursprache der Natur. Der Natur-

276 Kremer 2007, S. 50. 
forscher Peter Schlemihl sucht aber nicht mehr nach der Sprache des vernünftigen Chaos. Stattdessen betreibt er empirische Wissenschaft und systematisiert er die Pflanzen beider Erdhälften und tauscht afrikanisches Elfenbein gegen Sextanten, Instrumente und Bücher. Da die Zahl der bekannten Pflanzenarten durch seine Arbeit um mehr als ein Drittel vermehrt worden ist, trägt er zur Taxonomie der Natur bei.

Peter Schlemihl ist ein Held, der der ,unschuldigen' Vormoderne entstammt, sich auf die moderne Welt des ökonomischen Utilitarismus, deren Fremdbestimmung gerade durch phantastische und märchenhafte Elemente als Scheinwelt symbolisiert wird, vergeblich einlässt, ehe er ihr mithilfe des Phanstastischen halbwegs entkommt. Durch diese Flucht erkennt er sein Wesen. Aus dem Märchenhelden wird schließlich ein moderner Mensch. Das Phantastische hat sein Recht, allerdings nur in der abgeschlossenen, illusionären Welt in dem Manuskript, das als verschlüsselte Fabel von den ebenfalls entarteten und modernen Menschen als ,nützliche Lehre“ [SW I, 66] gelesen werden sollte. 



\section{Theodor Storm: Der Schimmelreiter}

Wenn man den Aufbau der Geschichte von Hauke Haien in Der Schimmelreiter (1888) von Theodor Storm (1817-1888) betrachtet, findet man eine Konfliktdichtung, für die Storms eigenes Diktum von der Novelle als „Schwester des Dramas“ [LL 4, 409] gilt. Dieses größte Werk Storms gehört aber nicht lediglich wegen seines dramatisch strukturellen Aufbaus zu den Klassikern der realistischen Novellistik. 1872 schrieb Storm an Emil Kuh: „Zur Classicität gehört doch wohl, daß in den Werken eines Dichters der wesentliche geistige Gehalt seiner Zeit in künstlerisch vollendeter Form abgespiegelt ist [...]." “277 Storms produktive Zeit erstreckt sich von der späten Romantik und Goethe-Zeit über die Restauration und Biedermeierzeit zum Zeitalter des Realismus und der frühen Moderne. In seiner letzten Novelle sind die Spuren, die so viele geistige und soziale Zeitströmungen in dem 70-jährigen Autor hinterlassen hatten, auf komplizierte und kunstfertige Weise verschlungen. Deswegen gibt es bereits viele Forschungstexte zu fast allen Aspekten. Nur auf die Märchenadaption in Der Schimmelreiter haben die Literaturwissenschaftler bis jetzt kaum Acht gegeben, obwohl Theodor Storm ein begeisterter Leser von Volks- und Kunstmärchen war. Er sammelte nicht nur Volksmärchen und Sagen, sondern schrieb auch mehrere Märchen, unter denen das früheste Hans Bär (1837) ,in seinen Motiven an die ,Kinder- und Hausmärchen` der Brüder

\footnotetext{
277 Zit. nach Freund 1984, S. 11.
} 
Grimm und in seinem Stil an die künstliche Naivität des Biedermeier“ [LL 1, 671] anschließt, während die anderen Märchen, besonders Die Regentrude, Bulemanns Haus und Der Spiegel des Cyprianus, ein Nachklang der romantischen Kunstmärchen sind. Im Folgenden wird versucht, die Märchenadaptionen in Storms Meisterwerk $\mathrm{zu}$ analysieren und zur aktuellen Storm-Forschung einen neuen Gesichtspunkt steuern.

\subsection{Die Volksmärchenadaption in Der Schimmelreiter}

Seit Die Regentrude, Bulemanns Haus und Der Spiegel des Cyprianus - den drei Märchen 1864/65 schrieb Storm jahrzehntelang kein weiteres. Der Grund liegt in dem mangelnden Leserinteresse an dem Genre „Märchen“. Trotz der Tatsache, dass Storm seine Märchen umbenennen musste, um ein größeres Publikum zu erreichen, versuchte er noch einmal, sein Werk und das Genre Märchen zu verteidigen:

Bei der Antipathie des Publicums gegen das Wort „Märchen“- die Leute wittern dann gleich wirkliche, pure Poësie, wovor sie eine unglaubliche Angst haben -, bätte das Buch einen andern Titel haben sollen; ich habe nie etwas Besseres, mehr so recht aus dem Vollen Entsprungenes geschrieben, als diese „Märchen““278

Das Phantastische taucht aber bis in das letzte erzählerische Werk Storms auf. Besonders viele Motive aus mündlicher Erzähltradition, die er in den frühen Jahren gesammelt hatte, findet man in seinen späten Novellen wieder. Zwei Motive aus der von Theodor Mommsen und Karl Müllenhoff und Storm selbst angelegten Sammlung norddeutscher Volksmärchen, die später von dem nicht zum Druck gebrachten Manuskript Neues Gespensterbuch, einer Sammlung von Gespenstergeschichten, wieder aufgenommen wurde, verwendete Storm für seine letzte Novelle Der Schimmelreiter - „Das vergrabene Kind“ und „Die Meerweiber“. Diese Novelle ist in der Tat die realistische Adaption einer Gespenstergeschichte, die ihm jahrzehntelang im Kopf herumspukte. Die Novelle besitzt viele strukturelle und erzähltechnische Gemeinsamkeiten mit dem Genre Märchen.

Der Schimmelreiter ist keine frei erfundene Geschichte wie die meisten Volksmärchen. Die Novelle orientiert sich stattdessen an einer Sage. [HKE, 379] Die mündliche Überlieferung von Hauke Haiens Geschichte wird durch den Schulmeister und die beiden Ich-Erzähler der Rahmenerzählungen künstlerisch bearbeitet, was durch den Vergleich mit der volksmündlichen Version derselben Geschichte bei Antje Vollmers nochmal betont wird. Die Zeit- und Ortsangaben, die Psychologisierung sowie die detaillierte Darstellung tragen dazu bei, dem Text eine realistische Stimmung beizumessen. Die Welt sowohl in der Erzählung von dem Reiter als auch in der Rahmenerzählung von dem Schulmeister ist nicht eindimensional. Ein Nebeneinander von Diesseitigem und Jenseitigem kommt hauptsäch-

278 Brief an Gebrüder Paetel vom 02. Februar 1873. 
lich in der Rede mancher nichtaufgeklärten Dorfbewohner (das Seeteufel sehende junge Weib, der junge Knecht Carsten, die Arbeiter am Koog, Trien' Jans sowie die Dorfbewohner und der Deichgraf in der erzählten Zeit des Reiters) vor. Hauke Haien glaubt, Seeteufel in seiner Kindheit gesehen zu haben. Als Erwachsener erklärt er dieselbe spukhafte Erscheinung mit der Wirkung des Nebels auf Fischreiher und Krähen. In diesem Sinne scheint diese Figur eine Nachbildung des alten Wiesenbauern in Die Regentrude zu sein. ${ }^{279}$ Alles Übernatürliche in der Binnenerzählung des Schulmeisters wird als Aberglaube oder „Altweiberglaube“ [HKE, 55] relativiert. Das phantastische Wesen zeigt sich auf keinen Fall als selbstverständlich und fraglos der Welt zugehörig. Selbst der Freitod Hauke Haiens ist eher als persönliche Buße, denn als Vollzug eines göttlichen geweihten Schicksals zu verstehen.

Die komplizierte Rahmen-Binnen-Struktur des Erzähltextes, die Psychologisierung der Figuren, die feine Umweltbeschreibung und nicht zuletzt die zweifelhafte Stellung des Phantastischen im Schimmelreiter sprechen gegen Märchenhaftigkeit, insbesondere gegen die Flächenhaftigkeit und den abstrakten Stil als Eigenschaften des Märchens nach Max Lüthi. ${ }^{280}$ Der Erzähltext ist vielmehr eine moderne Novelle ${ }^{281}$. Es gibt allerdings andere Aspekte in diesem Erzähltext, die mit Lüthis Gattungsmerkmale des Märchens überstimmen. ${ }^{282}$

Unter anderem geben die Zeitangaben dem Text eine märchenhafte Tönung. Die Erzählzeit und erzählte Zeit der jeweiligen Rahmen- und Binnenerzählungen sind zwar angegeben, aber nicht als konkrete Jahreszahl, sondern als eine mehrstufige Rückwendung in immer ältere Zeiträume. „Was ich zu berichten beabsichtige, ist mir vor reichlich einem halben Jahrhundert im Hause meiner Urgroßmutter.“ [HKE, 14] ${ }^{283}$ Mit dem ersten Satz des Textes wird die Zeit der Überlieferung schon von der zweiten Hälfte des Jahrzehnts, den 1880ern, in die 30er Jahre verlegt. Die Erzählzeit der Binnenerzählung vom Reiter ist ebenfalls ,im dritten Jahr-

\footnotetext{
${ }^{279}$ Conrad und Freund (1987) haben in ihren Beiträgen die Märchenstruktur von Regentrude analysiert. Besonders Conrads These, dass Die Regentrude eine Vorstudie zu Schimmelreiter ist, ist sehr einleuchtend. Die Gegenüberstellung von Natur und Menschen sowie das Schreibexperiment von Storm, das Phantastische mit dem Realismus zu verbinden, indem das Phantastische auf eine der mehreren Deutungsschichten des Textes beschränkt wird, wird in Schimmelreiter übernommen und weiterentwickelt. Die versöhnende Harmonisierung zwischen dem Individuum und seiner Umwelt in Regentrude fehlt jedoch in der allerletzten Novelle des Autors.

${ }^{280}$ Lüthi 2005, S. $11 \mathrm{ff}$.

${ }^{281}$ Vgl. die Definition der ästhetischen Moderne in der Einleitung dieser Arbeit.

282 Die märchenhaften Bezüge bieten dem Erzähltext nur eine neue Lesart. Sie sprechen nicht dagegen - zum Teil sogar dafür, dass die Leser in der Erzählung auch eine Sage oder einen Mythos entdecken können.

${ }^{283}$ In der Wirklichkeit konnte Theodor Storm die Deichsage auf keinen Fall im Haus seiner Urgroßmutter gelesen haben. Denn die Frau Senator Elsabe Feddersen $(1741$ - 1829) war schon gestorben, als die Sage in der Hamburger Lesefrü̈bte 1838 erschien. Vgl. Eversberg 2010, S. 18. Der Autor verlegte seinen ersten Schauplatz der Erzählung in das Zimmer einer achtzigjährigen Urgroßmutter, vielleicht um eine Stimmung von einer vergänglichen Altertümlichkeit zu schaffen.
} 
zehnt unseres Jahrhunderts“ [ebd.]. Doch die erzählte Zeit der zweiten Binnenerzählung datiert aus dem vorigen Jahrhundert. Obwohl die erzählte Zeit genau berechenbar und historisch datierbar ist, wird eine temporale Ungenauigkeit erzählstrategisch erzeugt, sodass alle Ereignisse in Hauke Haiens Geschichte in einem historisch unverbindlichen Zeitraum aufzutreten scheinen, wie in einem zeitlosen Märchen. Die erzählte Welt um Hauke Haien erscheint ebenfalls nicht als ein realistisch dargestelltes Dorf, sondern als eine isolierte Welt in einem vergangenen Zeitalter.

Zweitens entspricht die Handlung dem Schema eines Zaubermärchens. Der Schimmelreiter ist ein moderner literarischer Text, durch seine Mehrdeutigkeit dessen Modernität schon gekennzeichnet ist. Je nach Lesart lässt sich der Erzähltext als realistische Novelle mit phantastischen Elementen, als Sage oder Märchentext verstehen, welche als verschiedene Erzählschichten des Erzähltextes erscheint. Wegen der schematischen Charaktere der Handlung erinnert der Erzähltext an die Handlung von Volksmärchen. Es findet sich das folgende märchenhafte Handlungsmuster: Der junge Held zieht aus dem Elternhaus aus und besteht eine oder mehrere Mutproben, wirbt um die Tochter eines Fürsten (Deichgraf), besiegt seine Nebenbuhler und vollendet seine Aufgaben, heiratet schließlich und erhält Reichtum sowie gesellschaftliches Ansehen. In dieser Handlung lässt sich eine Verbindung von Varianten verschiedener Märchentypen: Man and Wild Animals (AaTh 155-199) und The Princess's Hand Is Won (AaTh 850-869) entdecken.

Bei Hauke Haien ist die Reihenfolge dieses Handlungsschemas ein wenig verändert. Als Held der zweiten Binnenerzählung steht er im Zentrum aller Ereignisse und Verhältnisse. Der bedeutungsvolle Zwischenfall, die Tötung des Katers der Trien' Jans, wird als ein Kampf um eine Jagdbeute dargestellt (Motif-Index of Folk-Literature H1360 Tests of Prowess: Quest for dangerous animals). Der Kater, der normalerweise mit Mäuse- und Rattenfang zufrieden ist, zeigt sich als ein großes mächtiges Tier mit nicht zu bändigender Raubgier und einer scharfen Kralle [HKE, 23], also als ein gefährlicher monströser Gegner des jungen Hauke Haien. Die Herrin des Katers ist Trien' Jans, die deutlich Züge einer märchenhaften Hexe trägt. Der „Kampf“ ist nicht nur eine Inszenierung des Konflikts zwischen dem vollkommen allein stehenden Helden und der Natur, sondern weist auf Haukes Bruch mit dem Mütterlichen hin. Denn der Angorakater ist das Einzige, was Trien' Jans Sohn ihr zurückgelassen hat. Das Tier ist für die Mutter der Ersatz für den verstorbenen Sohn. Der Fluch der alten Mutter hat zwar keine Verbindung mit Haukes tragischem Untergang, assoziiert sich aber mit der Vernichtungsdrohung der ,Mutter Natur', wenn man die Märchenbezüge in dem Erzähltext berücksichtigt, weil das Wasser in der germanischen Mythologie oft weiblichmütterliche Bedeutung hat. „Wie sich die Germanen vorstellten, daß die menschlichen Seelen vor ihrer Geburt im Wasser weilten, so nahmen sie auch an, daß sie 
nach dem Tode dorthin zurückkehrten [...]." ${ }^{284}$ Obwohl das Wasser in Die Regentrude durch ein positives Frauenbild immer auch erfrischende Lebenskraft symbolisiert, besitzt es in Der Schimmelreiter nur noch die negative Bedeutung - das Reich des Todes, das immer mit dem abergläubisch Weiblichen verkoppelt ist. In der Märchenschicht ist Hauke schon nach der Mutprobe zum Untergang im Wasser vorbestimmt, hat daher bereits hier einen entscheidenden Schritt getan. „Der Kampf mit dem Tier läßt sich als eine der typischen Mutproben im Rahmen eines Initiationsritus auffassen, durch die Hauke instand gesetzt wird, den Schritt in die gesellschaftliche Öffentlichkeit zu tun. “285

Erst nach der Mutprobe darf Hauke Haien ausziehen, weil die Kate seines Vaters für „zwei Herren“ $[\mathrm{HKE}, 25]$ zu klein ist ${ }^{286}$. Hauke müsse sich einen Dienst besorgen - die Rede des Vaters erinnert den Leser an den Anfang zahlreicher Volksmärchen, zum Beispiel des Märchens von einem, der auszog, das Fürchten zu lernen (KHM Nr. 4): „du wirst groß und stark, du musst auch etwas lernen womit du dein Brot verdienst"[KHM I, 41], so sagt der Vater dem Helden im Märchen. Ebenfalls wie in einem Volksmärchen findet Hauke eine Arbeit als Kleinknecht bei einem Deichgrafen, der „dumm wie 'ne Sattgans“ [HKE, 25] ist und eine junge Tochter hat. „Selbstverständlich“ verliebt sich Hauke Haien in diese Tochter Elke, weil sie sich - auf der realistischen Ebene - als gute Rechner verstehen. In der Märchenschicht des Textes ist seine Liebe zu ihr noch selbstverständlicher, weil der Vater von Elke ein „Graf“ ist und Hauke durch diese Eheschließung zu Ansehen gelangen kann. Zugleich lernt er seinen Gegner und Nebenbuhler Ole Peters kennen. Nach dem individuellen Triumph ${ }^{287}$ in einem Eisboselspiel - ein früher Höhepunkt der Erzählung - besiegt er auch den Nebenbuhler und kauft einen Trauring für Elke. Nach dem Tod des Deichgrafen heiratet Hauke Elke, wird Deichgraf und der reichste Mann im Dorf aufgrund des väterlichen Erbes und der Güter, die Elke von ihrem Vater geerbt hat und ihm vor der Hochzeit übertragen wurden. [HKE, 48] Bis dahin ist die Handlung über Haukes Aufstieg schon märchenhaft genug: Der arme Hauke Haien heiratet eine reiche Frau und wird der angesehenste und reichste Mann in seiner Welt. „Mit der stetig aufsteigenden Entwicklungslinie ist beim Leser eine Erwartungshaltung begründet, die sich auf weitere Erfolge der Hauptgestalt richtet. " 288 Dann beginnt Hauke Haien

\footnotetext{
${ }^{284}$ Beit, zit. nach Fasold 1997, S. 155.

${ }^{285}$ Freund 1984, S. 61.

286 „[Z]wei Herren können darauf nicht sitzen“ [HKE, 25].

287 ,[...E]ine Todesstille war auf beiden Seiten; alle Augen folgten der fliegenden Kugel, man hörte ihr Sausen, wie sie die Luft durchschnitt; plötzlich, schon weit vom Wurfplatz, verdeckten sie die Flügel einer Silbermöve, die ihren Schrei ausstoßend vom Deich herüberkam; zugleich aber hörte man es in der Ferne an die Tonne klatschen. ,Hurrah für Hauke!' riefen die Marschleute und lärmend ging es durch die Menge: ,Hauke! Hauke Haien hat das Spiel gewonnen! “ " [HKE, 37] Hauke ist auch bereit, den Sieg dieses Gruppenspiels an sich zu reißen: „Ihr mögt schon recht haben; ich glaube auch, ich hab’ gewonnen!“' [ebd.]

288 Freund 1984 S. 61.
} 
mit einer neuen Heldentat - dem Deichbau - einem Werk „auf Tod und Leben“ [HKE, 52], so
daß das große Vorland, das unserer Hofstatt gegenüber beginnt und dann nach Westen ausgeht, zu einem festen Kooge eingedeicht werde: die hohen Fluten haben fast ein Menschenalter uns in Ruh gelassen; wenn aber eine von den scblimmen wie- derkommt und den Anwachs stört, so kann mit einem Mal die ganze Herrlichkeit zu Ende sein. [ebd.]

Der Lesererwartung scheint erfüllt zu sein, als Hauke seinen Hauke-Haienkoog errichtet und zu dem beruflichen Erfolg noch ein familiäres Glück - eine Tochter im neunten Ehejahr - feiert. Wie in einem Volksmärchen erscheinen Privates und Berufliches eng miteinander verbunden.

Der Aufbau der Binnenerzählung über Hauke Haien folgt allerdings „einer wohldurchdacht angelegten Erwartungstäuschung “289. Nach dem Höhepunkt lebt er mit seiner Familie nicht vergnügt bis an sein Ende. Er stirbt als ein Scheiternder mit seiner Familie wegen der Unachtsamkeit auf seine Umwelt. Der Held scheitert und somit auch die Vollendung eines Märchens. Die Handlung der Binnenerzählung wird so konstruiert, dass sie sich der typischen Märchenhandlung nähert, dann aber absichtlich davon abweicht.

Drittens ist die Personalkonstellation tendenziell auf den Helden hin konstruiert. Hauke Haien steht nicht nur zweifelfrei im Zentrum der Handlung, er ist auch ein ehrgeiziger und herrschbegieriger Einzelgänger. Obwohl er im Vergleich zu seinen abergläubischen Mitmenschen deutlich aufklärerische Züge trägt, spielt das vormodern Märchenhafte bei ihm eine wichtige Rolle. Mit Max Lüthis Kategorien gesprochen gilt diese Figur als ,isoliert' und ,allverbunden'. ${ }^{6} 290$ Schon als Kind fällt er durch seine Intelligenz und Ungeselligkeit unter Schulkameraden auf. Bei ihm ist keine persönliche Entwicklung zu finden. Er „entwickelt [sich] zu dem, was er von Anfang an ist ${ }^{\text {‘291 }}$. Die anderen Figuren sind zwar nicht wie im Volksmärchen namenlos, beziehen sich aber alle auf Hauke Haien. Sie zeichnen sich als Haukes Vater, Frau, Nebenbuhler, Arbeitgeber und Unterstellte aus. Besonders nachdem Hauke seine Pläne für den Deichbau entworfen hat, ist die ganze Dorfgemeinschaft unterteilt in Haukes Unterstützer und Gegner, wobei die Feindseligkeit des Hauptgegners Haukes Ole Peters unter anderem mit dessen Eifersucht auf Haukes privaten und beruflichen Erfolg verknüpft ist. Der erzählende Schulmeister scheint seine Figurenkonstellation in Form eines Einzelhelden und dessen Mitmenschen aufgebaut zu haben.

Schließlich ist die Binnenerzählung des Schulmeisters erzähltechnisch wie ein Märchen in verschiedene Episoden gestaltet. Während seiner Erzählung unterbricht sich der Schulmeister viermal, so dass diese grob wie ein Drama mit fünf

\footnotetext{
289 Freund 1984, S. 62.

290 Lüthi 2005, S. 49.

291 Hermand 1969, S. 256.
} 
Akten strukturiert wird: die Einführung von Hauke Haiens tüchtiger und mathematisch begabter Persönlichkeit, seine Jugend im väterlichen Haus, seine Dienstzeit beim alten Deichgrafen, Haukes erste Jahre als Deichgraf und schließlich die Deicharbeit, die zu Haukes tragischem Ende führt. Die jeweiligen Episoden in Haukes Leben (zum Beispiel der Kampf mit dem Kater, das Eisboselspiel und der Kauf des Schimmels) sind zwar nicht wie im Märchen isoliert, bilden aber zusammen eine klar bestimmbare und lineare Struktur.

Die Annahme liegt nahe, dass der Schulmeister versucht, Hauke Haiens Biographie auf eine märchenhafte Weise zu stilisieren, zum einen, weil dieser Erzählstil am praktischsten für seine mündliche Übertragung ist, zum anderen, weil er (beziehungsweise der Autor) durch die absichtliche Annährung und Abweichung vom Märchen die Märchenbezüge seines Textes klarmachen möchte, sodass sein Zuhörer (beziehungsweise der Leser) merkt, Hauke Haiens Geschichte sei ein gescheitertes Märchen.

\subsection{Der Schimmelreiter und romantische Kunstmärchen}

Theodor Storm war „ein romantischer Realist oder ein realistischer Romantiker“292. Die erzählten Welten in seinen Novellen sind häufig zweideutig: Sie lassen sich sowohl aus einer realistischen als auch von einer phantastischen Perspektive her betrachten. Storm lebte im Zeitalter der Realisten, aber in der wehmütigen, mysteriösen und manchmal brutalen romantischen Welt fühlte Storm sich vertraut, weil die Geschichten, die er als Kind bei Lena Wies, einer Schwester seines Kindermädchens, gehört hatte, faszinierend und spukhaft waren. „In ihren Geschichten schwebte er zwischen Schauder und Behagen, es war gemütlich und ungemütlich, am Ende der Geschichten waren viele offene Fragen, mehr Wachheit als Müdigkeit und eine Portion Angst vor Spuk und Gespenstern, die ihn verfolgten. "293 Die Spätromantiker Heinrich Heine und Joseph von Eichendorff gehörten zu Storms Lieblingsdichtern. Besonders Eichendorffs Dichtung mit ihrer Heimwehstimmung fand einen Nachklang in Storms Heimatdichtung.

Wie es bei den Romantikern der Fall ist, ergänzt sich das Leben Storms durch seine Dichtung. Die Regentrude, die Storm 1863/64 im Krankenbett verfasste, diente beispielsweise als Zufluchtsstätte für den Dichter: „Es ist, als müsste ich zur Erholung von der unerbittlichen Wirklichkeit ins äußerste Reich der Phantasie flüchten." 294

Der Schimmelreiter galt zur Zeit seiner Veröffentlichung schon als nicht mehr zeitgemäßes Werk. Paul Heyse lobte diese Novelle in einem Brief vom 02. Mai

\footnotetext{
292 Detering/Spreckelsen/Demandt 2014, S. 6.

293 Missfeldt 2014, S. 37. Später glaubte Storm fälschlicherweise, dass Lena Wies ihm auch „die Sage von dem gespenstischen Schimmelreiter" erzählt habe. [LL 4, 179]

294 Brief an die Eltern am 29. 12. 1863. LL 4, 620.
} 
1888: „Dann ist es ja auch ganz gedeihlich, daß einer aus der alten Schule einmal wieder etwas geleistet hat, was den Besten das Herz bewegt." Die Ansicht dieser nostalgischen Bemerkung teilte Storm, da er sie in einem Brief vom 09. Mai 1888 an Ferdinand Tönnies noch zitierte. ${ }^{295}$ Es ist eine romantische Wehmut im Text, die nach dem längst Vergangenen greift. In einer realistischen Welt, deren Weltansicht eine Vermischung der Aufklärung und des Aberglaubens ist, schwebt das Phantastische unschlüssig in der Luft, was an die Märchenerzählungen von E. T. A. Hoffmann erinnert.

In Der Schimmelreiter sind zahlreiche romantische Motive und poetische Grundfiguren verborgen. Die Natur als Ort der Phantasie hat die Novelle mit dem Werk Ludwig Tiecks, Joseph von Eichendorffs und Wilhelm Hauffs gemeinsam. Wie Der blonde Eckbert und mehrere andere Texte der „kranken“ Romantik (besonders des „letzten Romantikers“ Richard Wagner), ist die Novelle eine Verfallsgeschichte. Die wenig erotische Beziehung zwischen Hauke Haien und Elke erscheint wegen der beiderseitigen mathematischen Begabung geschwisterlich. Diese gewissermaßen „inzestöse“ Ehe könnte die neun kinderlosen Ehejahre und die Geburt des schwachsinnigen Kindes als Strafe erklären, wobei die inzestöse Liebe ein Hauptmotiv vieler romantischer Texte (Der blonde Eckbert, Die Elixiere des Tenfels, Der Ring des Nibelungen) ist. Auch die Tätigkeit des Erzählens gehört zu den zentralen Motiven der Romantik.

Im Folgenden behandelt dieses Kapitel die poetischen Grundfiguren, die Storm von den Romantikern erlernt hatte und die zur Konstruktion der Textstruktur des Schimmelreiter beitragen.

\subsubsection{Die romantische Reflexion}

Wie oben erwähnt, wirkt die „ranke“ [HKE, 26] Elke mit einem etwas hageren Arm äußerlich und innerlich geschwisterlich im Verhältnis zu dem hageren Hauke. Die beiden sind ungefähr gleich alt. Er gilt nicht als eine männliche Schönheit ${ }^{296}$ und sie fällt auch mehr durch ihre Intelligenz und Abstammung als durch ihre körperliche Schönheit auf. ${ }^{297}$ Die beiden haben starke Charaktere, sind „beide angeborene Rechner“ [HKE, 29] und müssen beide „in wirklichkeitsbezogener Tätigkeit aufgehen“"298. Die beiden lieben sich als Geliebte und „ebenbürtige Part-

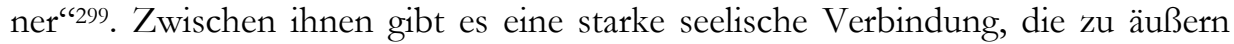
keine sprachliche Liebeserklärung notwendig ist. Ein Handdruck [HKE, 33] oder ein Lächeln [HKE, 45] reicht aus. Elke ist die treueste Unterstützerin von Haukes

\footnotetext{
295 Vgl. Cowen 1985, S. 306.

${ }^{296}$ Dazu hat Louise Forssell eine genauere Untersuchung verfasst. Vgl. Forssell 2006, S. 190 - 193.

${ }^{297}$ Anders als die früheren Heldinnen in Storms Novellen ist die weibliche Weichheit und Schönheit Elkes stark abgeschwächt. Nur einmal wurden ihre „hübschen Mädchenlippen“ [LL 3, 686] als ein Kompliment des Pastors gepriesen.

298 Amlinger 1989, S. 69.

299 Amlinger 1989, S. 69.
} 
Plänen. Sie teilt seit der Eheschließung sein Schicksal. Nach der Geburt liegt Elke im hellen Kindbettfieber und redet irre. Aus ihren Phantasien schreit die Kranke vorhersagend: „Wasser! Das Wasser! [...] Halt mich! [...] In See, ins Haf hinaus? O lieber Gott, ich seh ihn nimmer wieder!“ [HKE, 67] Diese im Wahn gesprochenen Worte deuten sowohl auf ihr eigenes als auch auf Haukes Schicksal voraus, denn die beiden verbinden sich. Elkes Fieber wiederholt sich später in dem Marschfieber des Deichgrafen. Hauke Haien wird ebenfalls so schwer krank, dass er „kaum derselbe Mann“ [HKE, 80] zu sein scheint und körperlich sowie geistig ermattet.

Bevor Hauke in der tödlichen Sturmflut zum Deich reitet, ergreift er Elkes Hände und

drückte sie wie im Krampfe in die seinen: „Das muß ich, Elke."

Sie erhob langsam ibre dunklen Augen zu ihm, und ein paar Sekunden lang sahen sie sich an; doch war's wie eine Ewigkeit. „Ja, Hauke", sagte das Weib; ,ich weiß es wohl, du mußt!" $[\ldots]$

„Das ist unser Kampf!“ sprach Hauke. [HKE, 88, Hervorhebung im Original]

Mit einem Blick verstehen sie sich. Elke akzeptiert Haukes Schicksal als gemeinsames. Die Ehefrau ist wörtlich seine Mitleidende. Seit der Heirat sind alle Leiden des Deichgrafen in ihr reflektiert und die ihren umgekehrt in Hauke. In diesem Sinne ist die Figur Elke eine weibliche Widerspiegelung Hauke Haiens.

Ist der Schulmeister eine zweite Widerspiegelung Hauke Haiens? Nach seiner Erzählung zeigt er dem Zuhörer sein Mitleid mit dem Deichgrafen. Identifiziert er sich deswegen mit dem aufklärerischen Deichgrafen?

Der Schulmeister ist ein ernst zu nehmendes Individuum mit Bedeutung für den ganzen Text, nicht nur für die Rahmenerzählung. Die Parallelität zwischen dem Schulmeister und Hauke Haien ist auffällig. Hauke ist ein Einzelgänger mit aufgeklärter Mentalität, der mit einem Werk Spuren hinterlassen will. Der Schulmeister steht als „Aufklärer“ ebenfalls außerhalb der Gemeinde. Die beiden Figuren haben also Gemeinsamkeiten in Bezug auf die Aufgeklärtheit und Einsamkeit. Doch erkennt der Schulmeister nicht alle Tätigkeiten und Eigenschaften von Hauke Haien an. Schon am Anfang seiner Erzählung bestimmt er die geistige Leistung des Deichgrafen in einer nüchternen Art. Hauke Haien versteht von Deich- und Sielsachen nur mehr, ,als Bauern und Hofbesitzer sonst zu verstehen pflegen; aber es reichte doch wohl kaum; denn was die studierten Fachleute darüber niedergeschrieben, davon hatte er wenig gelesen; sein Wissen hatte er sich, wenn auch von Kinderbeinen an, nur selber ausgesonnen" [HKE, 17]. Der Schulmeister andererseits hat studiert. Der neue Deichgraf achtet den Schulmeister als einen Lehrer: „[U]nser Schulmeister hat Ihnen wohl schön was weis gemacht." [HKE, 95] Haukes unsozialen Aktivismus kritisiert er als ehrgeizig und 
egozentrisch. ${ }^{300}$ Dass der Schulmeister Hauke Haien mit Sokrates und Christus, die geistigen Lehrer und Wegbereiter der Menschheit, die sich für ihre Mitmenschen aufopferten und Hauke Haien an Geist und sozialem Verhalten deutlich überlegen waren, vergleicht, bedeutet keine Überschätzung von Haukes Persönlichkeit. Der Schulmeister ist Pädagoge. Er erzählt die Geschichte von einem Scheiternden und lässt die Zuhörer selbst „die Spreu vom Weizen sondern“ [HKE, 17]. Er will die Zuhörer durch Haukes Tragödie vor der Gefahr von Voreingenommenheit und Einseitigkeit warnen: „[E]inen Gewaltsmenschen oder einen bösen stiernackigen Pfaffen zum Heiligen, oder einen tüchtigen Kerl, nur weil er uns um Kopfeslänge überwachsen war, zum Spuk und Nachtgespenst zu machen - das geht noch alle Tage." [HKE, 95] Die Gemeinde verkennt Hauke Haiens Leistung für das Dorf, während Hauke aus Selbstsucht die wichtige Bedeutung der Umwelt verkennt. Der Schulmeister richtet hier nach Storms Prinzip der „Verbergung, Auslassung und Andeutung“, um dem Zuhörer einen „kreativgenerativen Impuls des Punktuellen, Einzelnen und Erscheinenden“ zu geben. ${ }^{301}$

Im ursprünglichen Schluss der Novelle gibt der Schulmeister nach seiner Erzählung noch eine vernünftige Erklärung für die Erscheinung des Schimmelreiters auf dem Deich:

„Sie wollen einwenden, Sie haben ibn selbst gesehen! Was Sie gesehen haben, weiß ich nicht: es könnte auch ein Leibhaftiger, das heißt, ein Mensch gewesen sein; dort draußen auf dem Sophienhof, der Besitzer hat einen Bruder bei sich, einen alten wunderlichen Junggesellen; die Leute halten ihn für einen Narren, er selbst treibt Astronomie und bält sich für einen großen Wetterkundigen. Der hat ein hageres Angesicht und ein paar tiefliegende Augen und reitet am liebsten im fliegenden Sturm auf den Deichen bin und wieder; ob er einen Schimmel hat, weiß ich nicht zu sagen; unmöglich ist das nicht. Aber - einerlei, mag reiten wer da will, nur den Deichgraf Hauke Haien laßt mir aus dem Spiel; der hat wie kaum ein Andrer seine Rub' verdient!" [HKE, 378]

Storm strich diese Stelle in seiner letzten Korrekturarbeit, „weil sie zu sehr aus der Stimmung fiel“"302. Wäre diese Stelle beibehalten worden, würden die Leser den Eindruck bekommen, der Schulmeister wolle den Ich-Erzähler der Rahmenerzählung auf eine aufgeklärt-entmystifizierende Sichtweise hinlenken. Was von der Erzählweise des Schulmeisters ausgeht, ist ein „Impuls, sich mit der menschlichen Erkenntnissituation und seinem moralischen Verhalten kritisch auseinanderzusetzen." “303

\footnotetext{
300 Als die Arbeiter versuchten, den neuen Koog zugunsten des Alten durchzustechen, stieg der Zorn Hauke Haien in die Augen: „Kennt Ihr mich? [...] Wo ich bin, hat Ole Peters nichts zu ordinieren! Fort mit Euch! An Euere Plätze, wo ich Euch hingestellt!“ [HKE, 91] Der diktatorische Befehl an die Mitmenschen ist ein eindeutiger Ausdruck von den negativen Seiten von Haukes Persönlichkeit.

301 Aust 2006, S. 237.

302 An Paetel am 03. 03. 1888.

303 Freund 1984, S. 66.
} 
Die Erzählung des Schulmeisters ist für sich schon als Kunstwerk zu betrachten. Er erzählt die historischen Tatsachen nach den Überlieferungen, aber Hauke Haiens Monologe, Gedanken und sonstige unsichtbare Szenen können nicht überliefert werden. Diese müssen als Erfindung des Schulmeisters gelten. Er hat die Fakten kreativ bearbeitet. Indem der Schulmeister ein Kunstwerk (die zweite Binnenerzählung) schafft und den Zuhörer (den Leser) erzieht, wird der Schulmeister zum Stellvertreter des Autors. Der Heimatdichter Storm entnahm immer poetisches Material aus seiner eigenen Biographie. In seinem gesamten Werk gibt es stets ein einziges Vorbild: sich selbst. Der Schulmeister ist ein alter ego Storms. Denn auch Storm verstand sich immer als einen Poeten, der zu den poetischen Realisten gehörte. Die poetischen Realisten sahen die Aufgaben des Dichters und ihres Werkes darin, eine Synthese zwischen der Wirklichkeitsnachbildung und idealisierenden Überhöhung anzustreben ${ }^{304}$ und „,den Leser zu erheben und mit der Welt zu versöhnen, indem sie die Wirklichkeit im Lichte einer höheren Wahrheit verklär[ten]“.305 Storm zeigt seinen Lesern die Gegenüberstellung des Ideals mit der herben Wirklichkeit. Es war sein Ziel, seine Leser „in einer herben Nachdenklichkeit über die Dinge [des] Lebens zurückzulassen“.306

Storm hat „Geschichten geschrieben, die nur ein einziges Motiv behandeln: das der gescheiterten Liebe und des gescheiterten Lebens“"307. Dies ist auch das Motiv des Schulmeisters. Wie der Schulmeister vorgestellt wird, ist auffällig:

Abseits hinter dem Ofen, ein wenig gebückt, saß ein kleiner hagerer Mann in einem
abgeschabten schwarzen Röcklein; die eine Schulter schien ein wenig ausgewachsen.
[...S]eine bei dem spärlichen grauen Hauptharr noch immer mit dunklen Wimpern
besäumten Augen zeigten deutlich, daß er nicht zum Schlaf hier sitze. [...]
„Sie sehen wohl“, raunte der Deichgraf mir ins Obr; ,er ist immer noch ein wenig
bochmütig; er hat in seiner Jugend einmal Theologie studiert und ist nur einer verfehl-
ten Brautschaft wegen hier in seiner Heimat als Schulmeister behangen geblieben."
[HKE, 16f]

Einen grauen unbeweglichen Gelehrten mit scharfen Augen, der zum Erzählen eingeladen wird, findet man bereits in der Novelle Ein Bekenntnis, die 1886/87 parallel zu Der Schimmelreiter verfasst wurde. Es ist die Hauptfigur jener Novelle, Franz Jebe. Wenn man zurückblickt, tritt eine ähnliche Figur in Storms erstem Meisterwerk Immensee auf, nämlich der gealterte Reinhard. Er erscheint in seiner Stadt „fast [wie] ein Fremder“ [LL 2, 295]. Nach der gescheiterten Liebesgeschichte vertieft er sich einsam in seine Studien. Wenn man die beiden Novellen vergleicht, erhält man den Eindruck, dass der Schulmeister ein alter ego Reinhards ist. Während Hauke Haien und Elke Volkerts mit ihrer Charakterstärke und persönli-

\footnotetext{
304 Aust 2006, S. 24.

305 Lohmeier 2012, S. 103.

306 Zitat aus Storms Brief an Erich Schmidt im September 1881. Zit. nach Lohmeier 2012, S. $103 f$.

307 Missfeldt 2014, S. 130.
} 
cher Reife dem schwachen und romantisch gesinnten Reinhard gegenüberstehen, schuf Storm mit dem Schulmeister ein Nachbild seiner früheren Helden und reflektierte dadurch seine sämtlichen Novellen mithilfe seiner letzten. Aus der Sicht der früheren romantisch gesinnten Helden wird die Geschichte eines neuen vorwärtsstrebenden Helden erzählt. Durch den Schulmeister, der immer wieder Bemerkungen zu seiner Erzählung und der erzählten Hauptfigur macht, vollendete Theodor Storm sein Gesamtwerk nicht zuletzt durch die romantische Selbstreflexion zu dieser Novelle. Mit Der Schimmelreiter ist die gesamte Dichtung Storms abgeschlossen.

Schließlich reflektieren sich das Erzählen und das Erzählte gegenseitig. „Wenn die novellistische Erzählsituation im Deich ihren Repräsentanten findet, dann lässt sich umgekehrt die Geschichte des Deichbaus als eine Spiegelung über die Verfertigung des Textes, als eine Werktheorie, verstehen.“308 Der Erzählakt und der Deichbau sind miteinander verschränkt, denn während das Erzählen den Deichbau zum Gegenstand hat, wird das Erzählen von der Existenz des Deichs gesichert. Die Binnenerzählung des Schulmeisters und die Rahmenerzählung des Reiters vereinigen sich durch den Deich, weil die Geschichte vom Schimmelreiter nur so lange erzählt wird, wie auch der Deich hält. ${ }^{309}$ Dementsprechend gefährden die Risse, die den Durchbruch des Deichs androhen, auch das Erzählen. Als der Deich überprüft werden muss, wird das Erzählen unterbrochen [HKE, 43]. Als die Zuhörer zur Rettung des Deichs hinausgehen, wird die Überlieferung der Deichgeschichte bedroht. Ob der Deich erhalten werden kann und ob die Erzählung weiterhin überliefert werden kann, diese Sorge trägt ein Gespenst, das zugleich Gegenstand der Erzählung ist. Auf diese Weise bilden die Binnenerzählung und ihr Gegenstand eine abgeschlossene Einheit.

Der Ich-Erzähler des inneren Erzählrahmens ist in den äußeren Erzählrahmen zurückgetreten. „Es handelt sich demnach um eine körperlose Stimme, die einem Subjekt zugeordnet wird, von dem man nicht mit Sicherheit sagen kann, dass es wirklich anwesend ist [...].“310 Der äußere Erzählrahmen seinerseits ist ebenfalls ein instabiler Rahmen, weil der erinnernde Ich-Erzähler nach der Erinnerung nicht wieder auftaucht, sodass der äußere Rahmen unverortet in der Leere schwebt. Die beiden Rahmenerzähler sind ,Gespenster' und die beiden Rahmenerzählungen sind somit bodenlos, weshalb die geschlossene Binnenerzählung vom Deichbau und Deichgrafen sich gespensterhaft von der realen Welt isolieren muss und märchenhaft erscheint.

\footnotetext{
308 Theisohn 2008, S. 105. Hervorhebung im Original.

${ }^{309}$ Vgl. Theisohn 2008, S. 105.

310 Theisohn 2008, S. 109.
} 


\subsubsection{Der Schimmelreiter und die neue Mythologie der Romantik}

Ein Mythos zielt auf eine Erklärung des Unbekannten ab. Er will „berichten, nennen, den Ursprung sagen: damit aber darstellen, festhalten, erklären“"311. In einem Mythos wird das große Chaos einer fremden Welt durch sprachliche Symbole und menschliche Imagination festgehalten und ersetzt. Die Mythologie ,ist die Welt und gleichsam der Boden, worin allein die Gewächse der Kunst aufblühen und bestehen können".312 Als eine Poesie des Universums ist sie für die Romantiker besonders wichtig. Da es nicht mehr möglich ist, den Kosmos der antiken Mythologie in die moderne Poesie zu übertragen, fordern die Romantiker eine Neue Mythologie, eine Mythologie des Individuums. Denn „das allgemeine Element des Modernen [ist] die Originalität". 313 Das Ziel der Romantiker war es, eine moderne Literatur in mythischer Gestalt zu konstruieren, anstatt die antiken Mythen einfach zu restituieren. ${ }^{314}$ Anders als die aus der anthropomorphen Naturerklärung herauswachsende alte Mythologie soll die Neue Mythologie künstlich sein. Sie soll nämlich die Welt und gleichsam der Boden der neueren Poesie werden. Es ist die ästhetische Form, die für die Neue Mythologie entscheidend ist. Friedrich Schlegels Entwurf einer Neuen Mythologie ist eine

semiotische Intensität der Verbindung bildhafter und ideeller Elemente zu einem allegorischen Zeichengefüge, in dem alle Zeichen in einem Verhältnis der Verwandlung und Verschiebung zueinander stehen und zunächst einer selbstreferentielle Funktion gehorchen, bevor sie insgesamt wieder auf Welt abbildbar sind. ${ }^{315}$

Ein Mythos soll - gleich dem Theater - das kollektiv Gültige dem Volk darstellen.

Die Binnenerzählung in Der Schimmelreiter über den Deichgrafen ist eine Erzählung, die eine mit dem Mythos vergleichbare Funktion hat, weil sie sich darauf bezieht, geheimnisvolle Erscheinungen zu erklären und die Angst des Zuhörers zu beseitigen.

Doch ist diese Erzählung keine Volkserzählung. Die mündliche Wiedergabe der Geschichte des Deichgrafen ist nicht aus dem Volksglauben hervorgegangen, sondern ein von sozialen Konventionen abhängendes Konstrukt mit eingewobenen volkstümlichen Vorstellungen. In dieser komplizierten Binnenerzählung verbinden sich ein realistisches und ein mythisches Erzählen. Das realistische Erzählen basiert auf den überlieferten Fakten, während das mythische Erzählen ein Prozess der Mythenabbildung durch die Gemeinde ist. In ihm sind die phantastischen Elemente wie der geheimnisvolle Schimmel, der ungewöhnliche Tod des Deichgrafen und der Schimmelreiter auf dem Deich - ganz im Gegensatz zu ihrer Bedeutung im realistischen Erzählen - keine Zufälle. Stattdessen sollen sie, wie die

\footnotetext{
311 Horkheimer/Adorno 1988, S. 14.

312 Schelling II, S. 233 f.

313 ebd. S. 275.

314 Kremer 2007, S. 111.

315 Kremer 2007, S. 113.
} 
kleinen Motive mit märchenhaften Bezügen, eine kausale Verbindung mit der Lebensgeschichte Hauke Haiens haben. Das abergläubische und mythische Gedenken der Dorfgemeinde zielt in der Tat darauf, Zusammenhänge zu finden. Was die Gemeinde nicht begreifen kann, erklärt sie nach der vertrauten Ordnung und den überlieferten Formen. Indem die Gemeinde mit dem Meer durch das Menschenopfer eine Art Tauschgeschäft anschließt, kommuniziert sie mit der Natur und besänftigt ihre dunklen Kräfte. Indem die Gemeinde Hauke Haiens raschen Aufstieg als das Ergebnis eines Teufelspaktes versteht, macht sie seinen unverständlichen Ehrgeiz verständlich für sich. Entsprechende sieht sie in dem Tod des Deichgrafen in einer „Sintflut" eine Vorbestimmtheit und Notwendigkeit aufgrund seiner Versündigung. Auf diese Weise bannt man das Unbekannte im Mythos. Solange der Mythos erzählt wird, gilt Hauke Haien so gut wie das wilde und chaotische Meer als Bedrohung und als ein Außenseiter für die Gemeinde. In diesem Mythos wird Hauke Haiens Wesen mithilfe der Tradition vom Teufelspakt erklärt und ersetzt. Dementsprechend musste seine Persönlichkeit zu einer hageren Gestalt auf einem Schimmel geschmälert werden - zu einem Symbol für diese Gemeinde.

Die mythischen Vorstellungen des Volkes sind nicht nur in die Erzählung des Schulmeisters eingewoben, sondern werden auch durch diese reflektiert. Die mündliche Erzählung des Schulmeisters ist ein höchst artifizielles Kunstwerk und das Ergebnis einer Selektion von Materialien. Doch dient die mythischabergläubische Ansicht vom Kampf des Menschen mit der Natur als Grundlage der ganzen Erzählung. Auf dieser Grundlage bilden mehrere mythische Symbole das dämonische Meer, der Kater einer hexenhaften alten Frau, der teuflische Schimmel etc. - mit ihren konventionellen Bedeutungen eine mythische Tiefenstruktur für die realistische Erzählung und machen deren Welt zweideutig. Dadurch werden dem Schimmelreiter auf dem Deich am Ende der Erzählung zwei Deutungsschichten zugeordnet: In der realistischen Schicht steht dort das scheiternde Individuum vor seinem Tod, das seine Fehler büßen will, während in der mythischen Schicht der Deichgraf bereit ist, sein Leben mit der Naturkraft gegen die Erhaltung des Deiches zu tauschen. Eine in sich stimmige und vollständige mythische Geschichte lässt sich als selbständiger Bestandteil aus der Erzählung des Schulmeisters entnehmen.

Als Außenseiter in der Gemeinde erzählt der Schulmeister seine Erzählung ihr und einem Fremden. Zugleich spricht er für die Gemeinde, weil er nach Meinung des neuen Deichgrafen ,,von uns hier Ihnen das am besten erzählen [könne] “ [LL 3, 638] Er versteht besser als das Volk zu erzählen. In seiner Erzählung verbinden sich die Kollektivität und die Individualität. Das Volk (die Gemeinde) ist sowohl Gegenstand als auch zunächst Publikum seiner Erzählung. Eine romantische Utopie, in der das Volk als „Ort des Kunstwerks“316 sich selbst mithilfe eines

316 Schleiermacher, zit. nach Kremer 2007, S. 113. 
eigenen lebendigen Mythos erziehen will, wird jedoch wegen der fehlenden Verbindung mit dem Volk nicht realisiert. Theodor Storm wollte keine romantische Utopie schaffen, in der das Volk sich selbst mithilfe der eigenen Poesie erzieht. Der zweite Teil seiner Binnenerzählung hat nur noch einen individuellen Adressaten - wie die Binnenerzählungen in seinen früheren Novellen. In der Giebelstube wird „ein Vertrauensverhältnis zwischen Erzähler und Publikum“317 aufgrund „eingestandener begrenzt subjektiver Perspektive“318 hergestellt. Ein bloß sachlich berichtendes Erzählverfahren tritt zugunsten eines analytischen Erzählverfahrens zurück. Dementsprechend tritt die historische Wahrheit über Hauke Haien hinter die didaktische Absicht des Schulmeisters zurück.

\subsection{Das Scheitern eines Märchens}

,[A]lles poetische muss mährchenhaft seyn“ [N II, 691], deklarierte der Romantiker Novalis. Gleich dem Misslingen der romantischen Utopie in Der Schimmelreiter muss das Märchenhafte in diesem Text allerdings auch scheitern.

Jost Hermand und Winfried Freund haben jeweils ein Porträt Hauke Haiens in ihren Untersuchungen gezeichnet. Die beiden Forscher sehen in ihm einen gründerzeitlichen ,Übermenschen`, ein Phänomen aus der Zeit des Dichters. Während das Bürgertum versagte, gelang es dem großen Einzelnen in den siebziger Jahren des 19. Jahrhunderts, einen vereinigten Staat zu begründen.

Ideologisch gesehen, ergab sich daraus eine allgemeine Wendung zum Genie, meist in Form cäsarischer Gewaltnaturen oder Übermenschen, wäbrend Worte wie "Menge" oder „Masse" eine auffällige Bedeutungsverscblecbterung erfubren. ${ }^{319}$

Der Emporkömmling Hauke Haien ist für die beiden Forscher ein Vertreter der zeitgenössischen Ideologie. Hauke lebt zu einer Zeit der gesellschaftlichen Wandlung. Das persönliche Schicksal ist nicht nur durch die angeborene Herkunft, sondern auch durch die individuelle Stärke bestimmt. Hauke hat wie viele Märchenhelden eine niedrige Herkunft. Anders als die nicht psychologisierten Helden ist er aber durch sein herkunftsbezogenes Minderwertigkeitsgefühl gekennzeichnet. Er beharrt zu sehr auf der eigenen Leistung und will seine Überlegenheit demonstrieren. Andererseits ist Hauke Haien kein alleinherrschendes Genie. Obwohl er „,von Jugend auf auf das männliche Prinzip reduziert erscheint" ${ }^{\text {“320 }}$, ist er kein Patriarch. Aufgrund seiner warmen Fürsorge für seine schwachsinnige Tochter sowie seiner gleichberechtigen Beziehung zu seiner Frau steht er vielmehr für kleinbürgerlichen

\footnotetext{
317 Aust 2006, S. 239.

318 Aust 2006, S. 239.

${ }^{319}$ Hermand 1969, S. 251.

${ }^{320}$ Freund 1984, S. 72. Im Gegensatz zu der romantischen Auffassung der Frau breitete sich die Vorliebe für männliche Macht in der Gründerzeit aus, was zugleich eine Ausbreitung von einer allgemeinen Sucht nach Krieg und Herrschaft sein konnte, deren Gefahr Storm schon ahnte.
} 
Familienmenschen. In ihm liegt eine Mischung zwischen dem gründerzeitlichen Übermenschen und Revolutionär nach dem großen Vorbild von Bismarck einerseits und dem Bürger, der sich nur auf die eigene Familie verlässt andererseits. Mit dieser Figur setzte sich Storm kritisch mit dem Übermenschen auseinander, weil ein Übermensch ,in Form cäsarischer Gewaltnaturen“321 nur ein mythisches Bild ist. In der Novelle soll eine Figur als Individuum mit menschlichen Schwächen gezeigt werden. Ein potenzieller Wohltäter kann wegen Geltungssucht zum gesellschaftlichen Schädling werden.

Zugleich ist Hauke Haien auch eine überzeitliche Gestalt. Sein fast frevelhafter Größenwahn besitzt nämlich eine überzeitliche Dimension. Denn die Geschichte eines Menschen, „der das Heldische in das bürgerliche Arbeits- und Willensethos,

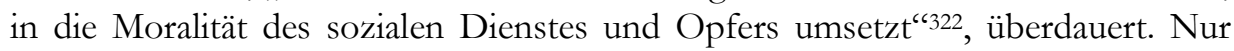
deswegen kann der Schulmeister diese Geschichte als einen lehrhaften Mythos erzählen und der Reiter kann seine Erzählung „beschlafen“ [HKE, 95].

Wenn man die Geschichte von Hauke Haien als einen märchenhaften Text liest, entdeckt man weitere Märchenbezüge in seiner Persönlichkeit. Er entwickelt sich nicht und lebt mit seiner Familie, die ihn widerspiegelt, als eine geschlossene Einheit, die sich von der Gemeinde distanziert. Besonders nachdem er den geheimnisvollen Schimmel gekauft hat, ist er auf seinem Pferd höher als die anderen und erhebt sich somit über das Wirkliche, was ihn, der eigentlich ein Erneuer und Wohltäter sein soll, zu einem märchenhaften Alleinherrscher und Repräsentanten der alten herrschaftlichen Ordnung macht. Dieses Verkommen trotz des topografischen Erhebens verläuft parallel zu Peter Munks Verderben in dem spätromantischen Märchen Das kalte Herz von Wilhelm Hauff. Als eine Märchenfigur kämpft er stetig: anfangs gegen den großen Angorakater, dann gegen das Meer, gegen die abergläubische Gemeinde und schließlich gegen das egozentrische Ich. In Wahrheit hat er nur einen Feind: die elementare, widervernünftige Dämonie der Naturgewalten. ${ }^{323}$ Gleich vielen Märchenhelden kämpft Hauke nicht um das gemeinsame Wohl der Mitmenschen, sondern vielmehr aus egozentrischen Gründen. ${ }^{324}$ Jeder Kampf erscheint als eine Episode in seinem Lebensmärchen, während der Deichbau die letzte und wichtigste Aufgabe für ihn ist. Ohne Rücksicht auf die

\footnotetext{
${ }^{321}$ Hermand 1969, S. 251.

322 Martini, zit. nach Cowen 1985, S. 316.

${ }^{323}$ Loeb 1963, S. 125. Die überdimensionale Macht des Irrationalen, des Abgründigen und Daseinsbedrohenden zeigt sich auch in dem Größenwahn von Hauke Haien, obwohl eine eigene Willensdämonie, ,die sich an der klaren Überlegenheit seines Geistes und der visionären Kraft des Bildes entzündet, dessen Konturen ihm unverrückbar vor Augen stehen“ (Loeb 1963, S. 143), wenn diese mit vernunftbestimmter Ausrichtung bestimmt ist, nicht teuflisch ist. Denn der Mensch tritt somit in die Sphäre des Individuellen.

324 „Aber Hauke wollte seine Beute - es mag ein Eisvogel gewesen sein - diesmal nicht hergeben und kehrte sich nicht an die Gier des Tieres.“ [HKE, 22] „,Es muß gehen!“ sprach er bei sich selbst. ,Sieben Jahr im Amt; sie sollen nicht mehr sagen, daß ich nur Deichgraf bin von meines Weibes wegen!““ [HKE, 50]
} 
Gemeinde arbeitet Hauke Haien als Einzelkämpfer und Außenstehender, obwohl der Deichbau ein gemeinsames Unternehmen der Gemeinde ist. Diese letzte Aufgabe vollendet Hauke zwar, aber als Mensch muss er scheitern. Er vertreibt bei der Sturmflut die Arbeiter, die den neuen Deich durchstechen wollen, „damit der alte Deich nicht bricht“ [HKE, 91], und bewahrt den Hauke-Haienkoog. Er opfert das Heimatdorf und Menschenleben zugunsten des eigenen Werkes, weshalb die Gemeinde ihn als den Schimmelreiter symbolhaft bannen muss. Die Stimmen der Mitmenschen und damit die Vielfältigkeit seiner Welt berücksichtigt Hauke Haien nicht, was zu seinem späteren Scheitern führt und ihm Züge eines Märchenhelden verleiht. Das Märchenhafte in der Persönlichkeit Hauke Haiens erscheint als etwas Vormodernes und Asoziales. Der Egoismus verhindert Hauke Haiens Humanisierung. Er ist ins Märchen und in sein eigenes Werk verbannt.

Ein Märchen ist zeitlos, kennt weder eine historische Kontinuität noch einen konkreten Gesellschaftsbezug. Das 18. Jahrhundert ist allerdings schon nicht mehr das Zeitalter von Einzelgängern. Es ist vielmehr eine Zeit des Wandels der Alleinherrschaft zu Humanisierung und Demokratie. Eine Synthese von individueller Stärke und gesellschaftlicher Bezogenheit muss gefunden werden, aber der durch die Liebe ausgewogene Mittelweg zwischen Aufklärung und dem ursprünglichen Zustand in Die Regentrude ist in diesem Zeitalter schon nicht mehr möglich. Ein individuelles Werk muss sich sowohl in die sozialen als auch in die historischen Kontexte einpassen. Hauke Haiens neuer Deich ist aber keine Weiterentwicklung des alten Deichs und der Tradition. Der Deichbruch ereignet sich dort, „wo der neue [Deich] auf den alten stieß“ [HKE, 91], was die Ursache der Katastrophe andeutet: „Altes und Neues verbinden sich nicht organisch miteinander, weil der Held mit seinen hochfliegenden Plänen nicht auf das Vergangene aufbaut." 325 Der Held scheitert daran, die Beziehung zwischen sich und seiner Umwelt richtig einzuschätzen. ,[[]ch habe meines Amtes schlecht gewartet" [HKE, 92], so ruft er in den Sturm hinaus, was er im Leben nie gemerkt hat.

Wo der Held scheitert, ist ein humanisierter Mensch geboren. Nach Freund ist das Selbstopfer von Hauke „Sühne für ein egoistisch verfehltes Leben und der radikale Versuch einer Wiedergutmachung“326. Mit seinem Tod bringt er sich selbst zum Opfer anstelle des Hundeopfers, das er den Deicharbeitern zuvor versagt hatte. Das bedeutet zugleich seine Anerkennung der Ambivalenz und Vielfältigkeit in seiner Welt, auch wenn dazu Aberglauben und Gegenstimmen gehören. Eine solche Anerkennung weist auf Hauke Haiens Wandlung hin. Erst „im Augenblick seines Scheiterns“"327 ist er zum modernen sozialen Menschen gereift. Dieser freiwillige Tod in deutlich christlichem Gestus („Herr Gott, nimm mich; verschon die Andern!“ [HKE, 94]) kennzeichnet das Ende des Märchens und den

\footnotetext{
325 Harnischfeger 2000, S. 31.

326 Freund 1984, S. 79.

327 Freund 1984, ebd.
} 
Anfang der Humanisierung. Der Märchenheld Hauke Haien muss an seiner Unzeitgemäßheit scheitern und mit ihm scheitert sein Märchen.

Theodor Storm reflektierte durch das Scheitern des Märchens in Der Scbimmelreiter kritisch das romantische Märchenideal und die eigene romantische Nostalgie. Die Zeit des Märchens sollte nun beendet werden, aus der Storm viel geschöpft hatte. Es ist jetzt Zeit, einen Blick auf die zeitgenössischen ehrgeizigen Individuen zu werfen und einen neuen Mittelweg zwischen individueller Leistung und sozialen Bedingungen zu finden. „[]ch hätte sie [diese Novelle] vor 10 Jahren schreiben sollen." ${ }^{228}$ Mit dieser Novelle warnte der greise Dichter vor der rücksichtlosen Ich-Sucht eines zeitgenössischen Supermanns, einem Produkt des gründerzeitlichen Zeitalters 15 Jahre zuvor.

328 Brief an Tochter Elsabe am 17. 02. 1888; LL 3, 1082. 


\section{Exkurs: Andersen: Peer im Glück}

Hans Christian Andersens fiktives Werk besitzt häufig deutliche Parallelen zu seinem eigenen Leben. Dass die Leser sein Werk - unter anderem seine Märchen und Geschichten - als Geschichte seines Lebens verstehen und sein Leben und Werk gleichsetzen, war durchaus im Sinne Andersens [MLM, 218].329 Obwohl er in seiner Autobiographie schrieb, dass in seinem Improvisator, O. Z. und Nur ein Spielmann nicht nur er selbst in seiner abgesonderten Partikularität, sondern zugleich der bedeutungsvolle Kampf dargestellt werde, den viele durchgemacht haben [MLM, 95]. Er versuchte unter anderem, mit der Darstellung von „der gekränkten, ungerecht behandelten Menschheit" [ebd., 95] sein eigenes Leiden zu Papier zu bringen.

1870 verfasste und veröffentlichte Andersen seinen letzten Roman Peer im Glück (Lykke-Peer). In seinem Tagebuch schrieb er am 29. 04. 1870, dass dieses Werk als Märchen konzipiert sei, was an den thematischen Parallelen zwischen dem Roman und den „Alltagsmärchen“ (Das Unglaublichste, Wer war die Glücklichste, Was die ganze Familie sagte usw.), die Andersen 1870/1871 verfasste, erkennbar ist. Dieser Roman weist viele autobiographische Bezüge und intertextuelle Spuren zu Andersens früheren Märchen und Geschichten sowie zu deren Prätexten - (vor allem den romantischen Märchen, 1001 Nacht und der Bibel) auf. Andersen, der seiner Schreibtechnik selbst bewusst war, wies seine Leser im Roman selbstbezüg-

${ }^{329}$ Vgl. J. Andersen 2005, S. 421. 
lich darauf hin: „,[d]as Gelesene wurde, wie Erlebtes, zu einem Kapitel seiner eigenen Lebensgeschichte; die melodiöse Musik entsprach dieser Stimmung ganz und gar.“ [PiG, 92] Der Roman ist also aus Andersens eigenen Erlebnissen und den von ihm gelesenen und gehörten Geschichten komponiert, wobei die letzteren ihn stark beeinflusst hatten oder mit seiner Stimmung vermischt waren.

Dieser Exkurs untersucht aus intertextueller Perspektive die drei wichtigsten Gruppen der Grundlagen dieses Romans: die romantische Literatur, Andersens eigene Märchen und Geschichten sowie sein „Lebensmärchen“ - seine Autobiographie. Hierbei werden die Struktur des weniger bekannten Romans sowie einige wichtige Motive genauer untersucht.

\subsection{Die deutsche Romantik und Peer im Glück}

Wie viele romantische Romane - zu denen auch Andersens eigener Erstlingsroman Fußreise von Holmens Kanal zur Ostspitze von Amager in den Jahren 1828 und 1829 (1829) zählt, der unter dem Einfluss von Novalis, Friedrich Schlegel, Jean Paul, Heinrich von Kleist, Adelbert von Chamisso, Ludwig Tieck und E. T. A. Hoffmann entstand ${ }^{330}$ - handelt der letzte Roman des dänischen Märchenautors vom Prozess des Künstlerwerdens sowie von der Vervollkommnung seiner Persönlichkeit, was eines der Lieblingsthemen der romantischen Bildungsromane und der romantischen Märchen ist. Andere häufig vorkommende Themen und Motive in der romantischen Literatur, z. B. Kindheitskult, Außenseitertum, Natur und Orientalismus, verarbeitete Andersen in seinem Roman ebenfalls. Wichtige strukturelle und erzähltechnische Aspekte der Romantik - Transzendentalpoesie, romantische Ironie, die Vermischung verschiedener Gattungen und die poetische Selbstreflexion - spielten ebenfalls eine wichtige Rolle.

\subsubsection{Fragment}

Auffällige Gemeinsamkeit von Andersens Fußreise von Holmens Kanal zur Ostspitze von Amager in den Jabren 1828 und 1829 (in dieser Arbeit als Fußreise abgekürzt) und vielen frühromantischen Werken ist die Fragment-Eigenschaft des Textes. Dass Andersens Erstling im dreizehnten Kapitel auf seine eigene Struktur reflektiert ${ }^{331}$ und den Lesern mitteilt, ein jeder könne nach eigenem Belieben das leergelassene vierzehnte Kapitel ausfüllen, ist ohne Zweifel eine getreue Aufnahme von Schlegels Interpretation des Fragments: „Ein Fragment ist ein selbstbestimmter und selbstbestimmender Gedanke.“332 Der unabgeschlossene Text wird als ein offener

\footnotetext{
${ }^{330}$ J. Andersen 2005, S. 166.

331 „Unglücklicherweise sehe ich erst jetzt, daß mein Buch aus dreizehn Kapiteln besteht. Da es zu spät ist, Veränderungen vorzunehmen, möchte ich, damit keins der Kapitel stirbt, das heißt übersprungen wird, noch ein vierzehntes Kapitel hinzufügen." [PiG, 318]

332 KA XVIII, S.305.
} 
Prozess bearbeitet, weist über sich selbst hinaus und tritt mit der Umwelt in Verbindung. 333

Peer im Glück ist kein romantisches Fragment mehr. Trotzdem wird die Fragment-Eigenschaft der Romantik durch die immer wieder vorkommenden phantastischen Elemente, die typisch für Andersens Werk sind, beibehalten. Nach der Analyse von Andersens Geschichten durch Berendsohn sind die meisten erfundenen Erzählungen des Märchenerzählers entsprechend aufgelockert:

Die Phantasieströmung füllt sie mit poetischem Leben von Rand zu Rand. Wo er Teile der alten Formen leibt, macht er sie zum Spielraum seiner persönlichen Phantasie, wie auch die deutschen romantischen Märchendichter es tun. Man kann seine bewegliche Phantasie auch eine Reise- und Wanderphantasie nennen. ${ }^{334}$

Berendsohn preist diese „Phantasieströmung” als ein wichtiges Merkmal von Andersens Textform und seiner Erzählkunst. ${ }^{335}$ In Die Schneekönigin beispielsweise werden die Geschichten von verschiedenen Blumen im Garten der Zauberin nacheinander geschildert. Zumeist sind es Frauengeschichten. Sie tragen zwar zur Ausbildung von der Heldin Gerda bei, sind aber trotzdem unabhängig von der Handlungsstruktur und ohne zwingende Notwendigkeit für den Märcheninhalt. Diese Lebensbilder sind kleine, offene Fragmente, die in lockerer Verbindung zum Rahmentext existieren. Weil solche Fragmente kurze Ausschnitte aus anderen Geschichten sind, bleiben sie im Text ,grenzenlos und unerschöpflich“336, spiegeln sich gegenseitig und nähern sich einander an. In diesem Sinne ist jedes Werk Andersens eine Miniatur von Schlegels idealem „absolutem Buch“337, also ein Gesamttext mit jedem Einzeltext als Moment der unendlichen Annäherung an die Vollkommenheit.

Peers Vita ist ebenfalls eine sehr locker gebaute Geschichte ohne heftige Konflikte. Jeder Teil, der eine Lebensphase Peers erzählt, ist an sich schon eine kleine Geschichte eines Glückskindes. Zusammen bereiten sie diese Geschichte für das endgültige große „Glück“ vor. In die Geschichten Peers sind noch einige Fragmente aus dem Leben anderer Figuren integriert: Jungfer Frandsens gescheiterte Karriere als Tänzerin und ihre Jugendliebe, die Erzählung einer Witwe vom Grab und der Leiche ihres verstorbenen Kindes, die gescheiterte Liebe des jüdischen Gesangmeisters und die Liste der Taten großer Männer, von denen Peer in der Pension hört. Die Geschichten von Frandsen und dem Gesangmeister handeln vom Glück, das zugleich das Thema der Rahmenerzählung ist. Die Erwähnung der historischen Persönlichkeiten kündigen Peers Schicksal an: „welch ein Segen,

\footnotetext{
333 Schlegel bestimmt diesen Prozess mit dem Sinnbild eines Igels. Vgl. Kremer 2007, S. 95.

334 Berendsohn 1973, S. 208.

335 Berendsohn 1973, S. 213.

336 KA II, 215.

337 KA II, ebd.
} 
sterben in der Freude des Sieges!“ [PiG, 51] Mit Schlegel gesprochen, sind diese Binnengeschichten Varianten derselben romantischen Bildungsgeschichte.

Die Erzählung der Witwe 338 enthält das Motiv des Todes. Es ist möglich, dass die Trennung von Leiche und Grabstein die Zerstörung der Einheit von Seele und Körper nach dem Tod eines Individuums bedeutet. Da die Unsterblichkeit im Schmetterling - das Symbol für die Seele - liegt, gehört das, was auf der Erde übrigbleibt, nicht mehr dem Verstorbenen („Meine Leiche“ und „mein Grab“, wie die Witwe sagt). Wenn man das Ende von Peer im Glück und die Binnenerzählung der Witwe vergleicht, ist eine Analogie auffällig: Das Urteil des Erzählers über Peer nach dessen Tod ist von Peers Wesen (von seiner Seele) getrennt. Das Urteil, dass Peer der Glückliche unter Millionen sei, gehört mit Peers Leiche zu dem Übriggebliebenen. Ob das Urteil Peers Wesen entspricht, wird in einem späteren Abschnitt untersucht werden.

\subsubsection{Poetische Selbstreflexion}

Es kommt häufig vor, dass die romantische Literatur selbstbeobachtend die eigene ästhetische Form thematisiert. Das kann wie im Falle der Komödie Der gestiefelte Kater so geschehen, dass die Zuschauer und Schauspieler, also die Handlungsträger, ihre Stimmungen äußern; oder wie es am Ende von Andersens romantischer Fußreise der Fall ist, dass der Erzähler - und zugleich auch der fiktive Autor des Buches Fußreise - die sowohl fiktiven als auch wirklichen Leser direkt anspricht. Mithilfe solcher Formen der Selbstreflexivität ist das Dichten häufig Thema der romantischen Texte.

Peers Suche nach dem Glück wird vollendet, indem er sich zu einem Komponisten und Dichter entwickelt. So sagt Peer zu seinen bisher vollendeten Tätigkeiten: Das Werk des Bühnenkünstlers sei ephemer, vorübergehend und metaphorisch durch einen Meteor gekennzeichnet, während Dichter, Bildhauer, Maler und Komponisten weitaus glücklicher dran seien als die Bühnenkünstler. Diese strahlten und leuchteten neuen Generationen wie die Sonne [PiG 120f]. Peers Ausbildung fängt mit dem Tanzen an, geht über das Singen und das Schauspielen und endet mit dem Dichten und Komponieren. Der Prozess beginnt mit körperlicher Bewegung und entwickelt sich allmählich zu einer intellektuellen und künstlerischen Festigung des natürlichen individuellen Wesens.

Peers Weg zur künstlerischen Vervollkommnung ist gleichzusetzen mit einem Weg zur Selbstfindung:

Er dachte an sein Christentum, und er studierte seine Musik. Inwendig in ihm sang und klang es; er schrieb in Noten ganze Melodien, Lieder obne Worte. Schließlich scbrieb er Worte.

\footnotetext{
${ }^{338}$ Die Witwe klagt um ihre verstorbene Kind, dessen Grabstein geräumt ist.
} 
„Du bist ja Dichter, kleiner Peer!" sagte die Frau des Großkaufmanns, der er Text und Musik, brachte [...]. [PiG, 32]

Das Urteil wurde vor Peer Konfirmation und Schulausbildung geäußert. Als er nicht viel mehr als eine gattungsmischende „Kinderei“ [PiG, 29] kennt, wird sein dichterisches Talent schon entdeckt. Peer wird aber erst dann Gesamtkünstler, nachdem er Schulbildung erhalten und die Gesangskunst im Herzen üben gelernt hat. Die Rückkehr zum Ursprünglichen gleicht einer sublimierten Verbindung des Subjektiv-Individuellen und dem Natürlich-Originalen. Das ist mit der allegorischen Inszenierung der romantischen Geschichtsphilosophie in den Romanen und Märchen von Novalis - die Wiederaufnahme der verlorenen Naivität und die neue Herstellung einer neuen reflektierenden Einheit - vergleichbar. Peers persönliche und künstlerische Sublimation trifft zusammen mit seinem gesellschaftlichen Ansehen und seiner kunsthistorischen Stelle. Mit dieser Thematisierung - ein ,persönliches Märchen'von Andersen, sollte der Autor Resonanz bei der romantischen Aufhebung und dem Rücktritt des Alltäglichen zugunsten des Phantastischen ${ }^{339}$, finden. Der Roman lässt sich mit dem Märchenroman Heinrich von Ofterdingen vergleichen.

Heinrich von Ofterdingen von Novalis ist ein poetisch-allegorisches Buch. Heinrichs Reise nach Augsburg ist eher eine imaginierte Reise zu einem allegorischen Ort als eine geographisch-realistische. Die symbolische blaue Blume dient als kompositioneller Hinweis auf die Vielschichtigkeit des Textes. Mithilfe der blauen Blume in einer imaginierten Traumlandschaft merkt der Leser, dass sich die Reise nach Augsburg mehr als nur auf ein geographisches Ziel richtet, wie Heinrichs Liebe zu Mathilde mehr als nur sinnliche Liebe bedeutet. Eine allegorische „Einszu-Eins"-Deutung von Heinrichs Reise und seiner künstlerischen und persönlichen Ausbildung zu finden ist allerdings nicht möglich. Das Buch soll nicht als Gegenstand der Analyse von den Lesern behandelt werden, sondern als ein romantisches Lebensbuch, das mit seiner allegorischen Vielfältigkeit eindringlich macht, sich einzuschließen und aus sich eine Ganzheit zu bilden. Die jeweiligen verborgenen allegorischen Schichten sollen durch die Phantasie des „erwählten“ Lesers stetig ergänzt werden. Das Buch selbst schildert in diesem Sinne einen Werdeprozess.

Hans Christian Andersen war keine theoretisch ambitionierte Persönlichkeit. Vertiefte Kenntnisse über die philosophischen Voraussetzungen der romantischen Grundlagen durfte er bei dem Pensionsleiter Simon Meisling nicht erhalten haben. Dennoch bietet sein letzter Roman dem Leser die Möglichkeit, den Text als allegorisch verschlüsselt nach dem romantischen Vorbild zu verstehen. Darin vermischt Andersen nämlich verschiedene Gattungen und Erzählformen, wie er in einem früheren Roman formuliert hatte:

339 Gemäß Kremer einer „zyklische[n] Wiederherstellung der Ordnung“. Kremer 2007, S. 189. 
Ich finde, dass die Märchendichtung das am weitesten ausgedehnte Reich der Poesie ist. Es reicht von den blutdampfenden Gräbern der Vorzeit bis zu dem Bilderbuch mit frommen Legenden für Kinder und nimmt Volksdichtung wie Kunstdichtung in sich auf. Das Märchen ist Repräsentant aller Poesie. Wer möchte, Kann das Tragische, das Komische, das Naive, die Ironie und den Humor bineinlegen und hat zugleich lyrische Saite, das Kindlich-Eräählende und die Sprache der Naturbeschreibung zu seinen Diensten. Sind wir darin einig, zeigt dann nicht gerade dieser Repräsentant der Poesie, die Märchendichtung, eine solche Aladin-Natur?340

Der Roman ist eine Vereinigung von mehreren Gattungen. Das angesprochene Märchenideal spiegelt sich wiederum in Peers gedichtetem Kunstwerk wieder: eine Oper, die drei Kunstgattungen vermischt und Armida, Zauberflöte, Richard Wagners Musik mit der Naturstimme vereinigt. Der Roman nennt diese neue Kunst „Zukunftsmusik“ [PiG, 111], die auch mit dem romantischen Begriff Gesamtkeunstwerk übereinstimmt.

Die Idee von einem Gesamtkunstwerk erscheint aber schon 1838 in Andersens Brief an Heinriette Hanck, in dem er schrieb, dass er nach einer Poesie suche, die für sein Zeitalter geeignet sei. Nur durch das Märchen, das wegen des imaginiert kindlichen und freien Tones frei vom Gattungszwängen ist und das Unvereinbare vereinigen kann, konnte er dieses Ziel erreichen.

Peers Ausbildung zum Künstler birgt eine Vielfältigkeit von allegorischen Schichten - unter anderem die märchenhafte Geschichte eines Glückskindes und die Vita eines Gottesmenschen. Diese Schichten und die Romanwirklichkeit existieren im Text als ein romantisches „Miteinander von Wirklichkeit und Nichtwirklichkeit“"341, was durch den märchenhaften Erzählton und die Verwendung von biblischer Sprache ${ }^{342}$ erzeugt wird. Ein Beispiel des Märchentons findet man am Romanende:

Da durchfuhr ihn ein Feuer, sein Herz schwoll an wie bisher nie, er bückte sich, griff nach dem Kranz, hob ihn ans Herz und sank in derselben Sekunde zurück. - Obnmächtig? Tot? - Was war? - - Der Vorhang fiel.

„Tot!" echote es. Gestorben in der Freude des Sieges, wie Sophokles bei den Olympischen Spielen, wie Thorvaldsen im Theater, während der Symphonie von Beethoven. Im Herzen war eine Ader gebrochen, und wie mit einem Blitzschlag endeten hier seine Tage, endeten obne Schmery, endeten in irdischem Jubel, in Ausübung seiner irdischen Mission. Der Glückliche unter Millionen! [PiG, 135f, Hervorhebung von Z.Y.]

\footnotetext{
340 J. Andersen 2005, S. 254.

341 Lüthi 1996, S. 4.

342 „Das Land war da! Das Kind des Glücks würde hineingelangen.“ [PiG, 128] Dieser Ausdruck ist eine Anspielung auf das Reich Gottes in der Bibel. [Mt 12, 28]
} 
Die kursiv hervorgehobenen Sätze sind die Bemerkungen des Erzählers zu Peers Tod. Würden sie gestrichen, sähe man nur einen banalen plötzlichen Herztod, der dem verschlechterten Gesundheitszustand von Peer während seiner Operndichtung ${ }^{343}$ entspricht. Die Romanwirklichkeit und die Märchenschicht werden durch den Erzählton getrennt. Die besondere Rolle des Romanerzählers als einflussreicher Vermittler zwischen der Geschichte und dem Leser ist ein weiterer Beleg für das sich selbst kommentierende Verfassen.

Einen „verbindliche[n] Katalog der Bedeutungen“"344 findet der Leser in Andersens Roman wie in den romantischen Märchenromanen nicht. Als ein kompositionelles Symbol kann man das Bernsteinherz betrachten, das wegen der abergläubischen Deutung durch die Großmutter als ein Talisman fungiert, und die leitmotivistische Ofenecke von Madame Hof, die auf das lange ersehnte häusliche Glück verweist; eine zweite Gruppe von Symbolen bilden die ausgestreuten Stoffe aus Andersens eigenen Märchen: der standfeste Zinnsoldat und die Balletttänzerin, die Nachtigall, die Schneekönigin usw., durch die Peer im Glück sich an die Seite von Andersens Meisterwerk aufstellt, das das Außenseitertum, die Integrationsproblematik und die Religiosität thematisiert. Zur letzten Gruppe gehören die thematisierten Motive aus der gelesenen Literatur: die Samson-Geschichte aus der Bibel, die weiße Dame nach einem Roman von Walter Scott, einem von Andersens Lieblingsdichtern, das orientalische Märchen von Aladin nach der Operdichtung von Oehlenschläger und Schillers Ballade Der Ring des Polykerates ${ }^{345}$. Es ist ein fruchtloses Unterfangen, mit jeder Handlung in Andersens Roman nach dem entsprechenden Ereignis in diesen zitierten Texten zu suchen. Eine thematische Gemeinsamkeit lässt sich allerdings zwischen den Texten finden. Die Oper von Boïeldieu, das Märchen von Aladin und Schillers Ballade handeln von märchenhaftem Glück, wobei das grenzenlose und Unheil hervorrufende Glück im Ring des Polykrates Parallelen zu Peers grenzenlosem aber frommem Glück, das durch seinen Tod sublimiert wird, besitzt. Die christliche Religiosität in diesem Roman steht viel mehr für die Vorsehung. Wie in Andersens berühmtesten Märchen Die kleine Seejungfrau, Die Schneekönigin und das dem Schicksal gehorchende hässliche Entlein, übernimmt Gott die Stelle des deus ex machina, die im Volksmärchen und Barockmärchen häufig eine Fee besitzt. Die Hauptfiguren dieser Texte sind „Erwählte" und gekennzeichnet durch Gehorsam und Naivität. Andersen verwendete den in der Schneekönigin schon zitierten Satz über das Himmelreich aus der Bibel auch in Peer im Glück: „Wahrlich ich sage euch: Es sei denn, daß [sic] ihr umkehret und werdet wie die Kinder, so werdet ihr nicht ins Himmelreich kommen. " Nicht eine intuitiv handelnde Person, sondern ein intelligentes und „umkehren-

\footnotetext{
343 „Die frische Farbe wich von seinen Wangen, seine Augen strahlten heller als zuvor.“ [PiG, 122]

344 Kremer 2007, S. 107.

345 Anders als die anderen Prätexte ist Schillers Ballade von Andersens Roman nur thematisch angespielt. Keine konkrete Stelle von der Ballade wird zitiert und erwähnt. 346 Lutherbibel 1912: Matthaeus 18:3.
} 
des“ Kind meint Andersen damit: Ein erwachsenes anmutiges „Kind“, das auf die mysteriöse Weisheit des Schöpfers vertraut und dessen Wille mit dem Gottes identisch ist. Peer ist ein angeborenes Genie „von Gottes Gnaden“ [PiG, 105] und „innerlich ist er kein Jahr älter geworden“ [PiG, 134]. Zipes bemerkt in seinem Beitrag zu Peer und seinen Geschwistern in Andersens Märchen:

[t]beir success is a reflection of God's grace and mysterious but intelligent design. There is, of course, an autobiographical aspect to this paradigmatic tale [Der Reisekamerad - Z. Y.] that Andersen told to bimself time and again to sanctify his rise from poverty to wealth and fame. All of his novels and many of his tales, such as "The Bronze Pig", "The Swineherd", "The Ugly Duckling", "Tb and Little Christina", "Clod Hans", and "The Ice Maiden" are variations on the same theme that can also be found in "The Snow Queen": trust in God's design, and you will fare well, even if you should die. ${ }^{347}$

Das Sterben bedeutet in mehreren Texten Andersens - unter anderem Die kleine Seejungfrau und Das kleine Mädchen mit den Schwefelhölzchen - Transformation und religiöse Sublimation. In der Märchen- und Religionsschicht des Textes hat Peer durch sein makelloses Leben und die gesamtkunstwerkhafte Oper Gottes Gnade und Intelligenz bestätigt, weshalb er ins Land des ewigen Glücks gehen darf. In der fiktiv dargestellten Wirklichkeit aber wird ein Kompromiss durch Peers Tod geschlossen, denn er stirbt und ist dadurch von dem beißenden Problem befreit, das Peer nach dem „Knall“ noch hätte erreichen können. „Gestorben in der Freude des Sieges.“ $[\mathrm{PiG}, 136]$ Peer muss seinen eigenen Untergang nicht mehr erleben. ${ }^{348}$ Sein Tod ist eine Versöhnung zwischen der Wirklichkeit und dem Märchenhaften. Die unendliche Annährung an Vollkommenheit wird durch den Tod beendet. Peer ist von der Zukunft und von der Entwicklung, von der Romantik befreit. Das last sich als eine ironische Bemerkung zu den romantischen Vorbildern lesen.

Eine solche Versöhnung zwischen dem Romantischen und dem Realistischen unterscheidet Andersen von dem Frühromantiker Novalis und zeigt Andersens Stellung zwischen Romantik und Biedermeier. ${ }^{349}$

\footnotetext{
347 Zipes 2006, S. 229.

348 Der Tod der Hauptfiguren in „Die kleine Seejungfrau“ und „Das kleine Mädchen mit den Schwefelhölzchen" kann auch als Kompromiss mit einem unerreichbaren Wunsch verstanden werden. ${ }^{349}$ Wie viele Zeitgenossen fühlte sich Andersen verpflichtet, die Wirklichkeit auf realistische Weise zu schildern, weshalb die neuere gesellschaftliche Ordnung sowie die neueren Erfindungen wie die Eisenbahn in seinem Text vorkommen. Zugleich erfüllte er durch die märchenhafte Struktur des Romans die Bedürfnisse der biedermeierlichen Leser nach Poetisierung der Wirklichkeit und moralischer Gerechtigkeit.
} 


\subsection{Andersens Märchen und Erzählungen als Prätexte zu Peer im Glück}

Nachdem Peer im Glück abgeschlossen war, las Andersen seinem Freund Rasmus Nielsen den Romananfang vor. Nielsen bewunderte das neue Werk mit dem Kommentar, dass Andersen eine neue Richtung gebahnt habe, zwischen Roman und Märchen. ${ }^{350}$ Der Text erschien fünf Jahre vor Andersens Tod, als die meisten seiner Märchen schon gedichtet worden waren und der letzte Roman des Autors (Sein oder nicht sein, 1857) dreizehn Jahre zuvor veröffentlicht worden war. Das Buch erschien schließlich als ein kurzer Roman mit autobiographischen Zügen, es lässt sich aber auch als ein Rückblick auf das Gesamtwerk des Autors inklusive der Märchendichtung lesen. Um die motivistischen und strukturellen Einflüsse von Andersens Märchen und Geschichten auf Peer im Glück zu untersuchen, müssen zunächst einige Merkmale von Andersens Märchendichtung zusammenfasst werden.

\subsubsection{Merkmale von Andersens Märchendichtung}

Andersen war seit seiner Kindheit ein Kenner von Volks- und Kunstmärchen. Der romantischen Märchentheorie, dass die alltäglichen Regeln durch die Märchensprache gebrochen und ins Phantastische umgewandelt werden sollen, war er, der Ludwig Tieck, die Gebrüder Grimm, Chamisso, Heinrich Heine und viele andere kannte, zugetan. 1835 erschien das erste Märchenheft von Andersen, in dem er ,alte Märchen erzählt, die [er] als Kind gehört hatte" [MLM, 144], aber dies auf seine eigene Weise. Andersens Märchen unterscheiden sich stark vom traditionellen Volks- oder Kindermärchen, obwohl ,in ihnen recht eigentümlich das Kindliche ausgedrückt" 351 wird. Andersen schrieb viel eher für Erwachsene als für Kinder, trotz des Namens seiner ersten Sammlung - die 1835 und 1837 veröffentlichten Hefte von Märchen, erzählt für Kinder. Die kunstvolle Transformation sentimentaler Themen ins Naive war für die zeitgenössische dänische Literatur eher neu, und Andersen war sich bewusst, dass er innerhalb des Märchengenres etwas Neues geschaffen hatte. In seinem Text verbergen sich überall kunstvoll verschachtelte Verweise auf seine Quellentexte sowie auf die eigentlichen Themen, die anstößig für Kinder und viele erwachsene Leser sein konnten. Dazu gehört die Diskussion über gesellschaftliche und individuelle Problematik - unter anderem die Homoerotik des Autors. „Gegen die auch dann noch drohende Anstößigkeit der Mitteilung schützt die Märchenhaftigkeit des Stoffes. “352, so Detering.

\footnotetext{
${ }^{350}$ Hans Christian Andersens Tagebucheintragung am 28. 08. 1870.

351 Andersens Brief vom 11. - 14. 06. 1834 an Otto Müller. Anderseniana 1993, S. 33 - 34. Zit. nach J. Andersen 2005, S. 289.

352 Detering 2002, S. $188 f$.
} 
In Andersens Märchen entwickelt sich das Leben der Figuren mehr nach dem realistischen Modell als nach dem zauberhaften. Es gibt die Suche nach dem Glück und ein glückliches Ende, aber auch Schwierigkeiten, Trauer und sogar Tragik. Manche „happy endings“ sind wegen der im Text angedeuteten Ironie zweifelhaft. Beispielsweise existiert die Liebe zwischen dem Zinnsoldaten und der kleinen Balletttänzerin nur in seinem Wunsch und die endgültige Vereinigung der beiden im Tod scheint eher zufällig als glücklich und rührend zu sein. Auch in der Geschichte Das Unglaublichste, die fast zur selben Zeit mit Peer im Glück geschrieben wurde, hat die Prinzessin nichts gegen ihre Hochzeit mit dem bösartigen Mann einzuwenden, weshalb ihre spätere Eheschließung mit dem richtigen Bräutigam willkürlich zu sein scheint.

„So even where Andersen's fairy tales have the appearance of being true fairy tales, they often place themselves in a context, miming the fairy tale and imitating the gestures of children's literature, but bebind this surface they are far beyond both. ' ${ }^{353}$

\subsubsection{Präsenzformen von Märchen in Peer im Glück}

In Peer im Glück findet man viele Motive aus Andersens Märchen und Geschichten. Diese Elemente bilden zusammen mit den Bibelrequisiten nicht nur die Oberflächenstrukturen, sondern auch das innere Wesen des Textes.

Die Märchen und Geschichten sind intertextuell auf verschiedene Art und Weise präsentiert in Peer im Glück. Unter anderem erkennt man eine erste Gruppe von namenlosen Märchen, die im Text direkt erwähnt werden. Als Peers Großmutter ihn den Enkel „mit dem Goldapfel in der Hand“ [PiG, 10] nennt, bezeichnen Peers Eltern dieses Wort von als „Märchen“. Die Großmutter selbst wird als eine Märchenfrau dargestellt, da sie - wie diejenige der kleinen Seejungfrau - Peer seltsame und wunderbare Geschichten von der weiten Welt schenkt, in denen Prinz und Prinzessin auftreten. Die Märchen der Großmutter werden später mit dem ersten Theaterstück, das Peer gesehen hat, verglichen. Der Inhalt dieser Märchen wird nicht erzählt, aber sie führen beim kleinen Peer zu einer märchenhaften Weltansicht: „Das waren lauter Tanz-Leute vom Ballett, was Peer aber nicht wußte, er dachte, sie kämen aus den Märchen, die die Großmutter erzählt hatte.“ [PiG, 19] Die Funktion dieser namenlosen Märchen liegt genauer darin, dass ein Vergleich zwischen ihnen und Peers Theaterkarriere sowie seinem Leben angedeutet wird. Nach Erzählung der Großmutter und während eines Theaterspiels gibt sich Peer als Prinz aus, was sowohl dem Vergleich zwischen Prinzen und Künstlern als auch der Gemeinsamkeit zwischen Peer und einer naiven Märchenfigur entspricht.

Eine zweite Gruppe bilden die Märchen, die im Text explizit referiert wird, unter anderem das orientalistische Märchen von Aladin nach der Oper von Oehlenschläger. Sowohl Peer selbst als auch dem Erzähler ist der Bezug Aladins auf den

353 Mylius 2006, S. 172. 
Romanhelden bewusst. Beide sehen den Zusammenhang zwischen Peer und dem armen Aladin, der das Glück erhält. Der Erzähler kommentiert sogar, die Oper Aladin solle ein Stück des Herzens sein, „daß dieser junge Mann, der abends so in seiner Rolle lebte und atmete, noch inniger lebte: sich ein paar Stunden später in ein mächtiges Werk von Tönen vertiefte, das aus seiner Seele hervorbrach“ [PiG, 129]. Peer verbindet seine eigene Geschichte - die Romanwirklichkeit - mit dem Aladin-Stoff in seiner Oper, wobei noch ein Hinweis auf diese Selbstbezogenheit in der Oper-Darstellung zu finden ist: das Vogelgezwitscher von Kuckuck und Drossel am Anfang des Stückes, das für das Aladin-Gemüt, einer Verkopplung von Natur- und Kindergemüt, steht. Der Leser erinnert sich an Peers bedeutungsvollen Traum während seiner Zeit in der Pension: der Kuckuck sagt voraus, dass Peer nicht lange leben solle:

da begann der Kuckuck auch, „Kuckuck! Kuckuck!", ja, es nabm kein Ende; er fubr fort, so daß Peer drauflos kuckuckte, und zwar so lebendig, als sei er selbst ein Kuckuck, sein „Kuck" klang aber lauter und heller; alle Singvögel quinquilierten mit, Peer sang ibnen nach, aber viel schöner: Er hatte seine Klare Kinderstimme und jubelte beim Singen. Er war so froh in seinem Herzen, und wachte davon auf, überzeugt, daß ein Nachball dessen in ihm war, daß die Stimme in ihm steckte, und wobl an einem hellen Pfingsttag morgens in aller Frische hervorkommen würde [...]. [PiG, 60f]

Neben diesen beiden Präsenzformen von Märchen im Text gibt es noch eine dritte. Hierbei handelt es sich um die Präsenz von Motiven aus Andersens Märchen und Geschichten. Diese haben allerdings auch charakterisierende Funktion und sind grundlegend für die Struktur des Romans. Dass ein Junge standfester und geeigneter für den Ballett-Tanz als ein Mädchen sei, ist sehr wahrscheinlich eine Anspielung auf Den standhaften Zinnsoldaten. Die schon zitierte Naturbeschreibung des nebligen Gartens entspricht Stellen aus Dem Elfenhügel und Der kleinen Seejungfrau. Die Funktion dieser „Märchenrequisiten“ besteht nicht in Herstellung eines speziellen inhaltlichen Zusammenhangs ist, sondern in der Andeutung von thematischen und strukturellen Gemeinsamkeiten zwischen den Texten. Um diese These zu erläutern, soll Andersens Märchen Die kleine Seejungfrau als Beispiel genommen werden.

Die kleine Seejungfrau bietet dem Roman viele Requisiten. In diesem Märchen gibt es, wie schon gesagt, ebenfalls eine alte Großmutter, die dem Enkelkind von der weiten Welt erzählt. Die durch die Königswitwe erzählte Menschenwelt zeigt sich für die Zuhörerin - die kleine Seejungfrau - als eine wunderbare Verwandlung ihrer eigenen Welt: Die Wälder in der Menschenwelt sind grün und die „Fische“ singen laut und herrlich zwischen den Bäumen. [A I, 69] Die kleine Seejungfrau sehnt sich also wie der kleine Peer nach einem „Märchen“. Da die kleine Seejungfrau in die Menschenwelt steigt und Peer erfolgreich auf der Bühne wird, was für ihn als Kind eine märchenhafte Angelegenheit war, können die beiden 
Figuren als ein Kind angesehen werden, das von seiner alltäglichen Wirklichkeit in die Märchenwelt hinüberwechselt. Sie erleben daher einen „Grenzüberschritt“ im Sinne von Jurij Lotmans Raumsemantik: Die räumliche Ordnung der erzählten Welt wird zum organisierenden Element und die nicht-räumlichen Charakteristika werden um dieses Element aufgebaut. ${ }^{354}$ Nur der semantische Grenzüberschritt der kleinen Seejungfrau wird tatsächlich durch die räumliche Ordnung von MeerLand-Luft gekennzeichnet, während der Grenzüberschritt Peers von der Unterklasse ins Theater keine eindeutige räumliche Grenze kennt.

Eine weitere Gemeinsamkeit zwischen der kleinen Seejungfrau und Peer ist ihre Stimmlosigkeit. Der Verlust der Stimme ist ein wichtiges Motiv, das auch in Andersens Märchen Die wilden Schwäne bearbeitet wird.

In Die wilden Schwäne akzeptiert die Heldin ihre Stummheit freiwillig als eine der beiden Bedingungen für die Erlösung ihrer Brüder:

„Deine Brüder können erlöst werden“, sagte sie [die Fee - Z. Y.], „, aber hast du Mut und Ausdauer? Wobl ist das Wasser weicher als deine feinen Hände, und doch formt es die harten Steine um, aber es füblt nicht die Schmerzen, die deine Finger füblen werden; es hat kein Her: leidet nicht Angst und Qual, die du aushalten mußt. Siehst du die Brennessel, die ich in meiner Hand halte? Von derselben Art wachsen viele rings um die Höble, wo du schläfst; nur die dort und die, welche auf des Kirchbofs Gräbern wachsen, sind tauglich, merke dir das. Die mußt du pfliicken, obgleich sie deine Hand voll Blasen brennen werden. Brich die Nesseln mit deinen Füßen, so erbältst du einen Flachs; aus diesem mußt du elf Panzerbemden mit langen Ärmeln flecbten und binden. Wirf diese über die elf Schwäne, so ist der Zauber gelöst. Aber bedenke wobl, daß du von dem Augenblick, wo du diese Arbeit beginnst, bis zu dem, wo sie vollendet ist, wenn auch Jahre darüber vergehen, nicht sprechen darfst. Das erste Wort, welches du sprichst, geht als tötender Dolch in deiner Brüder Heræ! An deiner Zunge hängt ibr Leben. Merke dir das alles." [A I, 143]

Die Stummheit gilt nach dem Wort der Fee als eine der beiden Proben, bevor Elisas Wunsch, ihre Brüder zu erlösen, erfüllt wird. Die Angst und Qual dieser Proben beziehen sich besonders auf die Stummheit, weil diese, freiwillig wie sie ist, eine fehlende Kommunikation zwischen dem Ehepaar verursacht.

Die Stummheit der Seejungfrau ist der Preis für ihre neuen Beine und eine Hürde für ihre Wunscherfüllung: „Du hast die schönste Stimme von allen auf dem Meeresgrund; damit glaubst du wohl, ihn bezaubern zu können, aber diese Stimme mußt du mir geben. Das Beste, was du besitzt, will ich für meinen kostbaren Trank haben!“ [A I, 81]

Wegen des Verlusts ihrer Stimme muss die Heldin die Wahrheit - ihre wahre Natur, ihre Rettung vom Prinzen und ihre Liebe zu ihm - verbergen, sodass sie

354 Vgl. Martinez/Scheffel 2007, S. 141. 
täglich unendliche Qualen leidet, ohne dass der Prinz es mit einem Gedanken ahnt. [A I, 87] Ihre Stimme ist vielmehr ein Spieleinsatz in einem verlorenen Spiel.

Ganz anders bei Peer. Peer verliert seine Stimme nicht. Sein Stimmbruch ist nur eine Pause in seiner Sängerkarriere und eine Voraussetzung seiner Gesangsübung im Herzen. Die Gemeinsamkeit mit dem Schweigegebot der Seejungfrau ist die Unsicherheit: Niemand weiß, wie lange der Stimmbruch dauert. „Vielleicht kam die Stimme gar nicht mehr" [PiG 32] und in diesem Falle müsste Peer - wie der Autor Andersen - die Sängerkarriere beenden. Das Schweigegebot ist eine notwendige Bedingung für die Rückkehr der Stimme, aber keine Garantie dafür.

Zugleich bringt der Stimmbruch Peer einige Vorteile: Er soll Sprachen und Wissenschaften in einer Pension erlernen, „was ihm dereinst zugute käme“ [PiG, 34] Wegen des Stimmbruchs kann er sich auf seine Konfirmation konzentrieren und an sein Christentum denken, während er inwendig singt. Da Peer seine Stimme wiedererhält, als er mit seiner Großmutter Chorlieder singt und da er ein erwähltes Glückskind ist, liegt es nahe, dass seine zunehmende Religiosität aufgrund des Stimmbruchs eine Voraussetzung für Peers Erfolg ist.

\subsubsection{Eine Phantasiewelt in Peer im Glück}

Als Peer sich in Verzweiflung befindet, weil seine Singstimme für „fort“ bestimmt worden ist, erlebt er im träumerischen Zustand eine Phantasiewelt im Garten der Pension. Dies ist eine entscheidende Stelle im ganzen Roman, in der das Christentum die dämonisch verführerische Sinnlichkeit besiegt. Die Szene fängt mit der folgenden Naturbestimmung an:

Das Moor war ein See, so tief und schwarzblau, mit Teichrosen, die in allen erdenklichen Farben leuchteten; auf dem Wasser tanzend, trugen sie ihn auf ihren Schleiern ans andere Ufer, wo der Hünenhügel sein Grün abgelegt hatte und sich türmte zu einem Schloß von Wolken; die Wolken aber waren aus Marmor; blübende Goldbäume und kostbare Steine umrankten die mächtigen Marmorblöcke; jedwede Blüte war gar ein farbenprächtiger Vogel, der mit menschlicher Stimme sang. Es war wie ein Chor von tausend und abertausend fröhlichen Kindern. War das der Himmel oder war's der Elfenhügel? [PiG, 67f]

Die Moor- oder Sumpfsymbolik tritt in Andersens Werk häufig auf. 355 Der Dichter verknüpfte die Moorsymbolik mit den sexuellen Triebkräften der Menschen, da sie das eigene schlammige Innere des Menschen veranschaulicht. ${ }^{356}$ Der Nebel überm Moor erinnert Peer an den Tanz der Elfenmädchen, die ihn in Tanz und Spiel - in seinen Tod - hineinziehen. Die Art und Weise, wie Peer die phantastisch-imaginierte und stark personifizierte Natur erlebt, entspricht Andersens speziellen Schreibart von der Umwelt im Märchen. Nach Brendsohn hat Andersen

355 Die kleine Seejungfrau, Schlammkönigs Tochter, Nur ein Spielmann und so weiter. 356 J. Andersen 2005, S. 437. 
„eine sehr starke Wirklichkeitsphantasie“. Der Dichter fasst viel mehr in der Umwelt auf und

erlebt mehr als gewöhnliche Menschen, die alles ibrem engen Interessenkreis einund unterordnen. Seine Gefüble sind stärker gebunden an die mannigfaltigen Erscheinungen der Umwelt; seine Phantasie holt sie daher in buntem Reichtum in seine Dichtung hinein. Der realistische Dichter weckt (wie alle realistische Künstler) unsere Sinne, schafft uns neue Erlebnisse, erzengt neue Gefüble und Gedanken in uns und gibt uns seine neue Sprache für sie. 357

Die Umweltbeschreibung bei Andersen orientiert sich daher an dem sinnlichen Erlebnis. Er braucht seine fünf Sinne, sodass die Leser die Umwelt im Märchen miterleben. So finden sich in seinen Werken häufig farbenreiche Schilderungen. Am Anfang der Kleinen Seejungfrau sieht man beispielsweise transparentes Wasser, das „,so blau wie die Blätter der schönsten Kornblume und so klar wie das reinste Glas"[A I, 67] ist, weißen Sandboden, feuerrote und dunkelblaue Bäume, goldene Früchte und Blumen wie brennendes Feuer, blauen Sand wie die Schwefelflamme und blauen Schimmer. [A I, 67f] Ganz im Gegenteil zu dieser farbenreichen Umwelt ist die Umgebung des Wohnhauses der Meerhexe gestaltet, wo das Wasser herumwirbelt, also nicht durchsichtig ist, keine Blumen wachsen, der Sandboden grau und das Haus aus weißen Knochen ist. Die Farben hier sind eintönig.

„Wenn Wunder geschehen, sind sie meistens verbunden mit Licht und Glanz." 358 Auch die Lichteffekte auf dem Meeresboden und bei der Meerhexe sind ganz anders. Der Meeresboden ist hell beleuchtet, Perlen strahlen in jeder Muschelschale, die Früchte strahlen und die Blumen „brennen“ wie Feuer. Die Sonne erscheint wie eine Purpurblume, deren Kelch alles Licht ausströmt; die Polypen bei der Meerhexe ziehen sich erschrocken vor dem glänzenden Trank zurück, was andeutet, dass es bei der Hexe dunkel ist.

In der Umwelt entstehen verschiedene Bewegungen. Auf dem Meeresboden rühren sich die Bäume und Pflanzen „,bei der geringsten Bewegung des Wassers, gerade als ob sie lebten“ [A I, 67]. Alle Fische schlüpfen zwischen den Zweigen hindurch wie die Vögel in der Luft. Diese linearen Bewegungen stehen im Gegensatz zu den kreisförmigen und ausgangslosen Bewegungen im Sumpf bei der Hexe, „wo das Wasser gleich brausenden Mühlrädern herumwirbelte und alles, was es zu fassen bekam, mit sich hinunter in die Tiefe riß““ [A I, 79]. Neben diesen zermalmenden Wirbeln sieht die Heldin auch Polypen, die alles, was sie ergreifen können, fest umschlungen halten. Das „Wirbeln und Schweben“ kommt in Der kleinen Seejungfrau noch einmal vor, wenn die Heldin - ein Elementargeist - tanzt: „sie wirbelte mit im Tanz, schwebte“ [A I, 87].

Die Umwelt im nächtlichen Garten der Pension in Peer im Glück erscheint trotz des Nebels auch farbenreich und hell leuchtend. Die Gemeinsamkeit dieser Natur

\footnotetext{
357 Berendsohn 1973, S. 55.
}

358 Berendsohn 1973, S. 71. 
und dem Meeresboden ist auffällig. Die Stimmung des nebligen Gartens erscheint eher heiter und traumhaft als trüb und bedrohend. Andererseits werden die Tanzbewegungen der Elfen wiederholt als „,Wirbeln und Schweben“ dargestellt:

„Dergleichen hatte Peer im Ballett gesehen, auf der Bühne, wo die Elfenmädchen dargestellt waren, wirbelnd, schwebend, mit Schleiern aus Seide" [PiG, 66f];

„Ganz vorn im Nebel leuchtete deutlich eine weibliche Gestalt, und aus einen wurden

drei, aus dreien viele, Hand in Hand tanzende, schwebende Mädchen "[ebd., 67];

„Obne sich etwas dabei zu denken, tanzte er mit ihnen, aber nicht ihren Tanz; er wirbelte rundherum wie in dem unvergeßlichen Vampirtanz" [...] [ebd., 67];

„Die Wände des Schlosses bewegten sich, glitten aufeinander zu - schlossen sich um ihn. [...] Kein Ausgang war zu sehen. "[ebd., 68]

Es handelt um den gleichen kreisförmigen Tanz wie der des Elementargeists und das bedrohende Umschlingen der Polypen. In der von Peer empfundenen Umwelt vereinigen sich der fröhliche und seelenlose Meeresboden und der gefährliche und ausweglose Sumpf („Nebel gingen überm Moor“ und Peer befindet sich auch im Sumpf). Aus dieser Vereinigung entsteht eine leichtsinnige Verführung. Ein seelenloses Todesreich erscheint: „Eine Stunde hier sind hundert Jahre draußen [...], du bist schon eine Stunde hier. Alle, die du draußen kennst und liebhast, sind tot! bleib bei uns! - ja, bleiben mußt du, oder die Wände klemmen dich ein, daß dir das Blut aus deiner Stirne spritzt!“ [PiG 69]. Im Todesreich ist Peer der Sprechfähigkeit beraubt. Wenn man nicht sprechen kann, kann man sich nicht äußern und selbst erklären, wie es bei der stimmlosen Seejungfrau der Fall ist.

Das leblose Reich der Elementargeister Reich zeigt sich als eine Probe für Peer, der diese mit einer Paraphrase der Worte Jesu am Kreuz [Mt 27,46] besteht: „Mein Gott! Mein Gott! hast du mich verlassen?“ [PiG, 69]. Wie der christliche Gott die Stelle der hilfsbereiten Fee in Märchen übernimmt, steht die Hauptfigur, die sich auf Christus ausrichtet, im Zentrum der Geschichte. 


\subsection{Der glückliche Peer und das Lebensmärchen Andersens $^{359}$}

Im Dezember 1825 besuchte Andersen die Familie von Kommandeur Wulff, Leiter der Marineakademie. Die Gastgeber wohnten in einem der Palais von Schloss Amalienborg in Kopenhagen. Andersen bekam zwei Zimmer hinaus zum Platz. In der Kammer mit einer hohen gewölbten Decke konnte sich Andersen vorstellen, er sei auf einer Ritterburg, oder wie der Biograph Jens Andersen bemerkt, der junge Andersen fühlte sich wie Aladin im Palast des Sultans. Im Schreibzimmer beschrieb Andersen seine Eindrücke im Tagebuch am Montag, dem 19. Dezember:
„Jetrt bin ich allein in meiner Kammer - tausend Gefüble durchströmen mich - oh, was hat Gott doch für mich getan, es geht mir, wie es Aladdin gegen Ende des Stückes ausspricht, ${ }^{360}$ als er aus dem Fenster des Schlosses sieht.
Vor 5-6 Jahren ging ich auch dort unten, kannte nicht einen Menschen in dieser Stadt, und jetzt kann ich mich hier oben bei einer lieben und geachteten Familie an meinem Shakespeare laben - oh, Gott ist gut, ein Tropfen vom Honig der Freude läßt mich alle Bitterkeit vergessen, ob, Gott wird mich nicht verlassen - er hat mich so glücklich gemacht. "[HCAT, 18] ${ }^{361}$

Im Schicksal Aladins sah der Pensionsschüler ,sein persönliches Lebensmuster und Motiv zum Vorbild"362. Die Figur Peer in seinem letzten Roman spiegelt sich ebenfalls im Schicksal Aladins, also auch im Schicksal des Autors. In der Persönlichkeit von Peer und Andersen gibt es Parallelen: Die beiden sind sentimentalische Personen, werden aber als naiv geschildert.

Obwohl Forscher seit den letzten Jahrzehnten angefangen haben zu erkennen, dass Andersen mehr ein Dichter für Erwachsene als für Kinder war, sprachen

\footnotetext{
359 Hans Christian Andersens Märchen meines Lebens ist eine Autobiographie; Jens Andersens Hans Christian Andersen ist eine Biographie und Peer im Glück ist ein Roman mit autobiographischen Bezügen. Nachdem man die Biographie, die auf zahlreichen Briefe, zeitgenössischen Materialien und wissenschaftlichen Beiträge basiert, gelesen hat, bemerkt man die Unzuverlässigkeit von Andersens Autobiographie. Die Biographie von Jens Andersen und sogar Andersens Fiktionen kommen der Wirklichkeit näher als dessen Autobiographie. Lejeune bemerkt zu dieser Problematik: „,in der Biographie muß die Ähnlichkeit die Identität begründen, in der Autobiographie begründet die Identität die Ähnlichkeit. Die Identität ist der reale Ausgangspunkt der Autobiographie; die Ähnlichkeit ist der unmögliche Horizont der Biographie". [Lejeune, 42] Hans Christian Andersen und PiG kommen der Wahrheit nahe, aber MmL ist mit dem Autor identisch. Andersens Autobiographie ist deswegen in Bezug auf die Wahrheit noch problematischer, weil schon der Titel „Märchen meines Leben“ “ lautet. Der Titel lässt sich auf zwei Arten verstehen: entweder wollte der Autor damit manifestieren, dass sein glückliches Leben ein Märchen sei, oder der Leser soll diesen Text als ein Märchen aus seinen Gesamtmärchen lesen. Mit dem „Märchen von Andersens Leben“ in dieser Arbeit ist die Autobiographie des Autors gemeint.

360 Gemeint ist Adam Oehlenschlägers Stück Aladdin eller den forunderlige lampe (1805).

361 Vgl. J. Andersen 2005, S. 308 u. S. 340.

362 J. Andersen 2005, S. 99.
} 
viele seiner Zeitgenossen von Andersens ,rein kindlicher Dichternatur'.363 Tatsächlich aber reflektierte er sich in seinem Werk ganz bewusst. Seine dänische Autobiographie hat er „Märchen meines Lebens“ genannt. „[W]o die Wirklichkeit nicht den Erwartungen an ein ,Lebensmärchen“ entsprach, hat Andersen selbst [...] die Begebenheiten so redigiert und umorganisiert, daß das erlebte Leben und die Vorstellung vom Lebensmärchen sich in einem Brennpunkt vereinten: im Mythos von Hans Christian Andersen."364 Der Wirkung des Mythos war sich Andersen völlig bewusst und das Lebensmärchen musste er immer weiter dichten. In der schwedischen Tänzerin Jenny Lind beispielsweise, die ein „kluges und kindliches Gemüt” [MmL, 150] besaß, fand Andersen eine Schwester im Geiste [ebd., 150]. Jenny Lind zeigte sich Andersen gemäß als das echte Naturkind von angeborenem Adel. Ihr Auftreten auf der Bühne tat „einem wohl wie ein Kirchgang, man wird ein besserer Mensch; man fühlt, daß Gott in der Kunst ist, und wo Gott Angesicht gegen Angesicht vor uns steht, da ist eine heilige Kirche” [ebd., 149f]. Lind stand nicht nur für das von Gottes Geist geschenkte Charisma, sondern wirkte auch veredelnder als alle Bücher und alle Menschen auf Andersen ein, verkörperte also die religiöse und moralische Bildungskraft der Kunstanmut und die poetische Natur. Diese Frau und Aladin mit dem Kindergemüt sollten für ihn als ideales Vorbild - als seelische Geschwister gelten. Jenny Lind könnte auch ein Vorbild der Romanfigur Peer sein, der mit der gänzlich frommen Melodie oder mit der Unschuld seines Gesangs ,alle Zuhörer mit sich riß“ [PiG, 134]. Peer ist allerdings - wie Andersen - eine über sich selbst reflektierende Persönlichkeit.

Sowohl der Autor als auch die Figur fühlt sich als erwählt. Andersen setzte schon als junger Mann „Gott” und „,kindlichen Geist” gleich, weil er die Kraft, die hinter der Schöpfung steht, als „den kindlichen Geist, der die ersten Menschen beseelte, den mächtigen Gott, der so wundersam alles mehr und mehr erschuf' definierte. ${ }^{365}$ Auch in seinem späteren Werk wird das Kindliche immer mit der Gesundheit, der Kraft und dem Göttlichen assoziiert (Schneekönigin, Peer im Glück).

Nicht nur die Parallelen zur Persönlichkeit des Autors, sondern auch viele Stichworte aus Andersens früherem Leben findet man in Peer im Glück. In der Tat findet fast jede Phase in Peers Leben bis zu seiner Karriere als Sänger ihr Vorbild in Andersens Biographie. Die niedrige Herkunft des Autors wird durch die Gegenüberstellung von Peers Familie und der Familie des Großhändlers veranschaulicht. Der frühe Tod von Peers Vater im Feldzug entspricht dem Tod von Andersens Vater. Wie Andersens Großmutter erzählt diejenige Peers dem Enkel Märchen und Geschichten. In seinen ersten Jahren in Kopenhagen versuchte Andersen wie Peer, sich als Tänzer und Sänger durchzuschlagen und fühlte sich von den Mittänzern und Zuschauern verlacht, was auch in Peer im Glück umschrieben ist. Der Stimmbruch gilt sowohl für Andersen als auch für Peer als eine wichtige Le-

363 Vgl. Möller-Christensen 1996, S. 135; J. Andersen 2005, S. 400.

364 Möller-Christensen 1996, S. 140.

365 J. Andersen 2005, S. 122. 
benswende. Auch Biographen wie Jens Andersen nehmen den Roman als wichtige Fiktionalisierung des Lebenswegs seines Autors.

Andererseits werden diese Aspekte in Peer im Glück anders, zum Teil gegenseitig verarbeitet, als es im Leben des Autors der Fall war. Seitdem Andersen 1819 nach Kopenhagen aufgebrochen war, sah er seine Mutter und Großmutter nicht mehr. Peer bricht seinen Verkehr mit der Familie aber nie ab. Andersens erste Auftritte auf der Bühne 1820/1821 verliefen unglücklich. Zur selben Zeit besuchte er die Ballettschule des Königlichen Theaters in Kopenhagen. Als Schüler wurde er nur im Notfall als Statist auf der Bühne eingesetzt. Er bekam eine kleine Rolle als Troll im Ballettstück in vier Akten Armida, das am 12. 04. 1821 uraufgeführt wurde. Bei der Premiere stürzte Andersen kopfüber in eine künstliche Felsspalte. Das Publikum reagierte mit einem „unheilverkündende[n] Gekicher” auf das Stück. 366

Im Gegensatz dazu tanzt Peer sehr gut. Der ungeschickte Sturz von Andersen wird im Roman durch das unauffällige Zerreißen des Kostüms ersetzt. Der deutlichste Unterschied liegt in der Sängerkarriere von Andersen und Peer. Obwohl Andersen behauptete, dass das Theater seine Welt sei [MmL, 44], musste er aus der Chor- und Tanzschule entlassen werden, nachdem seine Singstimme wieder an Fülle zu gewinnen angefangen hatte, da die Teilnahme an derselben für ihn zu nichts führen könnte, so die Direktion des Königlichen Theaters [ebd. 47]. Peer aber erhält nach dem Stimmbruch und der todkranken Erfahrung den Triumph auf der Bühne. In seiner Kehle „steckten Millionen“ [PiG, 71].

Besonders das Ende des Romans scheint eine verschönerte Autobiographie des Autors zu implizieren. Zu den bekanntesten Anekdoten Andersens gehört, dass er häufig Zettel mit dem Wort „scheintot“ auf seinem Nachttisch zu deponieren pflegte. Rüdiger Görner gibt dieser Gewohnheit zwei Erklärungen: „[e]ntweder daß er glaubte, das Leben eines bereits Scheintoten zu führen, oder daß er Furcht davor hatte, eines Tages bei noch lebendigem Leibe begraben zu werden““367. Am 18. 06. 1870, zwei Monate vor dem Abschließen von Peer im Glück. (nach dem Tagebuch am 07. 08. 1870), schrieb der 65-jährige Dichter, er würde lieber sterben,

„, bevor diese Generation mich und meine Natur-Wirksamkeit vergißst; was ich an Huldigung erreichte, wird vom neuen Geschlecht vergessen oder bekrittelt werden. [...] Das seufze ich, der ich mehr Glück als Millionen andere bekam. - Kann das vergeben und vergessen werden wie ich selbst hier" [HCAT, 529].

Peer stirbt im Augenblick des Triumphs und muss nicht mehr im Schatten seines Triumphs verbleiben. Andersens aber lebte noch fünf weitere Jahre, in denen er häufig Bemerkungen wie „verstimmt“ und „lebenssatt“ in seine Tagebücher schrieb.

366 Vgl. J. Andersen 2005, S. 42f.

367 Görner: Nachwort. PiG, 365. 
Erdichtete Andersen durch einen vollkommenen Helden sein Leben als ein Märchen, das seine früher unerfüllt gebliebenen Wünsche erfüllte? Was der Autor als junger Mann erhofft hatte, scheint die Figur Peer eines nach dem anderen erhalten zu haben: Die Anerkennung seines Lehrers und seiner Mitmenschen, besonders durch die Collin-Familie, die zu den Vorbildern der fiktiven GroßhändlerFamilie gehört, der Erfolg auf der Bühne und dem „Glücksfall“ - das Fallen im Glück. Andersen, der im Erzählung „es ist herrlich zu leben [...] das sei das schönste Märchen“ [A II, 463] (W as die ganze Familie sagte), im Tagebuch aber „[ich bin] des Lebens müde, lebenssatt" [HACT, 534] schrieb, schuf aus Peers Geschichte sein persönliches Lebensmärchen.

In seiner Autobiographie schrieb Andersen, dass sein Leben ein schönes Märchen ist:

Mein Leben ist ein bübsches Märchen, so reich und glückselig! Wäre mir als Knabe, als ich arm und allein in die Welt hinaus ging, eine mächtige Fee begegnet und hätte gesagt: ,wähle deine Laufbahn und dein Ziel, und dann, je nach deiner Geistesentwicklung und wie es der Vernunft gemäß in dieser Welt sein muß, beschütze und fübre ich dich!" - mein Schicksal bätte nicht glücklicher, klüger und besser geleitet werden können. Meine Lebensgeschichte wird der Welt sagen, was sie mir sagt: es gibt einen liebevollen Gott, der. Alles zum Besten führt. [MmL 9]

Andersen wiederholte diese Behauptung, dass das Leben das schönste Märchen sei, immer wieder in seiner Autobiographie, aber tatsächlich ist diese Behauptung eine Lüge.

„He tried to believe in this lie, but it is because Andersen could not live the life of a lie that he constantly told this lie, hoping for God's protection. When he was truthful, be obliquely criticized himself for pretending to be something he could never be. [...] Not only did he suffer from class discrimination throughout his life, but his own inadequacies as a writer were apparent to him, or made apparent to him, and ironically, he was at his best and most oblique when he exposed himself. " 368

Im Vergleich mit seiner Autobiographie, die sein Leben verschönert, verrät das fiktive Werk Andersens häufig die Wahrheit seines Lebens. Einerseits erzählt der Autor viel mehr von der Misere des Volkslebens in seinen Märchen und Geschichten als in seiner Autobiographie. Von der Armut und dem früheren Leben seiner Mutter Anna Marie Andersdatter als Bettlerin und Mutter einer unehelichen Tochter beispielsweise, redete Andersen in Märchen meines Lebens sowie in Lebensbuch $^{369}$ nicht. Nur in den fiktiven Geschichten Das kleine Mädchen mit den Schwefelbölzerm und Sie tangte nichts wird die dunkle Seite des Lebens seiner Mutter indirekt

\footnotetext{
368 Zipes 2006, S. 234.

${ }^{369}$ Die beiden Bücher sind autobiographische Schreibung von Andersen. 1832 entstand Lebensbuch ohne äußeren Anlass, während MmL 1855 im Rahmen der 1853 begonnenen Ausgabe Samlede Skrifter (Gesammelte Schriften) erschien [MmL 221].
} 
angedeutet. Andererseits wird im fiktiven Werk, unter anderem in Märchen, die öffentlich verborgene Homosexualität des Autors versteckt angedeutet. Das Märchen mit eindeutiger Handlungsebene und daraus abgeleiteter schärferer Konturierung der Schauplatz-Konzeption und Figurenkonstellation bietet dem Autor die Möglichkeit, sein Geheimnis - die Homosexualität - als versteckte Information in die Märchengeschehnisse zu übersetzen. „Gerade diese märchenhafte Geschlossenheit und märchenhafte Glaubwürdigkeit des Geschehens aber immunisiert die autobiographischen Züge dieser Geschichte gegenüber nicht eingeweihten Lesern." ${ }^{370}$ Während die Autobiographie die Wahrheit von Andersens Leben verhüllt, enthüllt sein fiktives Werk diese auf indirekte Weise.

Ist Peer im Glück, ein autobiographischer Rückblick auf das frühere Leben und ein fiktiver Märchenroman eines 65-jährigen Dichters, mehr als Verhüllung oder Enthüllung zu lesen?

Im Roman wird mindestens ein Leitmotiv von Andersens Leben verhüllt: Seine Zuneigung zu Männern. Die in $O . Z$. noch implizierte Homoerotik scheint in Peer im Glück zu einer „Prinz-und-armes-Kind“-Beziehung zwischen Felix und Peer verharmlost zu werden.

Die beiden jungen Männer sind am selben Tag im selben Haus geboren. Peer wird „Glückskind“ genannt, während Felix das Glück im Vornamen trägt und als Kind eines reichen Vaters auch ein Glückskind ist. Die beiden haben immer die gleiche Sehnsucht - das Kutschieren, die Zuneigung zum selben Mädchen. Als Felix den kleinen Peer als Prinzen mit Krone auf der Bühne sah, wäre er gern an Peers Stelle gewesen. Zwischen den beiden Figuren gibt es eine innere, seelische Verbindung. Sie sind als Zwillinge, sowohl wegen der Geburt am gleichen Tag als auch seelisch, konzipiert.

Das Vorbild für eine solche Seelenverwandtschaft zweier Männer kommt im früheren Roman $O . Z$. vor. Die Titelfigur Otto Zostrup wünscht sich eine reine und zugleich intime Beziehung zu seinem Freund Wilhelm. Die beiden Männer können sich ohne körperliche Nähe umarmen und küssen: „Beide Männer sollen sich so rein und unschuldig wie möglich gegenübertreten können, nur dann wird ihre Freundschaft das himmlische Niveau erreichen können, in dem man sich am nächsten ist - nicht körperlich, sondern geistig. Nur so wird man zur Zwillingsseele." 371

Die geistige Liebesbeziehung zwischen Freunden war Andersens Wunsch. Im Jahr 1831 - also fünf Jahre vor der Veröffentlichung des Romans O. Z. - schrieb Andersen in einem Brief an Edvard Collin, den der Dichter mehr als alle anderen liebte:

„Von allen Menschen sind Sie derjenige, den ich in jeglicher Hinsicht als meinen wabren Freund betrachte; seien Sie es immer, lieber Collin. Ich bedarf wirklich ei-

\footnotetext{
370 Detering 2002, S. 201.

371 J. Andersen 2005, S. 213 f.
} 
nes offenen Herzens, aber der Freund, den ich als einen solchen lieben kann, muß auch Geist haben, ich muß ibn in dieser Hinsicht achten können, und daran fehlt es im Grunde den wenigen anderen, die ich so recht liebe. Nur Sie sind unter den Gleichaltrigen derjenige, dem ich mich wirklich verbunden füblen kann. "372

Daher bat er Collin, ihn zu duzen, was Collin ablehnte. Collin war Jurist, Staatsbeamter und Familienmann. Er war der Meinung, dass Andersen eine „krankhafte weiche Stimmung“ habe. Zu Andersens Stück Agnete und der Meermann, dessen psychologischer Hintergrund sowie der gesamte Handlungsverlauf sich an Andersens eigener Geschichte orientierten und das Andersen selbst als das gemeinsame Geisteskind von sich und Collin bezeichnete, schrieb er, Andersen habe „nicht die Besonnenheit, die feste Sicherheit und die Macht“ über die Gedanken. ${ }^{373}$ Den charakteristischen Unterschied zwischen beiden kannte Andersen. Collin war der männliche und stärkere und hielt an den Mannestugenden fest. Andersen war der weiche, androgyne und schwärmerische. „,[G]erade meine Weichheit, meine halbe Weiblichkeit, ließ mich an Ihnen festhalten“374, schrieb Andersen am 24. 09. 1833 an Collin. Dass er in Collin viele herrliche Eigenschaften sehe, steht im selben Brief.

Eine direkte Übersetzung der Beziehung zwischen dem jungen Andersen und dem jungen Edvard Collin in diejenige von Peer und Felix im Roman liegt schon deswegen nicht vor, weil dort nicht von homoerotischer Liebe die Rede ist. Zwischen Peer und Felix besteht allerdings auch ,unleugbar eine Art von Sympathie, so verschieden sie auch waren" [PiG, 108], obwohl sie sich als junge Erwachsene - wie es zwischen Andersen und Collin der Fall war - siezten. Felix nennt Peer seinen einzigen Freund. Er ist die lebenslustige Heiterkeit und Liebenswürdigkeit selbst. Peer ist der glücklichere und der begabte Künstler. Für Peer ist Felix besser als er selbst, weil Felix „tapfer“ sei, was Andersens Beschreibung Edvard Collins entspricht. ${ }^{375}$ Peer fällt dieses Urteil, nachdem er durch den Brief seiner Großmutter erfahren hat, dass Felix seine Rechtschaffenheit trotz des kleinen Unmuts zwischen den beiden wegen eines Mädchens preist, während Peer seinerseits ob der Ungerechtigkeit der Standesdifferenzen zwischen ihm und Felix zornig war. Mit dieser Ahnung hat er sein Kindergemüt verloren. Felix ist also deswegen tapferer, weil er den angeborenen Unterschied zwischen sich und Peer nicht beachtet und diesen als einen gleichberechtigen Freund behandelt.

Felix Zuneigung zu Frauen wird speziell betont. Als Felix Peer darum beneidet, dass der Sänger „da oben im Theater bei all den kleinen Mädchen aus und ein gehen" könne, sieht in Peer aber „nichts sonderlich Beneidenswertes" [PiG, 96]. Peer erscheint zwar als heterosexueller Mann, aber in seiner Liebe zu Frauen findet sich immer etwas Zweideutiges.

\footnotetext{
372 Brief am 19. 05. 1831 von Andersen an Edvard Collin. Zit. nach J. Andersen 2005, S. 219 f.

373 Brief am 29. 08. 1833 von Edvard Collin an Andersen. Zit. nach J. Andersen 2005, S. 250.

374 Brief am 24. 09. 1833 von Andersen an Edvard Collin. Zit. nach J. Andersen 2005, S. $219 f$.

375 Edvard Collin „,besaß [...] eine Keckheit“. [MmL 81]
} 
Peer im Glück ist kein kindliches Märchen, in dem die Erotik überhaupt keine Rolle spielt. Die Sexualität verkörpert sich in den tanzenden Elfenmädchen in Peers Phantasie. Peer erlebt eine entsprechende Erfahrung im Traum. Die tanzenden Elfen sind gefährlich verlockend und sündig. Eine von ihnen übernimmt das Aussehen der Apothekerstochter, ist aber ,im Rücken hohl [...], einzig und allein eine schöne Vorderseite, hinten offen, gar nichts drin“ $[\mathrm{PiG}, 68]^{376}$. Die dämonische weibliche Körperlichkeit ohne Inhalt veranschaulicht Peers Haltung zur Geschlechtlichkeit, die durch den Glauben und Geist überwunden werden muss. Diese Haltung entspricht einer Bemerkung Andersens zur Geschlechtlichkeit: „Gott, führe mich zum Vernünftigsten und Besten! Ich halte diese Befriedigung nicht für eine Sünde, finde es aber mit solchen Wesen ekelhaft und gefährlich und eine unverzeihliche Sünde mit einem unschuldigen Wesen." [HCAT, 109].

Peers Liebe zu Frauen ist nicht erotisch gefärbt. Das erste Mädchen, das Peer liebt, ist die schöne und rührende Apothekerstochter und ein „Naturkind“. Zwischen ihr und Peer gibt es eine Sympathie und immer stärkere „Innigkeit“. Man muss an Andersens Bewertung seiner frühen Liebe zu Riborg Voigt denken: das Mädchen sei ein „geistreiche[s], kindliche[s] Wesen“, wie es Andersen noch nie gesehen hatte. ${ }^{377}$ Dieselbe Kindlichkeit findet Peer im zweiten Mädchen, mit dem er sich gut versteht - die sechszehnjährige Baronesse, „ein unschuldsvolles, schönes Kind“" $\mathrm{PiG}, 113]$. Es ist auch die unschuldige Baronesse, die das Wort „Aladin" - das Sinnbild von Peers Leben - ausspricht. Die Geschlechtlichkeit der beiden Mädchen wird abgeschwächt, indem die Kindlichkeit und die Unschuld statt des Aussehens und der Weiblichkeit wiederholt betont werden. Die Beziehung zwischen Peer und ihnen zeichnet sich mehr durch eine Innigkeit und geistige sowie seelische Verwandtschaft als durch erotische Liebe aus. Auf die vom Autor erwünschte Form der Liebe - eine nicht-erotische Liebe zwischen Seelenverwandten - die Andersen in seinen Beziehungen zu Riborg Voigt, Edvard Collin, Jenny Lind, Jonas Collin dem Jüngeren usw. suchte, wird durch Peers Beziehungen zu Felix und den beiden Mädchen angespielt. Diese Beziehungen sind ein Anschlusspunkt zwischen Andersens Leben und dem fiktiven Roman und eine zumindest teilweise - Enthüllung der Wirklichkeit. Keine der drei Beziehungen ist idealisiert. Während die Apothekerstochter mit dem dicken Ratsherrn verlobt ist, ${ }^{378}$ ist Peers Beziehung zur Baronesse noch keine Liebe. Die Freundschaft von Felix zu Peer ist ebenfalls zweifelhaft.

Mit der Freundschaft zwischen diesen beiden wird die „Seelenzwillings“Beziehung zwischen Andersen und dem lebenspraktischeren Edvard Collin assoziiert. Allerdings ist die Freundschaft beider Figuren ganz anders konzipiert. Felix

\footnotetext{
${ }^{376}$ Mit dem hinten offenen weiblichen Körper wird die ,Frau Welt', eine Personifikation von Lust und Begierde, assoziiert.

377 Brief am 01. 01. 1831 H. C. Andersens brevveksling med Lucie \& B. S. Ingemann. Zit. nach J. Andersen 2005, S. 191.

378 Das Vorbild Riborg Voigt heiratete den Forstkandidaten Jakob Bøving.
} 
spielt nämlich die Rolle eines aktiv Werbenden in ihrer Freundschaft, während Andersen sich nach Collin sehnte. ${ }^{379}$ Felix ist auch derjenige, der nach einer Streitigkeit um eine Versöhnung bittet. Edvard Collin dagegen sandte Andersen das Manuskript von Agnete und der Meermann zurück und schrieb fast zwei Monate lang (von Anfang Januar bis zum Ende Februar 1834) keinen Brief an Andersen, nachdem er das Manuskript, das bei ihm eine unangenehme Empfindung erregt hatte, gelesen hatte. Schließlich war es nicht sehr wahrscheinlich, dass der besonnene Collin und Andersen wie die beiden Figuren im Text Arm in Arm in der Stadt gingen.

Ist die Freundschaft zwischen Peer und Felix eine Idealisierung der Beziehung zwischen Andersen und Collin? Entscheidend ist, dass die beiden Figuren als junge Erwachsene sich siezen, obwohl sie sich als kleine Kinder schon kennengelernt haben und im selben Haus aufgewachsen sind. Dass Collin am 28. 05. $1828 \mathrm{im}$ Brief Andersens Duz-Antrag klar und entschieden zurückwies, betrübte Andersen sehr lange. Noch in seinem 1847 veröffentlichen Märchen Der Schatten verarbeitete er diese alte Geschichte in der Beziehung zwischen dem „sklavisch ernied-

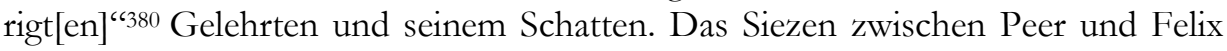
weist seinerseits auf das Fehlen echter Intimität hin. Ihr ausgesöhntes Verhältnis ist vielmehr eine Versöhnung zwischen Felix' Lebenslust und der Geistigkeit Peers. Er nennt ihn seinen einzigen Freund, weil er die Begleitung Peers braucht, um junge Damen anzuziehen. Die Freundschaft der beiden Figuren ist daher nicht nur keine Idealisierung der Andersen-Collin-Freundschaft, sondern überdies ironisch konzipiert.

Auch die Anerkennung durch die Familie des Großkaufmanns stimmt mit Andersens Wunsch, von den Collins anerkannt zu sein, nicht überein. Der bürgerliche Großkaufmann ist nicht - wie Jonas Collin - der Förderer des jungen Peer. Der heimliche Wohltäter ist der künstlerisch gleichartige Gesangsmeister. Dieser ist nicht nur Künstler, sondern auch Jude und daher gesellschaftlicher Einzelgänger. Wie Peer hat er eine unglückliche Liebesgeschichte durchgemacht. Er ist derjenige im Roman, der Peer am nächsten steht. Dass er statt des Großkaufmanns Peer fördert, ist ein Zeichen dafür, dass nur ,gleichartige“ Menschen Peer am besten verstehen und anerkennen. Die von Andersen erwünschte Anerkennung erreichte Peer nur, indem er „wie Blumen in ein Wasserglas“ [PiG, 116] den bürgerlichen Salon schmückte.

Peers Erfolg in der Pension ist ein ironischer Gegensatz zu Andersens eigenen Erfahrungen in der Pension. Andersen besuchte die Pensionsschule unter Rektor Simon Meisling zwischen 1822 und 1827. Diese Zeit war für den Dichter geistig bedrückend, „die finsterste, die unglücklichste Zeit in meinem Leben“ [MmL, 61]. „Der Rektor hatte meine sich unverhohlen aussprechende weiche Natur durchaus mißverstanden, meine überströmenden Gefühle waren lächerlich gemacht und

379 Briefwechsel Andersen/Collin, zit. nach Detering 2002, S. 180.

${ }^{380}$ Detering 2002, S. 182. 
zurückgedrängt worden" [MmL, 63], so Andersen in seiner Autobiographie. Wegen seiner poetischen Natur war er für den autoritären Meisling ein Dorn im Auge. Im Lebensbuch notierte Andersen ein Wort des Lehrers: „Sie sind ein stupider Kerl, aus Ihnen wird nie etwas!“ [Lebensbuch, 85].

Peer hingegen wird, wie Andersen es erwünschte, mit Vorzug von den übrigen Schülern behandelt und alles in der Schule geht für ihn gerade nicht „fabrikmäßig“ zu [Vgl. Lebensbuch, 77]. Er bekommt keine „Handschmitze“ wie seine Mitschüler und im wahren Leben der junge Andersen, und macht größere Fortschritte als die anderen. Rektor Gabriel preist sein Talent und ihm wird sogar erlaubt, die Rolle Romeos im Theaterstück zu spielen. Diese Freiheiten und der Erfolg scheinen eine Idealisierung von Andersens Erlebnissen zu sein. Doch empfinden seine Mitschüler anstelle von Peer dieselbe geistige Bedrückung wie Andersen. Der Mitschüler Madsen fühlt sich eingesperrt: ,[e]s war eine Grausamkeit von Eltern und Lehrern, daß ein Mensch seine beste, schönste Jugendzeit vertun sollte, Grammatik, Namen und Jahreszahlen lernen, was keiner mag, statt seine Freiheit zu genießen, tüchtige Luft zu holen, herumzuschlendern mit der Büchse im Nacken, als guter Schütze.“ [PiG, 45]. Ein anderer Schüler, Primus, erleidet „Handschmitze“. Nicht Peer, sondern die beiden Nebenfiguren stehen hier für den Dichter. Damit wird Peers Glück in der Schule als etwas Unwahrscheinliches stilisiert und insofern als ein Märchen ironisch lesbar.

Peers Erfolg als Sänger endet mit seinem Tod auf der Bühne, was als märchenhafte Versöhnung mit der Realität gesehen werden kann.

Dass Peer im Augenblick des Triumphs an Herzversagen stirbt, ist eine romantischironische Pointe, die aufgesetzt erscheinen mag, als Verweigerung des Liebestodes oder scblicht als Glücksfall. Denn es bleibt Peer erspart, sich neu beweisen oder im Schatten seiner Aladin-Oper etwas Neues, noch Zukïnftiges schaffen zu müssen. 381

Das Ende Peers kann zugleich als Parodie auf das Ende des ersten Grimm'schen Märchens Der Froschkönig oder der eiserne Heinrich gelesen werden: „es waren doch nur die Bande, die vom Herzen des treuen Heinrich absprangen, weil sein Herr erlöst und glücklich war" [KHM I, 32]. Einerseits befreit der Herzinfarkt ${ }^{382}$ Peer von dem Leid, als Schatten seines Triumphs weiterzuleben, andererseits aber macht der plötzliche Tod aus ihm „ein hübsches Feuerwerk, das hinfährt und erlischt" [PiG, 120], wie er es selbst vorhergesagt hat. Zugleich entkommt Peer seinem Widerspruch, ein sentimentalischer und selbstbeobachtender Künstler zu sein und von den Mitmenschen als naiv und kindlich bezeichnet zu werden. Mit dieser Flucht vor der Wirklichkeit wird Peer „der Glückliche unter Millionen“. Das lese ich als eine ironische Bemerkung zu der fragmentarischen und zweideutigen Romantik durch den Autor.

\footnotetext{
381 Görner: Nachwort. PiG, 379f.

382 Der tatsächliche Herzinfarkt wird im Text zum Bruch einer Ader im Herzen märchenhaft verharmlost.
} 
Damit soll diesen Teil abschließend, die These gegeben werden, dass der Roman Peer im Glück weder eine Verschönerung des frühen Lebens von Andersen noch eine Verhüllung der Wahrheit seines Lebens ist, sondern deren fiktional transformierte Enthüllung. Mit Peer im Glück versuchte Andersen nicht, eine Idylle aus seiner eigenen Geschichte zu schaffen. Der Roman ist zwar ein Rückblick auf die wichtigen Phasen seines frühen Lebens, aber die ehemaligen Träume von Andersen - Erfolg in der Schule, Glück auf der Bühne und die Anerkennung durch die Bürger - werden nur unter einer Bedingung erfüllt, nämlich der Wirklichkeit zu entkommen. Die Realität ignorierend ist die Pension ein freier Ort, alle kommen ihm offen und liebreich entgegen und das Leben Peers endet in irdischem Jubel. Andersen war sich bewusst, dass Peer nur im Märchen „der Glückliche unter Millionen“ sei. Er schrieb im letzten Kapitel von Märchen meines Lebens: „meine Lebensgeschichte [wird] der beste Kommentar zu allen meinen Arbeiten sein [...].“ [MmL, 218] Sein letzter Roman ist hingegen ein Kommentar zu seiner Autobiographie: Die Behauptung, dass sein Leben ein hübsches Märchen sei, steht in zweifelhaftem Licht. Nur wenn man das Leben als ein Märchen liest, ist es tatsächlich schön. Dies ist der Grund, weshalb der Roman einen märchenhaften Titel trägt. 



\section{Thomas Mann: Königliche Hoheit}

Nach der Eheschließung glaubte der einst einsam leidende Schriftsteller Thomas Mann, dass sein Glück märchenhaft sei: seine Katia sei eine „Märchenbraut“ [GW XIV, 119]:

Nichts gleicht meinem Glück. Ich bin vermählt, ich habe eine außerordentlich schöne junge Frau - eine Prinzessin von einer Frau, wenn man mir glauben will, deren Vater königlicher Universitätsprofessor ist und die ibrerseits das Abiturientenexamen gemacht hat, ohne deshalb auf mich berabzusehen, sowie zovei blühende, zu den böchsten Hoffnungen berecbtigende Kinder. [...] Sähen die Wächter meiner Jugend mich in meiner Pracht, sie müßten irre werden an allem, woran sie geglaubt. [GW XIV, 166f]

Die Schilderung seines Glücks mit einem träumerisch stolzen Ton erinnert an den Anfang der Autobiographie von Thomas Manns Lieblingsschriftsteller Hans Christian Andersen:

Mein Leben ist ein bübsches Märchen, so reich und glücklich. Wäre mir als Knabe, als ich arm und allein in die Welt binausging, eine mächtige Fee begegnet und bätte gesagt: ,Wähle deine Laufbabn und dein Ziel, und dann, je nach deiner Geistesentwicklung und wie es der Vernunft gemäß in dieser Welt sein muß, 


\section{beschütze und führe ich dich!" - mein Schicksal bätte nicht glücklicher, klüger und besser geleitet werden können. ${ }^{383}$}

Die beiden Schriftsteller glaubten mit einem gewissen Überlegenheitsgefühl an das Erwählt-Sein ihres Lebens. Thomas Mann bediente sich häufig Märchenvorbilder, um seine vorbestimmte Stigmatisierung und sein Erwählt-Sein auszudrücken. In seinem gesamten Werk inklusive seiner Briefe beschreibt Thomas Mann sein Leben mithilfe von Märchen ${ }^{384}$ : den standhaften Zinnsoldaten nannte er das „Symbol seines Lebens" ${ }^{\text {385; }}$ in Tonio Kröger, seiner Erzählung mit autobiographischen Bezügen, die auch ein Vorläufer von Königliche Hoheit ist, ${ }^{386}$ erscheint die sehnsüch-

\section{$383 \mathrm{MmL}, 9$.}

384 Es gibt zwar keine schriftliche Bestätigung durch Thomas Mann, es lässt sich aber nicht ausschließen, dass Thomas Mann tatsächlich Parallel zwischen seinem Leben und Märchen entdeckte. In Der standhafte Zinnsoldat gibt es eine Stelle:

„Da kam plötzlich eine große Wasserratte, die unter dem Rinnsteinbrett wohnte.

,Hast du einen Paß?" fragte die Ratte. ,Her mit dem Paß!"

Aber der Zinnsoldat schwieg still und bielt das Gewehr noch fester.

Der Kabn fubr davon und die Ratte hinterher. Hu! wie fletschte sie die Zähne und rief den Holzspänen und dem Stroh zu: ,Haltet ihn! Er hat keinen Zoll bezahlt! Er hat den Paß nicht gezeigt! " [A I, 132]

Während die Szene, die Thomas Mann sehr entzückte, als er die damals noch jugendliche Katia Pringsheim in einer Münchener Trambahn beobachtete, in Katias Memoiren so geschildert wird:

„Als ich aussteigen wollte, kam der Kontrolleur und sagte: Ibr Billet!

Ich sag: Ich steig bier grad aus.

Ihr Billet mußi ham!

Ich sag: Ich sag Ihnen doch, daß ich aussteige. Ich hab's eben weggeworfen, weil ich hier aussteige.

Ich muß das Billet - Ihr Billet, hab ich gesagt!

Jetzt lassen Sie mich schon in Rub! sagte ich und sprang wütend hinunter.

Da rief er mir nach: Mach daß d' weiterkimmst, du Furie!"Mann, Katia 2000, S. $21 \mathrm{f}$.

Es wäre denkbar, dass Thomas Mann in der Münchener Studentin einen Text seines Lieblingsschriftstellers fand, dessen Hauptfigur er später das Symbol seines Lebens nannte, und dass diese Entdeckung zusammen mit der Durchsetzungskraft Katias ihn so beeindruckte, dass er daraus in Königliche Hobeit eine Szene über Imma Spoelmanns Durchbrechen der Regeln entwickelte:

„Sie schickte sich an, auf dem Bürgersteige vorm Schloß zwischen den Gliedern hindurchzugehen. Der Unteroffizier mit der heiseren Stimme sprang vor. „Kein Durchgang!“ schrie er und hielt den Kolben seines Gewehrs vor sie hin. ,Kein Durchgang! Umkehren! Abwarten!‘ Da aber wurde Miss Spoelmann zornig., Was fällt Ihnen ein!' rief sie. ,Ich habe Eile!‘ [... Und dabei schob sie mit der Linken den Kolben mitsamt dem verdutzten Unteroffizier beiseite und ging mitten zwischen den Gliedern hindurch, - ging geradeaus ihres Weges, bog linker Hand in die Universitätsstraße und entschwand den Blicken." [GKFA 4.1, 221f]

385 Am 09/10. 02. 1955 an Agnes E. Meyer; Br. III, 375

386 In dem essayistischen Monolog spricht Tonio Kröger: „Einen Künstler, einen wirklichen, nicht einen, dessen bürgerlicher Beruf die Kunst ist, sondern einen vorbestimmten und verdammten, ersehen Sie mir geringem Scharfblick aus einer Menschenmasse. Das Gefühl der Separation und Unzugehörigkeit, des Erkannt- und Beobachtetseins, etwas zugleich Königliches und Verlegenes ist in seinem Gesicht. In den Zügen eines Fürsten, der in Civil durch eine Volksmenge schreitet, kann man etwas Ähnliches beobachten.“ [GKFA 2.1, 272f] Hier markierte Thomas Mann zum ersten Mal in seinem Werk die Analogie von Künstler und Fürst, die er 1903 in einem Brief an Opitz als „,ein symbolisches, ein repräsentatives Dasein“ [GKFA 21, 251] bestimmte. In demselben Brief wird der Titel von Königliche Hoheit, die damals noch als eine Künstler-Novelle geplant wurde, zum ersten Mal 
tig liebende kleine Seejungfrau als Lebenssymbol des Titelhelden. Das ebenfalls autobiographisch geprägte Werk Königliche Hoheit wird schon von dem Autor als „lehrhaftes Märchen“ [GKFA 14.1, 242] bezeichnet. ${ }^{387}$ In diesem Roman werden sowohl das Märchen als Gattung mit strukturellen Merkmalen als auch thematisch-motivische Details der einzelnen Märchentexte adaptiert. Die Märchenadaption spielt eine zentrale Rolle für die Struktur des Romans. Es ist auch zu bemerken, dass das Autobiographische häufig nicht in der dargestellten Wirklichkeit des fiktionalen Textes zu finden ist, sondern in den märchenhaften Zügen. Trotz der großen Bedeutung des Märchenhaften für den Roman erscheint Königliche Hoheit als ein realistisch erzähltes Werk, was zu Missverständnissen bei zahlreichen zeitgenössischen Lesern führte. Die Beziehungen zwischen der realistischen Kulisse, der Märchenadaption und den autobiographischen Bezügen richtig zu bestimmen, ist entscheidend für das Verständnis von Königliche Hoheit, die von den Kritikern häufig als „zu leicht empfunden“ [GW XI, 573] und deswegen geringgeschätzt wird. Der Roman, der nach Thomas Mann „eines der Experimente meines Lebens" [GW XI, 573] war, ist ein kompliziert verschlüsselter Text, wobei nicht zuletzt die Märchenelemente der Schlüssel zur Botschaft des Romans sind. Es ist die Aufgabe dieses Kapitels, die Verhältnisse zwischen Märchen und Wirklichkeit in Königliche Hoheit zu untersuchen. Entsprechend den drei Kategorien werden Märchen und Realismus in der Textoberfläche (der täuschende Realismus des Textes), Märchen und Autobiographie als Substanz des Textes sowie die Bedeutung von Märchen und Wirklichkeit für die Figurenkonstellation beobachtet.

\subsection{Die Funktion des Realistischen in dem Märchenroman Königliche Hoheit}

Der Roman Königliche Hoheit besitzt ein realistisches Milieu. Das Schreibverfahren der Buddenbrooks wiederholend, sammelte Thomas Mann Materialien aus verschiedenen Quellen für sein Projekt der Fürstennovelle, aus dem später ein Fürstenroman wurde. Er bediente sich autobiographischer Vorgaben und Quellen. Details wie die „Geschichte mit dem Guttaperchapapier“388, das Samuel Spoelmann Klaus Heinrich einmal holt, sowie der erste gemeinsame Ausritt von Klaus Heinrich und Imma Spoelmann werden in Katia Manns Memoiren als wirkliche Geschehnisse bestätigt, wobei der Ausritt in der Wirklichkeit eine Radtour war. Die meisten Figuren des Romans haben Modelle aus Thomas Manns Lebenswelt: Während hinter Klaus Heinrich, der fürstlichen Familie und den Spoelmanns die Geschichten der Mann- und Pringsheim-Familien stehen, erkannten die zeitgenössischen

\footnotetext{
erwähnt: das neue Werk solle ein „Gegenstück“ [GKFA 21, 251] zu Tonio Kröger sein.

387 Mit der Bezeichnung meinte Thomas Mann allerdings mehr das wunderbare Milieu des Textes als die Gattung Märchen. Vgl. Petersen 1973, S. 217.

388 Mann, Katia 2000, S. 67. Vgl. GKFA 4.2, 95f.
} 
Leser in Dr. Überbein, Dr. Sammet, Knobelsdorff, der Gräfin Löwenjoul und vielen anderen Charakteren Züge ihrer eigenen Zeitgenossen wieder. ${ }^{389}$ Darüber hinaus sammelte Thomas Mann literarische und historische Quellen zur Darstellung des fürstlichen Lebens und der ökonomischen Verhältnisse im Großherzogtum und in Amerika. Seine Vorlagen sind „Memoiren, Briefsammlungen, historische Berichte über ein Zeitalter, in dem das Selbstbekennerische mit dem Aristokratischen so oft zusammenfloß“. ${ }^{390}$ Zeitungs- und Zeitschriftenartikel boten Thomas Mann ebenfalls reale Vorbilder für sein fiktives Herzogtum. ${ }^{391}$ Zahlreiche Informationen über die Finanzierung des Staates und des Fürstenhauses erhielt Thomas Mann brieflich bspw. von dem Rechtsanwalt Dr. Ballin, etwa über Besteuerungsverhältnisse im Herzogtum Braunschweig, und von dem Münchener Schriftsteller Robert Prinz. Historische Romane und die Hofnovelle Ibre Hoheit von Herman Bang dienten Thomas Mann zum Teil in seinem Roman als direkte Vorlagen. ${ }^{392}$ Thomas Mann nennt seine Schreibtechnik „höhere[s] Abschreiben“393. Er will so wirklichkeitsgetreu wie möglich erzählen. Das Aneignen stellte er stets höher als das Erfinden. ${ }^{394}$ Wie er 1945 zu Doktor Faustus erläuterte, geht es bei seinem Werk um realistische Plausibilität: „Was ich brauche sind ein paar charakterisierende, realisierende Exaktheiten ${ }^{395}$ (man kommt mit wenigem aus), die dem Leser ein plausibles, ja überzeugendes Bild geben“396. Realistische Beschreibungen von Schauplätzen (z. B. die „,mit weißer, hier und da gelbfleckiger und eingerissener Seide bekleidet[en]" Wände [GKFA 4.1, 62] und der Tisch mit einer „achteckige[n] Platte aus milchiger Perlmutter“ [GKFA 4.1, 63] in dem Silbersaal, die an das Schloss der Schneekönigin aus Andersens gleichnamigem Märchen erinnert) und des Aussehens der Figuren (z. B. die Bekleidung und das Aussehen von Imma Spoelmann, als Klaus Heinrich sie zum ersten in Delphinenort sieht [GKFA 4.1, 247] ${ }^{397}$ sorgen für solche ,Exaktheiten' und damit ein realistisches

\footnotetext{
${ }^{389}$ Das biographische Vorbild des Selbstmord begehenden Hauslehrers Raoul Überbein, der in den Notizen und früheren Entwürfen Hutzelbein heißt, ist bspw. der ebenfalls durch Selbstmord endende Münchener Arzt Hutzler. Vgl. GKFA 4.2, 96.

390 Wyling 1967, S. 73. Um einige Beispiele zu nennen, Thomas Mann liest die Memoiren der Baronesse Cecile de Courtot, denen er einige Figurennamen und Eigennamen entnimmt, historische Romane wie Unwiederbringlich von Fontane, Gertrude Athertons Hofroman Rulers of Kings und Herman Bangs Novelle Ihre Hobeit sowie Andrew Carnegies Anweisungen für Kaufleute Empire of Business. ${ }^{391}$ Die Zeitungsmeldung unter der Rubrik „Tagesneuigkeiten“ über den Verkauf von zwei Schlössern des Kaisers bot Thomas Mann ein reales Vorbild.

392 Thematische und motivische Parallelen zwischen Königliche Hoheit und Ibre Hoheit vergleichen Gremler 2003, S. 98ff und Marx 1995, S. 187 f.

393 An Theodor Adorno vom 30. 12. 1945; Br. II, 470.

394 Vom 28. 03.1906 an Kurt Martens; Br. I, 62.

395 Aufgehoben im Original.

396 Vom 30. 12. 1945 an Theodor W. Adorno; Br. II, 470.

397 „Sie war wunderbar gekleidet: in ein Hausgewand aus ziegelfarbener Rohseide und mit offen herniederhängenden Ärmeln, dessen ganzes Bruststück aus einer schweren Goldstikkerei bestand. An einer Perlenkette lag ein großer, eiförmiger Edelstein auf ihrem bloßen Halse, dessen Haut die Farbe angerauchten Meerschaums hatte. Ihr blauschwarzes, seitwärts gescheiteltes und schlicht
} 
Milieu. Schon relativ früh gab Thomas Mann in einem Brief zu, dass „die Détails [ihm] die Hauptsache sind. Sie sind so anregend!“"398. Sein Roman verbaut Details. So wird in seinen Notizen zu Königliche Hobeit „Einzelheit an Einzelheit gereiht“"399 und aus ,aberhundert Einzelinspirationen“ [GW VIII, 452] entstand sein Roman.

Es wäre allerdings abwegig, Königliche Hoheit aufgrund des realistisch gezeichneten Milieus für ein realistisches Werk zu halten. Zahlreiche zeitgenössische Interpretationen verstanden diesen Roman als einen politischen Hofroman, was Thomas Mann einen „öffentliche[n] Irrtum“ [GKFA 14.1, 241] nannte. Ein „deutscher Fürst“", der pseudonym mit Prinzessin Fedora von Schleswig-Holstein identisch ist, fand sich bspw. durch dieses Buch ,in seiner modernen Menschlichkeit gekränkt“ [GKFA 14.1, 238], da er sich dem Vorwurf einer „Welt- und Lebensfremdheit" [GKFA 14.1, 238] ausgesetzt sah. Solche Interpretationen, die Manns Roman „allzu real“ [GKFA 14.1, 238] nahmen, erschienen dem Autor von Anfang an „unverständig und unzulänglich“ [GKFA 14.1, 238]. Die Romanwirklichkeit in Königliche Hoheit ist, wie Trapp zutreffend formuliert, „eine Illusion tatsächlicher Wirklichkeit" 400 . Der täuschende Realismus diente Thomas Mann vielmehr „als allegorisches Kleid für mancherlei ideelle Absichten“ [GKFA 14. 1, 238]. Diese ideellen Absichten von Königliche Hoheit sind nach Thomas Mann die Verwandlung des melancholischen Künstlers Tonio Kröger zu einem Fürsten sowie die experimentelle Verbindung von Hoheit und Glück. Ein Dichter müsse nach Thomas Mann nicht tatsächlich unbedingt dichten. Der, „dessen Leben symbolisch ist" [GKFA 14. 1, 242], sei ein Dichter. Der Roman ist so wie Tonio Kröger autobiographisch und damit ein Experiment mit Thomas Manns eigenem Leben. Er ist eher ein auf Details basierendes Kunstwerk als ein naturalistischer Roman. Königliche Hobeit sei nicht „geworden“" und „gewachsen“, sondern

durchaus ein geformtes Buch, auf Maß und Verhältnis gestellt, verständig, durchsichtig, gedanklich beherrscht, - beherrscht von einer Idee, einer intellektuellen Formel, die sich überall spiegelt, sich überall in Erinnerung bringt, möglichst lebendig gemacht wird, durch hundert Details die Illusion des Lebens zu erzengen sucht und doch ursprüngliche, warme Lebensfülle nie erreicht. Ein Kunstwerk, nicht Leben. Formal genommen, Renaissance, nicht Gotik [GKFA 13.1, 105f]

Die ,anregend[en]“ Details zielen daher ebenfalls auf die ideellen Absichten ab, nämlich auf das artistische Dasein. Warum entwirft der Autor das täuschende realistische Milieu und wie gibt er seinen Lesern zu erkennen, dass dieser „Realismus" in seinem Text trügerisch ist?

geknotetes Haar zeigte eine Neigung, ihr in glatten Strähnen in Stirn und Schläfen zu fallen." [GKFA 4.1, 247]

398 Vom 14. 03. 1902 an Hilde Distel; Br. I, 32.

399 Wysling 1967, S. 67.

400 Trapp 1975, S. 467. 
Das Konzept, eine täuschende Fiktionswirklichkeit zu erstellen, entnahm Thomas Mann der Philosophie Schopenhauers. Nach Schopenhauer, der die Welt als Vorstellung (die empirische Welt) von der Welt als Wille (dem Wesen, das der Zeit und des Raums enthoben ist) unterschied, beruht „die Vielheit der Welt, ihre Unterschiedenheit in Objektives und Subjektives“401 auf Täuschung und „Ich und $\mathrm{Du}$, Ich und Welt [sind] metaphysisch wesensgleich“402. Entscheidend für Thomas Mann war in Analogie dazu nicht die naturalistische Behandlung der Dingwelt in seinem Werk, sondern die Orientierung am „Ich“, das das wahre Wesen der Welt entblößt. Es ist immer das Ich, von dem in Manns Text die Rede ist: „Wie aber kann ich mein ganzes Selbst preisgeben, ohne zugleich die Welt preiszugeben? Meine Vorstellung, mein Ereignis, mein Traum, mein Schmerz?"“ [GW X, 22, Aufhebung im Original - Z. Y.]. Die Lebenswirklichkeit sollte nach Thomas Mann so geschildert werden, dass sie einerseits nicht als das ,Ding an sich ${ }^{`}$ angenommen wird, und andererseits als die Vielfalt der subjektiven Welt zu entziffern ist. „Zuverlässig ist die Lebenswirklichkeit nur als Vorwand und als Darstellungsmittel einer wesenhaft anderen Wirklichkeit.“"403 Daher gilt die Fiktionswirklichkeit in Thomas Manns Werk als Maske und Kulisse seines Kerns, die für die Selbstdarstellung notwendig sind. Die Scheinhaftigkeit der realistischen Maske wird im Werk selbst als solche Kenntnis gemacht.

Das zu verbergende und gleichzeitig dennoch zu präsentierende Selbstverständnis des Autors als Person, das hinter der Kulisse von Königliche Hoheit steht, ist deren Außerordentlichkeit, die Thomas Mann schon als Kind gespürt hatte. ${ }^{404}$ Als er 1903 Königliche Hoheit plante, wollte Mann ein fürstliches „Gegenstück zu ,Tonio Kröger““ [GKFA 21, 251] schreiben. In den früheren Fragmenten sind die Themen und Motive des selbstbewussten Künstlerseins und der nicht der Norn entsprechenden Liebesverhältnisse von Tonio Kröger beibehalten, während sie in dem Roman durch das sonderbare Dasein eines Ensembles von ,aristokratischen Monstren“ [GKFA 13.1, 107] allegorisch ersetzt sind. Das Motiv der Stigmatisierung wird bei dem missgebildeten Prinzen Klaus Heinrich, der mischblutigen Milliardärstochter Imma Spoelmann, bei Raoul Überbein und weiteren Varianten der „Erscheinungsformen von Stigmatisierung ${ }^{“ 405}$ wiederholt und unterschiedlich verarbeitet. Diese Wiederholung der Figurenkonstellation in Königliche Hoheit ist ein Vorläufer dessen, was Thomas Mann später mythische Wiederholungen nennt.

\footnotetext{
401 Kristiansen 1995, S. 824.

402 Kristiansen 1995, S. 824.

403 Kristiansen 1995, S. 826.

404 „Ich erwache z. B. eines Morgens mit dem Entschluß, heute ein achtzehnjähriger Prinz namens Karl zu sein. Ich kleidete mich in eine gewisse liebenswürdige Hoheit und ging umher, stolz und glücklich mit dem Geheimnis meiner Würde. Man konnte Unterricht haben, spazierengeführt werden oder sich Märchen vorlesen lassen, ohne daß dieses Spiel einen Augenblick unterbrochen zu werden brauchte; und das war das Praktische daran." [GKFA 14.1, 80]

405 Detering 2005, S. 130.
} 
In Freud und die Zukunft definiert Thomas Mann seinen Begriff vom Mythos so, dass „das Typische auch schon das Mythische ist" [GW VIII, 920]. In Königliche Hoheit gilt der Sonderfall als „typisch“. Durch die verschiedenen Erscheinungsformen der Sonderlinge wird der Mythos jeweils unterschiedlich experimentell durchgeführt: Klaus Heinrich und Imma Spoelmanns Versuch, sich mit einem Ebenbürtigen zu verbinden, ist zugleich eine Verbindung von Hoheit und Glück; Ditlinds Verzicht auf die fürstliche Identität und Integration in die Bürgerwelt stellt einen weiteren Weg zum Glück dar; der Großherzog, hinter dem Heinrich Mann steht, gibt seine Pflicht als Fürst auf und erstarrt in seiner Einsamkeit. In Dasein als lebensferner Dichter Axel Martinis, in dem Wahnsinn der Gräfin von Löwenjoul, in dem Selbstmord Raoul Überbeins usw. werden mehrere Alternativen zu Klaus Heinrichs glücklichem Ende dargestellt, die sogar wahrscheinlicher als das Happy Ending des Helden erscheinen, das der Autor selbst als „populär verlogen“"406 bewertet. Die „Vertauschbarkeit“ [GKFA 12.1, 257], die Thomas Mann in Felix Krull ein Gedankenexperiment von Möglichkeiten nennt, demaskiert das realistische Milieu in Königliche Hoheit als Artefakt.

Ein anderes Mittel, mit dem das Wesen des Werkes sich zu erkennen gibt, ist die textuelle Verwendung von Leitmotiven. Imma Spoelmanns Stimme, die ,aus einer tiefen und einer hohen [Stimme], mit einem Bruch in der Mitte" [GKFA 4.1, 230] besteht, die im Roman mehrmals wiederholt wird und ,als identisches Element in verschiedenen Bedeutungs- und Sinnzusammenhängen auftaucht ${ }^{6407}$, ist eines dieser Leitmotive, die die verschiedenen Dimensionen und Schichten des Textes zu einer künstlichen Einheit verflechten. Darüber hinaus sorgt die gebrochene Stimme Immas, ihre „Pagen-Anmut“ [GKFA 4.1,231] zusammen mit der wunderbaren Bekleidung 408 sowie der Hautfarbe des „angerauchten Meerschaums" [GKFA 4.1, 247] dafür, dass die Figur Imma an eine knabenhafte oder androgyne Figur aus der Weltliteratur erinnert: die kleine Seejungfrau aus Hans Christian Andersens gleichnamigem Märchen, die sich knabenhaft bekleidet und die Liebe des Prinzen nicht erlangen kann, was im Gegensatz zu Immas glücklichem Ausgang steht. Durch solche intertextuellen Zitate deutet der Autor auf die Märchenvorlagen des Romans hin und die Bedeutung der Hofgeschichte wird um eine märchenhafte Dimension erweitert: es ist nämlich nicht nur von ,aristokratischen Monstren" in der Romanhandlung die Rede, sondern auch von Figuren aus der Märchenwelt wie der kleinen Seejungfrau, Kay und Gerda, dem standhaften Zinnsoldaten sowie Hänsel und Gretel und anderen, deren Wesen mit dem außerordentlichen Dasein des Autors in verschiedener Hinsicht verwandt sind. Um das wahre Sein hinter der objektiven Vielfalt zu entdecken, müssen die Adaptionen der einzelnen Märchenmotive erkannt werden. Auf diese wird im nachfolgenden Kapitel näher eingegangen.

\footnotetext{
406 Vom 28. 01. 1910 an Ernst Bertram; Br. I, 81.

${ }^{407}$ Kristiansen 1995, S. 830.

408 Siehe Anmerkung 395.
} 


\subsection{Die Märchenstruktur und Märchenmotive in Königliche Hoheit}

Noch bevor der Roman fertiggestellt wurde, verfasste Thomas Mann 1907 einen Ankündigungstext für Königliche Hoheit, der in der Weihnachtsausgabe der Nenen Rundschau 1907 ohne Verfassername erschien. In diesem ,Waschzettel' wird hervorgehoben, dass der erste Roman Thomas Manns seit Buddenbrooks ein Fürstenroman sei, aber keine „wohlfeile Serenissimus-Satire“ [GKFA 14.1, 180]. Die Geschichte
ist romantisch zwar nur in Hinsicht auf ihre abentheuerliche Fabel und nicht in irgend einem reaktionären Sinne; aber ibre Subjektivität macht sie beinahe zum Gegenteil einer Satire, nämlich zu einem Bekenntnis, und wo sie dennoch satiri- siert, da tut sie es nur soweit, als ein Märchen es kann und mag. Denn diese Geschichte von dem kleinen populären und doch so einsamen Prinzen, der nach gewissen mißglückten Ausflügen in den „Bürgergarten“ seine Prinzessin - eine besondere Art von Prinzessin - fand und zugleich seinem bedürftigen Lande zur Wohlfahrt verhalf, dieser epische Scherz voller musikalischer Beziehungen und symbolischer Zweideutigkeiten ist ein Märchen: das Märchen von der Form und von der Sebnsucht, von der Repräsentation und vom Leben, von der Hoheit und vom Glück [GKFA 14.1, 180]

Der Autor habe den neuen Roman, gemäß dieser Ankündigung, als einen Märchenroman entworfen, was er nach der Veröffentlichung des Buches in seinen Essays und Briefen bestätigte. ${ }^{409}$ Es wäre allerdings abwegig, den Roman deswegen schon als ein Kunstmärchen zu verstehen. Vielmehr zeigen diese Aussagen, dass dem Märchenhaften in dem Roman eine besondere Bedeutung beigemessen wird. ${ }^{410}$

Nach Petersen beschäftigte Thomas Mann sich nicht mit der Märchen- und Lustspielforschung. „Er meint, wenn er von den Märchenelementen seines Romans spricht, lediglich das Irreale, Irrationale, Wunderbare, Unglaubliche sowie die Tatsache, daß er bestimmte Märchenmotive in seinen Roman eingehen läßt.“"411 Damit stimmt das Märchenhafte in dem Roman u.a. mit Bolte/Polívkas Wesensbestimmung des Märchens überein: „Unter einem Märchen verstehen wir seit Herder und den Brüdern Grimm eine mit dichterischer Phantasie entworfene Erzählung besonders aus der Zauberwelt, eine nicht an die Bedingungen des wirklichen Lebens geknüpfte wunderbare Geschichte.“412 Denn die Geschichte des Romans, die in einem fiktiven Herzogtum spielt und von der Erlösung der Hoheit

409 Vgl. Über „Königliche Hoheit“ [GKFA 14.1, 242] und Brief vom 28. 04. 1944 an A. E. Meyer [Br II, 364]. An den beiden Stellen wird Königliche Hoheit jeweils als „lehrhaftes Märchen“ und ,allegorisches Märchen“ genannt.

410 Vgl. Petersen 1973, S. 217.

411 Petersen 1973, S. 217.

412 Bolte/Polívka 1963, Bd. 4, S. 4. Vgl. Petersen 1973, S. 218. 
durch die Liebe erzählt, ist durch eine ,raumzeitliche Unbestimmtheit“ [GKFA 4.2, 69] gekennzeichnet und zeigt damit kein „realistisches Sittenbild aus dem Hofleben zu Anfang des zwanzigsten Jahrhunderts" [GKFA 14.1, 242]. Zu der Definition von Märchen lässt sich allerdings nach Max Lüthi noch ergänzen, dass nicht das Wunderbare an sich das Märchen kennzeichnet, sondern die Art und Weise, wie das Wunderbare im Märchen verwendet wird: Während das Wunderbare in den benachbarten Gattungen Sage und Legende als etwas Geheimnisvolles und zu Erklärendes erscheint, zeigt sich das Wunderbare im Märchen als selbstverständlich. ${ }^{413}$ In Königliche Hoheit erscheint das Wunderbare einerseits in den doppeldeutigen Prophezeiungen, nach deren Muster die Handlung des Romans ,selbstverständlich` läuft, andererseits in den stigmatisierten Charakteren, mit denen der Held der Geschichte sich ganz ohne Betonung des Absonderlichen verbindet. Imma Spoelmann und ihr Vater gelten als „halb Weltwunder und halb infam“ [GKFA 4.1, 292]. Die Gräfin Löwenjoul und der Hund Percy sind „wunderlich" [GKFA 4.1, 232]. Das Außerordentliche gilt in diesem Roman als normal und Klaus Heinrich wundert sich nicht darüber, da er selbst ebenfalls wegen seiner Behinderung und seiner fürstlichen Herkunft außerordentlich ist. Königliche Hoheit entspricht deswegen dem Verfahren von Märchen, das Außerordentliche als normal zu präsentieren.

Thomas Mann unterschied das Volksmärchen dadurch von dem Kunstmärchen, dass er das Kunstmärchen aufgrund seiner Intertextualität als modern bezeichnete. ${ }^{414}$ Dagegen stand das Volksmärchen „für das Bekannte, oft Gehörte $^{\text {“415, }}$, dessen Mann sich bediente, um die Struktur des eigenen Romans zu bilden. Die Struktur von Königliche Hoheit entspricht einerseits derjenigen eines Zaubermärchens: ein einsamer Prinz wirbt um eine reiche und schöne ,Prinzessin' und rettet mithilfe eines Wunders - der Mitgift seiner Braut - sein Land. Die Geschichte endet mit dem Versprechen eines märchenhaften allgemeinen Glücks und mit dem Selbstmord von Überbein - der die Rolle des Gegenspielers des Helden spielt. Das Märchen als Gattung wird mit seinen Gattungsmerkmalen adaptiert. Die Handlung des Romans ist relativ einsträngig. ${ }^{416}$ Mithilfe der Kapiteltitel wird die Geschichte Klaus Heinrichs in mehrere Episoden gegliedert; alle Figuren beziehen sich auf den Helden; märchenhafte „Isolation und Allverbundenheit" "417 zeigen sich im Roman als Klaus Heinrichs Isoliert-Sein vom Volk und als seine äußerliche sowie seelische Verbundenheit mit dem Volk und den anderen Sonderlingen.

\footnotetext{
413 Vgl. Lüthi 2005, S. 6.

414 Hamacher 1996, S. 74. Vgl. Maar, S. 46.

415 Hamacher 1996, S. 79.

416 Das Verfahren anderer stigmatisierter Charaktere lässt sich als Ergänzungen oder Alternativen zu Klaus Heinrichs Geschichten verstehen.

417 Lüthi 2005, S. 37.
} 
Andererseits weicht der Roman ganz absichtlich von der Volksmärchenstruktur ab. Es ist nicht der Prinz, der in die Fremde auszieht und Heldentaten vollbringt, sondern die Heldin. Imma Spoelmann, die Prinzessin von besonderer Art, zieht in das Land des Prinzen ein und erlöst ihn mit ihrer Liebe aus seiner Einsamkeit. Insofern nimmt sich Königliche Hoheit das Kunstmärchen Die Schneekönigin von Hans Christian Andersen zum Vorbild. Dass Klaus Heinrich der aktiv im Land wandelnden und sich integrierenden Imma gegenüber eher passiv handelt, versetzt den männlichen Helden in den äquivalenten Status einer zu erlösenden Märchenprinzessin. Diese Umkehrung der üblichen Geschlechterrollen erfolgt ebenfalls im Anschluss an Andersens Märchen (Die Schneekönigin, Die kleine Seejungfrau, Die wilden Schwäne). Dass die Handlung des Romans dem Märchenmuster folgen soll, erscheint aufgrund der drei Prophezeiungen und der geheimnisvollen Vorgeschichte der Grimmburger Sippe als schicksalhaft ${ }^{418}$. „Der Dichter entrückt also seine Geschichte von Anfang an der dem Leser vertrauten Realität, indem er die Geburt des Prinzen mit einer Aura des Wunderbaren umgibt.“"419

Über die Gattungsmerkmale hinaus werden auch zahlreiche Motive und Stoffe aus Volks- und Kunstmärchen adaptiert, die nicht nur die Oberfläche des Textes dekorieren, sondern auch. die Tiefe mitbestimmen. 420 Teilweise werden Details und ganze Szenen aus Märchenvorlagen präzise zitiert. Dieses „,höhere Abschreiben“" zeigt, dass die Märchen als eine der bedeutendsten Quellen von Königliche Hoheit gelten können. Es ist allerdings auffällig, dass die Märchenbezüge trotz ihrer Signifikanz im Roman in Thomas Manns Notizen und Materialien, die, wie schon gezeigt wurde, zum großen Teil aus Details bestehen, nirgendwo erwähnt werden: „Die Märchen gehören zum immer schon gewussten, archetypischen Grundbestand von Thomas Manns Werk" [GKFA 4.2,138].

In dem Kommentarband zu Königliche Hoheit der Großen Kommentierten Frankfurter Ausgabe sortiert Heinrich Detering die Märchenvorlagen dieses Romans nach fünf Klassen. Im Folgenden werden die motivischen und thematischen Märchenadaptionen nach diesem Vorbild geschildert. ${ }^{421}$

Zuerst wird die Volksmärchen-Bearbeitung der Brüder Grimm leitmotivisch im Roman zitiert. Dass Klaus Heinrich und Ditlind im Alten Schloss ,stöbern' und sich einmal verlaufen, spielt auf das Märchen von Hänsel und Gretel (KHM Nr. 15) an, womit die Motive der kindlichen Angst in einer bedrohlichen Welt sowie der Suche nach Ausweg und Glück assoziiert werden. [GKFA 4.2,139] Die Episode des Stöberns kommt bereits in dem dritten der drei früheren Fragmente von Königliche Hoheit vor, die wahrscheinlich 1905/06 verfasst wurden und zurzeit im

\footnotetext{
418 Ein Beispiel ist der Brauch, dass die Nachkommen der herrschenden Familie auf der Stammburg geboren werden müssen. Mit den beiden Fürsten, die diesem Gesetz nicht folgten, hat es „ein unnatürliches und nichtswürdiges Ende genommen". [GKFA 4.1, 13]

${ }^{419}$ Petersen 1973, S. 220.

420 Maar 1997, S. 46. Vgl. Petersen 1973, S. 218.

421 Die Märchenbezüge, die Deterings Kommentarband entdeckt haben, sind jeweils durch die Abkürzung GKFA 4.2 mit Seitennummer und eckigen Klammern gekennzeichnet.
} 
Thomas-Mann-Archiv aufbewahrt werden. Im selben Fragment wird das Leitmotiv des Stöberns mit einem Bezug auf das Dornröschen-Märchen (KHM Nr. 50) verbunden [GKFA 4.2, 139], das zu der Märchensammlung Grimms gehört und auf Charles Perraults La belle au bois dormant (1696/97) in Contes de ma Mère l'Oye zurückgeht:

Klaus Heinrich ward nie völlig vertraut mit dem Grundriß des väterlichen Schlosses, es hörte nicht auf, Geheimnisse und unentdeckte Gegenden vor ibm zu bergen [...] und oft dachte er, daß es ganz so dem Dornröschen im Schloß ihrer Ahnen ergangen sein müsse, als sie darin das von aller $W$ elt vergessene Turmitimmer aufstöberte, wo mit Raabe und Kater die alte Frau saß und spann. [GKFA 4.2, 560]

Diese Stelle mit dem Bedrohungs- und Erlösungsmotiv wurde in der veröffentlichten Ausgabe gelöscht. Doch versteckt sich eine Anspielung auf dieses Märchen vielleicht hinter den nach Moder duftenden Rosen, die aber auch eine märchenhafte freie Erfindung Thomas Manns sein können. Die Struktur bildenden Motive von dem erlösenden Kuss und der Prophezeiung teilt Königliche Hoheit mit Dornröschen. Wysling hält Königliche Hoheit für einen Roman, in dem sich die Dornröschengeschichte verbirgt. ${ }^{422}$

Eine zweite Gruppe bilden die französischen Märchen. So ist es eine Französisch sprechende Madame aus der Schweiz, die Klaus Heinrich und Ditlind französische Märchen vorliest. Im dritten Fragment wird erklärt, Riquet à la Houppe aus dem gleichnamigen Märchen von Perrault (1697) sei die Märchenfigur, die Klaus Heinrich vor allem schätzt, da dieser Märchenprinz ,so abstoßend häßlich und so überaus geistreich war und schließlich durch die Prinzessin, die er liebte, sogar noch Schönheit gewann. Er selbst war hübsch, wie man sagte. Aber er fühlte sehr, $\mathrm{da}$ er einem Prinzen wohl anstehe, häßlich und geistreich zu sein ..." [GKFA 4.2, 558] In dem veröffentlichten Roman ist Klaus Heinrichs Hochschätzung des hässlichen und geistreichen Prinzen durch seine eigene hässliche, körperliche Behinderung ersetzt. Statt eines geistreichen Prinzen verkörpern die Liebesgeschichte und die Wandlung des naiven Klaus Heinrich zu einem selbstbewussten Menschen die Moral des Märchens von Perrault: „Tout est beau dans ce que l'on aime; / Tout ce qu'on aime a de l'esprit.“ [zit. nach GKFA 4.2, 140]

Die dritte Gruppe bilden die orientalischen Märchen aus 1001 Nacht und die biblischen Stoffe, die mit den orientalischen Märchen motivisch verwandt sind. „Vogel Roch“, die Bezeichnung für Samuel Spoelmann, ist ein Leitmotiv aus Sindbad der Seefahrer [GKFA 4.2, 140], während sich die andere leitmotivisch verwendete Bezeichnung „Leviathan“ auf das Alte Testament bezieht. Fatme, der Name von Immas arabischer Milchschimmelstute, „die Herr Spoelmann von einem Fürsten aus dem Morgenlande zum Geschenk erhalten hatte“ [GKFA 4.1, 248],

422 Vgl. Wyslings Thomas Mann. Ein Leben in Bildern. Wysling 1994, S. 46. 
verweist ebenfalls auf seine orientalisch märchenhafte Herkunft. In Thomas Manns Notizen aus den Jahren 1906/07 stehen einige weitere Schilderungen des orientalischen Hoflebens („Der Sultan trinkt kolossal viel Whisky“ [GKFA 4.2, 44]), die im Roman jedoch nicht benutzt werden. Es liegt nah, dass Mann in seinem früheren Entwurf das exotische Leben sowie den Kontrakt zwischen der märchenhaften Abgeschlossenheit und dem Eindringen der abendländischen Kultur im Nahen Osten noch ausführlicher beschreiben wollte, was einerseits ein märchenhaftes Milieu hervorrufen, andererseits zusammen mit dem Leben der Milliardärstochter Imma Spoelmann sein eigenes Leben widerspiegeln sollte.

Die bedeutendsten Märchenvorlagen von Königliche Hoheit sind jedoch die Kunstmärchen von Hans Christian Andersen, der Thomas Manns Lieblingsdichter war und ihm den ,tiefste[n] und nachhaltigste[n] ${ }^{“ 423}$ Eindruck gab. Nach Detering wird u.a. auf drei Märchen Andersens in Königliche Hoheit angespielt: Die Schneekönigin, Die kleine Seejungfrau und Der standhafte Zinnsoldat.

Thomas Mann bezog sich schon in seinem ersten Roman Buddenbrooks mehrmals auf Die Schneekönigin: die sprechenden Namen Kai und Gerda sowie die künstlerische Kälte der schönen Mutter von Hanno bspw. verweisen auf die Existenz Der Schneekönigin in der erzählten Welt. In Königliche Hoheit wird die Beschreibung vom Palast der Schneekönigin realistisch überformt und der Name der Schneekönigin wird erwähnt, damit erkennbar wird, dass der Silbersaal des Alten Schlosses von Klaus Heinrichs Eltern diese Bedeutung trägt. ${ }^{424}$ Durch den Vergleich der beiden Stellen aus den beiden Texten in dem Kommentarband [GKFA 4.2, 142] lässt sich feststellen, dass die Kälte, das ,glasig hell[e], durch gelbliche Einlagen in große Vierecke geteilt[e] Parkett, das sich wie eine Eisfläche vor ihm [Klaus Heinrich - Z.Y.] ausbreitete" [GKFA 4.1, 62], die versilberten Armstühle mit weißer, zerschlissener Seide sowie das förmliche Gleichmaß der Anordnung, „das rein von Zweck und Bequemlichkeit sich selbstgenügend darstellte" [GKFA 4.1, 63] realistische Ebenbilder der Wände aus Schnee, der Fenster und Türen aus schneidenden Winden, des Nordlichts, des zugefrorenen Sees des leeren Schneesaales sind. Während die ,zugleich schöne und beherrschende, eigensüchtige und gefühlskalte“ [GKFA 4.2,143] Mutter Klaus Heinrichs sich mit der Schneekönigin identifiziert, entspricht das Heldenpaar des Romans Kay und Gerda im Märchen: Das Herz Klaus Heinrichs erstarrt in dem silbernen Kerzensaal. Erst nachdem Imma sein wahres Sein als eine inhaltlose Existenz, die „zum Schein auf die Welt gekommen" [GKFA 4.1,332] ist, entblößt, treten ihm Tränen in die Augen, was auf die Erlösung Kays durch Gerda hinweist. ${ }^{425}$ Darüber hinaus trägt Imma,

${ }^{423} 1928$ an die Berliner Zeitschrift Die Dame; zit. nach GKFA 4.2, 141.

424 „Und es war kalt in dem silbernen Kerzensaal, wie in dem der Schneekönigin, wo die Herzen der Kinder erstarren." [GKFA 4.1, 63]

425 „[D]a weinte die kleine Gerda heiße Tränen, sie fielen auf seine Brust; sie drangen in sein Herz, sie tauten den Eisklumpen auf und verzehrten das kleine Spiegelstück darin [...]. Da brach Kay in Tränen aus: er weinte so, daß das Spiegelkörnchen aus den Augen schwamm; nun erkannte er sie und jubelte: ,Gerda! Liebe kleine Gerda! - Wo bist du nur solange gewesen? Und wo bin ich gewe- 
nach Michael Maar, mit ihrer bräunlichen Haut, den schwarzen Augen und kindlichen Schultern ${ }^{426}$ Züge des Räubermädchens aus demselben Märchen. ${ }^{427}$ Die beiden Kinderfrauen sind maskulinisiert: das Räubermädchen ist keck, wild und homoerotisch gesinnt in seiner Beziehung zu Gerda, während Imma mit ihrer „Pagen-Anmut" [GKFA 4.1, 231] eine doppelte Stimme ,aus einer tiefen und einer hohen, mit einem Bruch in der Mitte“ [GKFA 4.1, 230] besitzt und die sexuell misshandelte Gräfin Löwenjoul, die Gesellschaftsdame Immas, in ihren Halluzinationen von den ,liederlichen Weiber[n]“ [GKFA 4.1, 245] (homo)sexuell verfolgt wurde, die ,sich nachts auf [ihre] Brust sitzen und [sie] zwingen, ihren unanständigen Fratzen zuzusehen“ [GKFA 4.1,245]. In Imma Spoelmann vereinigen sich demnach mindestens zwei Figuren aus der Schneekönigin.

Imma weist auch Bezüge zu der kleinen Seejungfrau auf: Ihre Augen sprechen eine „dunkel fließende Sprache“ [GKFA 4.1, 359] und ihr „[b]lauschwarz[es]“ Haar fließt ,glänzend [...] zu beiden Seiten von ihrem Scheitel hinab“ [GKFA 4.1, 264]. Ihre Hautfarbe wird als „Meerschaum“ [GKFA 4.1, 247] oder „Blässe der Perlen“ [GKFA 4.1, 312] bezeichnet. Schließlich trägt sie ein „Kleid aus seegrüner, glänzender Seide“ [GKFA 4.1, 224] und lebt im Schloss Delphinenort mit einem Wintergarten ganz nach dem Vorbild des Gartens der kleinen Seejungfrau. ${ }^{428}$ Die leitmotivischen Bezugnahmen auf die kleine Seejungfrau verbindet Imma vor allem mit Klaus Heinrichs Schwester Ditlind, die ihm „wie die kleine Meernixe in dem Märchen, das Madame aus der Schweiz [ihnen] vorlas" vorkommt - „die eines Menschen Frau wurde und Beine erhielt statt ihres Fischschwanzes". [GKFA 4.1, 155] Wie die Seejungfrau sehnen sich die fürstlichen Geschwister nach dem menschlichen Glück, das durch die erotische Verbindung mit dem geliebten Menschen erreichbar ist.

sen?‘ Und er blickte ringsum. ,Wie kalt es hier ist! Wie weit und leer es hier ist!‘ [...] Und Gerda küßte seine Wangen, und sie wurden blühend; sie küßte seine Augen und sie leuchteten gleich den ihrigen; sie küßte seine Hände und Füße, und er war gesund und munter“ [A I 285]. Gemäß Detering ist Immas Kuss auf Klaus Heinrichs gehemmte Hand ebenfalls ein „höheres Abschrei-

ben" dieser Szene [GKFA 4.2,143f].

${ }^{426}$ „[Es] lag an dem kindlichen Gepräge ihres Köpfchens und der Schmalheit ihrer bräunlichen Schultern, daß sie so wie ein kleines Mädchen erschien. Ihre Arme waren wohl ausgebildet, und man konnte sehen, daß sie Sport trieb und Pferde zügeln. Aber vorm Handgelenk wurde auch der Arm wie der eines Kindes" [GKFA 4.1, 224]. Imma erscheint als eine Reiterin, während das kleine Räubermädchen auch ein Pferd des Prinzen und der Prinzessin zügelt.

${ }^{427}$ Maar 1997, S. 175.

428 „[...] Klaus Heinrich sah sich in einem Wintergarten, einem von schlanken marmornen Säulen gestützten gläsernen Gewölbe, dessen Boden mit großen, quadratischen, spiegelnden Marmorfliesen belegt war. Palmen aller Art erfüllten es, deren Schäfte und Fächer sich manchmal bis dicht unter die gläserne Decke erhoben. Ein beetartiges Blumenparterre, bestehend aus zahllosen, gleich den Steinen eines Mosaiks aneinandergesetzten Blumentöpfen, breitete sich im starken Mondlicht der Bogenlampen aus und erfüllte die Luft mit Wohlgeruch. Aus einem schöngemeißelten Brunnen rieselten silberne Quellen in ein marmornes Becken, und Enten von seltsam künstlich gefiederter Art schwammen auf der durchleuchteten Wasserfläche. Ein steinerner Wandelgang mit Pfeilern und Nischen nahm den Hintergrund ein.“ [GKFA 4.1, 242] 
Klaus Heinrichs verkrüppelte Hand ist allerdings deutlich stärker eine Parallele zu dem standhaften Zinnsoldaten von Andersen als zu der kleinen Seejungfrau, worauf Thomas Mann selbst in der Vorrede zur amerikanischen Ausgabe des Romans 1939 verweist. [GW XI, 575] In Andersens Zinnsoldaten sieht der Autor das Symbol seines eigenen Lebens. ${ }^{429}$ Der außerordentliche Zinnsoldat, ebenfalls „ein Malheur von Geburt" [GKFA 4.1, 91], bleibt bis zum Tod heroisch standhaft und verliebt sich in die kleine Tänzerin aus Papier aus dem Schloss von Papier, die ebenfalls immer nur auf einem Bein steht: „sie war auch standhaft. Das rührte den Zinnsoldaten. “430 Die beiden Außenseiter vereinigen sich im Feuer:

Der Zinnsoldat stand ganz beleuchtet da und füblte eine Hitze, die erschrecklich war; aber ob sie von dem wirklichen Feuer oder von der Liebe herrübrte, das wußte er nicht. [...] Er sah das kleine Mädchen an, sie blickte ibn an, und er füblte, daß er schmelze, aber noch stand er standhaft mit dem Gewehre im Arm. Da ging eine Thür anf, der Wind ergriff die Tänzerin und sie flog, einer Sylphide gleich, gerade in den Ofen zum Zinnsoldaten, loderte in Flammen auf und war verscbwunden, da schmolz der Zinnsoldat zu einem Klumpen $[\ldots]^{431}$

Die Geschichte von Klaus Heinrich und Imma entspricht der Märchenhandlung bis hin zu dem traurigen Ende. Die algebraische Studentin Imma spielt „in den Lüften $[\ldots]$ oder außerhalb der Luft" [GKFA 4.1,250] und kann auch als eine Art Sylphide gelten. ${ }^{432}$ Die Standhaftigkeit des Zinnsoldaten ist im Roman zu Klaus Heinrichs beständiger Formstrenge transformiert. Dass Klaus Heinrich sein repräsentatives Sein, das nur aus Form besteht, erkennt und allmählich das unförmige ,Sich-gehen-lassen` der Gräfin zulässt, markiert die Differenz zwischen ihm und dem Zinnsoldaten. 433

Die letzte Gruppe der Märchenvorlagen sind die deutschen Kunstmärchen und märchenhaften Erzählungen seit der Romantik sowie die verwandten Mythenadaptionen von Richard Wagners Opern. In dem erotischen Spiel von Klaus Heinrich und Ditlind am Springbrunnen in dem dritten Fragment des Romans ${ }^{434}$

\footnotetext{
429 „Immer habe ich eine Vorliebe gehabt für Andersens Märchen vom ,Standhaften Zinnsoldaten‘. Es ist im Grunde das Symbol meines Lebens.“ [Am 09/10. 02. 1955 an Agnes E. Meyer; Br. III 375] 430 A I, 133.

431 A I, 134.

432 Detering identifiziert Imma mit den Töchtern der Luft in Die kleine Seejungfrau. [GKFA 4.2, 144]

${ }^{433}$ Das langsame Einschmelzen des Zinnsoldaten zusammen mit der kleinen Tänzerin kann in anderer Hinsicht auch als eine lockere Haltung und die Entstehung der Menschlichkeit gelten. ${ }^{434}$ „,Heute wollen wir uns lieb haben', sagte er zu ihr, als sie klein waren; und das kam einer Abmachung gleich. Sie saßen dann am Rande des Springbrunnens und küßten einander und liebten sich, weil sie weich und hübsch waren.“[GKFA 4.2, 548] „Die Spiele Klaus Heinrichs mit Ditlind am Springbrunn erhielten eine weltabgeschiedene Innigkeit, und ihre Augen wurden ruhevoll, ihr Lächeln verträumt und ihre Bewegung süß und lässig dabei. ,Nun wollen wir tot sein', sagten sie schließlich zu einander; und dann lagen sie mit inbrünstig geschlossenen Augen in grüner Dämmerung auf dem Rande des Bassins, rührten sich nicht und athmeten nur gerade so viel, als nüthig war, deckten sich mit Stille zu, ließen sich ganz von ihr durchdringen und durchtränken, lösten sich
} 
lässt sich der tödliche Kuss in Fouqués Undine wiedererkennen, während dieses Kunstmärchen zudem ein zentrales Vorbild für Andersens Seejungfrau ist. Die inzestöse Intimität zwischen den Geschwistern dieser Szenen lässt wiederum Assoziationen zu den Geschwistern Siegmund und Sieglinde in ihrer Weltabgeschlossenheit aus Wagners Die Walküre zu. ${ }^{435}$

\subsection{Die Funktion der Märchenadaptionen und Königliche Hoheit als Kontrafaktur}

Es ist auf der Albrechtsstraße, [...] um Mittag, wochentags, zu einer gleichgültigen Jahreszeit. Das Wetter ist mäßig gut, indifferent. Es regnet nicht, aber der Himmel ist auch nicht klar; er ist gleichmäßig weißgrau, gewöhnlich, unfestlich, und die Straße liegt in einer stumpfen und nüchternen Beleuchtung, die alles Gebeimnisvolle, jede Absonderlichkeit der Stimmung ausschließt. [GKFA 4.1, 9]

So beginnt das Vorspiel von Königliche Hoheit, das, wie Richard Wagners Schrift über Theaterstücke definiert, dem Hauptteil des Romans vorausgeht. ${ }^{436}$ In dem Vorspiel ereignet sich ein „Wunder“, „[e]in phantastischer Auftritt“ [GKFA 4.1, 11], der in dem nächsten Abschnitt als berechtigte Alltäglichkeit entzaubert wird, in dieser raumzeitlosen Situation. Durch das „Wunder“ und die Aufhebung von Zeit und Raum werden die Leser ,mit einem Schlage von den Eindrücken des Alltagslebens“ abgeleitet und „,vor die Erscheinung einer idealen Welt“" versetzt. ${ }^{437}$ Mithilfe der Entzauberung des „Wunders“ durch den Erzähler werden die Leser wiederum von dem Geschehen in Distanz versetzt. Zusammen mit der Aura des Phantastischen, die die geheimnisvollen Vorgeschichten und die abergläubischen Prophezeiungen im ersten Kapitel herstellen, und der raumzeitlichen Unbestimmtheit im Hauptteil des Romans ${ }^{438}$ trägt diese Distanzierung des Geschehens

gleichsam in der Stille auf und fanden ein außerordentliches Glück darin [...]“ [GKFA 4.2, 557] Undine trat aus dem Brunnen aus und küsste ihren untreuen Ehemann „mit einem himmlischen Kusse, aber sie ließ ihn nicht mehr los, sie drückte ihn inniger an sich und weinte, als wolle sie ihre Seele fortweinen. Die Tränen drangen in des Ritters Augen und wogten im lieblichen Wehe durch seine Brust, bis ihm endlich der Atem entging und er aus den schönen Armen als ein Leichnam sanft auf die Kissen des Ruhebettes zurücksank." [FW, 118]

${ }^{435}$ In dieser Gruppe von Vorlagen soll nach Detering „Chamissos stigmatisiertem und deshalb vereinsamtem Peter Schlemihl“" eine besondere Rolle zukommen. [GKFA 4.2, 147f] In seinem Essay von 1911 über Chamisso erkennt Thomas Mann in dem schattenlosen Peter Schlemihl ein Ebenbild des außenseiterischen Dichters Chamisso. [GKFA 14.1, 325] Auch in den Betrachtungen eines Unpolitischen hält der Autor Tonio Kröger, das Vorbild für Klaus Heinrich, für einen „gute[n] Bruder Schlemihls" [GKFA 13.1, 101]. Die Verwandtschaft zwischen Schlemihl und Thomas Manns künstlerischen Figuren liegt wahrscheinlich an Schlemihls Sein als Grenzfigur zwischen der menschlichen und teuflischen Welt, wozu aber noch Beweise aus Thomas Manns Texten fehlen.

436 Wagner 1914, S. 125.

437 Wagner 1914, S. 125.

438 Während wirkliche Ortsnamen wie Berlin, Potsdam, Baden, Königsberg oder Karlsruhe in 
dazu bei, das „Wunder“ angesichts eines historisch realen Milieus innerhalb der feudalen sowie militärischen Rangordnung zu betonen und das Außerordentliche des Klaus Heinrich zu stilisieren. Die Geschichte des Prinzen spielt in einer isolierten Welt mit einer märchenhaften Aura, in der Wunder als Alltäglichkeit gelten können.

Erst mit der Integration der Spoelmanns wird ein wenig Wirklichkeit in das Märchenreich gebracht. Mit den Ortsnamen wie New York, Broadway oder Adirondacks ${ }^{439}$ und besonders mit der Schilderung des „Riesendampfers“ [GKFA 4.1, 256], mit dem die Spoelmanns von Amerika nach Europa gefahren sind, tritt geographische Wirklichkeit auf und die räumlichen Verhältnisse zwischen Amerika und „dem Land“ werden hergestellt.

Die märchenhafte Abgeschlossenheit des Landes wird jedoch auch durch die Integration der Spoelmanns nicht vollständig aufgehoben. Der kranke und einsame Eisenbahnkönig Samuel Spoelmann wirkt seinerseits geradezu märchenhaft („Leviathan und Vogel Roch“ [GKFA 4.1, 167]) für die Bewohner des Herzogtums. Die amerikanischen Trusts und der moderne Kapitalismus werden nicht integriert. Nur Samuel Spoelmann als kranker Rentner, der von dem „Blut der Witwen und Waisen" [GKFA 4.1, 168] befreit ist und sein Kapital werden aufgenommen. ${ }^{440}$ Der Roman bleibt bis auf die letzten Seiten in der Schwebe zwischen Märchen und Wirklichkeit. Die Geschichte endet in dem Silbersaal, der eine Nachbildung des Schlosses der Schneekönigin ist, in dem Klaus Heinrich und seine Braut Imma vom Volk von unten bejubelt werden und über die Verbindung von Hoheit und Liebe reden, was darauf hindeutet, dass die Kälte und Einsamkeit der Schneeköniginnenwelt noch immer nicht völlig überwunden ist.

Thomas Mann assoziiert seine Königliche Hoheit mit einem Lustspiel. ${ }^{441}$ Nach Petersen ist mit dem lustspielhaften Charakter die Heiterkeit des Romans gemeint. ${ }^{442}$ Das beschreibt den Sachverhalt jedoch noch nicht vollständig. Das Lustspiel ist für Thomas Mann u.a. ein ,Spiel', in dem die Kinder die Freiheit des Darüberstehens entdecken. ${ }^{443}$ Während des Spielens sind sie Herr der Geschichte und das Spiel gibt ihnen das Gefühl der Macht. In der autobiographischen Schrift On Myself schreibt Thomas Mann: „Zwischen Kinderspiel und Kunstübung ist in meiner Erinnerung kein Bruch, keine scharfe Grenze." [GW XIII, 54] Wie ein spielendes Kind stellt der Autor die bunten ,aristokratischen Monstren` wie Mari-

\footnotetext{
Thomas Manns Notizenmaterial noch festgehalten werden, sind diese Namen zusammen mit den „topographische[n] und historische[n] Spuren der realen Vorlagen“ im Laufe der Entstehungszeit getilgt. Dementsprechend sind die märchenhaften fiktiven Ortsnamen wie „Hollerbrunn“ oder „Delphinenort“ auffälliger betont [GKFA 4.2, 67].

439 Auffällig ist, dass Imma nach der Erwähnung dieser nordamerikanischen Gebirge noch sagt:

„Das ist Geographie, mein Prinz.“ [GKFA 4.1, 250]

${ }^{440}$ Vgl. Dedner 2001, S. 265.

441 Vom 28. 01. 1910 an Ernst Bertram; Br. I, 81.

442 Petersen 1973, S. 218.

443 Wysling 1996, S. 446.
} 
onetten auf die Bühne. Die vielfältigen Elemente aus Märchen sind Stoffe, mit denen er seine Charaktere im Spiel gestaltet. In zahlreichen Hauptfiguren sind Züge von mindestens einem Märchencharakter zu erkennen, etwa Züge der Schneekönigin bei der Großherzogin Dorothea, bei Ditlind Züge der Gretel und der kleinen Seejungfrau, bei Imma Spoelmann Züge der Tochter des Bergkönigs, Gerdas, der kleinen Seejungfrau, des Räubermädchens, der kleinen Tänzerin aus Papier usw., bei Klaus Heinrich Züge Kays, des standhaften Zinnsoldaten, Hänsels und weitere. Die Leser erkennen verschiedene Aspekte sowie mögliche Vorund Nachgeschichten des Charakters, je nachdem, welche Märchenbezüge sie in diesem Charakter bemerken. Der Romancharakter wird auf diese Weise intertextuell ,ergänzt ${ }^{6}$ und besitzt zugleich individuelle und typisierende Eigenschaften. An dem ,Spiel' nehmen auch bekannte Figuren der Märchenliteratur teil.

Thomas Mann bedient sich des Spiels, um die zugrundeliegende Idee darzustellen, nämlich seine eigene Geschichte. Klaus Heinrich soll nicht nur als ein Fürst oder eine aus mehreren Märchencharakteren zusammengesetzte Figur angesehen werden, sondern als Künstler-Allegorie, und zwar eines solchen Künstlers, der von der europäischen Dekadenz des fin de siècle stark beeinflusst worden ist. Der Lebensbegriff besitzt für einen Dekadent weder einen sozialen Aspekt noch eine zeitliche oder geschichtliche Dimension ${ }^{444}$, was durch das „symbolische[, [...] repräsentative] Dasein“ 445 eines Fürsten anschaulich ausgedrückt wird. Das Märchen, in dem die Zeit und der Raum abstrakt sind, ist daher ein geeignetes Mittel, um ein wirklichkeitsfernes Dasein zu schildern. Klaus Heinrich, der ein eher naives Gegenbild zu seinem sentimentalischen und lebensmüden Bruder Albrecht II ist und sein repräsentatives Dasein nur grob ahnt ${ }^{446,}$ kann und soll als eine Märchenfigur gelten. Erst als er Imma kennt, versteht er, dass er „,zum erstenmal ohne Reue und Schaden daran, was man [s]einen hohen Beruf nennt, [s]ich gehen lassen darf wie irgendeiner [...] “ [GKFA 4.1, 333]. Er ist der lebensfeindlichen Erziehung von Doktor Überbein entwachsen und wird damit selbständig. Die Liebe erlöst ihn aus seinem zinnsoldatischen Dasein und aufgrund der Erlösung gewinnt er Selbständigkeit. Er fängt damit an, Mensch zu werden. Dieser Vorgang vollendet sich paradoxerweise in einem Märchen. Dieser Vorgang wird nicht nur als „[d]ie Erfüllung“ der Prophezeiung betitelt, sondern die Erlösung selbst ist ein strukturbildendes Motiv des Märchens. Thomas Mann wusste selbst, dass der Schluss des Romans „ein bischen populär verlogen“ ist und dass „[i]m

\footnotetext{
444 Kurzke 1995, S. 115.

445 Vom 05. 12. 1903 an Walter Opitz; Br. I, 40.

446 Nachdem Klaus Heinrich dem Dichter Axel Martini begegnet ist, der genau wie er eine Hoheit ist [eBr./M 77, 03. 06. 1909 an Heinrich Mann], merkt der Prinz nicht, dass er seinem Ebenbild begegnet ist, sondern findet es nur schwer, ,eine feste Meinung über ihn zu gewinnen.“ Er sagt nur: „Er hat es nicht bequem und nicht leicht, das sieht man wohl, und das muß ja gewiß für ihn einnehmen. Aber ich weiß doch nicht, ob ich mich freuen kann, ihn kennen gelernt zu haben, denn er hat etwas Abschreckendes, [...] er ist bei all dem entschieden ein bißchen widerlich." [KH 178f]
} 
Grund [...] natürlich Überbein recht" ${ }^{* 47}$ hat. Während der Arbeit an Königliche Hoheit wurde die neue Familie Pringsheim ,wieder einmal fremd, gräßlich, demütigend, entwertend, entkräftend auf Thomas Mann.“" ${ }^{448}$ Der Gedanke, „dass ich mich nicht hätte menschlich attachiren und binden dürfen“ [GKFA 21,365], quälte den jungen Ehemann lange. Dass das Studium der Wirtschaftslehre dem praktischen Geschäft des Prinzen zu Ried-Hohenried gegenüber nur gegenstandslose Theorie ist und dass die Verbindung von Hoheit und Liebe in der Wirklichkeit kaum zu erreichen ist, wusste er schon. Auch die „Wendung zum Demokrati-

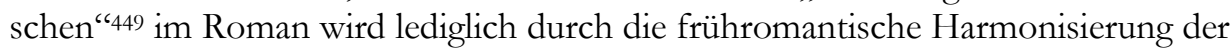
Wünsche des Volkes mit dem Willen des Fürsten angedeutet. Gerade deswegen ist das Märchenhafte für den Roman notwendig: Während die unbedarften Leser in dem letzten Kapitel des Romans ein opernhaftes happy ending sehen, erkennen die reflektierenden Leser, dass die Erlösung durch Liebe eine „märchenhafte Scheinlösung “450 ist. In dem abgeschlossenen, märchenhaften Land ist die „Lösung des

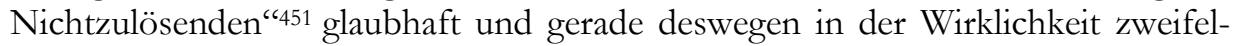
haft. Ob das Land den Märchenregeln folgt, bleibt offen, denn im letzten Kapitel wird absichtlich nicht erwähnt, ob die Rosen aus dem Alten Schloss an dem Tag der öffentlichen Glückseligkeit ,auf die natürlichste und lieblichste Art zu duften beginnen würden“ [GKFA 4.1, 50], obwohl dieses Kapitel „Der Rosenstock“ heißt. Über den Rosenstock wird lediglich gesagt:

\section{In das große Mittelbeet nämlich, vor der Auffahrt, sollte der Rosenstock aus dem Alten Schlosse verpflanzt werden, und dort, nicht mehr von modrigen Mauern umgeben, sondern in Luft und Sonne und dem fettesten Mergel, der beizubringen wäre, sollte er zusehen, was für Rosen er fortan trieb, - und den Volksmund Lügen strafen, wenn er verstockt und dünkelhaft genug dazu war. [GKFA 4.1, 392]}

Würden die Leser wegen des paratextuellen Hinweises im Titel des Schlusskapitels „Der Rosenstock“ im Anschluss an das „Erfüllungs“-Kapitel das, was der Erzähler durch die Blume zu sagen versucht, für wahr halten, nähmen sie ein märchenhaftes glückliches Ende wahr und schlössen sich dem abergläubischen Volksmund an. Glaubten die Leser, dass der Rosenstock natürlich zu duften anfange, machten sie aus dem Roman ein Zaubermärchen, genau so wie der Volksmund aus Klaus Heinrichs Leben das Märchen eines Prinzen zu dichten versucht.

Königliche Hoheit adaptiert Märchen einerseits. Andererseits weicht der Roman häufig von Märchenvorlagen ab. So wird bspw. das Ende von Die kleine Seejungfrau und Der standhafte Zinnsoldat im Roman vermieden. Klaus Heinrich scheint wie Kay

\footnotetext{
${ }_{447}$ Vom 26.01.1910 an Heinrich Mann, TM/HM BW, 85.

${ }^{448}$ Kontje 2009, S. 395.

449 Vom 28. 04. 1944 an Agnes E. Meyer; Br. II, 364.

450 Jendreieck 1997, S. 203.

451 Vom 26.01.1910 an Heinrich Mann, TM/HM BW, 84.
} 
in Die Schneekönigin der kalten mütterlichen Welt mithilfe der Liebe der kleinen Gerda/Imma entgangen zu sein. Doch weisen das Romanende im Silbersaal sowie die rituelle Verlobungszeremonie darauf hin, dass die Kälte und die Förmlichkeit der Märchenwelt nicht völlig beseitigt wird. Sowohl eine Schopenhauer'sche Erlösung im Tod als auch ein glückliches Märchenende wird absichtlich getilgt. Stattdessen stellt das letzte Kapitel ein offenes Ende dar, denn Klaus Heinrich und Imma erkennen ihre Aufgabe für die Zukunft: „Hoheit und Glück - ein strenges Glück“" [GKFA 4.1, 399], ein noch nicht erreichtes Ziel. Hans Rudolf Vaget nennt diese Erzähltechnik von Thomas Mann Kontrafaktur, die ,ihre Existenz dem Willen zum ,Etwas-dagegen-Machen', d.h., einer produktiv-kritischen Reaktion auf andere Texte ihre Existenz verdank $[t]$ “". ${ }^{452}$ Die schöpferische Umwertung von Märchenvorlagen bietet eine heitere und erwünschte Möglichkeit für das stigmatisierten Dasein. Zugleich müssen die Leser, die die Märchenvorbilder des Romans bemerken, die düsteren Varianten bei der Beurteilung des Romanausgangs berücksichtigen und das happy ending intertextuell hinterfragen. ${ }^{453}$ Klaus Heinrichs glückliche Verbindung mit Imma sowie seine heitere Zukunft werden durch die intertextuellen Assoziationen zu der kleinen Seejungfrau und dem Zinnsoldaten in Zweifel gezogen. Klaus Heinrichs Glück lässt sich nur als eine Variante von mehreren Märchencharakteren ansehen, was dem Status des Prinzen unter den ,aristokratischen Monstren` entspricht.

\subsection{Das Märchenhafte als Maske einer autobiographischen Schrift}

In Königliche Hoheit verbinden sich das Märchenhafte und das Fiktiv-Realistische miteinander. Die aufmerksamen Leser können die Existenz des Märchens als Gattung und als Text wahrnehmen. Doch sollen sie zugleich merken, dass das Märchen schon nicht mehr da ist. Das, worauf die zitierten Märchen verweisen wollen - also das Wesen hinter der realistischen Kulisse - wird durch das ,Zerknittern' der Märchenmotive wiederum verborgen. Michael Maar vergleicht Thomas Manns Versteckspiel mit dem Gewebe der Penelope. Jede Nacht wird aufgetrennt, was tagesüber gewoben worden ist. „Kunstmittel des enthüllenden Tarnens und beredten Verschweigens, in denen Thomas Mann nicht deshalb exzellierte, weil er wollte, daß man ewig an ihnen vorbeisehe." ${ }^{454}$ Das intertextuelle Spiel des Hin-und-Her-Schwebens zwischen Märchen und Romanwirklichkeit in

\footnotetext{
452 Vaget 1995, S. 538.

453 Gremler 2007, S. 106. Dort werden die zwei Wirkungen des Kontrafaktur-Verfahrens von Herman Bangs Ihre Hoheit durch Königliche Hoheit untersucht.

454 Maar 1997, S. 95. Vgl. Kesting 2000, S. 226f. Wie Detering hält auch Maar die sexuelle Besonderheit - die Homoerotik - Thomas Manns für das Motiv seiner literarischen Camouflage.
} 
Königliche Hoheit ist ebenfalls ein solches Blendwerk. Thomas Mann teilte seinen Lesern mit, dass er auch diesmal von seinem Leben erzählt. [GKFA 14.1, 243]

Königliche Hoheit zielt nicht darauf ab, bekannte Märchen realistisch nachzuerzählen. Das Wesen dieses Romans ist - wie das Wesen jedes fiktionalen Erzählwerks von Thomas Mann - eine Variante der Symbolisierung des eigenen Lebens. Dieses Schreibverfahren wird schon in dem Essay Bilse und Ich (1906) gerechtfertigt, als der Autor seine künstlerische Autonomie in Buddenbrooks verteidigen wollte: „Nicht von Euch ist die Rede, gar niemals, [...] sondern von mir, von mir ...“ [GKFA 14.1, 110]. 30 Jahre nach der ersten Veröffentlichung des Romans betont Thomas Mann im Vorwort zu einer amerikanischen Ausgabe von Königliche Hoheit noch ausdrücklich über dieses Schreibverfahren:

\section{Das Biographische ist das eigentlich bumane Element der Kritik; und gerade der Kritiker von Königliche Hoheit wird den biographischen Gesicbtspunkt kaum entbehren können. Der Roman ist das Werk eines jungen Ehemannes, und, ganz bestimmt von dem persönlichen Erlebnis menschlicher Lebensgrün- dung, umspielt er das Vorzugsthema meiner Jugend, das Künstlerthema von Einsamkeit und Außerordentlichkeit, den Tonio Kröger-Gegensatz von Kunst und Leben in dem Geiste heiterer Versöhnung von Strenge und Glück. [GW XVI, 50]}

Die Handlung des Romans ist zwar zum Teil freie Erfindung oder Umdichtung zeitgenössischer sowie historischer Angelegenheiten, ${ }^{455}$ schließt aber zum großen Teil eng an eigenes Erleben des Autors an. Wie oben schon erläutert stecken hinter den Romanhauptfiguren Thomas Mann selbst, seine Braut, sein Bruder, seine Schwester, seine Mutter, sein Schriftstellerkollege und seine Mitbürger. Während Klaus Heinrich als ein naives Alter Ego Thomas Manns erscheint, sind auch die anderen Sonderlinge mit dem Autor mehr oder weniger geistig verwandt. Der

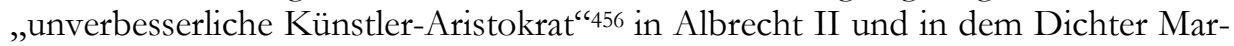
tini gilt bspw. nicht nur als Bildnis von Heinrich Mann und Kurt Martens, sondern auch als eine distanzierte Widerspiegelung des früheren künstlerischen Daseins von Thomas Mann selbst. Die Einsamkeit und die Sehnsucht nach Menschwerdung der kleinen Seejungfrau, die Thomas Mann in der Erzählung Tonio Kröger noch dem Titelhelden - einem anderen Alter Ego seinerseits - zugeschrieben hat, teilt er nun mit Imma Spoelmann und Ditlind. Alle aristokratischen Monstren, die verschiedene Erscheinungsformen desselben stigmatisierten und zugleich erwählten Wesens sind, sind von dem Autor subjektiv nach seinem Bilde gefärbt - die Art, wie D. Wislizenus das vom Großherzog erwählte Bibelzitat bearbeitet, gilt auch für das Schreibverfahren Thomas Manns: Er behandelt es

\footnotetext{
${ }^{455}$ Z. B. die Bezüge auf den verkümmerten Arm von Kaiser Wilhelm II und auf den Schönheitskult der Kaiserin Elisabeth von Österreich.

456 Detering 2005, S. 152.
} 
motivisch und sozusagen auf musikalische Art. Er wandte es hin und her, wies es in verschiedener Beleuchtung auf und erschöpfte es in allen Beziehungen; er ließ es mit säuselnder Stimme und mit der ganzen Kraft seiner Brust ertönen, und während es zu Beginn seiner Kunstleistung, leise und sinnend ausgesprochen, nur ein dünnes, fast körperloses Thema gewesen war, erschien es am Schluß, als er es der Menge zum letrtenmal vorführte, reich instrumentiert, voll ausgedeutet und tief belebt. [GKFA 4.1, 54]

Diese Stelle wird im letzten Kapitel des Romans wiederholt. In Königliche Hoheit erzählt Thomas Mann nur von einem Thema, nämlich davon, welche Wandlungen sich in der Lebensphase des Autors zwischen 1903 und 1909 vollendeten, was in dem Roman durch die mehrmaligen Wiederholungen zu einem persönlichen Mythos wird. Mit Klaus Heinrichs Wandlung von einem einsamen Prinzen zu einem sein Land rettenden Helden und glücklichen Bräutigam wird Thomas Manns eigene Wandlung von einem unbekannten ästhetizistischen Künstler, der seiner quälenden Liebe zu Paul Ehrenberg entsagen musste, zu einem berühmten Schriftsteller, Ehemann und Familienvater allegorisch geschildert. Zugleich entwirft Mann anhand der anderen außerordentlichen Figuren im Roman mehrere alternative Möglichkeiten für sich: Er hätte auch wie Albrecht II vereinsamen und zurücktreten, oder sich das Leben nach dem Vorbild Überbeins nehmen, oder auf die Hoheit verzichten und ein beschäftigter Bürger wie Ditlind werden können.

\subsection{Die Menschwerdung von Klaus Heinrich und die Märchenwerdung der Königlichen Hoheit}

Der opernhafte Schluss von Königliche Hoheit sei „ein bisschen populär verlogen“, da im Grunde natürlich Überbein Recht habe und Thomas Mann selbst nicht wirklich an die Synthese von Hoheit und Glück glaube, wie schon zitiert. ${ }^{457}$ Klaus Heinrich überwindet alle Schwierigkeiten im Roman und besiegt den Leistungsethiker. Gemeint ist damit der Satz aus Mozarts Märchenoper Die Zauberflöte, gegen den Überbein Einwände hat: „Er ist ein Prinz! [...] Er ist mehr als das; er ist ein Mensch!“ [GKFA 4.1, 96] Klaus Heinrich wird ein Mensch. Durch seine Liebe zu Imma vollendet er den entscheidenden Schritt der Sozialisierung, da der Mensch in Liebe aus seiner subjektiv verschlossenen Welt nach außen tritt. Die Liebe zu Imma ist zugleich ein Prozess der Selbsterkenntnis, denn Imma, die „[k]leine Schwester“ [GKFA 4.1, 313] Klaus Heinrichs, teilt mit ihm die wirklichkeitsferne Außerordentlichkeit. Der leere Spott und die leichtsinnige Rede Immas ist ein Gegenstück zu seinem eigenen repräsentativen Dasein. In den Beziehungen zu Imma wird Klaus Heinrich zum ersten Mal selbstbewusst und versucht ebenfalls zum ersten Mal, sich mit dem, was er repräsentiert, in Verbindung zu bringen,

${ }^{457}$ Vom 28.01.1910 an Ernst Bertram; Br. I, 81. 
indem er anfängt, Ökonomie zu studieren. Mit dem rein theoretischen Studium wird Klaus Heinrich jedoch kein richtiger Volkswirt werden. Es ist jedoch eine Andeutung der zukünftigen Wandlung des Prinzen zusammen mit seiner Braut sowie der Erlösung von seinem wirklichkeitsfernen Dasein.

Da die Erlösung das Happy Ending eines typischen Zaubermärchens ist, das als Gattung im Roman adaptiert wird, wird das gemeinsame Wirtschaftsstudium nicht nur als unpraktisch, sondern auch als unrealistisch entlarvt. Nur als Motiv in einer abgeschlossenen Märchenwelt wird das Studium und damit Klaus Heinrichs Verbindung mit dem von ihm Repräsentierten nicht von der realistischen Außenwelt beeinflusst. Während einerseits Klaus Heinrich seine Autonomie gewinnt und sich mit den anderen Menschen verbindet, wird andererseits seine Erlösung zu einer märchenhaften Scheinlösung entwertet.

Klaus Heinrich wird durch die Liebe Mensch, da er zuvor eher nur eine Märchenfigur ist. Wie oben schon erläutert, gilt er als naiv und vom Volk separiert, was zu den Charakteren eines typischen Volksmärchenhelden gehört. Die Verhältnisse mit ,Monstren' sind ihm zwar selbstverständlich, allerdings erscheint der Prinz märchenhaft, vor allem da er schon bei der Geburt von einer Märchenaura umgeben ist. Als ein Prinz, der in der Grimmburg nach der mysteriösen Familientradition geboren ist, wird er aufgrund seiner angeborenen Hemmung an der linken Hand, dem Zeichen seiner menschlichen Schwäche, mit einer ZigeunerProphezeiung von vor hundert Jahren in Verbindung gebracht: „durch einen Fürsten ,mit einer Hand" [werde] dem Lande das größte Glück zuteil werden“ [GKFA 4.1, 51]. Klaus Heinrich ist kein Fürst „mit einer Hand“, sondern seine eine Hand ist nur verkrüppelt. Die Prophezeiungen pflegen sich jedoch ,,in der Weise zu erfüllen, daß Umstände eintreten, die man, einigen guten Willen vorausgesetzt, in ihrem Sinne deuten kann. Und gerade durch die großzügige Fassung jeder rechten Weissagung wird das sehr erleichtert" [GKFA 4.1, 37]. Das Volk wird die Andeutung der Prophezeiung für das Ganze nehmen und den bedingenden Teil der Weissagung für erfüllt erklären, ,und zwar spätesten dann, wenn auch das Weitere, die eigentliche Verheißung sich irgend bewahrheiten sollte, es wird reimen und deuten, wie es das immer getan hat, um erfüllt zu sehen, was geschrieben steht.“ [GKFA 4.1, 37] Das Volk ist gewillt, in der behinderten Hand des Prinzen die Bedingung der Weissagung zu sehen und aus dem Prinzen ein Märchen zu dichten, da dies die einzige Möglichkeit ist, die Schwäche des unnahbaren Prinzen für ein positives Zeichen für Glück zu deuten, statt den Prinzen aufgrund seiner körperlichen Schwäche zu demütigen. ${ }^{458}$ In der Tat ist das Volk gewöhnt, von dem Fehler an der Person Klaus Heinrichs abzusehen, wenn man ihn grüßt. [GKFA 4.1, 325] Erst als „die eigentliche Verheißung sich [...] bewahrheiten“ wird, nämlich als Klaus Heinrich und die reiche Erbin Imma Spoelmann kurz vor

${ }^{458}$ Bspw. mit der Bowle. 
der Verlobung stehen, spricht das Volk wieder von der Prophezeiung der Zigeunerin und bemerkt den etwas zu kurzen linken Arm von Klaus Heinrich:

Da geschah es, daß eine Erinnerung, eine wunderliche Wortfügung vom öffentlichen Bewußtsein Besitz ergriff ... niemand kann sagen wer zuerst darauf hinwies, darauf zurückwies, - das steht nicht fest. Vielleicht war es eine Frau, vielleicht ein Kind mit gläubigen Augen, dem man es irgendwann zum Einschlafen erzählt, - Gott weiß es. [GKFA 4.1, 325]

Es geht hier nicht darum, dass die Prophezeiung plötzlich ins Gedächtnis zurückgerufen wird. Vielmehr bleibt „eine gespenstische Gestalt“ [GKFA 4.1, 325] vom Schatten eines alten Zigeunerweibes immer in der Gesinnung des Volkes erhalten. Das Volk wartet seit der ersten Begegnung des Paares auf die glückliche Erfüllung der Weissagung, denn „[n]ichts war weniger befremdend, nichts einleuchtender und natürlicher, als Klaus Heinrich an ihrer [Immas - Z. Y.] Seite zu sehen“ [GKFA 4.1, 325].

Klaus Heinrich gilt für das Volk einerseits als ein Fall ,,in allzugroßer Abgeschiedenheit" [GKFA 4.1, 327], der sich höher als das Volk befindet, und mit dem als „,aller Gemeinschaft und Gleichartigkeit entrückte[s] Menschenkind“ [GKFA 4.1, 324] Imma Spoelmann zusammengehört. Andererseits wird er als ein typischer Repräsentant des Volks selbst angesehen: eine neue Straße in der nördlichen Vorstadt erhält den Namen „Klaus-Heinrich-Straße“ [GKFA 4.1, 69]; zahlreiche Bürgerkinder in Stadt und Land werden nach dem Prinzen benannt [GKFA 4.1, 77] und wie das Volk hat auch Klaus Heinrich den ,breiten, ein wenig zu hoch sitzenden Wangenknochen“ [GKFA 4.1, 189, vgl. GKFA 4.1, 87]. Das Volk liebt Klaus Heinrich, so wie es Mizzi Meyer, die Soubrette ohne besondere Begabung, liebt:

[s]olange sie, geschmückt, geschminkt und von allen Seiten beleuchtet, der Menge gegenüber auf den Brettern stand, war sie in der Tat die Verklärung des Volkes selbst, - ja, das Volk beklatschte sich selber, indem es sie beklatschte, und darin ganz allein berubte Mizzi Meyers Macht über die Gemüter. [GKFA 4.1, 189]

Wenn das Volk die gehemmte Hand von Klaus Heinrich übersähe, fände es in ihm lediglich einen Repräsentanten seiner selbst. ${ }^{459} \mathrm{Im}$ zweiten Roman von Thomas Mann ist noch nicht von Mythen die Rede, sondern von märchenhafter Typologie. Klaus Heinrich soll von einem märchenhaften Prinzen zu einem richtigen Märchen des Volkes erhöht werden, was durch seine Rettung des Landes geschieht. ${ }^{460}$ Der Prinz bringt dem Land das größte Glück ,mit einer Hand', und

\footnotetext{
${ }^{459}$ Dieses Verfahren ist ein Vorläufer der mythischen Verallgemeinerung in den Joseph-Romanen. 460 Thomas Mann nennt den Roman zwar eine Annäherung an die Demokratie, im Text wird aber u.a. eine romantische Harmonie zwischen dem Willen des Fürsten und dem Wunsch des Volkes gezeigt.
} 
zwar gerade durch seine Menschwerdung, die mit Immas Kuss auf seine gehemmte linke Hand beginnt. Das Märchenhafte und das Wahre Klaus Heinrichs verknüpfen sich, indem seine Verbindung mit Imma Spoelmann, die für ihn das Ende seines märchenhaften Daseins sowie seine Menschwerdung bedeutet, für das Volk umgekehrt die Vollendung eines Märchens von einem heldischen Prinzen, der sein Land rettet. Die beiden parallelen Vorgänge gehören jeweils zu der subjektiven Ebene Klaus Heinrichs und zu der öffentlichen Ebene des Landes, sind aber eng miteinander verwoben, da sowohl der Prinz als auch das Land eine in sich abgeschlossenen Größe ist, die, in allzugroßer Abgeschiedenheit von der praktischen Welt" [GKFA 4.1, 327] liegt. Die Scheinlösung für den Prinzen ist auch eine Scheinlösung für das Land, wobei der Unterschied darin liegt, dass der Prinz sich vom Märchen lösen will, während das Volk sich vom Märchenwunder des Eilboten betrügen lässt. Während Klaus Heinrich versucht eine neue Ordnung im Land herzustellen, wendet sich sein Volk an das vormoderne Märchenwunder, was schon darauf hindeutet, dass eine wirkliche Verbindung zwischen dem Prinzen und dem von ihm repräsentierten Volk noch nicht hergestellt ist. 


\section{Schluss/Ausblick}

Die Märchenadaption in epischen Texten ist keine komplett neue Erfindung Christoph Martin Wielands oder anderer Autoren, die diese Arbeit behandelt hat. In der Tat sind die Adaptionen mythischer und volksliterarischer Stoffe durch Verserzählungen und Prosa ein traditionelles Verfahren der westlichen Literatur seit Homers Epen. Die hoch- bis spätmittelalterlichen deutschsprachigen Romandichtungen in Prosa sind einerseits Übersetzungen, Bearbeitungen und Umschreibungen fremdsprachiger - vor allem französischer - Texte, ${ }^{461}$ andererseits ,originale ${ }^{6}$ Bearbeitungen heroisch-archaischer oder sagenhafter Stoffe. ${ }^{462}$ Mit dem Beginn der Umsetzung französische Texte ins Deutsche im großen Rahmen im 15. Jahrhundert wurden Stoffe aus französischen Heldenepen, „die ,historische

\footnotetext{
${ }^{461}$ Die erste deutschsprachige Adaption der französischen „Unterhaltungsliteratur“ ist die Fragment bleibende Übersetzung des französischen Lancelot en prose, die um 1250 begonnen wurde und folglos blieb. Detering/Sina/Jeßing/Meid/Meier/Schnell 2013, S. 21f. Die Umsetzung französischer Texte in deutsche Prosa im großen Rahmen begann erst in der ersten Hälfte des 15. Jahrhundert.

${ }^{462}$ Die frühen deutschen Prosaromane nehmen oft den Troja-Krieg oder Alexander den Großen als Stoff. Die Geschichte des deutschsprachigen Romans gibt einen exemplarischen Blick auf diese Romane: sie sind beispielsweise das um 1391 entstandene Buch von Troja von Hans Mair, das auf die Historia destructionis Troiae (1287) beruht, Johannes Hartliebs Alexander, der um 1450 entstand und nach lateinischen Prosavorlagen verfasst wurde, und Aithiopica Historia (1559), die deutsche Übersetzung nach einer lateinischen Fassung von Heliodors Liebesroman Aithiopika (3. Jahrhundert) durch Johannes Zschorn. Detering/Sina/Jeßing/Meid/Meier/Schnell 2013, S. 22 f.
} 
Stoffe aus der Frühzeit der französischen Geschichte behandeln" 463 - Herpin, Sibille, Loher und Maller, Huge Scheppel, Haimonskinder ${ }^{464}$ - und höfisch-dynastische Stoffe - Melusine, Pontus und Sidonia, die schöne Magelona und die Hystori von dem Keyser Octaviano ${ }^{465}$ von dem deutschen Prosaroman aufgenommen. Die Stoffe der mittelalterlichen deutschen Prosaromane zeichnen sich durch eine Vorliebe für Abenteuer, Liebesgeschichten, das Wunderbare (zum Beispiel bei Melusine) und Exotismus aus, die mit den späteren Volksmärchenstoffen übereinstimmen.

Die spätmittelalterlichen sowie frühneuzeitlichen Adaptionen archaischer und höfisch-dynastischer Vorlagen haben keine reflektierende Auseinandersetzung mit der Weltanschauung dieser Vorlagen. Die Welt in den älteren Vorlagen erscheint wie ein Spiel nach Art der labyrinthischen Anlagen, die zur Mode jener Zeit gehörten; das System ist nicht enträtselbar, zumindest für die Einsicht der Menschen; nur Gott überschaut in grandioser Allmacht die Spielregeln; die Wahrheit bleibt also hinter Schleiern verborgen; das irdische Dasein steht auf dem wankenden Boden des Umsonst und der Unbeständigkeit. Aber die Hoffnung besteht, dass die Güte Gottes den Menschen aus dem Labyrinth herausführt, den Irrfahrten ein Ende setzt - wenn der Mensch sich moralisch bewährt hat, wenn er seiner himmlischen Bestimmung treu geblieben ist. ${ }^{466}$

Die Weltordnung in den Vorlagen ist nicht von Menschen, sondern von einer transzendentalen Kraft kontrolliert. Sowohl die Stoffe beziehungsweise die Schauplätze als auch die Weltordnung der Vorlagen wird von dem Prosatext übernommen. Doch zielt diese Adaption nicht darauf ab, die ferne exotische Welt nachzubilden und die Leser dadurch zu unterhalten, sondern auf einen religiösen, politischen oder moralischen Zweck, nämlich die fatalistische und antikeheidnische Machtlosigkeit des Menschen durch die christliche Allmacht zu ersetzen. Die drei Merkmale der makroepochalen ästhetischen Moderne nach Dirk von Petersdorff - der Verlust der Ganzheit von Perspektiven, die Autonomie des Subjekts statt einer Verpflichtung zu Religion, Moral, Politik oder Wissenschaft und die Unmöglichkeit, eine neue einheitliche Weltordnung zu rekonstruieren, sind diesen deutschen Prosatexten im Spätmittelalter und in der frühen Neuzeit fremd. Ihre Adaptionen älterer oder - wie im Falle der deutschsprachigen Umschreibung der Melusine-Sage ${ }^{467}$ - märchenhafter Vorlagen unterscheidet sich von der intertex-

\footnotetext{
${ }^{463}$ Detering/Sina/Jeßing/Meid/Meier/Schnell 2013, S. 23.

${ }^{464}$ Detering/Sina/Jeßing/Meid/Meier/Schnell 2013, S. $23 \mathrm{ff}$.

465 Detering/Sina/Jeßing/Meid/Meier/Schnell 2013, S. 25.

466 Hillebrand 1983, S. 31.

467 Die Melusine-Sage hat ihren Ursprung in den antik-mythischen Sirenen- und Nixenstoffen. Diese Stoffe wurden in den mittelalterlichen lateinischen Überlieferungen des 12. und 13. Jahrhunderts als die tragische Liebes- und Familiengeschichte eines Mannes und seiner dämonischen Frau umgesetzt. Im 13. und 14. Jahrhundert wurde diese Geschichte mit der Sage vom Haus Lusignan verbunden. Einer der mehreren französischen Melusine-Romane, den von Couldrette um 1400 verfasste, wurde von Thüring von Ringoltingen ins Deutsche übersetzt und stark bearbeitet (handschriftliche Überlieferung seit 1467, Erstdruck 1474).
} 
tuellen Adaption literarischer Vorlagen in den modernen Texten jedoch unter anderem durch das Fehlen einer Auseinandersetzung mit den Vorlagen.

Die vorliegende Arbeit hat sechs Erzähltexte untersucht. Die Untersuchung begann mit Wielands Die Abentheuer des Don Sylvio von Rosalva, der sich an der Grenze zwischen Rokoko- und Aufklärungsliteratur befindet, und endete mit Thomas Manns zweitem Roman Königliche Hoheit, der für den Autor ein Meilenstein auf dem Weg zur Demokratie war. Alle diese Texte beschäftigen sich mit der Adaption und der kritischen Abweichung mehrerer Märchenprätexte auf unterschiedliche Weisen. Zwischen den jeweiligen Texten aus verschiedenen literarischen Epochen bestehen auch intertextuelle Bezüge.

Christoph Martin Wieland gilt für die deutsche Literaturgeschichte als der Dichter, der „im deutschen Roman den ersten souveränen Erzähler als dialogisierenden Partner des Lesers einführt, der ein spezifisches interkommunikatives Vertrauensverhältnis herstellt, der dem Leser die Gewißheit gibt, mit ihm zusammen die wahren Wirklichkeitsverhältnisse dieser Welt zu durchschauen" ${ }^{468}$. In Don Sylvio von Rosalva, ein märchenhaftes und komödiantisches Gegenstück zu dem spanischen Roman Don Quijote, das die Leser unter anderem amüsieren soll, spielt der Erzähler eine solche ebenso Vertrauen erweckende wie gleichzeitig unzuverlässige Rolle für die Leser. Einerseits macht er die Märchenschwärmerei des Titelhelden zum Gegenstand des Spottes, andererseits verdeckt er den Lesern durch seine distanzierenden Bemerkungen die märchenhafte Handlung in der Geschichte des Don Sylvio. Eine lustspielhafte Gruppe von Figuren wird nach den jeweiligen intertextuellen Vorbildern entworfen. Die Figuren sind jeweils durch den eigenen Literaturgeschmack gekennzeichnet und damit eher Stereotypen als Individuen mit Wahrheitsansprüchen. Berücksichtigt der Leser zugleich die Romanhandlung und deren märchenhafte Struktur, bemerkt er eine Verbindung zwischen Märchenmotiven (die Erlösung durch eine Braut, das zu erreichende märchenhafte Glück) und der zeitgenössischen Wirklichkeit (die Überwindung der Märchenschwärmerei, die Integration in eine „schöne Gesellschaft" ${ }^{“}$ ). Das Märchenhafte/ Unrealistische (etwa die Herkunft Donna Felicias) und das Romanwirkliche verknüpfen sich gegen Ende des Textes immer mehr. Durch das Hin-und-Her zwischen Fiktion/Märchen und Wirklichkeit wird die Grenze zwischen den beiden Bereichen verwischt und eine Kombination zwischen den beiden - Don Sylvios selbst erdichtetes Lebensmärchen -entsteht in diesem Zwielicht. Durch diese Mehrdeutigkeit lässt der Autor Wieland seine aufgeklärten Leser selbst entscheiden, ob sie in dem Roman eine Integrationsgeschichte eines jungen Mannes in eine vernünftige Gesellschaft sowie die erbauende Funktion der Einbildungskraft finden, oder ob sie überhaupt ein scharfes Entweder/Oder zwischen den beiden Möglichkeiten sehen.

468 Hillebrand 1983, S. 35. 
Das Werden des Lebensmärchens gehört auch zu den thematischen Kategorien von Die Lebrlinge zu Sais und der gesamten Romandichtung Novalis'. Novalis war ein Kenner von Wielands Werk und mindestens in seiner Jugendzeit huldigte er Wieland begeistert in seiner Poesie. ${ }^{469}$ In Wielands Märchensammlung Dschinnistan oder auserlesene Feen- und Geistermärchen, teils neu erfunden, teils überset:ț und umgearbeitet (1786-89) fand Novalis den arabischen Namen Ginnistan (Phantasie) und adaptierte ihn in seinem eigenen Kunstmärchen von Eros und Fabel. Auch die didaktische Funktion des Märchens und die Liebe als der erste Schritt der Transzendierung des Individuums, von denen in Wielands Roman die Rede ist, kommen in Die Lebrlinge zu Sais vor, und zwar als Vorbereitung für die kommende Erlösung des Individuums aus dem Grübeln sowie der Welt aus der Erstarrung. Der Dichter erkennt den Verlust der Ganzheit (die verlorene Goldene Vergangenheit) seiner Welt und versucht, die Ganzheit in seinem Märchenroman wiederherzustellen, was mit der Selbsterkenntnis und der Selbstliebe des Individuums beginnt und mit der Verbindung von Erzähler und Zuhörer, Ich und Du und allen Ambivalenzen in der modernen Welt erfolgt. Die Wiederherstellung der Ganzheit ist in der Tat „ein Kampf der Bestimmung gegen die Mehrdeutigkeit, der semantischen Präzision gegen Ambivalenz, der Durchsichtigkeit gegen Dunkelheit, der Klarheit gegen Verschwommenheit. " ${ }^{470}$ Eine neue Ordnung soll in dieser ordnungslosen Welt hergestellt werden. Sie ist aber keine göttliche Ordnung mehr, sondern menschlich-subjektiv, denn das Goldene Zeitalter wirkt in dem Augenblick der schöpferischen Freiheit des Menschen.

Chamissos Peter Schlemibl ist eine Novelle, in der die Eindeutigkeit absichtlich fehlt: Bis jetzt wird heftig diskutiert, was für einen allegorischen Sinn der Schattenverlust des Titelhelden besitzt. In diesem Sinne kann die Novelle als ein modernes Rätselwerk gelten. In einer Auseinandersetzung mit einer vom Naturzustand entarteten fiktiven Umwelt, die einen parodisch märchenhaften Schein besitzt, wird der anfangs passiv gehorchende Titelheld allmählich zu einem modernen selbstbewussten Individuum. Das Märchenhafte gilt in Chamissos Text schon nicht mehr - wie bei Novalis - als das zukünftig Ideale. Es ist einerseits dämonisch bedrohlich, andererseits das notwendige Mittel, mit dem Schlemihl vor der realistischen Menschenwelt flieht. Es darf nur in dem plötzlich in Chamissos Zimmer auftauchenden Manuskript - als Selbstreflexion Peter Schlemihls - eingeschränkt präsent sein und keine Verbindung mit der Welt in der Rahmenerzählung haben. Mit dieser Novelle verabschiedet sich Chamisso von dem frühromantischen Ideal von der Wiederherstellung einer märchenhaften Ganzheit und versöhnt sich mit der Moderne.

Der Schimmelreiter lässt sich - Peter Scblemibl ähnlich - als eine Geschichte der Glückssuche lesen. Die Gegenüberstellung von aufklärerischen Fortschrittsgedanken und dem Aberglauben erscheint an sich bereits als Ambivalenz in einer mo-

${ }^{469}$ Vgl. Hitzel 1974, S. 10.

470 Bauman 2005, S. 20. 
dernen Gesellschaft. Hauke Haien ist ein Mensch, der an der Grenze zwischen Vormoderne und Moderne steht. Der Held versucht, eine Ordnung (seinen Deich) gegen das Chaos (einerseits die bedrohliche Kraft der Natur, andererseits die feindselige Volksstimme in seinem Dorf) zu schaffen, muss jedoch an der unkontrollierbaren Vielfältigkeit seiner Umwelt scheitern. An Konflikten zwischen dem Helden und seiner Umwelt scheitert auch das persönliche Märchen Hauke Haiens, da ein Märchenheld prinzipiell keine Umwelt und keine menschlichen Beziehungen zu seinen Mitmenschen haben kann. Hauke Haiens Geschichte ist also der nicht gelungene Versuch, ein Märchen in die moderne Welt zu übertragen.

Der Exkurs dieser Arbeit behandelte Hans Christian Andersens Roman Peer im Glück. Im Gegensatz zu Der Schimmelreiter und Peter Schlemibl erzählt dieser Roman die gelungene Variante einer Sublimationsgeschichte des Titelhelden, die mit Peers Tod in seinem Triumph als angesehener Künstler gipfelt und so endet. Die Geschichte ist allerdings mehrdeutig: Peers Triumph als Künstler bedeutet zugleich seinen Fall als Mensch, denn er verzichtet auf Liebe, freundschaftliche Verhältnisse, Gesundheit und schließlich auf das Leben. Aus dem Menschen wird ein Künstlersymbol, was als der Gegenwert seines Glücks gelten kann. Wie ein Zaubermärchen endet der Roman im größten Glück, das - als realer Tod - zugleich das größte Unglück für einen Menschen ist. In diesem Sinne hat der Roman nur dann ein glückliches Ende, wenn er als Märchen gelesen wird. Wie die Helden in Andersens Märchen trägt Peer auch autobiographische Bezüge des Autors. Der gealterte Andersen reflektiert die bedeutendsten Momente aus der frühen Phase seines Lebens parallel zu Peers Selbstreflexion durch seine Oper Aladin. Mit diesem Roman schrieb Andersen einen Kommentar zu seiner geschönten Autobiographie Märchen meines Lebens: ob die Leser Andersens eigenes Leben oder Peer im Glück als Märchen sehen, liegt am Leser als Rezipienten und eigentlichen Vollendender aller Kunstwerke.

Nach dem Vorbild seines Lieblingsautors Hans Christian Andersen behandelte auch Thomas Mann in jedem Werk sein eigenes Leben. Königliche Hoheit setzt die Geschichte seines frühen Lebens und seiner Liebesgeschichte zu Katia Pringsheim in eine Prinz-Geschichte um. Eine weitere Lesart des Romans ist - wie Don Sylvio von Rosalva und Die Lehrlinge zu Sais - die als Erlösungsmärchen: der Prinz wird durch die Liebe seiner Braut aus dem kalten einsamen Heim der Schneekönigin erlöst und wird menschlich. Zugleich wird die opernhafte Menschwerdung am Ende des Romans als ,populär verlogen' entlarvt: nicht nur gelingt Klaus Heinrich keine tatsächliche Verbindung mit dem Volk, sondern die Grenze zwischen Märchen und Wirklichkeit wird durch sein wundersames Glück noch einmal verwischt. Die repräsentative Bedeutung des Fürsten in dem modernen Fürstentum und der unrealistische Wunsch des Prinzen, wirklichkeitsnahe und nützlich zu sein, sind eine ironische Widerspiegelung des Mangels an einer einheitlichen Ordnung in den ersten Jahrzehnten des 20. Jahrhunderts. 
Mit Thomas Manns Königliche Hoheit wird das Schreibverfahren der Märchenadaption in der modernen deutschsprachigen Literatur keineswegs beendet. Schon Manns Der Zauberberg (1924) lässt sich als ein kompliziertes Werk mit verschlüsselten Märchenmotiven verstehen. 471 Auch Der Butt (1977) von Günter Grass mit einer Märchenkontur (Vom Fischer und seiner Frau) - der romantischen Tradition des Märchenverständnisses folgend - weist auf die Bestimmung des Märchens als „Träger einer, anderen Wahrheit ““472 durch den Autor hin. Die vorliegende Arbeit hat dagegen solche Erzähltexte untersucht, die je nach Bestimmungsweisen (die Moderne als Mikro- und Makroepoche) vormodern oder modern zu verstehen sind.

Zu den intertextuellen Verfahren der von dieser Arbeit behandelten Erzähltexte gehören die Kontrafaktur bestimmter Vorlagen (etwa die Bearbeitung von Märchenrequisiten durch alle sechs Texte), die Märchenparodie (insbesondere die verzerrende oder verspottende Wiedergabe von Vorlagen durch Don Sylvio von Rosalva und Das Märchen des Prinzen Biribinker), die paratextuelle Bezugnahme auf Märchen (beispielsweise der Romantitel Peer im Glück als eine Anspielung auf Hans im Glück oder die einzelnen Zwischentitel von Königliche Hoheit, insbesondere Die Erfüllung und Der Rosenstock).

Die sechs Erzähltexte bis auf Die Lehrlinge zu Sais erzählen jeweils die Entwicklungs- oder Lebensgeschichte ihrer Hauptfigur. Die Ausgangspunkte ihrer Entwicklung sind entweder eine eigene einseitige Weltanschauung (Don Sylvio von Rosalva) sowie eigene Einsamkeit (Königliche Hoheit) oder ein Streben nach Glück (Peter Scblemibl, Der Schimmelreiter, Peer im Glück): Diese Texte erzählen also im Grunde eine Erlösungsgeschichte oder von der Suche nach dem Glück. Das Romanfragment Die Lebrlinge zu Sais hat in den erhaltenen zwei Kapiteln keine eindeutigen Hauptfiguren. Da Novalis mit diesem Roman einen Naturroman plante und die Natur in dem zweiten Kapitel nach der Märchenerzählung zu sprechen beginnt, liegt es nahe, dass die zu erlösende Natur die eigentliche Hauptfigur sein soll und der Roman auf diese Weise auch eine Erlösungsgeschichte wird. Die Adaption des Handlungsschemas der Erlösungsmärchen ist eine Gemeinsamkeit der hier behandelten Texte. Das Märchenhafte wird eine verborgene Schicht des fiktionalen Textes, und der Text erhält eine weitere Bedeutungsebene. Es ist unvermeidlich in diesen sechs Erzähltexten, dass die Hauptfigur sich während ihrer Entwicklung mit der Umwelt auseinandersetzt und die Welt reflektieren muss, was im originalen Märchen nicht vorkommt und dazu führt, dass der Erzähltext sich von den Märchenvorlagen distanziert. Die Unrealisierbarkeit des Märchens in einer modernen Post-Märchen-Welt wird dadurch eine zentrale Problematik dieser Erzähltexte. Die Autoren der in dieser Arbeit analysierten Erzähltexte geben verschiedene Antworten darauf: Das Märchen ist noch nicht realisiert (Die Lebrlinge zu Sais); das Märchen muss scheitern (Peter Scblemibl und Der Schimmelreiter) oder das glückliche

471 Vgl. Maar 1997.

472 Filz 1997, S. 96. Vgl. Moser 2000, S. 117. 
Ende der Hauptfigur wird als nur in der Märchenschicht vorhanden vom Rezipienten subjektiv relativiert (Don Sylvio von Rosalva, Peer im Glück und Königliche Hoheit). Der Roman Wielands verwischt die Grenze zwischen Märchen und Wirklichkeit und Die Lehrlinge zu Sais zielen auf den Werdegang der Welt zu einem Märchen ab, was ein Bewusstsein der eigenen nicht märchenhaften Umwelt voraussetzt. Die anderen vier Erzähltexte stellen den märchenhaften Lebenslauf ihrer Hauptfiguren in Zweifel, indem sie eine mehrdeutige Tragikomödie unter realistischen Bedingungen aus den eindeutigen märchenhaften Lebensgeschichten schaffen. Das fiktive Individuum erkennt die realistischen Bedingungen auf dem Weg seiner Entwicklung und muss auf die Eindeutigkeit und Einsträngigkeit des Märchens verzichten. Gerade dieses Selbstbewusstsein macht aus einem Individuum einen modernen Menschen und aus einem Erzähltext moderne Kunst. Die Entwicklung und die Selbstreflexion der Figur setzen die Ambivalenzen zwischen Individuum und der Umwelt voraus und die Adaption der Märchenstruktur verleiht dem Text eine Mehrdeutigkeit. Die märchenhafte Ganzheit wird am Ende des Textes nicht oder nur subjektiv allegorisch (Die Lehrlinge zu Sais) wiederhergestellt. Die kritisch reflektierende Adaption von Märchen gehört also zu den Verfahren der modernen Dichtung. 



\section{Literaturverzeichnis}

\section{Primärliteratur}

Aarne, Antti (1973). The Types of the Folktale. A Classification and Bibliography. Translated and Enlarged by Thompson, Stith. Second Revision. Helsinki. (Abkürzung: AaTh)

Andersen, Hans Christian (1953/1982). Sämtliche Märchen und Geschichten. Hanau/Main. (Abkürzung: A)

- (2000): Hans Christian Andersen Tagebücher. 1825-1875. Herausgegeben und übersetzt von Perlet, Gisela. Göttingen. Erste Auflage 2003. (Abkürzung: HCAT)

- (1993): Lebensbuch: Herausgegeben, übersetzt und mit einem Nachwort von Perlet, Gisela. München. (Abkürzung: Lebensbuch)

- (2004): Märchen meines Lebens. Aus dem Dänischen von Michael Birkenbihl. Mit einem Nachwort von Mylius, Johan de. Frankfurt am Main/Leipzig. (Abkürzung: $\mathrm{MmL}$ )

— (1996): Schräge Märchen. Ausgesucht und aus dem Dänischen übertragen von Detering, Heinrich. Mit einem Essay von Maar, Michael. Frankfurt am Main.

- (2005): Sein oder nicht sein. Aus dem Dänischen von Gloßmann, Erik. Mit einem Nachwort des Übersetzers. Frankfurt am Main. 
- (2005): Peer im Glück/Fußreise vom Holmens Kanal zur Ostspitze von Amager in den Jahren 1828 und 1829/Tante Zahnweh. Aus dem Dänischen übersetzt von Bleibtreu, Renate/Perlet, Gisela. Nachwort von Görner, Rüdiger. Zürich. (Abkürzung: PiG)

Andersen, Hans Christian/Eisendecher, Lina von (2003). Briefwechsel. Herausgegeben von Raabe, Paul/Dal, Erik. Göttingen.

Grimm, Jacob/Grimm, Wilhelm (1980/2010): Kinder- und Hausmärchen. Ausgabe letzter Hand mit den Originalanmerkungen der Brüder Grimm. Mit einem Anhang sämtlicher, nicht in allen Auflagen veröffentlichter Märchen und Herkunftsnachweisen herausgegeben von Heinz Rölleke. Stuttgart. (Abkürzung: KHM)

Breitinger, Johann Jacok (1966). Critische Dichtkunst. Faksimiledruck nach der Ausgabe von 1740. Mit einem Nachwort von Bender, Wolfgang. Stuttgart.

Chamisso, Adelbert von (1975). Sämtliche Werke in zwei Bänden. Nach dem Text der Ausgaben letzter Hand und den Handschriften. Textredaktion Jost Perfahl. Bibliographie und Anmerkungen von Volker Hoffmann. München. (Abkürzung: SW)

Chamisso, Adelbert von (2014). Peter Schlemihls wundersame Geschichte. Hrsg. von Gräfe, Florian. Stuttgart.

Fouqué, Friedrich Freiherr de la Motte (1973). Werke. Herausgegeben von Ziesemer, Walther. Hildesheim/New York. (Abkürzung: FW)

Goethe, Johann Wolfgang von (1960). Goethes Werke. Herausgegeben von Trunz, Erich. Hamburg. (Abkürzung: HA)

Gottsched, Johann Christoph (1968ff). Ausgewählte Werke. Herausgegeben von Birke, Joachim/Birke, Brigitte. Berlin/New York.

Kant, Immanuel (1967). Beantwortung der Frage: Was ist Aufklärung? In: Ders.: Was ist Aufklärung? Aufsätze zur Geschichte und Philosophie. Herausgegeben von Zehbe, Jürgen. Göttingen. S. 55-61.

Mann, Thomas (1961ff) Briefe. Herausgegeben von Mann, Erika. Frankfurt am Main. (Abkürzung: Br.)

- (1968): Thomas Mann/Heinrich Mann, Briefwechsel 1900-1949. Frankfurt am Main. (Abkürzung: TM/HM BW)

— (1975): Dichter über ihre Dichtungen Bd. 14/1. Teil I: 1889-1927. Hrsg. v. Wysling, Hans unter Mitwirkung von Marianne Fischer. München. (Abkürzung: DüD)

— (1980ff): Gesammelte Werke in Einzelbänden. Hrsg. v. de Mendelssohn, Peter. Frankfurt am Main. (Abkürzung: GW)

- (1991f): Notizbücher: Edition in zwei Bändern. Hrsg. v. Wysling, Hans/ Schmidlin, Yvonne. Frankfurt am Main.

— (1993ff): Essays. Hrsg. v. Kurzke, Hermann/Stachorski, Stephan. Frankfurt am Main. 
— (2001-): Große kommentierte Frankfurter Ausgabe. Werke - Briefe - Tagebücher. Hrsg. v. Detering, Heinrich u.v.a. Frankfurt am Main. (Abkürzung: GKFA)

Novalis (1960ff). Schriften. Die Werke Friedrich von Hardenbergs. Herausgegeben von Kluckhohn, Paul/Samuel, Richard unter Mitarbeit von Ritter, Heinz/Schulz, Gerhard. Darmstadt. (Abkürzung: N)

— (1976): Dichter über ihre Dichtungen. Bd. 15. Herausgegeben von Mähl, HansJoachim. Passau.

- (1978ff): Werke, Tagebücher und Briefe Friedrich von Hardenbergs. Herausgegeben von Mähl, Hans-Joachim/Samuel. München/Wien.

Schlegel, Friedrich (1976ff): Kritische Friedrich-Schlegel-Ausgabe. Hrsg. v. Behler, Ernst unter Mitwirkung von Anstett, Jean-Jacques/Eichner, Hans. Paderborn. (Abkürzung: KA)

Storm, Theodor (1986). Sämtliche Werke in vier Bänden. Herausgegeben von Peter Goldammer. Berlin.

— (1987f): Sämtliche Werke. Herausgegeben v. Laage, Karl Ernst/Lohmeier, Dieter. Frankfurt am Main. (Abkürzung: LL)

- (1991): Neues Gespensterbuch. Beiträge zur Geschichte des Spuks. Herausgegeben v. Laage, Karl Ernst. Frankfurt am Main.

- (2014): Der Schimmelreiter. Novelle von Theodor Storm. Historisch-kritische Edition. Herausgegeben v. Eversberg, Gerd. Berlin. (Abkürzung: HKE)

Storm, Theodor - Heyse, Paul (1969/70/74). Briefwechsel. Herausgegeben v. Bernd, Clifford Albrecht. Berlin.

Storm, Theodor - Keller, Gottfried (1992). Briefwechsel. Herausgegeben v. Laage, Karl Ernst. Berlin.

Storm, Theodor - Mommsen, Theodor (1966). Theodor Storms Briefwechsel mit Theodor Mommsen. Herausgegeben v. Teitge, Hans-Erich. Weimar.

Storm, Theodor - Gebrüder Paetel (1984). Briefwechsel. Herausgegeben v. Berbig, Roland. Berlin.

Storm, Theodor - Storm, Ernst (2007). Briefwechsel. Herausgegeben v. Jackson, David. Berlin.

Thompson, Stith (1997). Motif-Index of Folk-Literature. A Classification of Narrative Elements in Folkstales, Ballads, Myths, Fables, Mediaeval Romances, Exempla, Fabliaux, Jest-Books, and Local Legends. Volume Three, F-H. Bloomington.

Wagner, Richard (1914) Über die Ouvertüre. In: Gesamte Schriften. Editiert v. Kapp, Julius. Leipzig. Bd. 7.

Wieland, Christoph Martin (1875): Wieland's Werke. Berlin. (Abkürzung: W)

- (1975): Wielands Briefwechsel. Herausgegeben v. Seiffert, Hans Werner. Berlin. (Abkürzung: Br.)

— (1984): Sämmtliche Werke. Hamburg. (Abkürzung: SW)

- (2001): Die Abenteuer des Don Sylvio von Rosalva. Erste Fassung. Herausgegeben v. Jørgensen, Sven-Aage. Stuttgart. 
- (2009ff): Wielands Werke. Historisch-kritische Ausgabe. Herausgegeben v. Manger, Klaus/Reemtsma, Jan Philipp. Berlin/New York. (Abkürzung: WW)

Wilde, Oscar (2005): The Complete Works of Oscar Wilde. General Editor: Small, Ian. Volume 3. The Picture of Dorian Gray. The 1890 and 1891 Texts. Edited by Bristow, Joseph. Oxford/New York.

\section{Sekundärliteratur}

Amlinger, Lore M. (1989). Von Immensee zum Schimmelreiter. Zur Entwicklung des Stormschen Helden. In: Schriften der Theodor-Storm-Gesellschaft 38. S. 63-72.

Andersen, Jens (2005). Hans Christian Andersen. Eine Biographie. Frankfurt am Main/Leipzig.

Apel, Friedmar (1978). Die Zaubergärten der Phantasie. Zur Theorie und Geschichte des Kunstmärchens. Heidelberg.

Arz, Maike (1996) Literatur und Lebenskraft. Vitalistische Naturforschung und bürgerliche Literatur um 1800. Stuttgart.

Atkins, Stuart (1946). Peter Schlemibl in Relation to the Popular Novel of the Romantic Period. In: The Germanic Review 21. Nr. 3. S. 191-209.

Aust, Hugo (2006). Realismus. Stuttgart/Weimar.

- (2012): Novelle. Stuttgart/Weimar.

Auteri, Laura (2005). Feen und Rokoko? Zu Wielands Don Sylvio und Idris und Zenide. In: Wieland-Studien V. Herausgegeben von Manger, Klaus und vom Wieland-Archiv Biberach. Sigmaringen. S. 9-21.

Bahr, Hermann (1971). Die Moderne. In: Die literarische Moderne. Dokumente zum Selbstverständnis der Literatur um die Jahrhundertwende. Ausgewählt und mit einem Nachwort herausgegeben v. Wunberg, Gotthart. Frankfurt am Main. S. 52-55.

Baldwin, Claire (2002). The Emergence of the Modern German Novel. Christoph Martin Wieland, Sophie von La Roche, and Maria Anna Sagar. Rochester.

Baltensweiler, Thomas (2004). Die Aporie in der bürgerlichen Familie. Zur Funktion des Erwerbssinns in Hans und Heinz Kirch und Der Schimmelreiter. In: Schriften der Theodor-Storm-Gesellschaft 53. S. 87-100.

Bark, Irene (1999). „Steine in Potenzen“. Konstruktive Rezeption der Mineralogie bei Novalis. Tübingen.

Bauman, Zygmunt (2005). Moderne und Ambivalenz. Aus dem Englischen von Suhr, Martin. Hamburg.

Baumgart, Reinhard (1964) Das Ironische und die Ironie in den Werken Thomas Manns. München. 
Baumgartner, Ulrich (1944) Adelbert von Chamissos Peter Schlemihl. Frauenfeld/ Leipzig.

Beck, Andreas (2013). Ästhetische Erziehung zur Promiskuität - die Geschichte des Prinzen Biribinker im Textgefüge des Don Sylvio von Rosalva. In: Die Grazie tanzt. Schreibweisen Christoph Martin Wielands. Herausgegeben v. Seidler, Miriam. Frankfurt am Main. S. 115-130.

Becker, Sabine/Kiesel, Helmut (2007). Literarische Moderne. Begriff und Phänomen. In: Literarische Moderne. Begriff und Phänomen. Herausgegeben v. Becker, Sabine/Kiesel, Helmut unter Mitarbeit von Krause, Robert. Berlin/ New York. S. 9-35.

- (2009): Jenseits der Metropolen. Thomas Manns Romanästhetik in der Weimarer Republik. In: Thomas-Mann-Jahrbuch 22. S. 83-97.

Begemann, Christian (2013). Figuren der Wiederkehr. Erinnerung, Tradition, Vererbung und andere Gespenster der Vergangenheit bei Theodor Storm. In: Wirklichkeit und Wahrnehmung. Neue Perspektive auf Theodor Storm. Herausgegeben v. Strowick, Elisabeth/Vedder, Ulrike. Bern. S. 13-38.

Behler, Ernst (1992). Frühromantik. Berlin/New York.

Beller, Manfred (2000). Stoff, Motiv, Thema. In: Literaturwissenschaft. Ein Grundkurs. Herausgegeben v. Brackert, Helmut/Stückrath, Jörn. Hamburg. S. 30-39.

Berd, Clifford Albrecht (1972). Theodor Storm und die Romantik. In: Schriften der Theodor-Storm-Gesellschaft 21. S. 24-37.

- (2003): Theodor Storm. The Dano-German Poet and Writer. Bern.

Berendsohn, Walter A. (1973). Phantasie und Wirklichkeit in den Märchen und Geschichten Hans Christian Andersens. Struktur- und Stilstudien. Walluf bei Wiesbaden.

Bergengruen, Maximilian (2004). Signatur, Hieroglyphe, Wechselrepräsentation. Zur Metaphysik der Schrift in Novalis' Lehrlingen. In: Athenäum. 14. Jahrgang. S. 43-67.

Berger, Willy R. (1978). Drei phantastische Erzählungen. Chamissos Peter Schlemibl, E. T. A. Hoffmanns Die Abenteuer der Silverster-Nacht und Gogols Die Nase. In: Arcadia 13 Sonderheft 3. S. 106-138.

Bertheau, Jochen (2002). Eine komplizierte Bewandtnis. Der junge Thomas Mann und die französische Literatur. Frankfurt am Main.

Bickenbach, Matthias (2013). Wielands „Noten-Prose“: Fußnoten als Störung und Vergnügen des Lesers. In: Die Grazie tanzt. Schreibweisen Christoph Martin Wielands. Herausgegeben v. Seidler, Miriam. Frankfurt am Main. S. 289-316.

Blumenberg, Hans (1969). Wirklichkeitsbegriff und Möglichkeit des Romans. In: Nachahmung und Illusion. Kolloquium Gießen Juni 1963. Vorlagen und Verhandlungen. Herausgegeben v. Jauß, Hans Robert. München. S. 9-27. — (1974): Säkularisierung und Selbstbehauptung. Frankfurt am Main. 
Böhn, Andreas (2001). Das Formzitat. Bestimmung einer Textstrategie im Spannungsfeld zwischen Intertextualitätsforschung und Gattungstheorie. Berlin.

Bollenbeck, Georg (2007). „Gefühlte Moderne“ und negativer Resonanzboden. In: Literarische Moderne. Begriff und Phänomen. Herausgegeben von Becker, Sabine/Kiesel, Helmut unter Mitarbeit von Krause, Robert. Berlin/ New York. S. 39-60.

Böckmann, Paul (1969). Der Widerstreit von Geist und Leben und seine ironische Vermittlung in den Romanen Thomas Manns. In: Wissenschaft als Dialog. Studien zur Literatur und Kunst seit der Jahrhundertwende. Herausgegeben v. Heydebrand, Renate von/Just, Klaus Günther. Stuttgart. S. 194-215.

Böhm, Karl Werner (1991). Zwischen Selbstzucht und Verlangen. Thomas Mann und das Stigma Homosexualität. Untersuchungen zu Frühwerk und Jugend. Würzburg.

Bolte, Johannes/Polívka, Georg (1963): Anmerkungen zu den Kinder- und Hausmärchen der Brüder Grimm. Leipzig.

Borcherdt, Hans Heinrich (1953/54). Das Vorspiel von Thomas Manns Königliche Hoheit. In: Wirkendes Wort 4. S. 359-364.

Borchmeyer, Dieter (1983). Repräsentation als ästhetische Existenz. Königliche Hoheit und Wilhelm Meister. Thomas Mann--s Kritik der formalen Existenz. In: Recherches Germaniques 13. S.105-136.

Bracht, Edgar (1987). Der Leser im Roman des 18. Jahrhundert. Frankfurt am Main.

Braun, Peter: Reiseschatten (2002). Peter Schlemibls wundersame Geschichte von Adalbert von Chamisso. In: Nischik, Reingard M./Rosenthal, Caroline (Hrsg.): Schwellentexte der Weltliteratur. Konstanz. S. 143-164.

Braungart, Wolfgang (2014). Das Kunstwerk als Individuum, der Autor als Subjekt. Versuch zur literarischen Moderne. In: Literaturgeschichte. Theorien Modelle - Praktiken. Herausgegeben von Buschmeier, Matthias/Erhart, Walter/Kauffmann, Kai. Berlin/Boston. S. 265-306.

Brenner, Peter J. (1976). Kritische Form. Zur Dialektik der Aufklärung in Wielands Roman Don Sylvio von Rosalva. In: Jahrbuch der deutschen Schillergesellschaft. 20. Jahrgang. S. 162-183.

Brenner, Peter (1981). Die Krise der Selbstbehauptung. Subjekt und Wirklichkeit im Roman der Aufklärung. Tübingen.

Brittnacher, Hans Richard/May, Markus (2013). Phantastik. Ein interdisziplinäres Handbuch. Stuttgart/Weimar.

Broich $^{1}$, Ulrich (1985). Formen der Markierung von Intertextualität. In: Intertextualität. Formen, Funktionen, anglistische Fallstudien. Herausgegeben v. Pfister, Manfred/Broich, Ulrich. Tübingen. S. 31-47.

- (1985)2: Zur Einzeltextreferenz. In: Intertextualität. Formen, Funktionen, anglistische Fallstudien. Herausgegeben von Pfister, Manfred/Broich, Ulrich. Tübingen. S. 48-52. 
Browne, Christine Geffers: Theodor Storm. Das Spannungsverhältnis zwischen Glauben und Aberglauben in seinen Novellen. New York/Washington D. C./Baltimore/Bern/Frankfurt am Main/Berlin/Brussels/Vienna/Oxford Lang.

Brüggemann, Heinz (2009). Peter Schlemihls wundersame Geschichte der Wahrnehmung. Über Adelbert von Chamisssos literarische Analyse visueller Modernität. In: Ders: Romantik und Moderne. Moden des Zeitalters und buntscheckige Schreibart. Würzburg. S. 123-170.

Brunkhorst, Martin (1979). Vermittlungsebenen im philosophischen Roman: Candide, Rasselas und Don Sylvio. In: Arcadia 14, H. 2. S. 133-147.

Budde, Bernhard (2000). Aufklärung als Dialog. Wielands antithetische Prosa. Tübingen.

Buddecke, Wolfram (1966). C. M. Wielands Entwicklungsbegriffe und die Geschichte des Agathon. Göttingen.

- (1985): Zur Einzeltextreferenz. In: Intertextualität. Formen, Funktionen, anglistische Fallstudien. Herausgegeben von Pfister, Manfred/Broich, Ulrich. Tübingen. S. 48-52.

Calhoon, Kenneth S. (1981). Language and romantic irony in Novalis' Die Lehrlinge zu Sais. In: The Germanic Review. Volume LVI, No. 3 (Summer). S. 51-61.

Coghlan, Brian (1968). Storms Novelleneingänge. Ein Beitrag zur Darstellung seiner späten Erzählkunst. In: Schriften der Theodor-Storm-Gesellschaft 17. S. 72-76.

Conrad, Maren (2013). Das realistische Märchen - Ein Oxymoron? Die Regentrude als experimenteller Text an den Grenzen des Realismus. In: Schriften der Theodor-Storm-Gesellschaft 62. S. 53-69.

Coupe, W. A. (1977). Der Doppelsinn des Lebens. Die Doppeldeutigkeit in der Novellistik Theodor Storms. In: Schriften der Theodor-StormGesellschaft 26. S. 9-21.

Cowen, Roy C. (1985). Der poetische Realismus. Kommentar zu einer Epoche. München.

Craig, Charlotte (1970). Christoph Martin Wieland as the Originator of the Modern Travesty in German Literature. Chapel Hill.

Dedner, Burghard (1983). Kultur und Wahrheit. Zur thematischen Dialektik von

Thomas Manns Frühwerk. In: Jahrbuch der deutschen Schillergesellschaft 27. S. 345-380.

— (2001): Über die Grenzen humoristischer Liberalität. Zu Thomas Manns Roman Königliche Hoheit. In: Bluhm, Lothar/Rölleke, Heinz (Hrsg.): „weil ich finde, daß man sich nicht ,entziehen“ soll“،. Gesammelte Aufsätze zu Thomas Mann und seinem Werk. Trier. S. 151-168.

Dehrmann, Mark-Georg (2002). Produktive Einsamkeit. Hannover.

Demandt, Christian (2010). Religion und Religionskritik bei Theodor Storm. Berlin.

Detering, Heinrich (2002): Das offene Geheimnis. Zur literarischen Produktivität eines Tabus von Winckelmann bis zu Thomas Mann. Göttingen. 
- (2005): „Juden, Frauen und Litteraten“: zu einer Denkfigur beim jungen Thomas Mann. Frankfurt am Main.

- (2010): Königliche Hoheit - Thomas Manns Märchen-Roman. Bonn.

- (2015): Königliche Hoheit. In: Blödorn, Andreas/Marx, Friedhelm (Hrsg.):

Thomas Mann Handbuch. Stuttgart. S. 25-31.

Detering, Heinrich/Sina, Kai/Jeßing, Benedikt/Meid, Volker/Meier, Albert/ Schnell, Ralf (2013): Geschichte des deutschsprachigen Romans. Herausgegeben von Meid, Volker. Stuttgart.

Detering, Heinrich/Spreckelsen, Tilman (2014). „Der realistische Geisterseher Storm“. Gespräch zwischen Heinrich Detering und Tilman Spreckelsen, moderiert von Christian Demandt. In: Schriften der Theodor-StormGesellschaft 63. S. 5-22.

Dierks, Manfred (1972). Studien zu Mythos und Psychologie bei Thomas Mann. München.

- (1995): Thomas Mann und die Mythologie. In: Koopmann, Helmut: (Hrsg.):

Thomas-Mann-Handbuch. 2. Aufl. Stuttgart. S. 301-306.

- (1996): Typologisches Denken bei Thomas Mann - mit einem Blick auf C. G. Jung und Max Weber. In: Thomas Mann Jahrbuch 9. S. 127-153.

- (2001): Thomas Mann und die Moderne. In: Thomas Mann. Ein Klassiker der Moderne. Fünf Vorträge zur Würdigung des Dichters aus Anlaß seines 125. Geburtstages. Hamburg. S. 8-26.

Diez, Max (1986). Novalis und das allegorische Märchen. In: Novalis. Beiträge zu Werk und Persönlichkeit Friedrich von Hardenbergs. Herausgegeben von Schulz, Gerhard. Darmstadt. S. 131-159.

Dipper, Christof (2009). Was ist eigentlich modern? Überlegungen eines Historikers zu einem interdisziplinären Gespräch. In: Internationales Archiv für Sozialgeschichte der deutschen Literatur. Band 34. 2. Heft. S. 198-209.

Dunker, Axel (2009). Fantastische Literatur. In: Handbuch der literarischen Gattungen. Herausgegeben von Lamping, Dieter in Zusammenarbeit mit Poppe, Sandra/Seiler, Sascha/Zipfel, Frank. Stuttgart. S. 240-247.

Easterlin, Nancy (2001). Hans Christian Andersen's Fish out of Water. In: Philosophy and Literature 25. 2. S. 251-277.

Ebel, Uwe (1994). Hans Christian Andersen. Politologie und Poetologie seines Werks. Metelen/Steinfurt.

Elsaghe, Yahya (2000). Die imaginäre Nation. Thomas Mann und das „Deutsche“. München.

Emmel, Hildegard (1972): Geschichte des deutschen Romans. Band 1. Bern/ München.

Endres, Johannes (2004). Der Schleier des Novalis. In: Novalis. Poesie und Poetik. Herausgegeben v. Uerlings, Herbert. Tübingen. S. 109-124.

Engel, Manfred (1997). „Träumen und Nichtträumen zugleich“. Novalis’ Theorie und Poetik des Traumes zwischen Aufklärung und Hochromantik. In: No- 
valis und die Wissenschaften. Herausgegeben von Uerlings, Herbert. Tübingen. S 143-168.

- (2014): Wir basteln uns eine Großepoche: Die literarische Moderne. In: Literaturgeschichte. Theorien - Modelle - Praktiken. Herausgegeben v. Buschmeier, Matthias/Erhart, Walter/Kauffmann, Kai. Berlin/Boston. S. 246-264.

Englert, Dorothea (1993). Literatur als Reflexionsmedium für Individualität. Systemtheoretische Studien zur Funktion des ästhetischen Sinnangebots bei Schiller und Novalis. Frankfurt am Main.

Erhart, Walter (1991). Entzweiung und Selbstaufklärung. Christoph Martin Wielands Agathon-Projekt. Tübingen.

— (2005): „Wüste in Tyrol“. Die Fremdheit des Schwärmers. In: Wieland-Studien IV. Herausgegeben von Manger, Klaus und vom Wieland-Archiv Biberach. Heidelberg. S. 132-146.

- (2016): Siebenmeilenstiefel, Kronometer, Geschichte der Pflanzen - Chamissos Zeit-Regime. In: Phantastik und Skepsis. Adelbert von Chamissos Lebens- und Schreibwelten. Herausgegeben. v. Berbig, Roland/Erhart, Walter/Sproll, Monika/Weber, Jutta. Göttingen. S. 47-62.

Ermatinger, Emil (1948). Deutsche Dichter 1700-1900. Eine Geistesgeschichte in Lebensbildern. Erster Teil. Vom Beginn der Aufklärung bis zu Goethes Tod. Bonn.

Evans, Tamara S. (1982). „Ich werde Besseres machen ..." Zu Thomas Manns

Goethe-Nachfolge in Tonio Kröger. In: Colloquia Germanica 15. S. 84-96.

Eversberg, Gerd (1999): Mündlichkeit/Schriftlichkeit/Drucktext. Literarische Produktion als Medienwechsel (am Beispiel von Sagen und Spukgeschichten). In: Theodor Storm und die Medien. Zur Mediengeschichte eines poetischen Realisten. Herausgegeben v. Eversberg, Gerd/Segeberg, Harro. Berlin. S. 49-66.

— (2000): „,Vor der Deichnovelle habe ich einige Furcht“. Storms letzter Schreibprozess im Spiegel der Schimmelreiter-Textzeugen. In: Stormlektüren. Festschrift für Karl Ernst Laage zum 80. Geburtstag. Würzburg. S. 323-348.

- (2004): Theodor Storm als Märchensammler. In: Schriften der Theodor-StormGesellschaft 53. S. 43-61.

- (2009): Raum und Zeit in Storms Novelle Der Schimmelreiter. In: Schriften der Theodor-Storm-Gesellschaft 58. S. 15-23.

- (2010): Der echte Schimmelreiter. So (er)fand Storm seinen Hauke Haien. Heide.

- (2011): Die Schimmelreiter-Sage. In: Schriften der Theodor-Storm-Gesellschaft 60. S. 67-92.

Ewen, Jens (2013). Moderne ohne Tempo. Zur literaturgeschichtlichen Kategorisierung Thomas Manns - am Beispiel von Der Zauberberg und Unordnung und frühes Leid. In: Wortkunst ohne Zweifel? Aspekte der Sprache bei Thomas Mann. Herausgegeben von Max, Katrin. Würzburg. S. 77-99. 
- (2016): Thomas Manns Ironie als literarischer Wahrheitspluralismus. In: Thomas Mann Jahrbuch 29. S. 45-56.

Fankhauser, Regula (1997). Des Dichters Sophia. Weiblichkeitsentwürfe im Werk von Novalis. Köln/Weimar/Wien.

Fasold, Regina (1997). Theodor Storm. Stuttgart.

Fauser, Markus (1991). Das Gespräch im 18. Jahrhundert. Rhetorik und Geselligkeit in Deutschland. Stuttgart.

Fiene, Otto (1974). Das humoristisch-ironische Spiel des Erzählens bei Wieland und Thomas Mann. Basel.

Filz, Walter (1997). Dann leben sie noch heute? Zur Rolle des Märchens in „Butt“ und „Rättin“. In: Arnold, Heinz Ludwig (Hrsg.): Günter Grass. Text + Kritik. Heft 1. S. 95-102.

Fischer, Robert (1990). Adelbert von Chamisso. Weltbürger, Naturforscher und Dichter. München.

Fix, Peter (1976). Königliche Hoheit. In: Fix, Peter u.v.a.: Das erzählerische Werk Thomas Manns. Entstehungsgeschichte - Quelle - Wirkung. Berlin/Weimar. S.60-107.

Flores, Ralph (1974). The Lost Shadow of Peter Schlemihl. In: The German Quarterly 47, Heft 4. S. 567-584.

Fludernik, Monika (2009). Roman. In: Handbuch der literarischen Gattungen. Herausgegeben von Lamping, Dieter. Stuttgart. S. 627-645.

Forssell, Louise (2006): „Es ist nicht gut, so ganz allein zu sein ...“ Männlichkeiten und Geschlechterbeziehungen in Theodor Storms später Novellistik. Stockholm.

Freund, Winfried (1984). Theodor Storm. Der Schimmelreiter. Glanz und Elend des Bürgers. Paderborn.

- (1987): Theodor Storm. Stuttgart.

Fricke, Harald (1984). Aphorismus. Stuttgart.

Frühwald, Wolfgang (1981): Hauke Haien, der Rechner. Mythos und Technikglaube in Theodor Storms Novelle Der Scbimmelreiter. In: Literaturwissenschaft und Geistesgeschichte. Festschrift für Richard Brinkmann. Herausgegeben v. Brummack, Jürgen und anderen. Tübingen. S. 439-457.

Gaier, Ulrich (1970). Krumme Regel. Novalis’ „Konstruktionslehre des schaffenden Geistes" und ihre Tradition. Tübingen.

Genette, Gérard (1993): Palimpseste. Die Literatur auf zweiter Stufe. Frankfurt am Main.

Görner, Rüdiger (2005). Thomas Mann. Der Zauber des Letzten. Darmstadt.

Graeber, Wilhelm (2003). „Leserpädagogik“: Zur gattungsinnovativen Funktion des Dialogs in französischen Aufklärungsromanen. In: Dialog und Dialogizität im Zeichen der Aufklärung. Herausgegeben v. VickermannRibémont, Gabriele/Rieger, Dietmar. Tübingen. S. 187-199.

Grätz, Manfred (1988). Das Märchen in der deutschen Aufklärung. Vom Feenmärchen zum Volksmärchen. Stuttgart. 
Greif, Stefan (1994). Märchen/Volksdichtung. In: Romantik-Handbuch. Herausgegeben v. Schanze, Helmut. Tübingen. S. 257-275.

Gremler, Claudia (2003). „Fern im dänischen Norden ein Bruder“: Thomas Mann und Hermann Bang. Göttingen.

Hädecke, Wolfgang (2011). Novalis. Biographie. München.

Haering, Theodor (1954). Novalis als Philosoph. Stuttgart.

Hamacher, Bernd (1996). Poetologischer Funktionen des Märchens bei Thomas Mann. In: Eicher, Thomas (Hrsg.): Märchen und Moderne. Fallbeispiele einer intertextuellen Relation. Münster. S. 69-114.

Harnischfeger, Johannes (2000). Modernisierung und Teufelspakt. Die Funktion des Dämonischen in Theodor Storms Schimmelreiter. In: Schriften der Theodor-Storm-Gesellschaft 49. S. 23-44.

Hartmann, Willi (1992). Der Gedanke der Menschenwerdung bei Novalis. Eine religionsphilosophische Untersuchung der Fragmente und Studienaufzeichnungen. Freiburg.

Haslinger, Josef (1981). Die Ästhetik des Novalis. Hain.

Heftrich, Eckhard (1969). Novalis. Vom Logos der Poesie. Frankfurt am Main.

Heinz, Jutta (1994). Von der Schwärmerkur zur Gesprächstherapie - Symptomatik und Darstellung des Schwärmers in Wielands Don Sylvio und Peregrinus Proteus. In: Wieland-Studien II. Herausgegeben v. Manger, Klaus/WielandArchiv Biberach. Sigmaringen. S. 33-53.

- (2008): Wieland-Handbuch. Leben - Werk - Wirkung. Stuttgart/Weimar.

Henderson, Fergus (1997). Romantische Naturphilosophie. Zum Begriff des „Experiments" bei Novalis, Ritter und Schelling. In: Novalis und die Wissenschaften. Herausgegeben von Uerlings, Herbert. Tübingen. S. 121-142.

Hentschel, Uwe (1996). Modern und unromantisch - Reiseerfahrungen im 18. und frühen 19. Jahrhundert. In: Aurora 56. S. 95-109.

Hermand, Jost (1969). Hauke Haien, Kritik oder Ideal des gründerzeitlichen Übermenschen? In: Ders.: Studien zur deutschen Literatur. Stuttgart. S. 250-268; S. 383ff.

Hiebel, Friedrich (1951). Novalis. Der Dichter der blauen Blume. München.

- (1972): Novalis. Deutscher Dichter - Europäischer Denker - Christlicher Seher. Bern/München.

Hillebrand, Bruno (1983). Zur Romantheorie in Deutschland. In: Handbuch des deutschen Romans. Herausgegeben v. Koopmann, Helmut. Düsseldorf.

Hillmann, Heinz (1980). Wunderbares in der Dichtung der Aufklärung. Untersuchungen zum französischen und deutschen Feenmärchen. In: Erforschung der deutschen Aufklärung. Herausgegeben v. Pütz, Peter. Königstein/Ts. S. 246-270.

Hohendahl, Peter Uwe (1969). Zum Erzählproblem des utopischen Romans im 18. Jahrhundert. In: Gestaltungsgeschichte und Gesellschaftsgeschichte. Herausgegeben v. Kreuzer, Helmut. In Zusammenarbeit mit Hamburger, Käte. Stuttgart. S. 79-114. 
Honold, Alexander (2010). Quijote im Wunderland. Wielands Don Sylvio als literarisches Sozialisationsmodell. In: Wieland/Übersetzen. Sprachen, Gattungen, Räume. Herausgegeben v. Menke, Bettine/Struck, Wolfgang. Berlin/ New York. S. 179-205.

Hörisch, Jochen (1995). Schlemihls Schatten - Schatten Nietzsches. Eine romantische Apologie des Sekundären. In: Athenäum 5. S. 11-42.

Horkheimer, Max/Adorno, Theodor (1988). Dialektik der Aufklärung. Philosophische Fragmente. Ungekürzte Ausgabe. Frankfurt am Main.

Horn, András (1998). Theorie der literarischen Gattungen. Würzburg.

Iser, Wolfgang (1972). Der implizite Leser. München.

Jackson, David A. (2015). „Sie können Ihren eigenen Augen doch nicht mißtrauen“. Noch einmal zum zweiten Rahmenerzähler in Theodor Storms Der Schimmelreiter. In: Schriften der Theodor-Storm-Gesellschaft 64. S. 53-73.

Jacobs, Jürgen (1969). Wielands Romane. Bern/München.

Jahn, Wolfgang (1981). Zu Wielands Don Sylvio. In: Christoph Martin Wieland. Herausgegeben von Schelle, Hansjörg. Darmstadt. S. 307-321.

Jauß, Hans Robert (1969). Nachahmungsprinzip und Wirklichkeitsbegriff in der Theorie des Romans von Diderot bis Stendhal. In: Nachahmung und Illusion. Kolloquium Gießen Juni 1963. Vorlagen und Verhandlungen. Herausgegeben v. Jauß, Hans Robert. München. S. 157-177.

Jendreiek, Helmut (1977). Thomas Mann. Der demokratische Roman. Düsseldorf. Jørgensen, Sven-Aage (1981). Christoph Martin Wieland, Der Sieg der Natur über die Schwärmerei oder die Abenteuer des Don Sylvio von Rosalva. In: Christoph Martin Wieland. Herausgegeben v. Schelle, Hansjörg. Darmstadt 1981. S. 328343.

- (2001): Nachwort. In: Die Abentener des Don Sylvio von Rosalva. Erste Fassung. Herausgegeben v. Jørgensen, Sven-Aage. Stuttgart. S. 509-531.

- (1986).: Vergangenheit und Vergänglichkeit. Zur Funktion des Erinnerns in Theodor Storms Novellen. In: Schriften der Theodor-Storm-Gesellschaft 35. S. 9-15.

Karasek, Hellmuth (1991). Königliche Hoheit. In: Thomas Mann Jahrbuch 4. S. 2944.

Kayser, Wolfgang (1955). Entstehung und Krise des modernen Romans. Stuttgart. - (1956): Das Problem des Erzählers im Roman. In: The German Quarterly. Vol. XXIX No. 1. S. 225-238.

- (1975): Die Anfänge des modernen Romans im 18. Jahrhundert und seine heutige Krise. In: Deutsche Vierteljahrsschrift für Literaturwissenschaft und Geistesgeschichte (28. Jahrgang) XXVIII. Band. S. 417-446.

Kesting, Hanjo (2000): Zauberer und Märchendichter. Thomas Mann und Hans Christian Andersen. In: Ders.: Das Nachlese. Göttingen. S. 219-231.

Kiesel, Helmut (2010): Klassische Moderne? Überlegungen zur Problematik einer Epochenbezeichnung. In: Klassische Moderne. Ein Paradigma des 20. Jahrhunderts. Herausgegeben von Ponzi, Mauro. Würzburg. S. 35-44. 
Kindt, Tom (2009): Novelle. In: Handbuch der literarischen Gattungen. Herausgegeben von Lamping, Dieter in Zusammenarbeit mit Poppe, Sandra/Seiler, Sascha/Zipfel, Frank. Stuttgart. S. 540-548.

- (2011): „Das Unmögliche, das dennoch geschieht.“ Zum Begriff der literarischen Phantastik am Beispiel von Werken Thomas Manns. In: Thomas Mann Jahrbuch 24. S. 43-56.

Klotz, Volker (1985). Dahergelaufene und Davongekommene. Ironisierte Abenteuer in Märchen von Musäus, Wieland und Goethe. In: Euphorion 79. Band. S. 322-334.

Kluckhohn, Paul (1960). Friedrich von Hardenberg Entwicklung und Dichtung. In: Schriften. Die Werke Friedrich von Hardenbergs. Erster Band: Das dichterische Werk. Herausgegeben v. Kluckhohn, Paul/Samuel, Richard unter Mitarbeit von Ritter, Heinz/Schulz, Gerhard. Darmstadt. S. 1-67.

Kontje, Todd (2009). Der verheiratete Künstler und die „Judenfrage“. Wälsungenblut und Königliche Hoheit als symbolische Autobiographie. In: Ansel, Michael/Friedrich, Hans-Edwin/Lauer, Gerhard (Hrsg.): Die Erfindung des Schriftstellers Thomas Mann. Berlin/New York. S. 387-410.

Koopmann, Helmut (1971). Thomas Mann und Schopenhauer. In: Pütz, Peter (Hrsg.): Thomas Mann und die Tradition. Frankfurt am Main. S. 180-200.

- (1980): Die Entwicklung des „intellektuellen Romans“ bei Thomas Mann.

Untersuchung zur Struktur von Buddenbrooks, Königliche Hoheit und Der Zauberberg. 3. erweiterte Aufl. Bonn.

- (1995) (Hrsg.): Thomas-Mann-Handbuch. 2. Aufl. Stuttgart 1995.

- (2005).: Heimat, Fremde und Exil im 19. Jahrhundert. In: Das verschlafene 19. Jahrhundert? Zur deutschen Literatur zwischen Klassik und Moderne. Herausgegeben. v. Knobloch, Hans-Jörg/Koopmann, Helmut. Würzburg. S. 25-41.

- (2015): Thomas Mann - Heinrich Mann. Die ungleichen Brüder. München.

Korff, Hermann August (1964). Geist der Goethezeit. Versuch einer ideellen Entwicklung der klassisch-romantischen Literaturgeschichte. Teil 3: Frühromantik. Leipzig.

Krauß, Andrea (2013). Linienführung. Ästhetisches Kalkül in Storms Schimmelreiter. In: Wirklichkeit und Wahrnehmung. Neue Perspektive auf Theodor Storm. Herausgegeben von Elisabeth Strowick und Ulrike Vedder. Bern. S. 149-168.

Kremer, Detlef (2007). Romantik. Lehrbuch Germanistik. Stuttgart/Weimar.

Kreuzer, Ingrid (1979). Novalis: Die Lehrlinge zu Sais. Fragen zur Struktur, Gattung und immanenten Ästhetik. In: Jahrbuch der Deutschen Schillergesellschaft. 23. Jahrgang. S. 276-308.

Kristiansen, Børge (1995). Das Problem des Realismus bei Thomas Mann. Leitmotiv - Zitat - Mythische Wiederholungsstruktur. In: Koopmann, Helmut: (Hrsg.): Thomas-Mann-Handbuch. 2. Aufl. Stuttgart. S. 823-835. 
Kroner, Peter Albert (1971). Adelbert von Chamisso. In: Deutsche Dichter der Romantik. Ihr Leben und Werk. Herausgegeben v. Wiese, Benno von. Berlin. S. 371-390.

Kurrelmeyer, Wilhelm (1919). The sources of Wieland's Don Sylvio. In: Modern Philology 16. Nr. 12. S. 141-152.

Kurth, Lieselotte E. (1969). Die zweite Wirklichkeit. Studien zum Roman des achtzehnten Jahrhunderts. Chapel Hill.

Kurth-Voigt, Lieselotte E. (1974). Perspectives and points of view: the early works of Wieland and their background. Baltimore/London.

Kurzke, Hermann (1999). Thomas Mann. Das Leben als Kunstwerk. München.

- (2010): Thomas Mann. Epoche - Werk - Wirkung. München.

Kuzniar, Alice A. (1985). „Spurlos ... verschwunden“: Peter Schlemibl und sein Schatten als der verschobene Signifikant. In: Aurora 45. S. 189-204.

Laage, Karl Ernst (1958). Das Erinnerungsmotiv in Theodor Storms Novellistik. In: Schriften der Theodor-Storm-Gesellschaft 7. S. 39-61.

- (1971): Der Schimmelreiter im Danziger Dampfboot. In: Schriften der TheodorStorm-Gesellschaft 20. S. 72-75.

- (1979): Der ursprüngliche Schluß der Stormschen Schimmelreiter-Novelle. In: Euphorion 73, S. 451-457.

- (1999): Theodor Storm. Biographie. Heide.

- (2014): Zur Rolle des Deichgespenstes in Storms Schimmelreiter. In: Schriften der Theodor-Storm-Gesellschaft 63. S. 40-46.

Lämmert, Eberhard (1970): Doppelte Optik. Über die Erzählkunst des frühen Thomas Mann. In: Rüdinger, Karl (Hrsg.): Literatur, Sprache, Gesellschaft. München. S. 50-67.

Lange, Victor (1967). Zur Gestalt des Schwärmers im deutschen Roman des 18. Jahrhunderts. In: Festschrift für Richard Alewyn. Herausgegeben v. Singe, Herbert/Wiese, Benno von. Köln/Graz. S. 151-164.

- (1979): Vermittlungsformen des Ideals. Rezeptionsästhetische Studien zu den Bildungsromanen Fieldings und Wielands (Tom Jones und Agathon). Konstanz.

Langer, Ilse (1975). Volksaberglaube und paranormales Geschehen in einigen Szenen des Schimmelreiters. In: Schriften der Theodor-Storm-Gesellschaft 24. S. $90-97$.

Langner, Beatrix (2008): Der wilde Europäer. Adelbert von Chamisso. Berlin.

Lahnstein, Peter (1987). Adelbert von Chamisso. Der Preuße aus Frankreich. Frankfurt a. Main/Berlin.

Lefebvre, Jean (2009). Nichts als Gespenster? Die Funktion des Deichreiters in den Rahmenhandlungen des Schimmelreiters. In: Schriften der TheodorStorm-Gesellschaft 58. S. 7-13.

Lejeune, Philippe (1994). Der Autobiographische Pakt. Aus dem Französischen von Wolfram Bayer und Dieter Hornig. Frankfurt am Main. 
Lehnert, Herbert (1971). Die Künstler-Bürger-Brüder. Doppelorientierung in den frühen Werken Heinrich und Thomas Manns. In: Pütz, Peter (Hrsg.): Thomas Mann und die Tradition. Frankfurt am Main. S. 14-51.

Leopold, Keith (1977). Wieland's Don Sylvio von Rosalva: The First Modern German Novel? In: Festschrift for Ralph Farrell. Edited by Stephens, Anthony/Rogers, H.L./Coghlan, Brian. Bern/Frankfurt am Main/Las Vegas. S. 9-16.

Leusing, Reinhard (1993). Die Stimme als Erkenntnisform - zu Novalis’ Roman Die Lehrlinge zu Sais. Stuttgart.

Lim, Jeong-Taeg (1988). Don Sylvio und Anselmus. Untersuchung zur Gestaltung des Wunderbaren bei C.M. Wieland und E.T.A. Hoffmann. Frankfurt am Main/Bern New York/Paris.

Litteck, Helmut (1996). Verweltlichung oder Entweltlichung? Zur Problematik von Eros- und Thanatos im Werk von Novalis und Arthur Schopenhauer. Düsseldorf.

Loeb, Ernst (1963). Faust ohne Transzendenz: Theodor Storms Schimmelreiter. In: Studies in Germanic Languages and Literatures. S. 121-132.

- (1965): Symbol und Wirklichkeit des Schattens in Chamissos Peter Schlemibl. In: Germanisch-Romanische Monatsschrift. Neue Folge 15. Heft 4. S. 398 408.

Lohmeier, Anke-Marie (2007). Was ist eigentlich modern? Vorschläge zur Revision literaturwissenschaftlicher Modernebegriffe. In: Internationales Archiv für Sozialgeschichte der deutschen Literatur. Band 32. 1. Heft. S. 1-15.

Lohmeier, Dieter (2012). Theodor Storms Schimmelreiter zwischen realistischer Novelle und Gespenstergeschichte. In: Schriften der Theodor-StormGesellschaft 61. S. 99-109.

Lommel, Michael (2007). Peter Schlemihl und die Medien des Schattens. In: Athenäum 17. S. 33-50.

Lorentzen, Tim (2005). Hermetische und erotische Metamorphosen. Zum Nachtgeschirr in Wielands Geschichte vom Prinzen Biribinker. In: Wieland-Studien IV. Herausgegeben v. Manger, Klaus/Wieland-Archiv Biberach. Heidelberg. S. 31-47.

Löwe, Matthias (2016). „Freund, es geht nicht mehr.“ Thomas Mann und die Normativität der ästhetischen Moderne. In: Thomas Mann Jahrbuch 29. S. 9-29.

Ludewig-Thaut, Dorothea (1975). Königliche Hoheit. Autobiographische Züge in Thomas Manns Roman. Bonn.

Luhmann, Niklas (1994). Liebe als Passion. Frankfurt am Main.

Lukas, Verena Anna (2000). Der Dialog im Dialog. Das Inzitament bei Friedrich von Hardenberg. Bern.

Lüthi, Max (1996). Märchen. Bearbeitet von Rölleke, Heinz. Stuttgart.

- (2005): Das europäische Volksmärchen. Tübingen/Basel.

- (2008): Es war einmal. Vom Wesen des Volksmärchens. Göttingen. 
Maar, Michael (1995). Geister und Kunst. Neuigkeiten aus dem Zauberberg. München/Wien.

Mähl, Hans-Joachim (1965). Die Idee des goldenen Zeitalters im Werk des Novalis. Studien zur Wesensbestimmung der frühromantischen Utopie und zu ihren ideengeschichtlichen Voraussetzungen. Heidelberg.

- (1971): Friedrich von Hardenberg (Novalis). In: Deutsche Dichter der Romantik. Ihr Leben und Werk. Unter Mitarbeit zahlreicher Fachgelehrter herausgegeben v. Wiese, Benno von. Berlin. S. 190-224.

Mahoney, Dennis F. (1997). Hardenbergs Naturbegriff und -Darstellung im Lichte moderner Chaostheorien. In: Novalis und die Wissenschaften. Herausgegeben v. Uerlings, Herbert. Tübingen. S. 107-120.

- (2001): Friedrich von Hardenberg (Novalis). Stuttgart.

Malsch, Wilfried (1991). Der ästhetische Schein des poetischen Staates. Zur Bedeutung Schillers für Novalis. In: Aurora 51. S. 23-39.

Mann, Katia (2000): Meine ungeschriebenen Memoiren. Frankfurt am Main.

Marchand, James W. (1984). Wieland's style and narratology. In: Christoph Martin Wieland. Nordamerikanische Forschungsbeiträge zur 250. Wiederkehr seines Geburtstages 1983. Herausgegeben von Schelle, Hansjörg. Tübingen. S. 1-32.

Marcuse, Ludwig (1972). Philosophie des Glücks von Hiob bis Freud. Zürich.

Martínez, Matías (1996). Doppelte Welten. Struktur und Sinn zweideutigen Erzählens. Göttingen.

Martinez, Matias/Scheffel, Michael (2007). Einführung in die Erzähltheorie. 7. Auflage, München.

Martini, Fritz (1964). Nachwort. In: Christoph Martin Wieland. Werke. Erster Band. München. S. 915-966.

Marx, Friedhelm (1995). Erlesene Helden. Don Sylvio, Werther, Wilhelm Meister und die Literatur. Heidelberg.

Marx, Leonie (1995). Thomas Mann und die skandinavischen Literaturen. In: Koopmann, Helmut: (Hrsg.): Thomas-Mann-Handbuch. 2. Aufl. Stuttgart. S. 164-199.

Mayer, Mathias/Tismar, Jens (2003). Kunstmärchen. Stuttgart.

Mayer, K. Otto (1892). Die Feenmärchen bei Wieland. In: Vierteljahrsschrift für Literaturgeschichte 5. S. 374-408 und 497-533.

McCarthy, John A. (1974). Fantasy and reality. An epistemological approach to Wieland. Bern/Frankfurt am Main.

- (1975): Wielands Metamorphose. In: Deutsche Vierteljahrsschrift für Literaturwissenschaft und Geistesgeschichte. XLIX. Band. S. 149-167.

- (1979): Christoph Martin Wieland. Boston.

Meier, Albert/Vrckovski, Simone (2014): Novelle. Eine Einführung. Berlin.

Mendelssohn, Peter de (1975): Der Zauberer. Das Leben des deutschen Schriftstellers Thomas Mann. Teil 1: 1875-1918. Frankfurt am Main. 
Menninghaus, Winfried (1999). Ekel. Theorie und Geschichte einer starken Empfindung. Frankfurt am Main.

Miller, Derrick R. (2013): Wieland's Parodistic, Exuberant, and Self-Conscious Post-Seraphic Erotic Style. In: Die Grazie tanzt. Schreibweisen Christoph Martin Wielands. Herausgegeben v. Seidler, Miriam. Frankfurt am Main. S. 99-113.

- (2013): Formen und Zeit in Christoph Martin Wielands Die Abenteuer des Don Sylvio von Rosalva. In: Die Grazie tanzt. Schreibweisen Christoph Martin Wielands. Herausgegeben v. Seidler, Miriam. Frankfurt am Main. S. 133151.

Miller, Norbert (1979). Chamissos Schweigen und die Krise der Berliner Romantik. In: Aurora 39. S. 101-119.

Miller, Steven R. (1970). Die Figur des Erzählers in Wielands Romanen. Göppingen.

Missfeldt, Jochen (2014). Du graue Stadt am Meer. Der Dichter Theodor Storm in seinem Jahrhundert. Stuttgart/München.

Möller-Christensen, Ivy (1996). Hans Christian Andersens Durchbruch in Deutschland: ein wahres Märchen. In: Grenzgänge. Skandinavischdeutsche Nachbarschaften. Herausgegeben v. Detering, Heinrich. Göttingen. S. 132-146.

Molnár, Géza von (1970). The Composition of Novalis’ Die Lehrlinge zu Sais. A Reevaluation. In: Publications of the Modern Language Association of America. Volume 85, No. 5. S. 1002-1014.

Moser, Sabine (2000). Günter Grass. Romane und Erzählungen. Berlin.

Müller, Bruno (1984). Novalis - Der Dichter als Mittler. Bern.

Müller-Solger, Hermann (1970). Der Dichtertraum. Studien zur Entwicklung der dichterischen Phantasie im Werk Christoph Martin Wielands. Göppingen.

Mylius, Johan de (2006). „Our time is the time of the fairy tale“: Hans Christian Andersen between Traditional Craft and Literary Modernism. In: Marvels \& Tales. Volume 20. Number 2. S. 166-178.

Nakai, Ayako (2004). Poesie und Poetik bei Novalis und die Signaturenlehre der Naturmystik. In: Novalis. Poesie und Poetik. Herausgegeben v. Uerlings, Herbert. Tübingen. S. 185-200.

Nassehi, Armin (2006). Der soziologische Diskurs der Moderne. Frankfurt am Main.

Neubauer, John (1971). Bifocal Vision. Novalis' philosophy of nature and disease. Chapel Hill.

- (1997): Das Verständnis der Naturwissenschaften bei Novalis und Goethe. In: Novalis und die Wissenschaften. Herausgegeben von Uerlings, Herbert. Tübingen. S. 49-64.

Neubauer, Wolfgang (1986). Zum Schatten-Problem bei Adelbert von Chamisso oder zur Nicht-Interpretierbarkeit von Peter Schlemihls wundersame Geschichte. 
In: Literatur für Leser. Zeitschrift für Interpretationspraxis und geschichtliche Textkenntnis 1. S. 24-34.

Neuhauser, Thomas (1981). Der Roman. In: Formen der Literatur in Einzeldarstellung. Herausgegeben v. Knörrich, Otto. Stuttgart. S. 297-312.

Neumann, Christian (2007). Eine andere Geschichte vom Schimmelreiter. Der

Subtext der Deichnovelle Theodor Storms aus literaturpsychologischer Perspektive. In: Schriften der Theodor-Storm-Gesellschaft 56. S. 129-148.

Neumann, Michael (1991). Unterwegs zu den Inseln des Scheins. Kunstbegriff und literarische Form in der Romantik von Novalis bis Nietzsche. Frankfurt am Main.

Neumeyer, Harald (2007). Theodor Storms Novellistik. In: Realismus. Epoche Autoren - Werke. Herausgegeben v. Begemann, Christian. Darmstadt. S. 103-120.

Nobis, Helmut (1976). Phantasie und Moralität. Das Wunderbare in Wielands Dschinnistan und der Der Geschichte des Prinzen Biribinker. Kronberg.

Oettinger, Klaus (1970). Phantasie und Erfahrung. Studien zur Erzählpoetik Christoph Martin Wielands. München.

Orlik, Franz (1997). Das Sein im Text. Analysen zu Thomas Manns Wirklichkeitsverständnissen und ihrem Wandel. Würzburg.

Osterkamp, Ernst (2013): Dämonisierender Realismus. Bemerkungen zu Theodor Storms Erzählkunst. In: Wirklichkeit und Wahrnehmung. Neue Perspektive auf Theodor Storm. Herausgegeben v. Strowick, Elisabeth/Vedder, Ulrike. Bern. S. 39-54.

Pavlyshyn, Marko (1982). Gold, Guilt and Scholarship. Adelbert von Chamisso's Peter Schlemibl. In: The German Quarterly 55. S. 49-63.

Peischl, Margaret T. (1983). Das Dämonische im Werk Theodor Storms. Frankfurt am Main.

Petersdorff, Dirk von (2009). Die Öffnung des ästhetischen Feldes. In: Internationales Archiv für Sozialgeschichte der deutschen Literatur. Band 34. 2. Heft. S. 228-234.

Petersen, Jürgen H. (1973). Die Märchenmotive und ihre Behandlung in Thomas Manns Roman Königliche Hoheit. In: Sprachkunst 4. S. 216-230.

Petrikowski, Nicki Peter (2012): Stellenkommentar zu Christoph Martin Wielands Die Abenteuer des Don Sylvio von Rosalva. Frankfurt am Main.

Pfefferkorn, Kristin (1988). Novalis. A Romantic's Theory of Language and Poetry. New Haven.

Pfister, Manfred (1985): Konzepte der Intertextualität. In: Intertextualität. Formen, Funktionen, anglistische Fallstudien. Herausgegeben v. Pfister, Manfred/Broich, Ulrich. Tübingen. S. 1-30.

- (1985): Zur Systemreferenz. In: Intertextualität. Formen, Funktionen, anglistische Fallstudien. Herausgegeben v. Pfister, Manfred/Broich, Ulrich. Tübingen. S. 52-58.

Pikulik, Lothar (1992). Frühromantik. Epoche - Werke - Wirkung. München. 
Pockels, C. F. (1788). Ueber die Verschiedenheit und Mischung der Charaktere. In: Beiträge zur Beförderung der Menschenkenntniß, besonders in Rücksicht unserer moralischen Natur. Herausgegeben von Pockels, C. K. Erstes Stück. Berlin.

Polheim, Karl Konrad (1981). Gattungsproblematik. In: Handbuch der deutschen Erzählung. Herausgegeben v. Polheim, Karl Konrad. Düsseldorf. S. 9-16.

Preisendanz, Wolfgang (1969). Die Auseinandersetzung mit dem Nachahmungsprinzip in Deutschland und die besondere Rolle der Romane Wielands (Don Sylvio, Agathon). In: Nachahmung und Illusion. Kolloquium Gießen Juni 1963. Vorlagen und Verhandlungen. Herausgegeben v. Jauß, Hans Robert. München. S. 72-95.

Ranke, Wolfgang (1992). Adaption und Intertextualität. Friedrich Dürrenmatts König Johann und die Tradition der deutschen Shakespeare-Bearbeitung. Sonderdruck aus Jahrbuch für Internationale Germanistik. Jahrgang XXIV. Heft 1.

Reble, Albert (1941). Märchen und Wirklich bei Novalis. In: Jahrbuch der Deutschen Schillergesellschaft. 19. Jahrgang. S. 70-110.

Reimann, Birgit (1995). Zwischen Harmoniebedürfnis und Trennungserfahrung. Das menschliche Naturverhältnis in Theodor Storms Werk. Zur dichterischen Gestaltung von Natur und Landschaft in Lyrik und Novellistik. Freiburg.

Renner, Rolf Günter (1991). Schrift und Natur und Zeichen des Selbst. Peter Schlemihls wundersame Geschichte im Zusammenhang von Chamissos Texten. In: Deutsche Vierteljahresschrift für Literaturwissenschaft und Geistesgeschichte 65, Heft 4. S. 653-673.

Rickes, Joachim (1998). Der sonderbare Rosenstock. Eine werkzentrierte Untersuchung zu Thomas Manns Roman Königliche Hoheit. Frankfurt am Main/ Berlin/Bern/New York/Paris/Wien.

- (2006): Die Romankunst des jungen Thomas Mann. Buddenbrooks und Königliche Hoheit. Würzburg.

Riedl, Peter Philipp (2005). Die „wahrhafte Tragödie der neuen Zeit“. Romantische Faust-Lektüre. In: Aurora 65. S. 107-125.

Roder, Florian (1992). Novalis. Die Verwandlung des Menschen. Leben und Werk Friedrich von Hardenbergs. Stuttgart.

- (1997): Menschwerdung des Menschen. Der magische Idealismus im Werk des Novalis. Stuttgart/Berlin.

Rogan, Richard G. (1981). The reader in the novels of C. M. Wieland. Las Vegas/ Bern/Frankfurt am Main.

Rölleke, Heinz (2002). Hans Bär. Theodor Storms früheste Märchendichtung intertextuell. In: Schriften der Theodor-Storm-Gesellschaft 51. S. 69-72.

- (2009): Kunstmärchen. In: Handbuch der literarischen Gattungen. Herausgegeben v. Lamping, Dieter in Zusammenarbeit mit Poppe, Sandra/Seiler, Sascha/Zipfel, Frank. Stuttgart. S. 447-451. 
Samwer, Julia K. C. (2009). Symbole der Erkenntnis. Zu Friedrich Schlegels Lucinde und Novalis' Heinrich von Ofterdingen. Würzburg.

Sauder, Gerhard (1974). Empfindsamkeit. Band 1. Stuttgart.

Schaefer, Klaus (1996). Christoph Martin Wieland. Stuttgart.

Schindler-Hürlimann, Regine (1963). Wielands Menschenbild. Eine Interpretation des Agathon. Zürich.

Schlitt, Christine (2008). Chamissos Frühwerk. Von den französischsprachigen Rokokodichtungen bis zum Peter Schlemibl (1793-1813). Würzburg.

Schmidt, Michael (2016): Peter Schlemibl und das romantische Spiel mit der Herausgeberfiktion. In: Phantastik und Skepsis. Adelbert von Chamissos Lebensund Schreibwelten. Herausgegeben. v. Berbig, Roland/Erhart, Walter/ Sproll, Monika/Weber, Jutta. Göttingen. S. 77-90.

Schößler, Franziska (2001). „Aneignungsgeschäfte“. Zu Thomas Manns Umgang mit Quellen in dem Roman Königliche Hoheit. In: Thomas Mann Jahrbuch 14, S. 249-267.

Schreiber, Jens (1983). Das Symptom des Schreibens. Roman und absolutes Buch in der Frühromantik (Novalis/Schlegel). Frankfurt am Main.

Schuhmacher, Hans (1977). Narziß an der Quelle. Das romantische Kunstmärchen. Wiebaden.

Schulz, Franz (1972). Die erzählerische Funktion des Motivs vom verlorenen Schatten in Chamissos Peter Schlemibls. In: The German Quarterly $45 \mathrm{Heft}$ 3. S. 429-442.

Schulz, Gerhard (1968). Die Poetik des Romans bei Novalis. In: Deutsche Romantheorien. Beiträge zu einer historischen Poetik des Romans in Deutschland. Herausgegeben und eingeleitet v. Grimm, Reinhold. Frankfurt am Main/Bonn. S. 81-110.

- (2101): Novalis. Leben und Werk Friedrich von Hardenbergs. München.

Schuster, Ingrid (1971). Theodor Storm. Die zeitkritische Dimension seiner Novellen. Bonn.

— (2003): Tiere als Chiffre. Natur und Kunstfigur in den Novellen Theodor Storms. Bern.

Schütz, Erhard (2005). „Das Ende muß es lehren, - auch diesmal.“ Figurationen medialer Prominenz in Thomas Manns Königliche Hoheit. In: Delabar, Walter/ Plachta, Bodo (Hrsg.): Thomas Mann. Berlin. S. 51-66.

Schwann, Jürgen (1984). Vom Faust zum Peter Schlemihl. Kohärenz und Kontinuität im Werk von Adelbert von Chamisso. Tübingen.

Segeberg, Harro (2007). Literarische Technik-Bilder. Studien zum Verhältnis von Technik- und Literaturgeschichte im 19. und frühen 20. Jahrhundert. Tübingen.

Seidler, Andreas (2008). Der Reiz der Lektüre. Wielands Don Sylvio und die Autonomisierung der Literatur. Heidelberg.

Seiler, Christiane (1977). Die Rolle des Lesers in Wielands Don Sylvio von Rosalva und Agathon. In: Lessing Yearbook IX. S. 152-165. 
Senckel, Barbara (1983). Individualität und Totalität. Aspekte zu einer Anthropologie des Novalis. Tübingen 1983.

Sengle, Friedrich (2005). Aufklärung und Rokoko in der deutschen Literatur. Herausgegeben von Bierwirth, Sabine. Heidelberg.

Silz, Walter (1946). Theodor Storm's Schimmelreiter. In: Modern Language Association of America 61. S. 762-783.

Singer, Herbert (1963). Der deutsche Roman zwischen Barock und Rokoko. Köln/Graz.

Speidel, Walter H. (1981). Thematische Dreistufigkeit in Die Lehrlinge zu Sais von Novalis. In: Sprache und Literatur. Festschrift für Arvel L. Streadbeck zum 65. Geburtstag. Herausgegeben von Knapp, Gerhard A./Schmidt, Wolff A. von. unter Mitarbeit v. Rahde, Heinz F. Bern/Frankfurt am Main/Las Vegas. S. 195-202.

Stadler, Ulrich (1990): Novalis - ein Lehrling Friedrich Schillers? In: Aurora 50. S. 47-62.

- (1997): Zur Anthropologie Friedrich von Hardenbergs (Novalis). In: Novalis und die Wissenschaften. Herausgegeben von Uerlings, Herbert. Tübingen. S 87-106.

Stahl, Karl-Heinz (1975). Das Wunderbare als Problem und Gegenstand der deutschen Poetik des 17. Und 18. Jahrhunderts. Frankfurt am Main.

Starnes, Thomas C. (2005). Christoph Martin Wieland: ein Mensch des Rokoko. In: Wieland-Studien V. Herausgegeben v. Manger, Klaus/Wieland-Archiv Biberach. Sigmaringen. S. 1-8.

Stein, Malte (2005). Grenzgänge. Zur Bedeutung des Wasserfrau-Motivs in Storms Erzählungen Auf der Universität und Der Schimmelreiter. In: Storm-Blätter aus Heiligenstadt 11. S. 19-32.

Storz, Gerhard (1971). Zusammenspiel zwischen Erzähler und Leser. In: Probleme des Erzählers in der Weltliteratur. Herausgegeben v. Martini, Fritz. Stuttgart. S. 409-421.

Striedter, Jurij (1955). Die Komposition der Lebrlinge zu Sais. In: Der Deutschunterricht 7. S. 5-23.

- (1985): Die Fragmente des Novalis als „Präfigurationen seiner Dichtung“. München.

Strowick, Elisabeth (2013): „Eine andere Zeit“. Storms Rahmentechnik des Zeitsprungs. In: Wirklichkeit und Wahrnehmung. Neue Perspektive auf Theodor Storm. Herausgegeben v. Strowick, Elisabeth/Vedder, Ulrike. Bern. S. $55-72$.

Struzek-Krähenbühl, Franziska (2009). Oszillation und Kristallisation. Theorie der Sprache bei Novalis. Paderborn.

Thalmann, Marianne (1961). Das Märchen und die Moderne. Zum Begriff der Surrealität im Märchen der Romantik. Stuttgart. 
Theisohn, Philipp (2008). Der Schimmelreiter. Gespenstisches Erzählen. In: Theodor Storm. Novellen. Herausgegeben v. Deupmann, Christoph. Stuttgart. S. 104-125.

Trapp, Frithjof (1975). Artistische Verklärung der Wirklichkeit. Thomas Manns

Roman Königliche Hoheit. In: Arntzen, Helmut u.v.a. (Hrsg.): Literaturwissen-

schaft und Geschichtsphilosophie. Festschrift für Wilhelm Emrich. Berlin/

New York. S.453-469.

Tschapke, Reinhard (1990). Anmutige Vernunft. Christoph Martin Wieland und die Rhetorik. Stuttgart.

Uerlings, Herbert (1990). Novalis und die Weimarer Klassik. In: Aurora 50. S. 2746.

- (1991): Friedrich von Hardenberg, genannt Novalis. Werk und Forschung. Stuttgart.

- (2004): Einbildungskraft und Poesie bei Novalis. In: Novalis. Poesie und Poetik. Herausgegeben von Uerlings, Herbert. Tübingen. S. 21-62.

Vaget, Hans Rudolf (1970). Der Dilettant. In: Jahrbuch der deutschen Schillergesellschaft 14. S. 131-158.

- (1995): Die Erzählungen. In: Koopmann, Helmut: (Hrsg.): Thomas-MannHandbuch. 2. Aufl. Stuttgart. S. 534-618.

Van Abbé, Derek (1977): Wieland and the ,Stately Homes' of Faëry. The Rococo Substructure of Don Sylvio de Rosalva. In: Papers Read Before the Society 1976-1977 - Publications of the English Goethe Society, New Series Vol. XLVII. S. 28-46.

Verweyen, Theodor/Witting, Günther (1987). Die Kontrafaktur. Vorlage und

Verarbeitung in Literatur, bildender Kunst, Werbung und politischem Plakat. Konstanz.

Verweyen/Witting (2007): Kontrafaktur. In: Reallexikon der deutschen Literaturwissenschaft: Neubearbeitung des Reallexikons der deutschen Literaturgeschichte. Bd. II Herausgegeben v. Braungart/Georg, Fricke, Harald/ Grubmüller, Klaus/Müller/Vollhardt, Jan-Dirk/Klaus, Friedrich. Weimar. S. 337-340.

Vierung, Jürgen (1976). Schwärmerische Erwartung bei Wieland, im trivialen Geheimnisroman und bei Jean Paul. Köln/Wien.

Vietta, Silvio (1992). Die literarische Moderne. Eine problemgeschichtliche Darstellung der deutschsprachigen Literatur von Hölderlin bis Thomas Bernhard. Stuttgart.

- (2010): Moderne Erzähltheorie: Narratologie der Romanliteratur der klassischen Moderne. In: Klassische Moderne. Ein Paradigma des 20. Jahrhunderts. Herausgegeben v. Ponzi, Mauro. Würzburg. S. 77-89.

Volkmann-Schluck, Karl-Heinz (1984). Von der Wahrheit der Dichtung. Interpretationen. Plato - Aristoteles - Shakespeare - Schiller - Novalis - Wagner - Nietzsche - Kafka. Herausgegeben von Janke, Wolfgang/Weyers, Raymund. Würzburg. 
Vordtriede, Werner (1963). Novalis und die französischen Symbolisten. Stuttgart.

Walach, Dagmar (1982). Adelbert von Chamisso. Peter Schlemihls wundersame Geschichte. Erläuterungen und Dokumente. Stuttgart.

Wedel, Alfred R. (1982). Zum Motiv der Schwärmerei in Chr. M. Wielands „Don Sylvio“: Illusion - Desillusion; Platonismus - Erotismus. In: Aufnahme Weitergabe. Literarische Impulse um Lessing und Goethe. Festschrift für Heinz Moenkemeyer zum 68. Geburtstag. Herausgegeben v. McCarthy, John A./Kipa, Albert A. Hamburg. S. 219-231.

Weinrich, Harald (1967). Für eine Literaturgeschichte des Lesers. In: Merkur XXI. Jahrgang, Heft 226-237. S. 1026-1038.

Weiss, Gernot (1996). Südseeträume: Schlemihls Suche nach dem Glück. In: Aurora 56. S. 111-126.

Wenzel, Peter (2008). Gattung, literarische. In: Metzler Lexikon Literatur- und Kulturtheorie. Herausgegeben von Nünning, Ansgar. Stuttgart/Weimar. S. $229 \mathrm{f}$.

Wiese, Benno von (1956): Chamisso. In: Ders.: Die deutsche Novelle von Goethe bis Kafka. Interpretationen. Bd. 1. Düsseldorf.

Wilpert, Gero von (1978). Der verlorene Schatten. Varianten eines literarischen Motivs. Stuttgart.

Wilson, W. Daniel (1981). The narrative strategy of Wieland's Don Sylvio von Rosalva. Bern/Frankfurt am Main/Las Vegas.

Wittmann, Lothar (1961): Theodor Storms Der Schimmelreiter. In: Deutsche Novellen des 19. Jahrhunderts. Interpretationen zu Storm und Keller. Herausgegeben v. Heinrich Gaese und anderen. Frankfurt am Main. S. 50-92.

Wolff, Eugen (1971). Die jüngste deutsche Literaturströmung und das Prinzip der Moderne. In: Die literarische Moderne. Dokumente zum Selbstverständnis der Literatur um die Jahrhundertwende. Ausgewählt und mit einem Nachwort herausgegeben von Wunberg, Gotthart. Frankfurt am Main. S. 3-42.

Wolff, Hans M. (1957). Thomas Mann. Werk und Bekenntnis. Bern.

Wolffheim, Hans (1949). Wielands Begriff der Humanität. Hamburg.

Wunberg, Gotthart (2001). Jahrhundertwende. Studien zur Literatur der Moderne. Tübingen.

Wührl, Paul-Wolfgang (1984): Das deutsche Kunstmärchen. Geschichte, Botschaft und Erzählstrukturen. Heidelberg.

Wysling, Hans (1967). Die Fragmente zu Thomas Manns Fürsten-Novellen. Eingeführt und ediert von Hans Wysling. In: Scherrer, Paul/Hans Wysling: Quellenkritische Studien zum Werk Thomas Manns. Bern/München. S.64-105.

- (1994): Thomas Mann. Ein Leben in Bildern. Frankfurt am Main.

- (1995): Königliche Hoheit. In: Koopmann, Helmut: (Hrsg.): Thomas-MannHandbuch. 2. Aufl. Stuttgart. S. 385-395.

- (1996): Ausgewählte Aufsätze 1963-1995. Herausgegeben v. Specher, Thomas/Bernini, Cornelia. Frankfurt am Main. 
Zagari, Luciano (1982): „Ein Schauspiel fürs Eros“. Nihilistische Dimensionen in Friedrich von Hardenbergs allegorischem Märchen. In: Aurora 42. S. 130142.

Zelger, Renate (1996). Teufelsverträge. Märchen, Sage, Schwank, Legende im Spiegel der Rechtsgeschichte. Frankfurt am Main.

Zipes, Jack (2006): Critical reflections about Hans Christian Andersen, the failed revolutionary. In: Marvels \& Tales. Volume 20, Number 1. S. 224-237. 
$\mathrm{D}$ iese Arbeit beschäftigt sich mit intertextuellen Theorien und untersucht Erzähltexte (von Wieland, Novalis, Chamisso, Storm, Andersen und Thomas Mann von der Aufklärung des 18. Jahrhunderts bis zur Klassischen Moderne des frühen 20. Jahrhunderts. Betrachtet werden neben den Märchenrequisiten auch die weniger auffälligen märchenhaften Textstrukturen, die eine Verknüpfung zwischen verschiedenen literarischen Gattungen (Novelle/Roman und Märchen) und eine Auseinandersetzung zwischen dem Märchenhaften und dem FiktivRealistischen zeigen. Aufgezeigt werden soll die Beziehung zwischen dem Schreibverfahren der Märchenadaption und der literarischen Moderne - einer literarischen Moderne, die eine gesellschaftliche Moderne reflektiert, welche durch ihre gesellschaftliche Ambivalenz und Pluralität gekennzeichnet ist (die Moderne als Makroepoche nach Anke Lohmeier und Dirk von Petersdorff). Die sechs Erzähltexte - Die Abentheuer des Don Sylvio von Rosalva, Die Lehrlinge zu Sais, Peter Schlemihls wundersame Geschichte, Der Schimmelreiter, Peer im Glück (als Exkurs und Ausblick in die zeitgenössische europäische Literatur) und Königliche Hoheit - gelten mit ihrer Vielfalt der Bedeutungsschichten als moderne Erzähltexte und stellen verschiedene Meilensteine in der Entwicklung des Moderne-Begriffes dar. 